\title{
Chronic oxidative stress and telomere shortening
}

Citation for published version (APA):

Houben, J. M. J. (2011). Chronic oxidative stress and telomere shortening. [Doctoral Thesis, Maastricht University]. Universiteit Maastricht. https://doi.org/10.26481/dis.20110121jh

Document status and date:

Published: 01/01/2011

DOI:

10.26481/dis.20110121jh

Document Version:

Publisher's PDF, also known as Version of record

\section{Please check the document version of this publication:}

- A submitted manuscript is the version of the article upon submission and before peer-review. There can be important differences between the submitted version and the official published version of record.

People interested in the research are advised to contact the author for the final version of the publication, or visit the DOI to the publisher's website.

- The final author version and the galley proof are versions of the publication after peer review.

- The final published version features the final layout of the paper including the volume, issue and page numbers.

Link to publication

\footnotetext{
General rights rights.

- You may freely distribute the URL identifying the publication in the public portal. please follow below link for the End User Agreement:

www.umlib.nl/taverne-license

Take down policy

If you believe that this document breaches copyright please contact us at:

repository@maastrichtuniversity.nl

providing details and we will investigate your claim.
}

Copyright and moral rights for the publications made accessible in the public portal are retained by the authors and/or other copyright owners and it is a condition of accessing publications that users recognise and abide by the legal requirements associated with these

- Users may download and print one copy of any publication from the public portal for the purpose of private study or research.

- You may not further distribute the material or use it for any profit-making activity or commercial gain

If the publication is distributed under the terms of Article $25 \mathrm{fa}$ of the Dutch Copyright Act, indicated by the "Taverne" license above, 


\section{Chronic oxidative stress and telomere shortening}

Joyce M.J. Houben 
C Joyce M.J. Houben, Maastricht 2010

ISBN 978-90-9025893-5

$\begin{array}{ll}\text { Omslagillustratie: } & \text { Marco Jeurissen } \\ \text { Lay-out: } & \text { Tim de Vos } \\ \text { Druk: } & \text { Drukkerij Castro, Riemst }\end{array}$
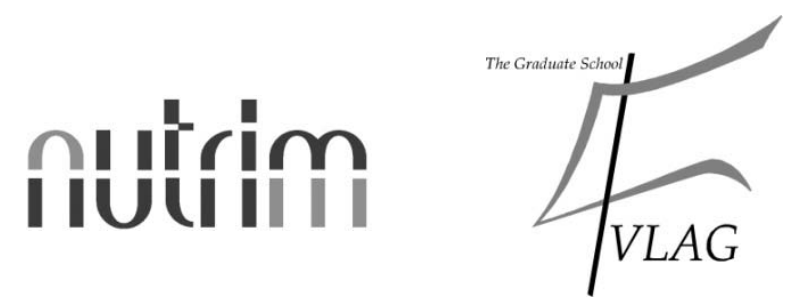

The studies presented in this thesis were performed at the Nutrition and Toxicology Research Institute Maastricht (NUTRIM), which participates in the Graduate School VLAG (Food Technology, Agrobiotechnology, Nutrition and Health Sciences), accredited by the Royal Netherlands Academy of Arts and Sciences. 


\title{
Chronic oxidative stress and telomere shortening
}

\author{
Proefschrift
}

ter verkrijging van de graad van doctor aan de Universiteit Maastricht, op gezag van de Rector Magnificus, Prof. mr. G.P.M.F. Mols volgens het besluit van het College van Decanen, in het openbaar te verdedigen op vrijdag 21 januari 2011 om 10.00 uur

door

Joyce M.J. Houben

geboren te Sittard op 18 april 1983 


\section{Promotores:}

Prof. dr. F.J. van Schooten

Prof. dr. E.F.M. Wouters

\section{Copromotor:}

Dr. ir. G.J. Hageman

\section{Beoordelingscommissie:}

Prof. dr. A. Bast (voorzitter)

Prof. dr. Ir. E.E. Blaak

Dr. Ir. D. van Heemst (Leids Universitair Medisch Centrum)

Prof. dr. R. Louis (University of Liege, Belgium)

Prof. dr. J.A. Staessen (KU Leuven, Belgium) 




\section{Contents}

$\begin{array}{lll}\text { Chapter } 1 \quad \text { General introduction } & 9\end{array}$

Chapter 2 Telomere length, oxidative stress, and antioxidant 45 status in elderly men: differences between Zutphen and Crete

Chapter 3 Telomere length and mortality in elderly men: the Zutphen Elderly Study

Chapter 4 Telomere shortening in chronic obstructive pulmonary disease

Chapter 5 Telomere shortening in COPD: potential protective effects of coffee consumption

Chapter 6 Telomere shortening in diabetic rats: effects of dietary intervention with fisetin and n-acetylcysteine

Chapter 7 Summary and general discussion

Nederlandse samenvatting

Dankwoord

Curriculum Vitae

List of Publications

Samenvatting voor de niet-wetenschapper 



\section{Chapter 1 \\ General introduction}

Based on:

Telomere length assessment: Biomarker of chronic oxidative stress? Free Radic Biol Med. 2008 Feb 1;44(3):235-46. Epub 2007 Oct 10.

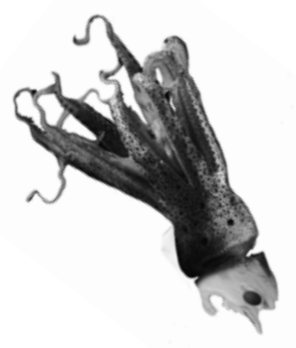

Joyce M.J. Houben

Harald J. Moonen

Frederik J. van Schooten

Geja J. Hageman 


\section{General introduction}

Telomeres are nucleoprotein structures at the end of chromosomes. They prevent chromosomal ends from being recognized as double strand breaks and protect them from end to end fusion and degradation [1-3]. Telomeres consist of stretches of repetitive DNA with a high G-C content [4,5]. Figure 1 illustrates the structure of the telomeres. In humans, the telomere terminus consists of 4 to $15 \mathrm{kbp}$ of the hexanucleotides 5'-TTAGGG-3' [6,7]. At each chromosomal end, the G-rich telomeric DNA strand runs $5^{\prime}$ to $3^{\prime}$ towards the terminus and protrudes 100-150 nucleotides beyond the complementary C-rich strand [3]. It is protected from degradation by intercalation into the double stranded telomere DNA, forming a telomeric loop (t-loop) [8].

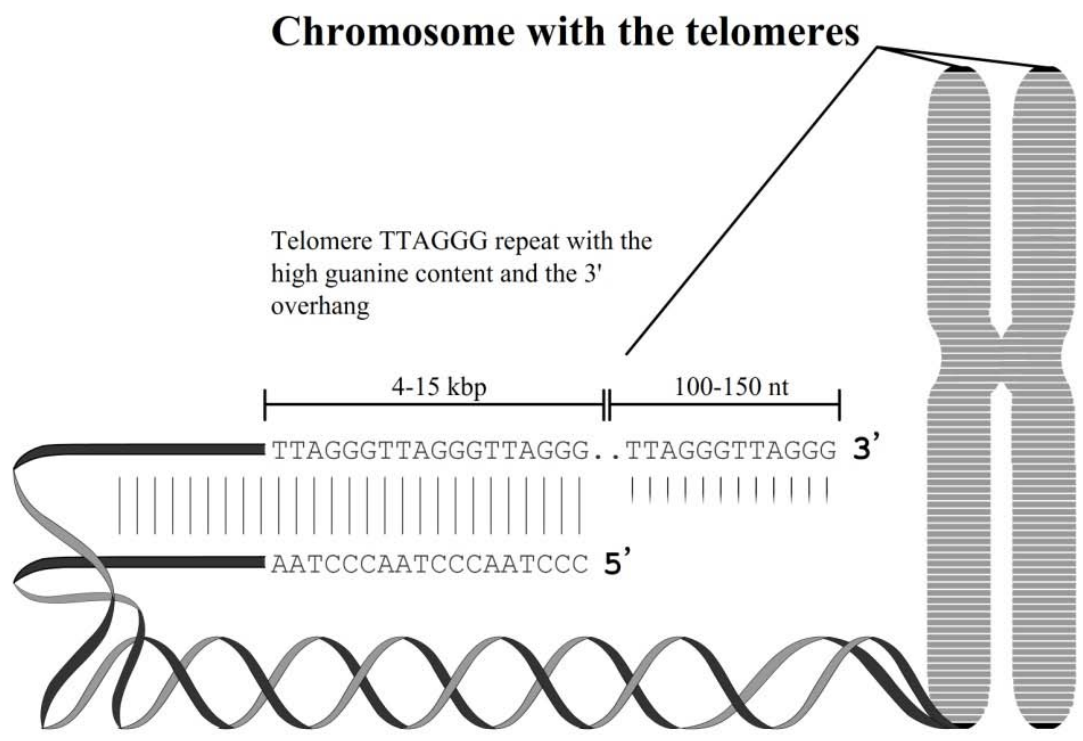

Figure 1. Structure of telomeres

In most proliferating cells telomere length $(T L)$ is dynamic, and with each cell division the lengths of telomeres in human somatic cells decrease gradually by 20 to 200 base pairs. Partially, this loss of base pairs is a consequence of the socalled end-replication problem. DNA polymerases are not able to replicate chromosomes completely, since one RNA primer remains on each daughter DNA strand. The last primers are removed by a 5'-3' exonuclease, but DNA 
polymerases cannot fill the gaps because there is no $3^{\prime}-\mathrm{OH}$ available to which a nucleotide can be added. As a consequence, the replication machinery has to leave a small region at the end (a piece of the telomere) uncopied. The endreplication problem leads to chromosome shortening with each round of cell division. Eventually, this will lead to elimination of the telomeres and, as a consequence, apoptosis or an irreversible growth arrest of the cells [9]. These senescent cells are irreversibly arrested in the G1 phase of the cell cycle [10]. For this reason telomeres may serve as a biological clock of the cell.

Besides the end-replication problem, other factors may contribute to telomere shortening.

Since human telomeres contain G-rich overhangs, the action of a 5'-to-3' specific exonuclease was suggested. The action of this exonuclease would shorten each telomere by half the overhang length per round of replication and it was suggested to be involved in the final degradation of RNA primers from the lagging strand of the DNA [11-13].

Both the end replication problem and the existence of an exonuclease only partially account for the loss of telomeres seen in cells, and therefore it was suggested that other mechanisms may be involved in accelerated telomere shortening. One of these mechanisms, DNA damage induced by oxidative stress, has been extensively studied and described by von Zglinicki et al. [6,8,11,14-18]. This lead to the hypothesis that measurement of TL can be used as a biomarker of chronic oxidative stress.

\section{Techniques to measure TL}

First, the different methods that are used to analyze TL are described, since the assessment of TL is important in understanding the relationship between oxidative stress and TL regulation.

In recent reviews by Nakagawa et al. [19] and by Lin et al. [20], the most important techniques to measure $T L$ are discussed. The most widely used method is the telomere restriction fragment (TRF) assay with Southern blot analysis. In this method, average lengths of telomeres are measured by creating TRFs using specific restriction enzymes and hybridization with a radioactive or fluorescent probe. The main disadvantage of this assay is the subjectivity of the results, since TRF lengths can differ as much as $5 \%$ depending on which restriction enzyme is used. This means that subtelomeric regions might be 
included in the determination of the TL. Other disadvantages of this method are the requirement of large amounts of DNA and the fact that the procedure is relatively time consuming $[19,20]$.

A second important method used to measure $T L$ is the fluorescence in situ hybridization (FISH), which can be subdivided in flow Fish and quantitative Fish. It allows the direct labeling of oligonucleotide probes to telomere sequences at the individual cell level. In this method, fluorescent dyes are used to visualize telomeres with fluorescence microscopy or with a digital imaging system. Flow FISH uses fluorescence activated cell sorting (FACS) to sort different types of cells, while quantitative FISH provides measurements of telomere lengths of individual chromosomes. In contrast to quantitative FISH, flow FISH allows the analysis of telomeres in cycling and non-cycling cells instead of metaphase preparation and the procedure can be carried out in one day. A disadvantage of this method is that it uses whole cells, which limits its suitability in studies where only DNA is available $[19,20]$.

A method that is recently developed by Baird [21], is the single TL analysis (STELA), which is a PCR based method that measures the lengths of telomeres at the individual chromosome level. First, a linker which consists of 7 repeats of TTAGGG followed by a 20 nucleotides containing noncomplementary tail, is annealed to the telomeric G-rich strand 3'-overhang. In the second step the linker is ligated to the 5 '-end of the complementary strand of the chromosome. PCR can then be performed using a primer that is identical to this tail, together with a chromosome-specific upstream primer located in the subtelomeric region, which can be made allele-specific by known polymorphisms in this region. The STELA was first developed for analysis of the human sex chromosome, the $X$ and $Y$ chromosomes, and it is suggested that this method can also be applied to other chromosomes $[20,21]$. However, its extension to all human telomeres will require sequence information for each allele as well as information on allelic frequencies. Since chromosome-specific primers are needed, chromosome-specific information can be obtained. This can either be an advantage or a disadvantage, depending on the purpose of the study.

Another PCR-based method is the quantitative polymerase chain reaction described by Cawthon [22]. It avoids many of the problems encountered by TRF analysis by using primers that are specifically designed to amplify telomeric hexamer repeats without generating primer dimer-derived 
products. In these primer template hybridizations, every sixth base is mismatched, whereas the last five bases at the 3 '-end of the primers are perfectly matched to complementary bases in the template [22]. This method measures relative telomere lengths by determining the factor by which a sample DNA differs from an arbitrary reference DNA in its ratio of telomere repeat copy number to single gene copy number. A disadvantage of this technique is that it does not provide absolute telomere lengths. This problem can be overcome by the use of cell lines with known TL. By adding reference DNA to each PCR reaction, a standard curve can be created and the absolute TL of the samples can be calculated. It has to be noted that the DNA has to be of good quality in order to get reproducible results. In comparison to TRF analysis and quantitative FISH, the measurement of telomere by quantitative PCR does not include the subtelomeric region which is highly variable between individuals. Furthermore, due to its simplicity and high throughput, it is very useful for large population studies where only DNA is required in stead of cells or tissue $[19,20,22,23]$.

The last method that will be discussed is the telomeric-oligonucleotide ligation assay (T-OLA). T-OLA measures the length of the G-rich telomeric 3' overhang by ligating telomeric repeat oligonucleotides hybridized to the overhang. Telomere shortening is proportional to the size of G-rich overhangs in human tissues. A difficulty with this method is, that it is unclear whether short overhangs imply slow telomere shortening or that it means that there are many senescent cells $[19,24]$.

As described above, there are different methods to determine TL and it depends on the type and aim of the study which method should be used. Each method has its specific advantages and disadvantages that make it more or less useful for a specific purpose. The discussed methods are shown in table 1. 
Table 1. Techniques to measure telomere length

\begin{tabular}{|c|c|c|c|}
\hline Technique & Procedure & Possible source of error & Remarks \\
\hline TRF (Southern Blot) & $\begin{array}{l}\text { Using specific restriction } \\
\text { enzymes, TRFs are created. } \\
\text { The next step is hybridization } \\
\text { with a radioactive or } \\
\text { fluorescent probe }\end{array}$ & $\begin{array}{l}\text { Subtelomeric regions } \\
\text { might be included }\end{array}$ & $\begin{array}{l}\text { - Large amounts of } \\
\text { DNA needed } \\
\text { - Time consuming }\end{array}$ \\
\hline Quantitative FISH & $\begin{array}{l}\text { Fluorescent dyes are used } \\
\text { to visualize telomeres with } \\
\text { fluorescence microscopy or } \\
\text { with a digital imaging system }\end{array}$ & $\begin{array}{l}\text { Performed on metaphase } \\
\text { spreads }\end{array}$ & $\begin{array}{l}\text { - Time consuming } \\
\text { - Small datasets } \\
\text { - Chromosome } \\
\text { specific }\end{array}$ \\
\hline Flow-FISH & $\begin{array}{l}\text { Flow-FISH uses fluorescence } \\
\text { activated cell sorting (FACS) } \\
\text { to sort different types of } \\
\text { cells }\end{array}$ & $\begin{array}{l}\text { Tight adherence to an } \\
\text { optimized protocol is a } \\
\text { premise }\end{array}$ & $\begin{array}{l}\text { - Use of whole cells } \\
\text { - Small datasets }\end{array}$ \\
\hline STELA & $\begin{array}{l}\text { PCR based method that } \\
\text { uses a linker of } 7 \text { TTAGGG } \\
\text { repeats }\end{array}$ & $\begin{array}{l}\text { Chromosome specific } \\
\text { primers are needed }\end{array}$ & $\begin{array}{l}\text { - Chromosome } \\
\text { specific }\end{array}$ \\
\hline Quantitative PCR & $\begin{array}{l}\text { PCR based method that } \\
\text { uses primers that are } \\
\text { specifically designed to } \\
\text { amplify telomeric hexamer } \\
\text { repeats without generating } \\
\text { primer dimer-derived } \\
\text { products }\end{array}$ & $\begin{array}{l}\text { DNA has to be of good } \\
\text { quality }\end{array}$ & $\begin{array}{l}\text { - High throughput } \\
\text { - Does not provide } \\
\text { absolute } \\
\text { telomere lengths }\end{array}$ \\
\hline
\end{tabular}

\section{Factors influencing telomere regulation}

Before discussing the role of oxidative stress in telomere shortening, other factors that are involved in telomere regulation will be discussed. In contrast to stem cells and germ line cells, telomeres in somatic cells shorten with each cell division. Cell proliferation is therefore considered to be one of the most important causes of telomere shortening. For instance, human diploid fibroblasts have a limited replicative life span in vitro due to telomere attrition, which leads to cellular senescence [1,25].

In addition, the enzyme telomerase is also involved in telomere stability and telomere shortening. Telomerase is a cellular reverse transcriptase that consists of two components, a reverse transcriptase subunit known as Telomerase Reverse Transcriptase (hTERT) and a Telomerase RNA Component (hTERC) [26]. Telomerase recognizes the tip of a G-rich strand of a telomeric DNA repeat sequence and elongates the telomere in the 5' $-3^{\prime}$ direction. The telomerase enzyme synthesizes a new copy of the repeat by using its RNA 
template (hTERC) [26]. After a couple of extension rounds of the parental DNA strand by telomerase, replication of the end of the chromosome can take place by using the "extensions" as template [27]. Regulation of telomerase activity is an area of intense investigation, but the exact mechanisms are not yet elucidated [28]. Human telomerase ribonucleoproteins pass through several stages before they start with telomere elongation, i.e. accumulation of RNA and regulation of hTERT transcription, transport to the nucleus, catalytic activation of the telomerase holoenzyme and recruitment of the telomerase enzyme to the telomeres $[28,29]$. Yet, in most human somatic cells telomerase activity is absent or very low. Only germ line cells and stem cells express sufficient telomerase to maintain their telomeres in a functional state for infinite time [15].

\section{TL in different cell types and tissues}

TL has been determined in a variety of tissues and it was observed that TL varies considerably from tissue to tissue. Cells in different tissues differ enormously in their turnover rate. Many of the differentiated cells that need continual replacement are unable to divide themselves. Replacement cells need to be generated from a stock of precursor cells, the stem cells or progenitor cells [27]. Most mature cells of the hematopoietic system are relatively short-lived. A relatively small population of hematopoietic stem cells divides and differentiates into other cell types. TL of human stem cells have been found to range from approximately 8 to $10 \mathrm{kbp}$, while the TL of lymphocytes was reported to be approximately 6 to $8 \mathrm{kbp}$. TL measured in whole blood ranged from 7 to $8 \mathrm{kbp}$ and TL measured in fetal tissues was found to be approximately $13 \mathrm{kbp}[22,30,31]$.

Although telomeres of stem cells are relatively long, the proliferative potential of most hematopoietic stem cells appears to be also limited and decreases with age [30]. In a study performed by Friedrich et al. [32], TL was measured by telomere restriction fragment analysis in three unrelated tissues (leukocytes, skin and synovial tissue) of nine elderly patients. Dependent on tissue specific proliferation rate, they found significantly shorter telomeres in leukocytes (6.5 kbp) compared to skin (7.8 kbp) and synovial tissue (7.9 kbp). A linear correlation was found after pair wise comparison of TL of two different tissues from the same donor. This suggests that genetic determination of the 
regulation of $T L$ is tissue-independent and indicates that measurement of $T L$ in, for instance, leukocytes could serve as a surrogate for relative TL in other tissues.

According to these data, it appears feasible to use easily accessible tissues to assess TL in stead of using tissues that are difficult to obtain. This was applied in a patient-control study by Broberg et al. [33], in which a negative association was found between TL in buccal cells and bladder cancer risk. TL was determined by quantitative PCR in buccal cells from 63 patients and 158 controls. A confounding factor might be that buccal cells are directly exposed to, for instance, cigarette smoke, which may give biased results among smokers. However, in this study no difference was found in TL between current smokers, former smokers and non-smokers within the groups of controls and cases [33].

From the currently available data it can be concluded that the rate of telomere shortening is approximately the same in different tissues, and therefore, easily accessible tissues, such as leukocytes from blood or buccal cells, may be used as surrogate tissue for TL assessment in tissues involved in the systemic effects of chronic diseases.

\section{Proteins involved in telomere regulation}

Various proteins play an important role in TL regulation. A complex formed by six telomere-specific proteins, namely telomeric repeat binding factors 1 and 2 (TRF1 and TRF2), TRF1-interacting protein 2 (TIN2), repressor activator protein 1 (Rap1), tripeptidyl peptidase 1 (TPP1), and protection of telomeres 1 (POT1), associates with the telomere sequence and protects the chromosome ends. These and some other important proteins at human telomeres, namely tankyrase 1 and 2, DNA-dependent protein kinase and Ku70/86 (the DNA-PK complex), ataxia telangiectasia mutated (ATM) and poly-ADP ribose polymerase-1 (PARP-1), which are involved in DNA repair and replication, are listed in table 2 [34-44]. 
Table 2. Proteins involved in telomere length regulation

\begin{tabular}{|c|c|}
\hline Telomere-binding protein & Function(s) \\
\hline \multicolumn{2}{|c|}{ Protection telomeres } \\
\hline Telomeric repeat binding factor 1 (TRF-1) & Protects chromosome ends \\
\hline Telomeric repeat binding factor 2 (TRF-2) & Protects chromosome ends \\
\hline Repressor activator protein 1 (RAP-1) & $\begin{array}{l}\text { Binds telomere sequences and protects } \\
\text { telomeres from non-homologous end-joining }\end{array}$ \\
\hline Protection of telomeres 1 (POT- 1 ) & Capping of the telomere \\
\hline \multicolumn{2}{|c|}{ Regulation telomeres } \\
\hline Tankyrase 1 and 2 & $\begin{array}{l}\text { Telomere length regulation via ribosylation of } \\
\text { TRF-1 }\end{array}$ \\
\hline Telomeric repeat binding factor 1 (TRF-1) & $\begin{array}{l}\text { Tankyrase } 1 \text { poly(ADP-ribosyl)ates TRF-1, which } \\
\text { then dissociates from the telomeric DNA. This } \\
\text { renders the telomere accessible for telomerase } \\
\text { and DNA repair enzymes }\end{array}$ \\
\hline TRF1-interacting protein 2 (TIN-2) & $\begin{array}{l}\text { TIN2 is a negative regulator of telomere } \\
\text { elongation that interacts with TRF1. In the } \\
\text { presence of telomerase activity, } \\
\text { overexpression of TIN2 inhibits telomere } \\
\text { elongation. }\end{array}$ \\
\hline $\begin{array}{l}\text { DNA-dependent protein kinase }+\mathrm{Ku} 70 / 86 \\
\text { (DNA-PK complex) }\end{array}$ & $\begin{array}{l}\text { DNA damage repair and regulation of telomere } \\
\text { length }\end{array}$ \\
\hline Ataxia telangiectasia mutated (ATM) & $\begin{array}{l}\text { ATM plays a dual role at telomeres, activating } \\
\text { the DNA damage response program at } \\
\text { dysfunctional telomeres and yet preventing } \\
\text { this activation at functional telomeres }\end{array}$ \\
\hline Poly-ADP ribose polymerase 1 (PARP- 1 ) & $\begin{array}{l}\text { Catalyzes the poly(ADP-ribosyl)ation of TRF-2, } \\
\text { disassociating it from the telomere and } \\
\text { allowing access to the DNA damage repair } \\
\text { machineries to repair damage }\end{array}$ \\
\hline
\end{tabular}

Since this thesis focuses on the relationship between TL regulation and oxidative stress, the role and function of the poly-ADP ribose polymerase (PARP) enzymes will be described specifically.

PARP enzymes are members of a large family of enzymes that use NAD+ as a substrate to transfer ADP-ribose onto glutamic acid residues of proteins. Upon binding to nicked DNA, PARP-1 forms homodimers and heterodimers with PARP-2. The activated enzyme catalyzes the cleavage of NAD+ into nicotinamide and ADP-ribose, synthesizing linear and branched poly(ADP-ribose) polymers that are covalently attached to nuclear acceptor proteins. The covalently attached poly(ADP-ribose) polymers, that are negatively charged, dramatically affect the function and DNA binding of target proteins, among which the DNA 
repair proteins XRCC1, DNA ligase III, BRCA-1 $[45,46]$. PARP enzymes therefore are considered to play an important role in maintaining genome integrity through modulation of multiple cellular responses and facilitating DNA repair $[47,48]$. Poly(ADP-ribosyl)ation represents a cellular response to DNA strand breakage induced by ionising radiation, alkylating agents or oxidative stress. In contrast to the cytoprotective effect of PARP-1 activity, severe damage to DNA can trigger over-activity of PARP-1, leading to severe NAD+ consumption as well as ATP depletion and consequently cell death due to failure of energy metabolism [49].

Several members of the PARP family have been found in association with telomeric DNA and are able to poly(ADP-ribosyl)ate TRF-1 and TRF-2, two telomere-specific DNA binding proteins [49]. TRF1 is thought to regulate TL and TRF2 is thought to protect chromosome ends [50]. Before telomerase can access the telomere and telomere elongation can take place, the t-loop structure of the telomere has to become unfolded. Tankyrase 1, a member of the PARP family, interacts with TRF1 through its ankyrin repeats and binds the acidic domain of TRF1. This domain is unique to TRF1, and for this reason, tankyrase 1 does not interact with TRF2. Tankyrase 1 poly(ADP-ribosyl)ates TRF1 , which then dissociates from the telomeric DNA [51]. This renders the telomere accessible for telomerase and DNA repair enzymes.

In a study by Chang et al. [52], siRNa (small interfering RNA) was used to knock down tankyrase expression in human cells. In the absence of tankyrase 1 , sister telomeres fail to separate and this leads to cell arrest in anaphase in human cells. In mice, tankyrase 2 appears not to be required for telomere maintenance, but is necessary for normal growth [53]. This might suggest that the mouse tankyrase 2 differs from human tankyrase 2 in its telomere function [54]. Additional studies, in which the gene encoding for PARP-1 is disrupted, support the role of PARP enzymes in TL regulation. PARP-1 knock-out mice show shorter telomeres in splenocytes and thymocytes as compared to wildtype controls. Furthermore, PARP-1 knock-out cells display a higher level of chromosomal abnormalities. In an in vitro study by d'Adda di Fagagna et al. [55], cells of PARP-1 knock-out mice showed 20 end-to-end chromosome fusions in 80 metaphase spreads, but none were found in 70 metaphase spreads in the cells of wild-type mice. These fusions led to an increased number of broken chromosomes and a 14-fold greater number of aneuploïd cells [55]. These results indicate the importance of PARP1-protein function in telomere 
maintenance and telomere regulation. The involvement of PARP-1 and PARP-2 in telomeric damage signaling suggests a possible link between DNA repair and TL regulation [49] which will be discussed in the next paragraph.

\section{How does oxidative stress cause telomere shortening?}

The contribution to telomere loss by oxidative DNA damage was, in many cases, reported to overrate the contribution by the end-replication problem [6]. Due to their high content of guanines, telomeres were demonstrated highly sensitive to damage by oxidative stress $[56,57]$. In addition, oxidative damage to bases has been reported to accumulate over the life span of a cell or an organism and may also significantly contribute to senescence. Senescent cells were found to contain $30 \%$ more oxidatively modified guanines in their DNA and four times as many free 8-oxodG bases [15]. Furthermore, reactive oxygen species (ROS), especially hydroxyl radicals, produce single strand breaks, either directly or as an intermediate step in the repair of oxidative base modifications. In contrast to the majority of genomic DNA, telomeric DNA was reported to be deficient in the repair of single strand breaks [58]. Consequently, telomeres appear to be especially sensitive for the accumulation of ROS-induced 8-oxodG DNA strand breaks $[15,56]$. Evidence for this increased sensitivity to ROSinduced 8-oxodG was obtained from two studies by Oikawa et al. $[59,60]$. In the first study, exposure of calf thymus DNA to $\mathrm{H} 2 \mathrm{O} 2$ plus $\mathrm{Cu}(\mathrm{II})$ caused oxidation of bases at the $5^{\prime}$ site of $5^{\prime}$-GGG-3' in the telomere sequence as measured using HPLC coupled with an electrochemical detector (HPLC-ECD) [60]. In the other study, WI-38 fibroblasts were irradiated with UVA and TL was determined by terminal restriction fragment length analysis [59]. To distinguish between telomeric DNA and non-telomeric DNA, a single stranded DNA fragment containing the telomere sequence was phosphorylated. The telomeric DNA fragment was annealed to its complementary strand and a non-telomeric DNA fragment was annealed to its complementary strand. In both studies it was shown that exposure of DNA to oxidative stress induced 8-oxodG formation at a higher level in telomere sequences than in non-telomere sequences $[59,60]$. Since the presence of unrepaired nucleotides or base damage might interfere with the replication fork, this may be a mechanism by which oxidative stress increases telomere shortening [6].

In addition to the direct effect of ROS on telomeric DNA, repair of oxidative lesions is less efficient in telomeres than in the rest of the genome. 
This was investigated by Petersen et al. [58], who exposed human fibroblasts to $\mathrm{H} 2 \mathrm{O} 2$ and measured the frequency of single stranded regions in telomeres and minisatellites. It was found that repeated exposure to oxidative stress increased the frequency of single strand breaks in both minisatellites and telomeres. However, single strand breaks in minisatellites were completely repaired after 1 day, whereas the repair in telomeres was much slower and incomplete [58]. An explanation for the repair deficiency in telomeres might be that the binding of TRF2 to telomeres blocks the access of DNA repair enzymes to telomeric strand breaks $[43,61]$. Furthermore, TRF2 inhibits the phosphorylation of the ATM kinase, which leads to an impaired DNA damage response [61,62]. TRF2 also interacts with polymerase $\beta$, which might have a negative effect on DNA repair $[61,63]$.

An increase in pro-inflammatory cytokines is often associated with oxidative stress, and part of the inflammatory condition [64]. In two studies by Beyne-Rauzy et al. $[65,66]$, telomerase activity was found to be negatively correlated with the pro-inflammatory cytokine tumor necrosis factor alpha (TNF- $\alpha$ ). TNF- $\alpha$ activates nuclear factor kappa B (NF-KB) and activator protein-1 (AP-1) transcription factors, and enhances the expression of pro-inflammatory genes, leading to an inflammatory response [67]. In KG1 cells (leukemic cells) that were treated with TNF- $\alpha$, a significant reduction in $T L$, as determined by flow-FISH, was observed. Further measurements showed an increase in the number of senescent cells as determined by a $\beta$-galactosidase assay [66]. In the second study, KG1 cells as well as normal bone marrow CD34+ hematopoietic progenitor cells (HPCs) (obtained from hematologically healthy patients undergoing hip surgery) were treated with TNF- $\alpha$ every two days for 14 days. hTERT gene expression was measured by quantitative RT-PCR. This study showed that TNF- $\alpha$ down-regulates the expression of the $h$-TERT gene in normal as well as in leukemic cells [65].

The autosomal recessive disorder ataxia-telangiectasia (A-T) represents a disease in which evidence was found for the relationship between chronic oxidative stress and telomere shortening. A-T is a disorder involving cerebellar degeneration, immunodeficiency and premature senescence. In most cases, mutations of the ataxia-telangiectasia mutated gene (ATM) account for this disease. ATM encodes a protein kinase that is activated in response to DNA strand breaks and is thought to be essential for maintaining chromosomal stability and telomere integrity. It has been suggested that A-T cells are in a 
chronic state of oxidative stress and have a defective maintenance or repair of telomeric DNA, contributing to their enhanced telomere shortening [68]. In addition, after in vitro exposure to hydrogen peroxide, fibroblasts from patients with A-T displayed shorter telomeres than control fibroblasts, as determined by $\mathrm{Q}-\mathrm{FISH}$. The A-T cells were not only characterized by enhanced telomere loss but also by the presence of extra-chromosomal fragments of telomeric DNA. It was concluded that ATM-deficient fibroblasts were much more sensitive to free radicals generated by hydrogen peroxide. [68]. More evidence for the role of oxidative stress in A-T was obtained from a study by Kamsler et al. [69], in which markers of the redox state in brains of ATM deficient mice were analyzed. ATM deficient mice showed a significant increase in the activity of thioredoxin and MnSOD and a significant decrease in catalase activity in the cerebella, indicative of increased levels of ROS [69].

In a study by Passos et al. [70], young and senescent cultures of human fibroblasts were compared. The senescent cells had higher ROS levels, dysfunctional mitochondria, more DNA double strand breaks and shorter telomeres and it was shown that mitochondrial ROS enhanced telomeredependent senescence [70].

\section{Antioxidants and telomere shortening}

Since oxidative modification and shortening of telomeres is induced by ROS, it is expected that antioxidants may be preventive. This appears to be supported by several studies. For example, Furumoto et al. [71] found an age-dependent telomere shortening in human vascular endothelial cells (HUVECs) in vitro, as determined by Southern blot analysis. This could be slowed down by Ascorbate2-O-phosphate (Asc2P), an oxidation-resistant derivative of vitamin C [71]. In this study, addition of $130 \mu \mathrm{M}$ Asc2P to HUVECs led to an extension of the cellular life-span and prevented cell size enlargement, which is an indication of cellular senescence $[71,72]$. Furthermore, it was found that age-dependent decline of telomerase activity could be inhibited by addition of Asc2P as determined by the TRAP assay. Asc $2 \mathrm{P}$ probably scavenges oxidative stressors in the cell, since fluorometry showed that Asc2P-treated cells had only half of the levels of oxidized reactive oxygen intermediates, as compared to non-treated cells [71]. Another study by Kashino et al. [72], showed that treatment of human embryonic cells (HE49) with $200 \mu \mathrm{M}$ ascorbic acid phosphoric ester magnesium salt (APM) decreased the level of oxidative stress, determined using 
a fluorogenic compound, prevented telomere attrition as measured by Soutern blot analysis and extended the replicative life span [72]. These results suggest that reduction of oxidative stress by antioxidant treatment might reduce the rate of telomere shortening and delay cellular senescence $[71,72]$. This has also been observed in chondrocytes by Yudoh et al. [73]. Chondrocyte senescence may contribute to the risk for cartilage degeneration by decreasing the ability of the cells to maintain and repair cartilage tissue. In this study, chondrocytes were isolated from cartilage explants and cultured in the presence of $100 \mu \mathrm{M}$ Asc2P or $0.1 \mu \mathrm{M} \mathrm{H} 2 \mathrm{O} 2$ in vitro and it was shown that oxidative stress induced telomere erosion, as determined by Southern blot analysis, and replicative senescence in chondrocytes. Treatment of chondrocytes with Asc2P showed a tendency to protect telomeres from shortening in comparison with the untreated control [73].

Further in vivo support for the relationship between oxidative stress and telomere shortening was obtained from a study by Tarry-Adkins et al. [74], where several oxidative stress markers were studied in male and female rats of the same age. Male rats showed lower antioxidant capacity than female rats. Moreover, female rats exhibited longer telomeres than male rats, as measured by Southern blot analysis. Expression levels of abundant antioxidant enzymes such as MnSOD, glutathione peroxidase I (Gpx I) and glutathione reductase in the renal cortex and medulla, were compared by Western blot, and the levels of MnSOD were higher in the female cortex as compared to the male cortex. The authors explained this by the fact that female rats have higher levels of estrogen. Estrogen enhances gene expression of MnSOD [75]. The decreased antioxidant levels in males may be partially responsible for acceleration of agerelated kidney telomere shortening [74]. Furthermore, Borras et al. [76] showed in proliferating 3T3 fibroblasts exposed to $10 \mu \mathrm{M}$ buthionine sulphoximine, depletion of cellular glutathione (GSH) and decreased telomerase activity. Repletion of cells with glutathione increased telomerase activity in a dosedependent manner [76]. In a recent cross-sectional study in Chinese elderly men it was found that the consumption of Chinese tea, which is rich in antioxidants, was positively correlated with TL [77]. Daily multivitamin use might also be beneficial for telomere maintenance as concluded from a study by Xu et al. They found a positive correlation between multivitamin use, especially the intake of vitamin E and C, and TL in women [78]. It can be concluded that antioxidants appear to support the maintenance of TL. 


\section{Chronic inflammatory diseases and oxidative stress}

Additional evidence for the role of oxidative stress in telomere shortening was found in mechanistic studies and population studies that investigated the association between TL and diseases in which chronic oxidative stress and inflammation play a major role.

In an in vitro study performed by Xu et al. [79], a relationship between homocysteine and aging was demonstrated. Homocysteine has been reported to exert atherogenic effects and this has been ascribed to increased hydrogen peroxide generation [79]. In this study, human umbilical venous endothelial cells were exposed to homocysteine in combination with copper. The rate of telomere shortening, as determined by Southern blot analysis, was increased in homocysteine treated cells and this was even more apparent when TL was plotted as a function of population doublings. It was observed that homocysteine treatment resulted in a nearly three-fold increase in the rate of telomere shortening and that this effect could be attenuated by the addition of catalase. Intracellular adhesion molecule 1 (ICAM-1) as well as plasminogen activator inhibitor 1 (PAI-1) expression was increased after chronic homocysteine treatment. These markers appeared to be overexpressed in senescent cells and this may contribute to atherosclerosis. Similarly, homocysteine treatment resulted in an increase in total PAI-1 protein levels. These results provide a potential mechanism linking increased production of ROS and decreasing TL to the development of senescence [79].

The possible association between telomere shortening and vascular pathobiology in vivo has been thoroughly reviewed by Edo and Andres [80]. Telomere shortening in circulating leukocytes has been associated with coronary and carotid atherosclerosis, premature myocardial infarction, and hypertension [81-83]. Age adjusted TRF length, as determined by Southern blot analysis, was shown to be shorter in hypertensive subjects with carotid artery plaques as compared to hypertensive subjects without plaques after adjustment for blood pressure levels, total cholesterol levels, presence of hypolipemic treatment, type of antihypertensive treatment and cigarette smoking [83]. Chang et al. [84] hypothesized that TL might serve as a marker of replicative age in human vascular tissue. In their study, human tissue samples were taken from the aortic arch, abdominal aorta, iliac artery and iliac vein. TL, determined by Southern blot analysis, showed an increased rate of telomere loss as a function of donor age in endothelial cells from iliac arteries compared 
to iliac veins. This is consistent with the greater propensity of iliac arteries to form atherosclerotic plaques. According to these results, measurement of TL might be a useful procedure to detect alterations of cellular turnover in tissues associated with cardiovascular diseases [84]. Recently, Brouilette et al. [85] compared telomere lengths at recruitment in 484 individuals who went on to develop coronary heart disease events with those from 1058 age-matched controls who remained free. They showed that individuals with shorter leukocyte $T L$, as determined by quantitative PCR, at the time of recruitment had a significantly higher risk of developing subsequent coronary heart disease. Similar findings were described by Yang et al. [86], showing that mean leukocyte $T L$ is a potential predictor of coronary artery disease. These findings indicate that the association of shorter telomeres with coronary heart disease is not a consequence of the disease [85].

In an in vitro study, human aortic endothelial cells were retrovirally infected with a dominant-negative form of TRF2 lacking both the Myb DNA binding domain and the NH2-terminal basic domain (TRF2D/N). TRF2 is essential for the formation of duplex loops of the telomere ends. Introduction of the TRF2D/N induced a growth arrest, with phenotypic characteristics of cellular senescence, as determined by a $\beta$-galactosidase assay, enlarged cell shapes and an increased expression of the adhesion molecule ICAM-1 [87]. This suggested that vascular endothelial cells with senescence-associated phenotypes are present in human atherosclerotic lesions, and that endothelial cell senescence induced by telomere shortening may contribute to atherogenesis [87].

In animal models, the link between $\mathrm{TL}$, oxidative stress and atherosclerosis has also been investigated. Spontaneously hypertensive rats (SHR) showed telomere attrition in the kidney as determined by Southern blot analysis $[80,88]$. In addition, the half-life of cells in the kidney but also in the heart and the aorta was decreased by $50 \%$ in SHR compared with healthy controls. This suggests increased cellular turnover and therefore accelerated cell aging in hypertension [88].

In a study performed by Poch et al. [89], late generation mice doubly deficient for Terc and apolipoprotein E showed shorter telomeres, but were protected from diet-induced atherogenesis, compared to atherosclerosis-prone ApoE-null mice with an intact Terc gene and longer telomeres measured by quantitative FISH. A possible explanation for the observed effect, might be that 
short telomeres limit the proliferation of leukocytes leading to a decreased atherogenicity [89]. It should also be taken into account that there are differences in telomere pathobiology between humans and mice, i.e. mice have much longer telomeres compared to humans and express telomerase activity in almost all their cells.

Diabetes has also been associated with telomere attrition [90,91]. In leukocyte DNA as well as in monocyte DNA, telomere shortening is found in type 2 diabetes patients. Since type 2 diabetes is associated with obesitas; obesity, resulting from a high intake of energy from carbohydrates and fats, might thus be a pro-inflammatory state with oxidative stress. Furthermore, increased concentrations of TNF- $\alpha$ and interleukin 6 (IL-6), associated with obesity and type 2 diabetes, have been reported to interfere with insulin action by suppressing insulin signal transduction. An interruption of insulin signal transduction might suppress the anti-inflammatory effect of insulin, which in turn might promote inflammation and, as a possible consequence, telomere attrition. Moreover, it has been shown that a low dose infusion of insulin reduces ROS generation by mononuclear cells, suppresses NADPH oxidase expression and intranuclear NF-KB binding [92-94].

Inflammatory bowel disease is another disease in which chronic inflammation plays a major role. In a study by Kinouchi et al. [95], specimens of cecal and rectal mucosa were obtained from 17 patients with ulcerative colitis (UC) aged $44.1 \pm 3.9$ years, and from 17 individuals with colon cancer aged 52.8 \pm 2.1 years, as noncolitis controls. TL was determined by Southern blot analysis of the DNA of the specimens. The results showed shortening of telomeres in the affected mucosa of individuals with UC. No relationship between TL and age was found [95]. However, no telomere shortening was observed in peripheral blood lymphocytes of patients with UC in a study by Getliffe et al. [96]. In this study, peripheral blood lymphocytes were isolated from 19 patients with ulcerative colitis, 17 patients with Crohn's disease (CD) and 18 noninflammatory bowel disease control patients. Age-related telomere loss, as determined by quantitative PCR, in peripheral blood lymphocytes was similar in ulcerative colitis, Crohn's disease and control patients. Among CD patients, those who smoked had lower levels of hTERT than non-smokers. In both the UC group and the control group only one patient smoked and this patient had lower hTERT levels than control non-smokers. With only two smokers included no detectable effect of smoking on telomerase activity or TL could be observed 
in patients and control subjects [96]. Because of the small number of subjects studied, there is no statistical power to detect differences between the two groups.

Prolonged, demanding, weight-bearing exercise has also been reported to cause both acute and more chronic muscle damage which may contribute to fatigued athlete myopathic syndrome (FAMS) [97]. In a study by Collins et al. [98], telomere lengths in muscle biopsies from athletes with exercise-associated fatigue were compared with those from controls. Subjects were matched for age, gender, height, weight and training history. It was demonstrated that these athletes had significantly shorter telomeres than their controls. The results suggested, that in an attempt to repair repeated bouts of exercise-induced muscle damage, the satellite cells of the patients had undergone more oxidative damage and more frequent rounds of replication, resulting in extensive shortening of the telomeres [98].

Besides the involvement of ROS in pathologies such as described above, these also appear to be involved in psychological pathologies [99]. This is supported in a study by Kuloglu et al. [100], where they found significant higher lipid peroxidation products in schizophrenic and bipolar disorder patients compared with healthy controls. In a study by Epel et al. [101], it was found that psychological stress, both perceived stress and chronicity of stress, was significantly associated with increased oxidative stress as determined by F2isoprostanes levels quantified from a 12-hour nocturnal urine sample. The study was performed in 58 premenopausal women who were biological mothers of either a healthy child or a chronically ill child, of which the latter were predicted to have greater environmental exposure to stress. In peripheral blood mononuclear cells, lower telomerase activity and shorter telomeres were detected, determined by the TRAP assay and quantitative PCR, in the group with greater exposure to stress. The groups were similar with respect to age, smoking behavior and vitamin use, but the high stress group had a significantly higher body mass index [101]. This may also be an explanation for the shorter telomeres detected in these women, since a higher body mass index is associated with higher leptin concentrations and increased NF-KB activation, indicative for increased inflammation [92,102]. Furthermore, obesity is the result of an increase in the number of adipocytes and these cells can secrete cytokines such as TNF- $\alpha$ and IL-6 [103]. 
A similar study was performed by Simon et al. [104]. TL was measured in 15 individuals with a mood disorder, 15 with a bipolar disorder with comorbid anxiety disorder, 14 with a bipolar disorder without anxiety and 44 agematched control subjects. DNA was extracted from leukocytes and TL was determined by Southern blot analysis. Adjustments were made for smoking behavior, age and gender. The study showed accelerated telomere shortening in individuals with mood disorders when compared to healthy control subjects. Smoking itself was not predictive of TL. Furthermore, in this study, no data on body mass index (BMI) or obesity were available and its role as a possible confounder could therefore not be determined. Since mood disorders might activate stress response mediators, chronic oxidative stress may have been the cause of the accelerated telomere shortening seen in these patients [104].

Recently, it was also found that childhood maltreatment is associated with shorter telomeres at adult age, as measured by quantitative PCR in leukocytes [105].

Both obesity and cigarette smoking are important risk factors in many age-related diseases, and are associated with increased oxidative stress and inflammation [92,106]. In a study by Valdes et al. [102], an association was found between obesity, cigarette smoking and TL. Venous blood samples were taken from women aged 18 to 76, and DNA was extracted from white blood cells. Individuals who had never smoked had longer telomeres than smokers, as determined by Southern blot analysis, and TL was negatively associated with leptin concentration in serum. BMI was not related to telomere shortening, suggesting that the mechanisms by which obesity affects TL might be better represented by leptin concentration than by BMI [102]. A possible mechanism that may be involved is the effect of obesity on leptin levels. Obesity has been associated with high serum concentrations of leptin and leptin is associated with NF-KB activation, which is a mediating factor in the production of reactive oxygen species and inflammatory cytokines [92,102]. In a very recent study, no relationship between TL and several measures of obesity could be found, but it should be noted that the study population was racially diverse, indicating other factors influencing TL [107].

The described studies provide evidence for an association between inflammation, oxidative stress and telomere shortening and it appears therefore relevant to investigate telomere shortening in other inflammatory diseases with low grade systemic inflammation and its possible contribution to 
disease pathophysiology. Most human studies focus on the relationship between TL and a specific disease, such as atherosclerosis, inflammatory bowel disease, obesity or diabetes. These are all diseases in which chronic inflammation plays a major role, as discussed above. Another group of diseases in which chronic inflammation plays a major role is the group of chronic lung diseases. A recent study investigated telomere shortening in smokers with and without chronic obstructive pulmonary disease (COPD). TL was determined by fluorescence in situ hybridization in circulating lymphocytes of non-smokers, smokers with normal lung function and smokers with moderate-to-severe airflow obstruction. In contrast to non-smokers, TL decreased faster with age in smokers. This study did not provide evidence for an enhanced telomere shortening in smokers developing COPD [108]. Another recent study did find an association between telomere shortening and COPD. Shorter telomeres were detected in COPD patients indicating an accelerated aging process. They could not find an association between TL and tobacco exposure [109].

\section{Possible models to investigate the relationship between TL and oxidative stress}

Various models have been developed and applied to investigate the relationship between TL and oxidative stress. The most common models used are in vitro studies, in which different cell lines are exposed to an oxidative stressor, such as hydrogen peroxide or tert-butyl hydroperoxide, for several passage numbers. Several studies have shown that chronic oxidative stress leads to enhanced telomere shortening in cultured cells $[11,17,56,57,68,110$ 112]. In a study performed by Kawanishi et al. [56], fibroblasts were irradiated with UVA. TL, as determined by terminal restriction fragment analysis, decreased with increasing irradiation dose. Furthermore, UVA irradiation dosedependently increased the formation of 8-oxodG in both fibroblasts and HL-60 cells [56]. In another study, human umbilical vein endothelial cells were exposed to $0.1 \mu \mathrm{M}$ tert-butyl hydroperoxide, a substrate of glutathione peroxidase, or $10 \mu \mathrm{M}$ L-buthionine-[S,R]-sulphoximine (BSO), an inhibitor of glutathione synthesis. Both treatments induced intracellular oxidative stress but had no cytotoxic or cytostatic effects. Nonetheless, treated cultures entered senescence prematurely as determined by a $\beta$-galactosidase assay. In cultures subjected to oxidative stress, Southern blot analysis demonstrated faster telomere shortening [110]. In addition to studies of telomere shortening in cell 
lines, animal models (mainly mice) have been studied extensively. In contrast to humans, rodent telomeres are generally much longer [113]. Especially mice have extremely long telomeres (up to $150 \mathrm{kbp}$ ) and express telomerase in many tissues. Nevertheless, telomere shortening is broadly studied in mice, especially in telomerase knock-out mice $[114,115]$. Telomerase knock-out mice as well as Ku86 knock-out mice have been developed to study telomere shortening. Ku86 has a protective role at mammalian telomeres and, as a consequence, Ku86 deficiency in mice results in telomeric fusion between long telomeres [115]. However, it is only after four to six generations that telomere shortening becomes a critical issue in these mice [116]. This makes mice a questionable model to study the relationship between telomere shortening and oxidative stress in humans. An alternative model is the rat, with telomere lengths ranging from 20 to $100 \mathrm{kbp}$ and in which, as opposed to mice, telomeres shorten with age in various tissues [116]. Since rat telomeres do not have to be modulated to detect shortening, a rat model might be more feasible in this perspective [117]. In a study by Cherif et al. [116], telomere lengths were assessed by Southern blot analysis in the kidney, pancreas, liver, lung and brain of male and female Wistar rats to determine lifespan. Previous studies reported relationships between kidney telomere shortening and longevity in the rat and differences in longevity between male and female rats. Males seem to have a shortened lifespan compared to their female counterparts [118,119]. In this study the percentage of short telomeres increased with age in the kidney, liver, pancreas and lung of both males and females, but not in the brain. Males had shorter telomeres than females in all organs, except in the brain, where lengths were similar. This suggests that there is a gender-related difference in lifespan and a tissue specific regulation of $T L$ in the rat [116].

In addition to mouse and rat models, telomere biology has also been studied in dogs [120]. In a study by Nasir et al. [120], the dog is proposed as an alternative model system. Telomere lengths measured by Southern blot analysis in canine PBMCs and tissues ranged from 12 to $23 \mathrm{kbp}$ and telomerase activity was detected only in tumor tissue and testis. This indicated that dogs share more similarities in telomere and telomerase biology with humans and for this reason might also be a more feasible model than the mouse [120]. Although chicken telomeres seem to resemble human telomeres for the greater part with lengths ranging from 8 to $20 \mathrm{kbp}$, the distribution of telomerase activity is similar to that in mice with many tissues displaying telomerase activity [121]. 
Since the dog model as well as the chicken model have not been investigated very thoroughly yet, it is unclear at the present whether these are feasible models to study the relationship between TL and oxidative stress in humans. TL has also been studied in bird species and in cattle. It has been shown that telomeres shorten more slowly in long-lived birds than in short-lived ones [122]. A recent study showed that the shortening rate of telomeres in free living corvids predicted survival. They concluded from their longitudinal data that the shortening rate of long telomeres may be a measure of 'life stress' may thus be a promising biomarker of the remaining lifespan [123]. In cattle it was found that there is a highly characteristic and individual TL pattern in each animal [124]. The applicability of these models in human telomere research has to be studied in more detail.

\section{Other important features of TL}

A reliable assessment of $T L$ is also important in investigating the relationship between oxidative stress and TL regulation, and there are different methods that are applied to analyze TL $[19,20]$. The choice for a specific method to determine TL will depend on the type and aim of the study. Each method has its advantages and disadvantages that make it more or less suitable for a specific purpose.

Another important feature of TL is heritability. TL appears not only to be determined by environmental factors, but also genetically [125-127]. In a recent study by Starr et al. [128], it was found that some polymorphisms related to oxidative stress are linked to increased telomere shortening.

Since telomere stability is influenced by multiple factors, genetic as well as environmental, it has been suggested that telomere shortening might serve as a biomarker of oxidative stress and disease progression and as a predictor of life expectancy [125]. This is illustrated by figure 2 . 


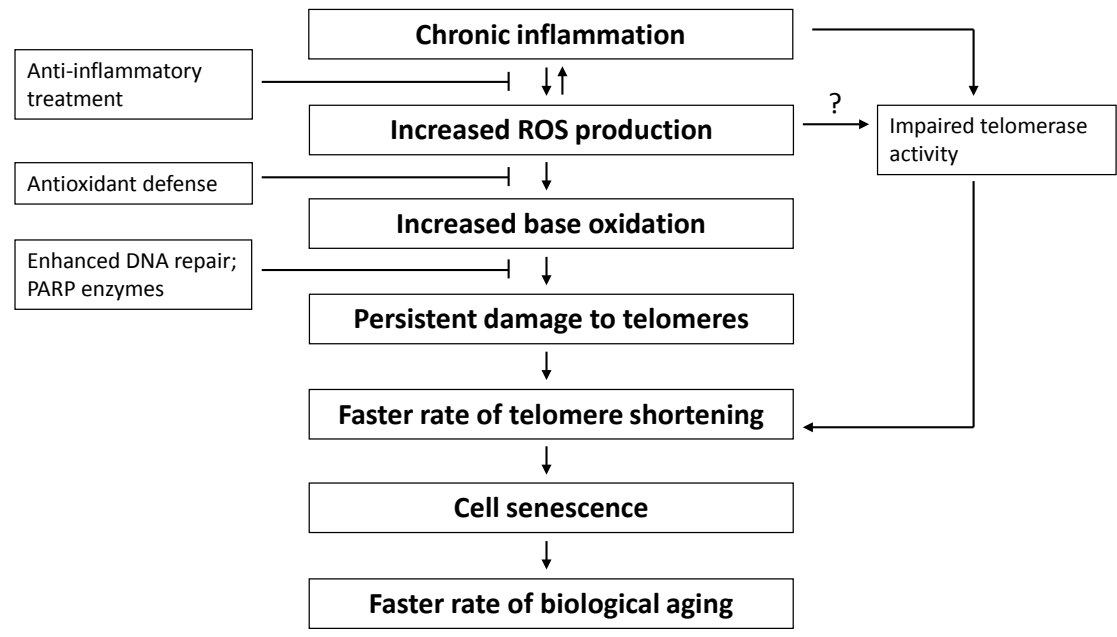

Figure 2. Telomere length as biomarker of disease progression

Recent studies have shown that telomere shortening can be a biomarker of premature cell senescence in vascular diseases and metabolic disorders, indicating the prognostic value of TL $[129,130]$. Telomere attrition in white blood cells seemed to be more closely associated with endothelial damage and atherosclerosis than chronological aging [129]. This was further supported in a study by Brouilette et al. [130], in which a strong association between leukocyte TL and premature myocardial infarction was found [130].

It appears therefore relevant to evaluate potential interventions to prevent or diminish telomere shortening as is illustrated in figure 2 . Antiinflammatory medication and antioxidant supplementation, reducing the state of chronic inflammation, appear to support telomere maintenance. In addition, stimulating the DNA repair capacity or the telomerase activity might also be advantageous to telomere maintenance and postpone cell senescence. 


\section{Aim and outline of this thesis}

Telomeres shorten with each cell division and are important in the maintenance of chromosomes. When the telomeres reach a critical length (threshold) the cell will go into senescence, leading to an irreversible growth arrest. Since TL in the somatic cells determines the number of cell divisions, TL has been proposed as a marker for biological age. Under conditions of chronic oxidative stress the rate of telomere shortening is increased. Since telomeres consist of the repetitive sequence TTAGGG, and have a high GC content, they are very vulnerable to base oxidation. Additionally, DNA strand breaks are less efficiently repaired at the telomeres when compared to the rest of our genome. This means that reactive oxygen species cause more damage to the telomeres and this damage is less well repaired.

Several inflammatory diseases have been linked to chronic oxidative stress and accelerated telomere shortening, such as diabetes, inflammatory bowel disease, atherosclerosis, chronic obstructive pulmonary disease and psychological health. It might therefore be of relevance to use TL as a marker of disease progression and survival. Besides oxidative stress, there are several other factors influencing TL and the rate of telomere shortening. Genetics play an important role in determining $\mathrm{TL}$, but environmental and lifestyle factors such as smoking, alcohol consumption, physical activity, body composition and coffee and tea consumption which affect oxidative stress levels, may contribute significantly to accelerated telomere shortening. Since oxidative modification and shortening of telomeres is induced by reactive oxygen species, it is expected that antioxidants may be preventive. Dietary interventions with antioxidants and/or anti-inflammatory agents might increase longevity by decreasing the levels of oxidative stress.

There are still many mechanisms that need to be unraveled and it is not clear yet whether TL is a useful biomarker.

The overall aim of this thesis was to evaluate the effects of chronic oxidative stress on telomere shortening and the possible use of TL as a biological marker of disease progression and aging.

The primary objectives of this thesis are:

- To investigate differences in $\mathrm{TL}$, oxidative stress markers and antioxidant status between elderly men from the Netherlands and from Greece 
- To determine whether telomere shortening is a predictor of mortality

- To examine telomere shortening in COPD patients

- To assess telomere shortening in COPD patients and relate these findings to lifestyle factors such as coffee and alcohol consumption.

- To investigate the effects of interventions with the flavonoid fisetin and the antioxidant $n$-acetylcysteine on telomere shortening and markers of oxidative stress in a diabetic rat model.

To study the effects of chronic oxidative stress and the antioxidant status on $T L$, in chapter $\mathbf{2}$ the results are described of a cross-country study of elderly men in the Netherlands and in Greece. In this study TL was measured by quantitative PCR and markers of oxidative stress and antioxidant status were determined to unravel the differences in TL between these two countries. In chapter 3 the possible use of TL as a marker for mortality is discussed, which was studied in the Zutphen elderly study. In this longitudinal study we measured telomere shortening over a period of 7 years. This study gives information on individual telomere shortening and its possible relationship with all-cause mortality, and disease specific mortality. In chapter 4 differences in TL between healthy controls and COPD patients were evaluated. TL was determined and SOD activity was measured to investigate the possible relationship between TL and antioxidant capacity.

Chapter 5 also describes patient-control study with healthy controls and COPD patients. In this study we confirmed previous results (chapter 4 ) and we measured additional relevant markers of oxidative stress and inflammation, i.e cytokines and we collected data on coffee, caffeine and alcohol consumption to investigate the possible effects of these dietary compounds on markers of oxidative stress and TL. In this study we also measured homocysteine levels. In chapter 6 we describe the effects of food interventions on TL in a diabetic rat model. Rats were injected with streptozotocin to induce diabetes, a disease that is marked by chronic oxidative stress. Two groups received either fisetin, a flavonoid, or n-acetylcysteine, an antioxidant, through their food. Several markers of oxidative stress were measured, TL was determined and gene expression of relevant genes was measured by quantitative PCR. Finally, in chapter 7, a general discussion of these findings together with their potential implications and future prospects is presented. 


\section{References}

1. Harley $\mathrm{CB}$, Futcher $\mathrm{AB}$, Greider $\mathrm{CW}$ : Telomeres shorten during ageing of human fibroblasts. Nature 1990;345:458-460.

2. Hayflick L: The Limited in Vitro Lifetime of Human Diploid Cell Strains. Exp Cell Res 1965;37:614-636.

3. Blackburn EH: Structure and function of telomeres. Nature 1991;350:569-573.

4. Moyzis RK, Buckingham JM, Cram LS, Dani M, Deaven LL, Jones MD, Meyne J, Ratliff RL, Wu JR: A highly conserved repetitive DNA sequence, (TTAGGG)n, present at the telomeres of human chromosomes. Proc Natl Acad Sci U S A 1988;85:6622-6626.

5. Meyne J, Ratliff RL, Moyzis RK: Conservation of the human telomere sequence (TTAGGG)n among vertebrates. Proc Natl Acad Sci U S A 1989;86:7049-7053.

6. von Zglinicki T: Oxidative stress shortens telomeres. Trends Biochem Sci 2002;27:339-344.

7. Harrington L: Those dam-aged telomeres! Curr Opin Genet Dev 2004;14:22-28.

8. von Zglinicki T: Telomeres and replicative senescence: Is it only length that counts? Cancer Lett 2001;168:111-116.

9. Greider CW, Blackburn EH: Telomeres, telomerase and cancer. Sci Am 1996;274:9297.

10. Joosten SA, van Ham V, Nolan CE, Borrias MC, Jardine AG, Shiels PG, van Kooten C, Paul LC: Telomere shortening and cellular senescence in a model of chronic renal allograft rejection. Am J Pathol 2003;162:1305-1312.

11. von Zglinicki T: Role of oxidative stress in telomere length regulation and replicative senescence. Ann N Y Acad Sci 2000;908:99-110.

12. Jennings BJ, Ozanne SE, Hales CN: Nutrition, oxidative damage, telomere shortening, and cellular senescence: individual or connected agents of aging? Mol Genet Metab 2000;71:32-42.

13. Makarov VL, Hirose $\mathrm{Y}$, Langmore JP: Long $\mathrm{G}$ tails at both ends of human chromosomes suggest a $\mathrm{C}$ strand degradation mechanism for telomere shortening. Cell 1997;88:657-666.

14. von Zglinicki T, Burkle A, Kirkwood TB: Stress, DNA damage and ageing -- an integrative approach. Exp Gerontol 2001;36:1049-1062.

15. von Zglinicki T, Martin-Ruiz C, Saretzki G: Telomeres, cell senescence and human ageing. Signal Transduction 2005;3.

16. von Zglinicki T, Martin-Ruiz CM: Telomeres as biomarkers for ageing and agerelated diseases. Curr Mol Med 2005;5:197-203.

17. von Zglinicki T, Pilger R, Sitte N: Accumulation of single-strand breaks is the major cause of telomere shortening in human fibroblasts. Free Radic Biol Med 2000;28:64-74. 
18. von Zglinicki T, Saretzki G, Docke W, Lotze C: Mild hyperoxia shortens telomeres and inhibits proliferation of fibroblasts: a model for senescence? Exp Cell Res 1995;220:186-193.

19. Nakagawa S, Gemmell NJ, Burke T: Measuring vertebrate telomeres: applications and limitations. Mol Ecol 2004;13:2523-2533.

20. Lin KW, Yan J: The telomere length dynamic and methods of its assessment. J Cell Mol Med 2005;9:977-989.

21. Baird DM, Rowson J, Wynford-Thomas D, Kipling D: Extensive allelic variation and ultrashort telomeres in senescent human cells. Nat Genet 2003;33:203-207.

22. Cawthon RM: Telomere measurement by quantitative PCR. Nucleic Acids Res 2002;30:e47.

23. Gil ME, Coetzer TL: Real-time quantitative PCR of telomere length. Mol Biotechnol 2004;27:169-172.

24. Saldanha SN, Andrews LG, Tollefsbol TO: Assessment of telomere length and factors that contribute to its stability. Eur J Biochem 2003;270:389-403.

25. Bodnar AG, Ouellette M, Frolkis M, Holt SE, Chiu CP, Morin GB, Harley CB, Shay JW, Lichtsteiner S, Wright WE: Extension of life-span by introduction of telomerase into normal human cells. Science 1998;279:349-352.

26. Blasco MA: Mammalian telomeres and telomerase: why they matter for cancer and aging. Eur J Cell Biol 2003;82:441-446.

27. Alberts B, Johnson A, Lewis J, Raff M, Roberts K, Walter P: Molecular Biology of the Cell. New York, Garland Science, 2004.

28. Collins K, Mitchell JR: Telomerase in the human organism. Oncogene 2002;21:564579.

29. Aisner DL, Wright WE, Shay JW: Telomerase regulation: not just flipping the switch. Curr Opin Genet Dev 2002;12:80-85.

30. Vaziri H, Dragowska W, Allsopp RC, Thomas TE, Harley CB, Lansdorp PM: Evidence for a mitotic clock in human hematopoietic stem cells: loss of telomeric DNA with age. Proc Natl Acad Sci U S A 1994;91:9857-9860.

31. Zhou J, Shen X, Huang J, Hodes RJ, Rosenberg SA, Robbins PF: Telomere length of transferred lymphocytes correlates with in vivo persistence and tumor regression in melanoma patients receiving cell transfer therapy. J Immunol 2005;175:70467052.

32. Friedrich $\mathrm{U}$, Griese $\mathrm{E}$, Schwab M, Fritz $\mathrm{P}$, Thon K, Klotz U: Telomere length in different tissues of elderly patients. Mech Ageing Dev 2000;119:89-99.

33. Broberg K, Bjork J, Paulsson K, Hoglund M, Albin M: Constitutional short telomeres are strong genetic susceptibility markers for bladder cancer. Carcinogenesis 2005;26:1263-1271.

34. Chiang YJ, Kim SH, Tessarollo L, Campisi J, Hodes RJ: Telomere-associated protein TIN2 is essential for early embryonic development through a telomeraseindependent pathway. Mol Cell Biol 2004;24:6631-6634. 
35. Myung K, Ghosh G, Fattah FJ, Li G, Kim H, Dutia A, Pak E, Smith S, Hendrickson EA: Regulation of telomere length and suppression of genomic instability in human somatic cells by Ku86. Mol Cell Biol 2004;24:5050-5059.

36. Kishi S, Zhou XZ, Ziv Y, Khoo C, Hill DE, Shiloh Y, Lu KP: Telomeric protein Pin2/TRF1 as an important ATM target in response to double strand DNA breaks. J Biol Chem 2001;276:29282-29291.

37. Takai H, Smogorzewska A, de Lange T: DNA damage foci at dysfunctional telomeres. Curr Biol 2003;13:1549-1556.

38. Gomez M, Wu J, Schreiber V, Dunlap J, Dantzer F, Wang Y, Liu Y: PARP1 Is a TRF2associated poly(ADP-ribose)polymerase and protects eroded telomeres. Mol Biol Cell 2006;17:1686-1696.

39. Karlseder J, Broccoli D, Dai Y, Hardy S, de Lange T: p53- and ATM-dependent apoptosis induced by telomeres lacking TRF2. Science 1999;283:1321-1325.

40. Pardo B, Marcand S: Rap1 prevents telomere fusions by nonhomologous end joining. Embo J 2005;24:3117-3127.

41. Hockemeyer D, Sfeir AJ, Shay JW, Wright WE, de Lange T: POT1 protects telomeres from a transient DNA damage response and determines how human chromosomes end. Embo J 2005;24:2667-2678.

42. Bekaert S, Derradji H, Baatout S: Telomere biology in mammalian germ cells and during development. Dev Biol 2004;274:15-30.

43. Ohki R, Ishikawa F: Telomere-bound TRF1 and TRF2 stall the replication fork at telomeric repeats. Nucleic Acids Res 2004;32:1627-1637.

44. O'Connor MS, Safari A, Xin H, Liu D, Songyang Z: A critical role for TPP1 and TIN2 interaction in high-order telomeric complex assembly. Proc Natl Acad Sci U S A 2006;103:11874-11879.

45. Masson M, Niedergang C, Schreiber V, Muller S, Menissier-de Murcia J, de Murcia G: XRCC1 is specifically associated with poly(ADP-ribose) polymerase and negatively regulates its activity following DNA damage. Mol Cell Biol 1998;18:3563-3571.

46. Oliver FJ, Menissier-de Murcia J, de Murcia G: Poly(ADP-ribose) polymerase in the cellular response to DNA damage, apoptosis, and disease. Am J Hum Genet 1999;64:1282-1288.

47. Smith S: The world according to PARP. Trends Biochem Sci 2001;26:174-179.

48. Virag L, Szabo C: The therapeutic potential of poly(ADP-ribose) polymerase inhibitors. Pharmacol Rev 2002;54:375-429.

49. Burkle A, Brabeck C, Diefenbach J, Beneke S: The emerging role of poly(ADP-ribose) polymerase-1 in longevity. Int J Biochem Cell Biol 2005;37:1043-1053.

50. Smith S, Giriat I, Schmitt A, de Lange T: Tankyrase, a poly(ADP-ribose) polymerase at human telomeres. Science 1998;282:1484-1487.

51. Cook BD, Dynek JN, Chang W, Shostak G, Smith S: Role for the related poly(ADPRibose) polymerases tankyrase 1 and 2 at human telomeres. Mol Cell Biol 2002;22:332-342. 
52. Chang W, Dynek JN, Smith S: NuMA is a major acceptor of poly(ADP-ribosyl)ation by tankyrase 1 in mitosis. Biochem J 2005;391:177-184.

53. Hsiao SJ, Poitras MF, Cook BD, Liu Y, Smith S: Tankyrase 2 poly(ADP-ribose) polymerase domain-deleted mice exhibit growth defects but have normal telomere length and capping. Mol Cell Biol 2006;26:2044-2054.

54. Chiang YJ, Nguyen ML, Gurunathan S, Kaminker P, Tessarollo L, Campisi J, Hodes RJ: Generation and characterization of telomere length maintenance in tankyrase 2deficient mice. Mol Cell Biol 2006;26:2037-2043.

55. d'Adda di Fagagna F, Hande MP, Tong WM, Lansdorp PM, Wang ZQ, Jackson SP: Functions of poly(ADP-ribose) polymerase in controlling telomere length and chromosomal stability. Nat Genet 1999;23:76-80.

56. Kawanishi S, Oikawa S: Mechanism of telomere shortening by oxidative stress. Ann N Y Acad Sci 2004;1019:278-284.

57. Sitte N, Saretzki G, von Zglinicki T: Accelerated telomere shortening in fibroblasts after extended periods of confluency. Free Radic Biol Med 1998;24:885-893.

58. Petersen S, Saretzki G, von Zglinicki T: Preferential accumulation of single-stranded regions in telomeres of human fibroblasts. Exp Cell Res 1998;239:152-160.

59. Oikawa S, Tada-Oikawa S, Kawanishi S: Site-specific DNA damage at the GGG sequence by UVA involves acceleration of telomere shortening. Biochemistry 2001;40:4763-4768.

60. Oikawa S, Kawanishi S: Site-specific DNA damage at GGG sequence by oxidative stress may accelerate telomere shortening. FEBS Lett 1999;453:365-368.

61. Richter T, Saretzki G, Nelson G, Melcher M, Olijslagers S, von Zglinicki T: TRF2 overexpression diminishes repair of telomeric single-strand breaks and accelerates telomere shortening in human fibroblasts. Mech Ageing Dev 2007;128:340-345.

62. Karlseder J, Hoke K, Mirzoeva OK, Bakkenist C, Kastan MB, Petrini JH, de Lange T: The telomeric protein TRF2 binds the ATM kinase and can inhibit the ATMdependent DNA damage response. PLoS Biol 2004;2:E240.

63. Fotiadou P, Henegariu O, Sweasy JB: DNA polymerase beta interacts with TRF2 and induces telomere dysfunction in a murine mammary cell line. Cancer Res 2004;64:3830-3837.

64. Floyd RA, Hensley K, Jaffery F, Maidt L, Robinson K, Pye Q, Stewart C: Increased oxidative stress brought on by pro-inflammatory cytokines in neurodegenerative processes and the protective role of nitrone-based free radical traps. Life Sci 1999;65:1893-1899.

65. Beyne-Rauzy O, Prade-Houdellier N, Demur C, Recher C, Ayel J, Laurent G, MansatDe Mas V: Tumor necrosis factor-alpha inhibits hTERT gene expression in human myeloid normal and leukemic cells. Blood 2005;106:3200-3205.

66. Beyne-Rauzy O, Recher C, Dastugue N, Demur C, Pottier G, Laurent G, Sabatier L, Mansat-De Mas V: Tumor necrosis factor alpha induces senescence and chromosomal instability in human leukemic cells. Oncogene 2004;23:7507-7516. 
67. Rahman I, Gilmour PS, Jimenez LA, MacNee W: Oxidative stress and TNF-alpha induce histone acetylation and NF-kappaB/AP-1 activation in alveolar epithelial cells: potential mechanism in gene transcription in lung inflammation. Mol Cell Biochem 2002;234-235:239-248.

68. Tchirkov A, Lansdorp PM: Role of oxidative stress in telomere shortening in cultured fibroblasts from normal individuals and patients with ataxia-telangiectasia. Hum Mol Genet 2003;12:227-232.

69. Kamsler A, Daily D, Hochman A, Stern N, Shiloh Y, Rotman G, Barzilai A: Increased oxidative stress in ataxia telangiectasia evidenced by alterations in redox state of brains from Atm-deficient mice. Cancer Res 2001;61:1849-1854.

70. Passos JF, Saretzki G, Ahmed S, Nelson G, Richter T, Peters H, Wappler I, Birket MJ, Harold G, Schaeuble K, Birch-Machin MA, Kirkwood TB, von Zglinicki T: Mitochondrial dysfunction accounts for the stochastic heterogeneity in telomeredependent senescence. PLoS Biol 2007;5:e110.

71. Furumoto K, Inoue E, Nagao N, Hiyama E, Miwa N: Age-dependent telomere shortening is slowed down by enrichment of intracellular vitamin C via suppression of oxidative stress. Life Sci 1998;63:935-948.

72. Kashino G, Kodama S, Nakayama Y, Suzuki K, Fukase K, Goto M, Watanabe M: Relief of oxidative stress by ascorbic acid delays cellular senescence of normal human and Werner syndrome fibroblast cells. Free Radic Biol Med 2003;35:438-443.

73. Yudoh K, Nguyen T, Nakamura H, Hongo-Masuko K, Kato T, Nishioka K: Potential involvement of oxidative stress in cartilage senescence and development of osteoarthritis: oxidative stress induces chondrocyte telomere instability and downregulation of chondrocyte function. Arthritis Res Ther 2005;7:R380-391.

74. Tarry-Adkins JL, Ozanne SE, Norden A, Cherif H, Hales CN: Lower antioxidant capacity and elevated p53 and p21 may be a link between gender disparity in renal telomere shortening, albuminuria, and longevity. Am J Physiol Renal Physiol 2006;290:F509-516.

75. Strehlow K, Rotter S, Wassmann S, Adam O, Grohe C, Laufs K, Bohm M, Nickenig G: Modulation of antioxidant enzyme expression and function by estrogen. Circ Res 2003;93:170-177.

76. Borras C, Esteve JM, Vina JR, Sastre J, Vina J, Pallardo FV: Glutathione regulates telomerase activity in 3T3 fibroblasts. J Biol Chem 2004;279:34332-34335.

77. Chan R, Woo J, Suen E, Leung J, Tang N: Chinese tea consumption is associated with longer telomere length in elderly Chinese men. Br J Nutr 2009:1-7.

78. Xu Q, Parks CG, DeRoo LA, Cawthon RM, Sandler DP, Chen H: Multivitamin use and telomere length in women. Am J Clin Nutr 2009;89:1857-1863.

79. Xu D, Neville R, Finkel T: Homocysteine accelerates endothelial cell senescence. FEBS Lett 2000;470:20-24.

80. Edo MD, Andres V: Aging, telomeres, and atherosclerosis. Cardiovasc Res 2005;66:213-221. 
81. Jeanclos E, Schork NJ, Kyvik KO, Kimura M, Skurnick JH, Aviv A: Telomere length inversely correlates with pulse pressure and is highly familial. Hypertension 2000;36:195-200.

82. Benetos A, Okuda K, Lajemi M, Kimura M, Thomas F, Skurnick J, Labat C, Bean K, Aviv A: Telomere length as an indicator of biological aging: the gender effect and relation with pulse pressure and pulse wave velocity. Hypertension 2001;37:381385.

83. Benetos A, Gardner JP, Zureik M, Labat C, Xiaobin L, Adamopoulos C, Temmar M, Bean KE, Thomas F, Aviv A: Short telomeres are associated with increased carotid atherosclerosis in hypertensive subjects. Hypertension 2004;43:182-185.

84. Chang $\mathrm{E}$, Harley $\mathrm{CB}$ : Telomere length and replicative aging in human vascular tissues. Proc Natl Acad Sci U S A 1995;92:11190-11194.

85. Brouilette SW, Moore JS, McMahon AD, Thompson JR, Ford I, Shepherd J, Packard $\mathrm{CJ}$, Samani NJ: Telomere length, risk of coronary heart disease, and statin treatment in the West of Scotland Primary Prevention Study: a nested case-control study. Lancet 2007;369:107-114.

86. Yang Z, Huang X, Jiang H, Zhang Y, Liu H, Qin C, Eisner GM, Jose PA, Rudolph L, Ju Z: Short telomeres and prognosis of hypertension in a chinese population. Hypertension 2009;53:639-645.

87. Minamino T, Miyauchi H, Yoshida T, Ishida Y, Yoshida H, Komuro I: Endothelial cell senescence in human atherosclerosis: role of telomere in endothelial dysfunction. Circulation 2002;105:1541-1544.

88. Hamet P, Thorin-Trescases N, Moreau P, Dumas P, Tea BS, deBlois D, Kren V, Pravenec $M$, Kunes J, Sun $Y$, Tremblay J: Workshop: excess growth and apoptosis: is hypertension a case of accelerated aging of cardiovascular cells? Hypertension 2001;37:760-766.

89. Poch E, Carbonell P, Franco S, Diez-Juan A, Blasco MA, Andres V: Short telomeres protect from diet-induced atherosclerosis in apolipoprotein E-null mice. Faseb J 2004;18:418-420.

90. Adaikalakoteswari A, Balasubramanyam M, Mohan V: Telomere shortening occurs in Asian Indian Type 2 diabetic patients. Diabet Med 2005;22:1151-1156.

91. Jeanclos E, Krolewski A, Skurnick J, Kimura M, Aviv H, Warram JH, Aviv A: Shortened telomere length in white blood cells of patients with IDDM. Diabetes 1998;47:482486.

92. Dandona P, Aljada A, Bandyopadhyay A: Inflammation: the link between insulin resistance, obesity and diabetes. Trends Immunol 2004;25:4-7.

93. Dandona P, Aljada A, Mohanty P, Ghanim H, Hamouda W, Assian E, Ahmad S: Insulin inhibits intranuclear nuclear factor kappaB and stimulates IkappaB in mononuclear cells in obese subjects: evidence for an anti-inflammatory effect? J Clin Endocrinol Metab 2001;86:3257-3265. 
94. Aljada A, Ghanim H, Mohanty P, Kapur N, Dandona P: Insulin inhibits the proinflammatory transcription factor early growth response gene-1 (Egr)-1 expression in mononuclear cells (MNC) and reduces plasma tissue factor (TF) and plasminogen activator inhibitor-1 (PAI-1) concentrations. J Clin Endocrinol Metab 2002;87:14191422.

95. Kinouchi Y, Hiwatashi N, Chida M, Nagashima F, Takagi S, Maekawa H, Toyota T: Telomere shortening in the colonic mucosa of patients with ulcerative colitis. J Gastroenterol 1998;33:343-348.

96. Getliffe KM, Al Dulaimi D, Martin-Ruiz C, Holder RL, von Zglinicki T, Morris A, Nwokolo CU: Lymphocyte telomere dynamics and telomerase activity in inflammatory bowel disease: effect of drugs and smoking. Aliment Pharmacol Ther 2005;21:121-131.

97. Lambert MI, St Clair Gibson A, Derman EW, Noakes TD: Regeneration after ultraendurance exercise. in Overload, Performance Incompetence and Regeneration in Sport. New York: Kluwer Academic/Plenum Publishers, 1999, 163-172.

98. Collins M, Renault V, Grobler LA, St Clair Gibson A, Lambert MI, Wayne Derman E, Butler-Browne GS, Noakes TD, Mouly V: Athletes with exercise-associated fatigue have abnormally short muscle DNA telomeres. Med Sci Sports Exerc 2003;35:15241528.

99. Tezcan E, Atmaca M, Kuloglu M, Ustundag B: Free radicals in patients with posttraumatic stress disorder. Eur Arch Psychiatry Clin Neurosci 2003;253:89-91.

100. Kuloglu M, Ustundag B, Atmaca M, Canatan H, Tezcan AE, Cinkilinc N: Lipid peroxidation and antioxidant enzyme levels in patients with schizophrenia and bipolar disorder. Cell Biochem Funct 2002;20:171-175.

101. Epel ES, Blackburn EH, Lin J, Dhabhar FS, Adler NE, Morrow JD, Cawthon RM: Accelerated telomere shortening in response to life stress. Proc Natl Acad Sci U S A 2004;101:17312-17315.

102. Valdes AM, Andrew T, Gardner JP, Kimura M, Oelsner E, Cherkas LF, Aviv A, Spector TD: Obesity, cigarette smoking, and telomere length in women. Lancet 2005;366:662-664.

103. Lehrke M, Lazar MA: Inflamed about obesity. Nat Med 2004;10:126-127.

104. Simon NM, Smoller JW, McNamara KL, Maser RS, Zalta AK, Pollack MH, Nierenberg AA, Fava M, Wong KK: Telomere Shortening and Mood Disorders: Preliminary Support for a Chronic Stress Model of Accelerated Aging. Biol Psychiatry 2006.

105. Tyrka AR, Price LH, Kao HT, Porton B, Marsella SA, Carpenter LL: Childhood Maltreatment and Telomere Shortening: Preliminary Support for an Effect of Early Stress on Cellular Aging. Biol Psychiatry 2009.

106. Burke A, Fitzgerald GA: Oxidative stress and smoking-induced vascular injury. Prog Cardiovasc Dis 2003;46:79-90.

107. Diaz V, Mainous III A, Player M, Everett C: Telomere length and adiposity in a racially diverse sample. International Journal of Obesity 2009:1-5. 
108. Morla M, Busquets X, Pons J, Sauleda J, MacNee W, Agusti AG: Telomere shortening in smokers with and without COPD. Eur Respir J 2006;27:525-528.

109. Savale L, Chaouat A, Bastuji-Garin S, Marcos E, Boyer L, Maitre B, Sarni M, Housset B, Weitzenblum E, Matrat M, Le Corvoisier P, Rideau D, Boczkowski J, Dubois-Rande $\mathrm{JL}$, Chouaid C, Adnot S: Shortened Telomeres in Circulating Leukocytes of Patients with Chronic Obstructive Pulmonary Disease. Am J Respir Crit Care Med 2009.

110. Kurz DJ, Decary S, Hong Y, Trivier E, Akhmedov A, Erusalimsky JD: Chronic oxidative stress compromises telomere integrity and accelerates the onset of senescence in human endothelial cells. J Cell Sci 2004;117:2417-2426.

111. Duan J, Zhang Z, Tong T: Irreversible cellular senescence induced by prolonged exposure to $\mathrm{H} 2 \mathrm{O} 2$ involves DNA-damage-and-repair genes and telomere shortening. Int J Biochem Cell Biol 2005;37:1407-1420.

112. Serra V, Grune T, Sitte N, Saretzki G, von Zglinicki T: Telomere length as a marker of oxidative stress in primary human fibroblast cultures. Ann N Y Acad Sci 2000;908:327-330.

113. Kipling D, Cooke HJ: Hypervariable ultra-long telomeres in mice. Nature 1990;347:400-402.

114. Blasco MA: Mice with bad ends: mouse models for the study of telomeres and telomerase in cancer and aging. Embo J 2005;24:1095-1103.

115. Xin Z, Broccoli D: Manipulating mouse telomeres: models of tumorigenesis and aging. Cytogenet Genome Res 2004;105:471-478.

116. Cherif H, Tarry JL, Ozanne SE, Hales CN: Ageing and telomeres: a study into organand gender-specific telomere shortening. Nucleic Acids Res 2003;31:1576-1583.

117. Hastings R, Li NC, Lacy PS, Patel H, Herbert KE, Stanley AG, Williams B: Rapid telomere attrition in cardiac tissue of the ageing Wistar rat. Exp Gerontol 2004;39:855-857.

118. Jennings BJ, Ozanne SE, Dorling MW, Hales CN: Early growth determines longevity in male rats and may be related to telomere shortening in the kidney. FEBS Lett 1999;448:4-8.

119. Hales CN, Desai M, Ozanne SE, Crowther NJ: Fishing in the stream of diabetes: from measuring insulin to the control of fetal organogenesis. Biochem Soc Trans 1996;24:341-350.

120. Nasir L, Devlin P, McKevitt T, Rutteman G, Argyle DJ: Telomere lengths and telomerase activity in dog tissues: a potential model system to study human telomere and telomerase biology. Neoplasia 2001;3:351-359.

121. Venkatesan RN, Price C: Telomerase expression in chickens: constitutive activity in somatic tissues and down-regulation in culture. Proc Natl Acad Sci U S A 1998;95:14763-14768.

122. Haussmann MF, Winkler DW, O'Reilly KM, Huntington CE, Nisbet IC, Vleck CM: Telomeres shorten more slowly in long-lived birds and mammals than in short-lived ones. Proc Biol Sci 2003;270:1387-1392. 
123. Salomons HM, Mulder GA, van de Zande L, Haussmann MF, Linskens $M H$, Verhulst $\mathrm{S}$ : Telomere shortening and survival in free-living corvids. Proc Biol Sci 2009;276:3157-3165.

124. Mayr B, Korb H, Oppeneiger T, Demetz F, Egger J: Highly characteristic and individual specific telomere length patterns in cattle. Vet J 2007.

125. Cawthon RM, Smith KR, O'Brien E, Sivatchenko A, Kerber RA: Association between telomere length in blood and mortality in people aged 60 years or older. Lancet 2003;361:393-395.

126. Nordfjall K, Larefalk A, Lindgren P, Holmberg D, Roos G: Telomere length and heredity: Indications of paternal inheritance. Proc Natl Acad Sci U S A 2005;102:16374-16378.

127. Slagboom PE, Droog S, Boomsma DI: Genetic determination of telomere size in humans: a twin study of three age groups. Am J Hum Genet 1994;55:876-882.

128. Starr JM, Shiels PG, Harris SE, Pattie A, Pearce MS, Relton CL, Deary IJ: Oxidative stress, telomere length and biomarkers of physical aging in a cohort aged 79 years from the 1932 Scottish Mental Survey. Mech Ageing Dev 2008;129:745-751.

129. Nakashima H, Ozono R, Suyama C, Sueda T, Kambe M, Oshima T: Telomere attrition in white blood cell correlating with cardiovascular damage. Hypertens Res 2004;27:319-325.

130. Brouilette S, Singh RK, Thompson JR, Goodall AH, Samani NJ: White cell telomere length and risk of premature myocardial infarction. Arterioscler Thromb Vasc Biol 2003;23:842-846 




\section{Chapter 2}

Telomere length, oxidative stress, and antioxidant status in elderly men: differences between Zutphen and

Crete
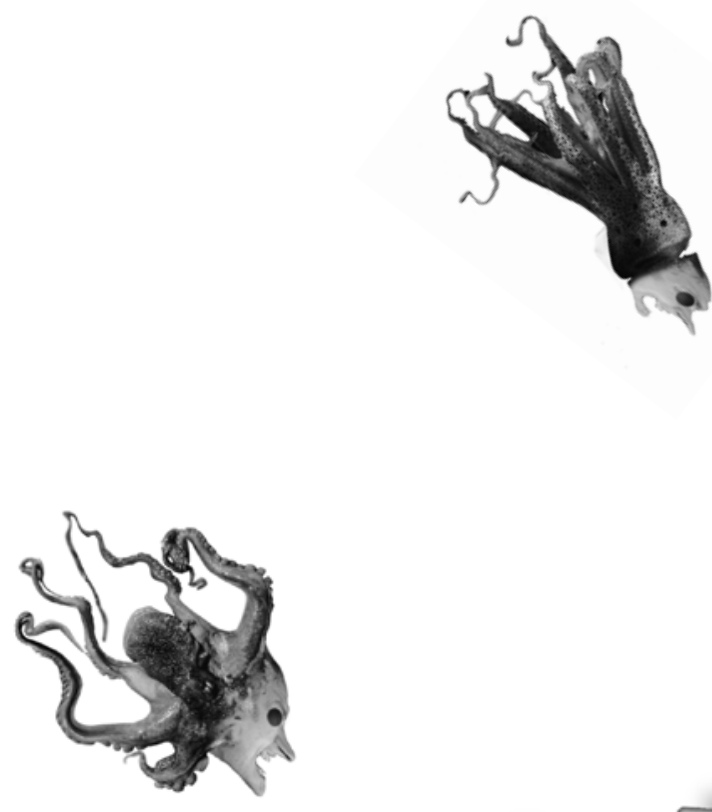

PNAS, submitted

Joyce M.J. Houben

Nathaly Rius Ottenheim

Anthony Kafatos

Brian Buijsse

Geja J. Hageman

Daan Kromhout

Erik J. Giltay

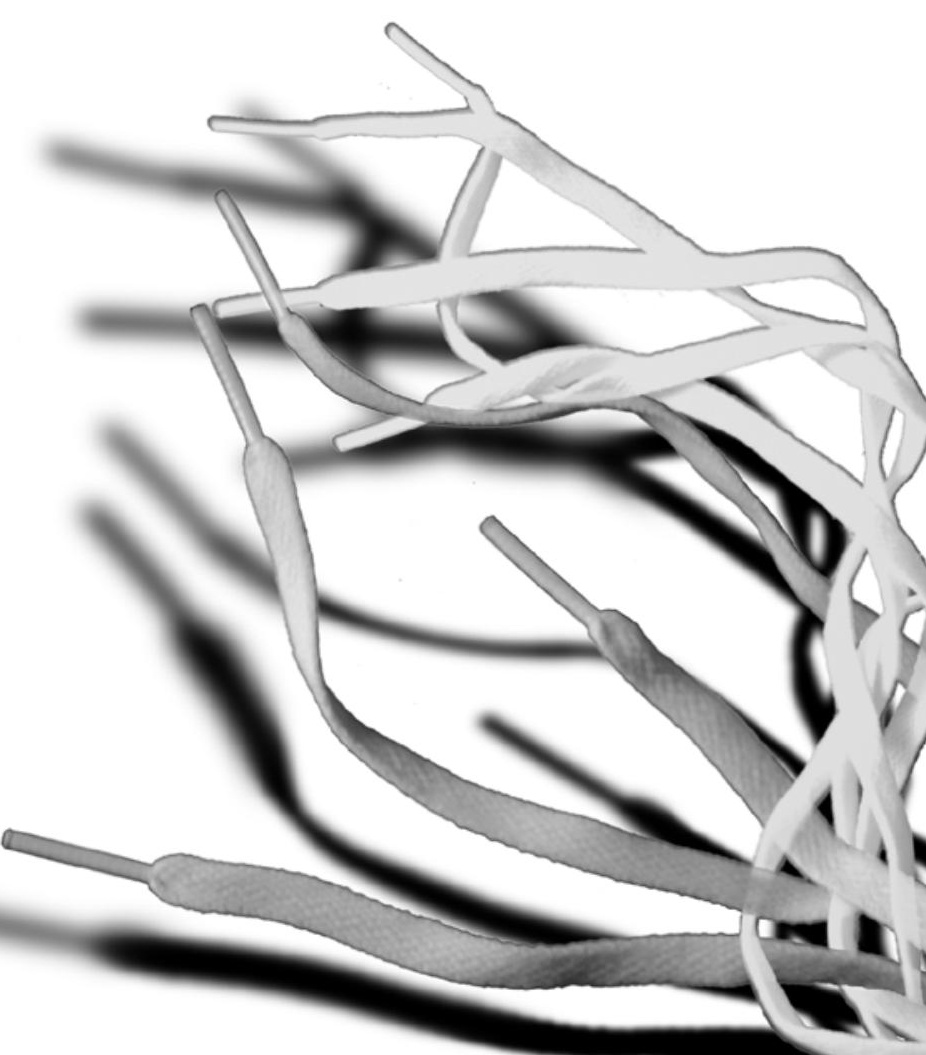




\section{Abstract}

The incidence of major chronic diseases such as cardiovascular diseases is lower in Mediterranean Southern Europe than Northern Europe. This may be due to a lower level of oxidative stress and a higher antioxidant status in people living around the Mediterranean Sea. Oxidative stress may influence the rate of shortening of telomeres, the nucleoprotein structures at the ends of chromosomes. We aimed to compare leukocyte telomere length (LTL) in elderly men from Northern and Southern Europe and to investigate the possible relationship between LTL and indicators of oxidative stress and antioxidant status.

LTL was measured by quantitative PCR and indicators of oxidative stress were measured in serum, antioxidant vitamins in plasma and endogenous antioxidants in serum.

We examined 143 elderly Dutch men (mean age 83.9 years) and 109 Greek elderly men (mean age 84.6 years) and found that the Greek men had significantly longer telomeres (geometric mean $4.95 \mathrm{kbp}, 95 \%$ confidence interval $(\mathrm{Cl}): 4.71-5.23 \mathrm{kbp}$ ) compared to the men from the Netherlands (4.76 $\mathrm{kbp}, 95 \% \mathrm{Cl}: 4.55-4.98 \mathrm{kbp} ; \mathrm{P}=0.001)$. Age was inversely associated with $\mathrm{LTL}(\beta=-$ $0.10, P=0.31$ in Cretan men and $\beta=-0.19, P=0.02$ in Dutch men). In all men LTL was not related to indicators of oxidative stress and plasma antioxidants. However, the endogenous antioxidants serum albumin $(\beta=0.18, P=0.007)$ and uric acid $(\beta=0.13, P=0.045)$ were positively associated with LTL. The ageadjusted difference between Crete and Zutphen was reduced by $30 \%$ after adjustment for serum albumin and uric acid.

We conclude that Greek elderly men have significantly longer LTL compared to Dutch counterparts. The endogenous antioxidants albumin and uric acid were positively associated with longer telomeres and may explain part of the longer LTL in Greek than in Dutch men. 


\section{Introduction}

Oxidative stress causes extensive damage to DNA, proteins, and lipids. This damage is a major contributor to aging and may afflict widely different degenerative diseases, such as cardiovascular diseases [1]. Blood levels of indicators of oxidative stress were higher and those of antioxidants were lower in Northern Europe compared to Mediterranean Southern Europe [2-5]. This may be one of the reasons for a lower occurrence of cardiovascular diseases in Mediterranean Southern compared to Northern Europe.

Recent studies suggested that the disturbance of the oxidative balance may play an important role in the rate of telomere shortening [6-8]. Telomeres are nucleoprotein structures at the end of chromosomes and shorten with each cell division in somatic cells, which can be explained by the end replication problem. However, under conditions of oxidative stress the rate of telomere shortening was increased $[9,10]$. Chronic oxidative stress is involved in many inflammatory diseases, and it has been frequently observed that telomeres shorten faster in subjects with chronic diseases such as cardiovascular diseases, inflammatory bowel disease, type 2 diabetes and chronic obstructive pulmonary disease [11-14].

We hypothesized that Greek elderly men might have longer leukocyte telomeres compared to Dutch counterparts, due to a lower level of oxidative stress because of differences in the balance between reactive oxygen species (ROS) and antioxidants. In this study telomere length of elderly men from Crete and The Netherlands were compared and we investigated the possible relationship between leukocyte telomere length (LTL) and markers of antioxidant status and oxidative stress within these two population groups.

\section{Materials and Methods}

\section{Study population}

The study population consisted of men aged at least 79 years living on Crete (Greece) and men of the same age living in Zutphen (The Netherlands). Both cohorts belong to the Seven Countries Study, a longitudinal study in which the relations of diet and other risk factors for chronic diseases are investigated [15]. In Crete 165 men (24\%) aged 79-96 were still alive in 2000 and leukocyte DNA could be obtained from 109 (66\%). In the Zutphen Elderly Study 240 men aged 
80-98 were still alive in 2000 and leukocyte DNA was available from 143 (60\%). The survey took place in Crete between May and August 2000, and in Zutphen between March and June 2000.

The Zutphen Elderly Study was approved by the Medical Ethics Committee of The Netherlands Organisation for Applied Scientific Research (TNO) and the study on Crete by a local medical ethics committee.

\section{Collection of data on risk factors and history of chronic diseases}

Body weight and height were measured according to standardized procedures. Body mass index (BMI) was calculated by dividing weight $(\mathrm{kg})$ by the square of the height $(\mathrm{m} 2)$. Information on cigarette smoking and alcohol consumption was collected by standardized questionnaires. The history of chronic diseases such as myocardial infarction, stroke, diabetes or cancer, and the presence of diabetes was assessed by questionnaire information and confirmed by letters from general practitioners.

\section{Leukocyte telomere length measurement}

Non-fasting blood samples were collected in the morning. In Crete, blood samples were allowed to stand for $2 \mathrm{~h}$ at room temperature, after which plasma en serum were obtained. In Zutphen, the samples were kept cool in a box with cool elements, and plasma and serum were obtained in the afternoon. Before transport within a few days of collection to the National Institute for Public Health and Environment (RIVM), the Netherlands, samples were stored in Zutphen at $-30 \stackrel{\circ}{\circ}$ and in Crete at $-80 \circ \mathrm{C}$. Samples from Crete were transported to the Netherlands on dry ice by plane. After arrival at the RIVM, all samples were stored at $-80 \circ \mathrm{C}$ until analyses. An aliquot of $200 \mu \mathrm{l}$ of buffy coat was used to extract genomic DNA with the QIAamp DNA Mini Kit (Qiagen, Venlo, The Netherlands) according to the manufacturer's protocol. The DNA was quantified using a Nanodrop instrument (Isogen Life Science, Belgium).

LTL was determined by quantitative PCR as described previously $[12,16]$. For 20 samples we repeated the telomere length measurement by using an additional reference gene, acidic ribosomal phosphoprotein PO (36B4), $300 \mathrm{nM}$ forward primer ( $5^{\prime}$ - CAGCAAGTGGGAAGGTGTAATCC -3 '), $500 \mathrm{nM}$ reverse primer (5'- CCCATTCTATCATCAACGGGTACAA - $\left.3^{\prime}\right)$, to study the correlation between the two measurements and to confirm the reproducibility of the method. 


\section{Measurement of indicators of oxidative stress and antioxidants}

The following serum indicators of oxidative stress were measured: hydroperoxides (enzymatic method, OxyStat assay; Biomedica, Vienna, Austria), malondialdehyde, (high-performance liquid chromatography, Chromsystems, Munich, Germany) and gamma-glutamyl transferase (Technicon SMAC analyser (Technicon Instruments Corp., Tarrytown, New York, USA). For the plasma antioxidant vitamins, the following parameters were measured: carotenoïds and tocopherols, both measured by high-performance liquid chromatography in the laboratory of the Division of Human Nutrition (Wageningen University, the Netherlands). The endogenous antioxidants albumin, total bilirubin and uric acid were measured in serum using a Technicon SMAC analyzer at the Leiden University Medical Center [2].

\section{Statistical analysis}

All data were presented as number (percentage), mean $\pm S D$, or back transformed geometric mean (25th percentile, 75th percentile), when appropriate. LTL and plasma oxidative stress and antioxidant markers were logarithmically transformed before analysis to approach normal distributions. For testing of differences between Cretan and Zutphen elderly men unpaired ttest, Mann Whitney $U$ test, or chi-squared test was used. Regression analysis was used to analyse the difference in LTL between countries while adjusting for age. In subsequent regression analyses, we adjusted for age, BMI, smoking status, alcohol use, history of chronic diseases (and country when all men were combined). Two-tailed $p<0.05$ was considered statistically significant. Statistical analyses were performed with SPSS for Windows (SPSS 17.0; SPSS Inc, Chicago, IL, USA).

\section{Results}

The characteristics of elderly men in Crete and Zutphen are described in Table 1. The mean age of Cretan men was 84.6 years and of men from Zutphen was 83.8 years. Among the Zutphen men there were more alcohol users and they had a higher average BMI compared to the men from Crete. In Zutphen, a history of chronic diseases was significantly more frequently present than in Crete, mainly due to the higher prevalence of cancer and stroke. 
Levels of oxidative stress parameters were significantly higher in Zutphen than in Crete. Cretan men had significantly higher levels of carotenoïds with the exception of beta-cryptoxanthin, whereas men in Zutphen had higher levels of tocopherols. The average levels of the serum endogenous antioxidants albumin and uric acid were significantly higher in Crete compared to Zutphen.

Table 1. Characteristics of elderly men in Crete (Greece) and Zutphen (The Netherlands) in 2000

\begin{tabular}{llllll}
\hline & $\mathbf{n}$ & Crete & $\mathbf{n}$ & Zutphen & P-value* \\
\hline Age (years) & 109 & $84.6(4)$ & 143 & $83.9(3.4)$ & 0.11 \\
\hline Cigarette smoking, no. (\%) & 109 & $11(10.1 \%)$ & 143 & $14(9.8 \%)$ & 0.94 \\
\hline Alcohol consumption, no. (\%) & 109 & $66(60.6 \%)$ & 143 & $108(75.5 \%)$ & 0.01 \\
\hline Body mass index (kg/m2) & 109 & $24.5(4.1)$ & 143 & $25.8(3.7)$ & 0.01 \\
\hline Myocardial infarction, no. (\%) & 109 & $16(14.7 \%)$ & 143 & $23(16.1 \%)$ & 0.76 \\
\hline Stroke, no. (\%) & 109 & $5(4.6 \%)$ & 143 & $23(16.1 \%)$ & 0.04 \\
\hline Diabetes, no. (\%) & 109 & $9(8.3 \%)$ & 143 & $18(12.6 \%)$ & 0.27 \\
\hline Cancer, no. (\%) & 109 & $6(5.5 \%)$ & 143 & $29(20.3 \%)$ & 0.001 \\
\hline Any chronic disease, no. (\%) & 109 & $28(25.7 \%)$ & 143 & $70(49.0 \%)$ & $<0.001$ \\
\hline Telomere length (kbp) & 109 & $4.95(4.71 ; 5.23)$ & 143 & $4.76(4.55 ; 4.98)$ & 0.001 \\
\hline & Indicators of oxidative stress: & & \\
\hline Hydroperoxides (mmol/l) & 109 & $32.5(14.2 ; 61.1)$ & 143 & $56.5(21.1 ; 142.5)$ & 0.002 \\
\hline Malondialdehyde (mmol/I) & 109 & $96(80 ; 110)$ & 143 & $102(90 ; 110)$ & 0.02 \\
\hline Gamma-glutamyl transferase & 109 & $20.3(15.0 ; 24.0)$ & 143 & $26.1(19.0 ; 35.0)$ & 0.001 \\
\hline (U/I) & & & & \\
\hline
\end{tabular}

Plasma antioxidant vitamins:

\begin{tabular}{lcllll}
\hline \multicolumn{7}{c}{ Carotenoids $(\mathrm{mg} / 100 \mathrm{ml}):$} \\
\hline Beta-cryptoxanthin & 109 & $7.15(4.57 ; 13.39)$ & 140 & $7.24(4.54 ; 13.74)$ & 0.91 \\
\hline Lycopene & 108 & $12.5(7.8 ; 21.4)$ & 106 & $4.3(2.7 ; 7.2)$ & $<0.001$ \\
\hline Beta-carotene & 109 & $20.9(13.4 ; 34.9)$ & 140 & $12.8(8.4 ; 19.9)$ & $<0.001$ \\
\hline Zeaxanthin & 109 & $2.24(1.65 ; 3.28)$ & 108 & $1.38(0.99 ; 2.18)$ & $<0.001$ \\
\hline Lutein & 109 & $20.4(15.2 ; 29.5)$ & 140 & $11.5(8.2 ; 16.3)$ & $<0.001$ \\
\hline \multicolumn{7}{c}{ Tocopherols $(\mathrm{mg} / 100 \mathrm{ml}):$} & & \\
\hline Alpha-tocopherol & 103 & $1.12(0.68 ; 1.76)$ & 139 & $2.15(1.50 ; 3.22)$ & $<0.001$ \\
\hline Gamma-tocopherol & 109 & $69.7(55.8 ; 87.6)$ & 140 & $84.5(69.3 ; 117.2)$ & $<0.001$ \\
\hline
\end{tabular}

\section{Serum endogenous antioxidants:}

\begin{tabular}{llllll}
\hline Albumin $(\mathrm{g} / \mathrm{l})$ & 109 & $41.4(40 ; 44)$ & 143 & $39.6(38 ; 42)$ & $<0.001$ \\
\hline Total bilirubin $(\mathrm{mmol} / \mathrm{l})$ & 109 & $9.2(7.0 ; 12.0)$ & 143 & $9.3(7.0 ; 12.0)$ & 0.89 \\
\hline Uric acid $(\mathrm{mmol} / \mathrm{l})$ & 108 & $0.38(0.31 ; 0.47)$ & 143 & $0.35(0.30 ; 0.41)$ & 0.009 \\
\hline
\end{tabular}

* P-value for differences between Cretan and Zutphen elderly men based on unpaired t-test, MannWhitney $U$ test, or chi-squared test. Data are mean (standard deviation), number (percentage) or back-transformed geometric mean (25th percentile, 75th percentile). 
Figure 1 shows that the median leukocyte TL was 190 bp longer in men from Crete than in men from Zutphen $(p=0.001)$. After adjusting for age, the difference between the two populations did not change. Age was inversely associated with TL $(\beta=-0.10, P=0.31$ in Cretan men and $\beta=-0.19, P=0.02$ in Dutch men).

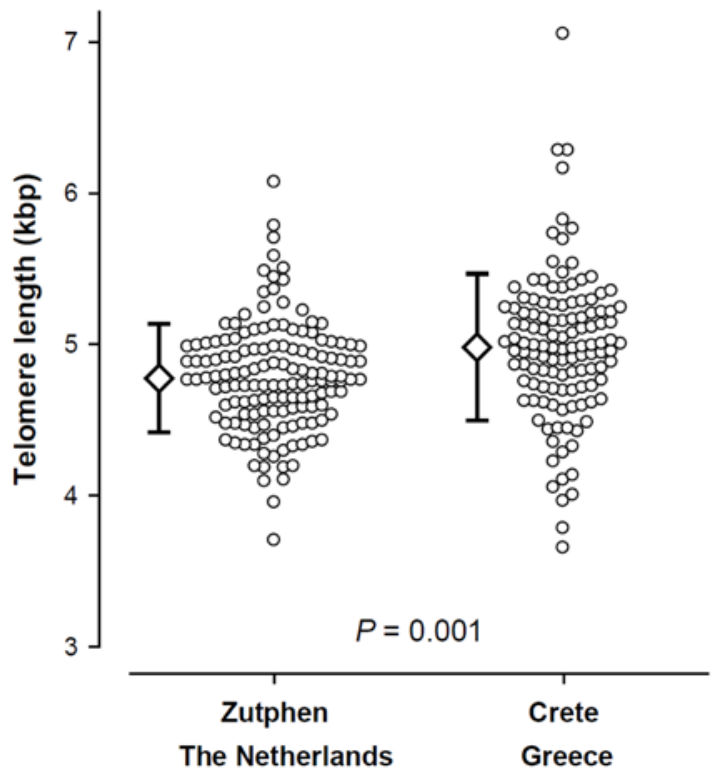

Figure 1. Leukocyte telomere length in 144 men from Zutphen in 2000, and 123 men from Crete in 2000. Error bars indicate the geometric mean with standard deviation. The overall univariate analysis of variance test for the difference between countries was $P=0.001$.

Consistent relationships of LTL with indicators of oxidative stress and plasma antioxidant vitamins were not observed in Crete and Zutphen. However, the serum endogenous antioxidants albumin and uric acid were positively associated with TL (Table 2 and Figure 2). The association with serum albumin was stronger in Crete and that with uric acid in Zutphen. These associations were also statistically significant in the combined group of Cretan and Zutphen men, also after adjustment for country. The age-adjusted difference in LTL between Crete and Zutphen men declined by $30 \%$ (with beta's changing from 0.233 to -0.162 ) after adjustment for serum albumin and uric acid. 
Table 2. Beta-coefficients of the relationship between telomere length and serum indicators of oxidative stress and antioxidant (capacity) in elderly men living in Crete and Zutphen in 2000

\begin{tabular}{|c|c|c|c|c|c|}
\hline & \multicolumn{2}{|c|}{ Unadjusted } & \multicolumn{3}{|c|}{ Adjusted* } \\
\hline & $\begin{array}{l}\text { Crete } \\
(n=109)\end{array}$ & $\begin{array}{l}\text { Zutphen } \\
(n=143)\end{array}$ & $\begin{array}{l}\text { Crete } \\
(n=109)\end{array}$ & $\begin{array}{l}\text { Zutphen } \\
(n=143)\end{array}$ & $\begin{array}{l}\text { All men } \\
(n=252)\end{array}$ \\
\hline \multicolumn{6}{|c|}{ Indicators of oxidative stress: } \\
\hline $\begin{array}{l}\text { Hydroperoxides } \\
(\mathrm{mmol} / \mathrm{l})\end{array}$ & $\begin{array}{l}-0.08 \\
(P=0.39)\end{array}$ & $\begin{array}{l}0.2 \\
(P=0.02)\end{array}$ & $\begin{array}{l}-0.02 \\
(P=0.86)\end{array}$ & $\begin{array}{l}0.18 \\
(P=0.04)\end{array}$ & $\begin{array}{l}0.08 \\
(P=0.19)\end{array}$ \\
\hline $\begin{array}{l}\text { Malondialdehyde } \\
(\mathrm{mmol} / \mathrm{l})\end{array}$ & $\begin{array}{l}0.05 \\
(P=0.59)\end{array}$ & $\begin{array}{l}0.08 \\
(P=0.40)\end{array}$ & $\begin{array}{l}0.03 \\
(P=0.75)\end{array}$ & $\begin{array}{l}0.06 \\
(P=0.57)\end{array}$ & $\begin{array}{l}0.05 \\
(P=0.44)\end{array}$ \\
\hline $\begin{array}{l}\text { Gamma-glutamyl } \\
\text { transferase (U/I) }\end{array}$ & $\begin{array}{l}0.04 \\
(P=0.67)\end{array}$ & $\begin{array}{l}0.05 \\
(P=0.56)\end{array}$ & $\begin{array}{l}0.04 \\
(P=0.67)\end{array}$ & $\begin{array}{l}0.03 \\
(P=0.75)\end{array}$ & $\begin{array}{l}0.03 \\
(P=0.67)\end{array}$ \\
\hline \multicolumn{6}{|c|}{ Plasma antioxidant vitamins: } \\
\hline \multicolumn{6}{|c|}{ Carotenoids (mg/100ml): } \\
\hline Beta-cryptoxanthin & $\begin{array}{l}0.15 \\
(P=0.11)\end{array}$ & $\begin{array}{l}0.01 \\
(P=0.91)\end{array}$ & $\begin{array}{l}0.13 \\
(P=0.20)\end{array}$ & $\begin{array}{l}0.01 \\
(P=0.90)\end{array}$ & $\begin{array}{l}0.07 \\
(P=0.29)\end{array}$ \\
\hline Lycopene & $\begin{array}{l}0.15 \\
(P=0.12)\end{array}$ & $\begin{array}{l}0.06 \\
(P=0.56)\end{array}$ & $\begin{array}{l}0.12 \\
(P=0.25)\end{array}$ & $\begin{array}{l}0.01 \\
(P=0.91)\end{array}$ & $\begin{array}{l}0.09 \\
(P=0.30)\end{array}$ \\
\hline Beta-carotene & $\begin{array}{l}0 \\
(P=0.99)\end{array}$ & $\begin{array}{l}0.07 \\
(P=0.42)\end{array}$ & $\begin{array}{l}-0.01 \\
(P=0.93)\end{array}$ & $\begin{array}{l}0.07 \\
(P=0.44)\end{array}$ & $\begin{array}{l}0.02 \\
(P=0.78)\end{array}$ \\
\hline Zeaxanthin & $\begin{array}{l}0.24 \\
(P=0.01)\end{array}$ & $\begin{array}{l}-0.02 \\
(P=0.81)\end{array}$ & $\begin{array}{l}0.24 \\
(P=0.02)\end{array}$ & $\begin{array}{l}-0.06 \\
(P=0.54)\end{array}$ & $\begin{array}{l}0.1 \\
(P=0.19)\end{array}$ \\
\hline Lutein & $\begin{array}{l}0.12 \\
(P=0.23)\end{array}$ & $\begin{array}{l}0.12 \\
(P=0.18)\end{array}$ & $\begin{array}{l}0.09 \\
(P=0.37)\end{array}$ & $\begin{array}{l}0.11 \\
(P=0.19)\end{array}$ & $\begin{array}{l}0.1 \\
(P=0.15)\end{array}$ \\
\hline \multicolumn{6}{|c|}{ Tocopherols (mg/100 ml): } \\
\hline Alpha-tocopherol & $\begin{array}{l}0.09 \\
(P=0.36)\end{array}$ & $\begin{array}{l}0.04 \\
(P=0.64)\end{array}$ & $\begin{array}{l}0.11 \\
(P=0.31)\end{array}$ & $\begin{array}{l}0.01 \\
(P=0.89)\end{array}$ & $\begin{array}{l}0.04 \\
(P=0.54)\end{array}$ \\
\hline Gamma-tocopherol & $\begin{array}{l}0.19 \\
(P=0.05)\end{array}$ & $\begin{array}{l}0.06 \\
(P=0.47)\end{array}$ & $\begin{array}{l}0.17 \\
(P=0.10)\end{array}$ & $\begin{array}{l}0.06 \\
(P=0.53)\end{array}$ & $\begin{array}{l}0.09 \\
(P=0.19)\end{array}$ \\
\hline \multicolumn{6}{|c|}{ Serum endogenous antioxidants: } \\
\hline Albumin (g/l) & $\begin{array}{l}0.27 \\
(P=0.005)\end{array}$ & $\begin{array}{l}0.15 \\
(P=0.08)\end{array}$ & $\begin{array}{l}0.25 \\
(P=0.02)\end{array}$ & $\begin{array}{l}0.1 \\
(P=0.28)\end{array}$ & $\begin{array}{l}0.18 \\
(P=0.007)\end{array}$ \\
\hline Total bilirubin (mmol/l) & $\begin{array}{l}0 \\
(P=0.98)\end{array}$ & $\begin{array}{l}0.16 \\
(P=0.06)\end{array}$ & $\begin{array}{l}-0.02 \\
(P=0.83)\end{array}$ & $\begin{array}{l}0.17 \\
(P=0.05)\end{array}$ & $\begin{array}{l}0.07 \\
(P=0.29)\end{array}$ \\
\hline Uric acid (mmol/l) & $\begin{array}{l}0.13 \\
(P=0.18)\end{array}$ & $\begin{array}{l}0.13 \\
(P=0.14)\end{array}$ & $\begin{array}{l}0.13 \\
(P=0.20)\end{array}$ & $\begin{array}{l}0.17 \\
(P=0.05)\end{array}$ & $\begin{array}{l}0.13 \\
(P=0.045)\end{array}$ \\
\hline
\end{tabular}

* Adjusted for age (continuous), body mass index (continuous), smoking (yes or no), alcohol use (yes or no), history of chronic diseases (and country, when all men are combined). P-values mentioned are based on testing whether beta-coefficients significantly differ from zero. 

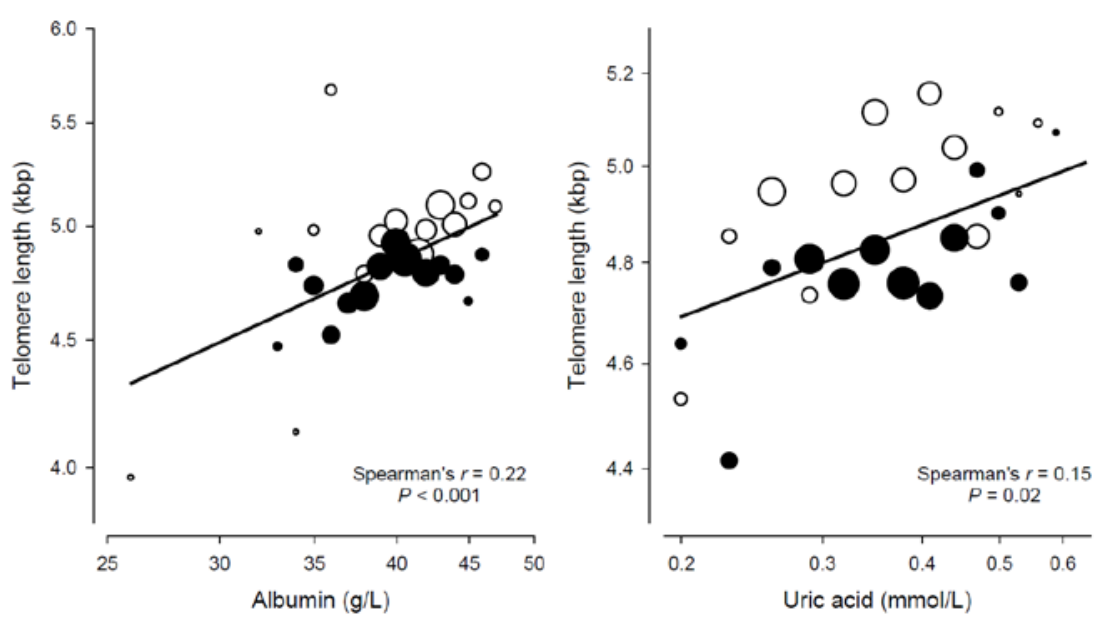

Figure 2. Bubble plots of serum levels of the endogenous antioxidants albumin and uric acid (on logarithmic scales) in relation with telomere length in elderly men living in Crete (०) and Zutphen $(\bullet)$. The bubble areas are proportional to the number of men. Univariate regression lines are shown for both populations combined, with non-parametric Spearman's correlation coefficients with its accompanying P-values.

\section{Discussion}

In this cross-cultural study, elderly men in Crete had significantly longer median leukocyte TL than Dutch counterparts. LTL was in both populations inversely related to age. Indicators of oxidative stress and of plasma antioxidant vitamins were not associated with LTL. The endogenous antioxidants serum albumin and uric acid were higher in Crete than in Zutphen and were positively associated with LTL. The age adjusted difference in LTL between Crete and Zutphen diminished after adjustment for serum albumin and uric acid.

Compared to Zutphen elderly men, the medium LTL was $190 \mathrm{bp}$ longer in Cretan men. Leukocyte telomeres shorten on average with 30-40 bp per year, which may indicate that the biological age of Cretan men is approximately 5 years younger than that of men from Zutphen [17-22]. This is compatible with the much lower all-cause mortality of the Cretan compared with the Zutphen cohort between 1960 and 2000 [23]. The inverse association between LTL and age was stronger in Zutphen than in Crete. This also suggests a better survival of the Cretan compared to the Zutphen men.

The observed higher LTL in Cretan compared to Zutphen elderly men may partly be explained by the higher level of serum albumin and uric acid in the Cretan men. Also the analysis that showed that $30 \%$ of the difference in LTL 
between Crete and Zutphen could be explained by serum albumin and uric acid supports this hypothesis. In contrast we did not find associations of plasma vitamin antioxidants with LTL. Our results suggest that endogenous antioxidants, and not plasma antioxidant vitamins, are of greatest importance in relation to LTL in elderly men.

To the best of our knowledge this is the first study that showed an association of LTL with serum albumin and uric acid and LTL. Both antioxidants are involved in scavenging lipid radicals. Albumin may provide antioxidant protection by functioning as a serum peroxidase in the presence of reduced glutathione, which is an intracellular antioxidant [24]. Albumin is an important extracellular antioxidant [25] and a marker for nutritional status [26], and many potential associations between its plasma concentration or modifications and mortality have been observed $[27,28]$. Higher concentrations of albumin were associated with lower mortality rates from cardiovascular disease and cancer [28], supporting the positive association between albumin and leukocyte TL, that we found in our study.

Uric acid is an antioxidant that prevents ascorbic acid oxidation; it scavenges peroxyl, hydroperoxyl superoxide radicals by binding transition metals, thereby preventing free radical reproduction [24]. Ames et al. hypothesized that uric acid may be an evolutionary antioxidant substitute for the loss of ability to synthesize ascorbate in higher primates. In humans, uric acid is present in blood at concentration close to maximum solubility. He suggested that these high levels may be the result of the evolution of effective protective mechanisms against oxygen radicals and may increase lifespan [29]. This hypothesis is compatible with our finding that increased serum uric acid concentrations were associated with longer leukocyte telomeres. It has also to be noted that uric acid has not only antioxidant, but also pro-oxidant properties and a high level of uric acid has been proposed as a risk factor for coronary heart disease [30].

Potential limitations of our study should be considered. The study participants were elderly men, which may limit the generalizability of our findings to men of younger age and to women. Survivor bias might have played a role, since our participants were very old and probably unusually healthy compared to their counterparts who already died. Moreover, the number of subjects was relatively small in this study. The study has also several strengths. We confirmed our LTL analysis by repetition of 20 samples with a different 
reference gene and found a strong correlation (reliability coefficient of 0.87 , $p<0.001$ ), excluding methodological variation due to potential fragmentation or loss of DNA during isolation. Various endogenous antioxidant parameters and indicators of oxidative stress were measured giving an overview of the oxidative balance in these subjects.

In summary, we conclude that Cretan elderly men have significantly longer leukocyte telomeres compared to Dutch counterparts. This is compatible with the higher life expectancy of the Cretan men. High levels of the serum endogenous antioxidants albumin and uric acid were associated with longer telomeres. Whether these associations are causal needs to be established in future studies. 


\section{References}

1. Briasoulis A, Tousoulis D, Antoniades C, Stefanadis C: The oxidative stress menace to coronary vasculature: any place for antioxidants? Curr Pharm Des 2009;15:30783090.

2. Buijsse B, Feskens EJ, Moschandreas J, Jansen EH, Jacobs DR, Jr., Kafatos A, Kok FJ, Kromhout D: Oxidative stress, and iron and antioxidant status in elderly men: differences between the Mediterranean south (Crete) and northern Europe (Zutphen). Eur J Cardiovasc Prev Rehabil 2007;14:495-500.

3. Lindsay DG, Astley SB: European research on the functional effects of dietary antioxidants - EUROFEDA. Mol Aspects Med 2002;23:1-38.

4. Olmedilla B, Granado F, Southon S, Wright AJ, Blanco I, Gil-Martinez E, Berg H, Corridan B, Roussel AM, Chopra M, Thurnham DI: Serum concentrations of carotenoids and vitamins $A, E$, and $C$ in control subjects from five European countries. Br J Nutr 2001;85:227-238.

5. Parfitt VJ, Rubba P, Bolton C, Marotta G, Hartog M, Mancini M: A comparison of antioxidant status and free radical peroxidation of plasma lipoproteins in healthy young persons from Naples and Bristol. Eur Heart J 1994;15:871-876.

6. Greider CW, Blackburn EH: Telomeres, telomerase and cancer. Sci Am 1996;274:9297.

7. Joosten SA, van Ham V, Nolan CE, Borrias MC, Jardine AG, Shiels PG, van Kooten C, Paul LC: Telomere shortening and cellular senescence in a model of chronic renal allograft rejection. Am J Pathol 2003;162:1305-1312.

8. von Zglinicki T, Martin-Ruiz C, Saretzki G: Telomeres, cell senescence and human ageing. Signal Transduction 2005;3.

9. Houben JM, Moonen HJ, van Schooten FJ, Hageman GJ: Telomere length assessment: biomarker of chronic oxidative stress? Free Radic Biol Med 2008;44:235-246.

10. von Zglinicki T: Oxidative stress shortens telomeres. Trends Biochem Sci 2002;27:339-344.

11. Brouilette SW, Moore JS, McMahon AD, Thompson JR, Ford I, Shepherd J, Packard $\mathrm{CJ}$, Samani NJ: Telomere length, risk of coronary heart disease, and statin treatment in the West of Scotland Primary Prevention Study: a nested case-control study. Lancet 2007;369:107-114.

12. Houben JM, Mercken EM, Ketelslegers HB, Bast A, Wouters EF, Hageman GJ, Schols AM: Telomere shortening in chronic obstructive pulmonary disease. Respir Med 2009;103:230-236.

13. Mori Y, Meltzer SJ: Honey, I shrunk the telomere: UC speeds aging. Inflamm Bowel Dis 2009;15:1432-1433. 
14. Savale L, Chaouat A, Bastuji-Garin S, Marcos E, Boyer L, Maitre B, Sarni M, Housset B, Weitzenblum E, Matrat M, Le Corvoisier P, Rideau D, Boczkowski J, Dubois-Rande $\mathrm{JL}$, Chouaid C, Adnot S: Shortened Telomeres in Circulating Leukocytes of Patients with Chronic Obstructive Pulmonary Disease. Am J Respir Crit Care Med 2009.

15. Keys A, Aravanis C, Blackburn HW, Van Buchem FS, Buzina R, Djordjevic BD, Dontas AS, Fidanza F, Karvonen MJ, Kimura N, Lekos D, Monti M, Puddu V, Taylor HL: Epidemiological studies related to coronary heart disease: characteristics of men aged 40-59 in seven countries. Acta Med Scand Suppl 1966;460:1-392.

16. Cawthon RM: Telomere measurement by quantitative PCR. Nucleic Acids Res 2002;30:e47.

17. Aviv A, Chen W, Gardner JP, Kimura M, Brimacombe M, Cao X, Srinivasan SR, Berenson GS: Leukocyte telomere dynamics: longitudinal findings among young adults in the Bogalusa Heart Study. Am J Epidemiol 2009;169:323-329.

18. Ehrlenbach S, Willeit P, Kiechl S, Willeit J, Reindl M, Schanda K, Kronenberg F, Brandstatter A: Influences on the reduction of relative telomere length over 10 years in the population-based Bruneck Study: introduction of a well-controlled high-throughput assay. Int J Epidemiol 2009;38:1725-1734.

19. Epel E, Merkin S, Cawthon R, Blackburn E, Adler N, Pletcher M, Seeman T: The rate of leukocyte telomere shortening predicts mortality from cardiovascular disease in elderly men. Aging 2009;1:81-88.

20. Iwama H, Ohyashiki K, Ohyashiki JH, Hayashi S, Yahata N, Ando K, Toyama K, Hoshika A, Takasaki M, Mori M, Shay JW: Telomeric length and telomerase activity vary with age in peripheral blood cells obtained from normal individuals. Hum Genet 1998;102:397-402.

21. Satoh H, Hiyama K, Takeda M, Awaya $\mathrm{Y}$, Watanabe K, Ihara $\mathrm{Y}$, Maeda H, Ishioka S, Yamakido M: Telomere shortening in peripheral blood cells was related with aging but not with white blood cell count. Jpn J Hum Genet 1996;41:413-417.

22. Slagboom PE, Droog S, Boomsma DI: Genetic determination of telomere size in humans: a twin study of three age groups. Am J Hum Genet 1994;55:876-882.

23. Kromhout $D$, Menotti $A$, Kesteloot $H$, Sans $S$ : Prevention of coronary heart disease by diet and lifestyle: evidence from prospective cross-cultural, cohort, and intervention studies. Circulation 2002;105:893-898.

24. George B, Osharechiren O: Oxidative stress and antioxidant status in sportsmentwo hours after strenuous exercise and in sedentary control subjects. African Journal of Biotechnology 2009;8:480-483.

25. Halliwell B, Gutteridge JM, Cross CE: Free radicals, antioxidants, and human disease: where are we now? J Lab Clin Med 1992;119:598-620.

26. Fuhrman MP: The albumin-nutrition connection: separating myth from fact. Nutrition 2002;18:199-200.

27. Horwich TB, Kalantar-Zadeh K, MacLellan RW, Fonarow GC: Albumin levels predict survival in patients with systolic heart failure. Am Heart J 2008;155:883-889. 
28. Phillips A, Shaper AG, Whincup PH: Association between serum albumin and mortality from cardiovascular disease, cancer, and other causes. Lancet 1989;2:1434-1436.

29. Ames BN, Cathcart R, Schwiers E, Hochstein P: Uric acid provides an antioxidant defense in humans against oxidant- and radical-caused aging and cancer: a hypothesis. Proc Natl Acad Sci U S A 1981;78:6858-6862.

30. Holme I, Aastveit AH, Hammar N, Jungner I, Walldius G: Uric acid and risk of myocardial infarction, stroke and congestive heart failure in 417,734 men and women in the Apolipoprotein MOrtality RISk study (AMORIS). J Intern Med 2009;266:558-570 




\section{Chapter 3}

\section{Telomere length and mortality in elderly men: the}

\section{Zutphen Elderly Study}

The Journal of Gerontology: Biological Sciences: 2010 Oct 1.

[Epub ahead of print]
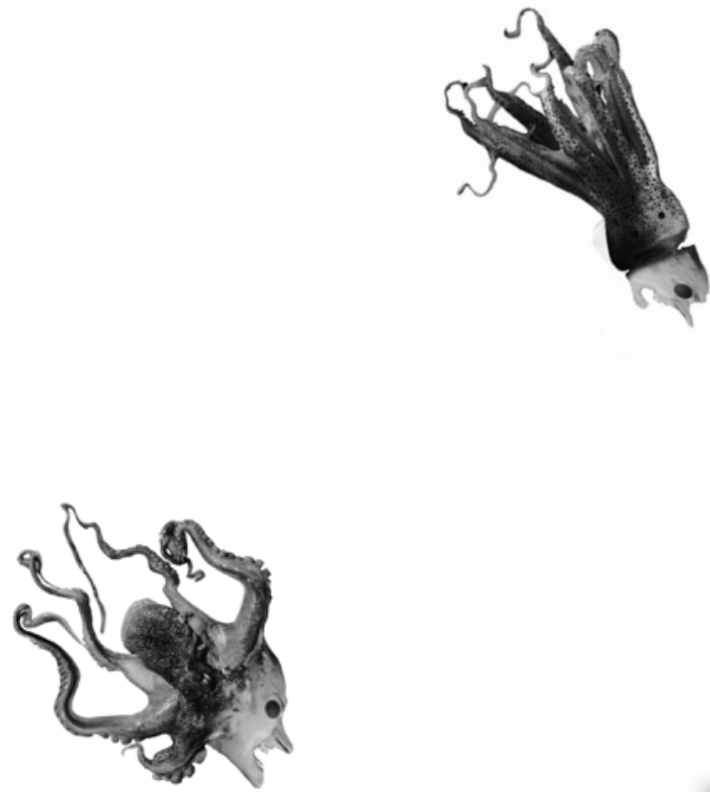

Joyce M.J. Houben

Erik J. Giltay

Nathaly Rius-Ottenheim

Geja J. Hageman

Daan Kromhout

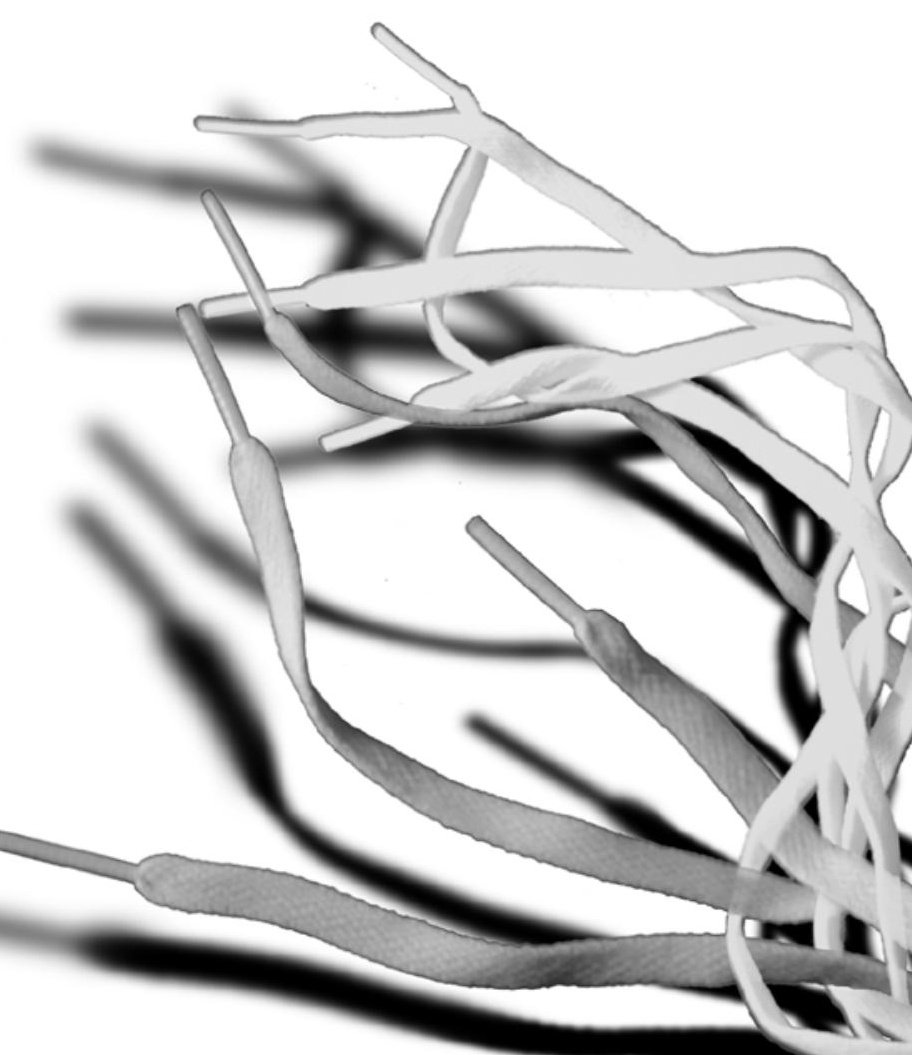




\begin{abstract}
Telomere shortening is a marker of aging and therefore telomere length (TL) might be related to disease progression and survival. To address these questions, we measured leukocyte telomere length (LTL) in male subjects from the Zutphen Elderly Study. LTL was measured by quantitative polymerase chain reaction in 203 men; mean aged 78 years in 1993 and 75 surviving subjects mean aged 83 years in 2000. During 7 years of follow-up 105 men died. Cox proportional hazards models were used to estimate hazard ratios (HR) for allcause and cause-specific mortality. We found that LTL declined with a mean of 40.2 bp per year and LTL values measured in 1993 and 2000 correlated significantly $(r=0.51 ; p<0.001)$. Longer telomeres at baseline were not predictive for all-cause mortality, cardiovascular mortality or cancer mortality. These results suggest that LTL is not a marker of mortality in men over age 70.
\end{abstract}




\section{Introduction}

In human somatic cells, telomeres, the nucleoprotein structures at the end of chromosomes, shorten with each cell division leading to an irreversible growth arrest of the cell. This process of senescence is associated with the aging process and telomeres have therefore been proposed as markers for biological aging $[1,2]$.

Most studies investigating telomere shortening are cross-sectional, focussing on differences between groups of subjects. Unfortunately, these studies give no information on the individual rate of telomere shortening over a period of time, rendering them inconclusive on individual susceptibility.

Furthermore, it can also not be concluded from these studies whether there is an association between TL and (disease-specific) mortality. It is therefore relevant to perform longitudinal studies in which these relationships are investigated [3-14].

Several chronic diseases have been linked to chronic oxidative stress and accelerated telomere shortening, such as cardiovascular disease (CVD) and cancer $[8,15,16]$. Epel et al. showed that short baseline TL was related to greater mortality from CVD in women. For men, the rate of telomere shortening was related to greater cardiovascular mortality [8]. The association of shorter telomeres with cancer morbidity and mortality is inconsistent. Although some studies show a relationship between short telomeres and cancer risk $[17,18]$ there are also studies showing an inverse relationship $[16,19,20]$.

We hypothesized that leukocyte telomere length ( $L T L)$ is a biological marker of all-cause and cause-specific mortality. To investigate this, we prospectively evaluated the rate of telomere shortening over a period of seven years in 203 men who were 73 to 91 years old at baseline as part of the Zutphen Elderly Study cohort. Furthermore, we investigated the relationship between LTL and all-cause and cause-specific mortality during seven years of follow-up.

\section{Materials and Methods}

\section{Study population}

The Zutphen Elderly Study consisted of 887 subjects in 1985 (response rate $70.1 \%$ ). Because no whole blood samples were available in 1985 , we defined 
1993 as our baseline measurement for the present analyses. The cohort of The Zutphen Elderly Study consists of men born between 1900 and 1920 . The study started in 1960 as the Dutch contribution to the Seven Countries Study. Between 1985 and 2000 the men were examined every 5 years. The purpose of the more recent survey was to gain insight into the changes and risk factors associated with physical, social, psychosocial, cognitive functions, and perceived health in very old men. The Zutphen Elderly Study consisted of 553 men in 1993, of whom 390 participated (response rate $71 \%$ ), and 345 had a blood sample. However, only 203 (59\%) buffy coats could be used for DNA isolation since 142 samples were unavailable. For the follow-up examination in 2000, 176 men enrolled in the study in Zutphen. Blood samples were available from 146 individuals. Because of the insufficient quality of the DNA of two of the participants, 144 men (82\%) were finally included in the present analysis. Only 75 men had also a blood sample available both in 1993 and in 2000. Written informed consent was obtained from all participants. The Zutphen Elderly Study (in 1993 and in 2000) was approved by the Medical Ethics Committee of the Netherlands Organization for Applied Scientific Research (TNO).

\section{Leukocyte telomere length measurement}

Non-fasting blood samples were collected in the morning. The samples were kept cool in a box with cooling elements, and plasma and serum were obtained in the afternoon. Samples were stored in Zutphen at $-30 \stackrel{\circ}{ } \mathrm{C}$ before transport to the National Institute for Public Health and Environment (RIVM), Bilthoven, the Netherlands, which took place within a few days after collection. After arrival at the RIVM, all samples were stored at $-80^{\circ} \mathrm{C}$ until analyses. An aliquot of $200 \mu \mathrm{l}$ of buffy coat was used to extract genomic DNA with the QIAamp DNA Mini Kit (Qiagen, Venlo, The Netherlands) according to the manufacturer's protocol. The DNA was quantified using a Nanodrop instrument (Isogen Life Science, Belgium).

$\mathrm{LTL}$ was determined by quantitative polymerase chain reaction ( $\mathrm{PPCR}$ ) as described previously [21,22]. Two master mixes were prepared, one with telomere primers and one with Human $\beta$ globin (HBG) primers (1x IQ SYBRgreen supermix from BioRad, CA, USA). To confirm reproducibility of the applied method, we repeated for 20 samples the leukocyte LTL measurement by using an additional reference gene, acidic ribosomal phosphoprotein PO (36B4), 300 nM forward primer (5'-CAGCAAGTGGGAAGGTGTAATCC -3'), 500nM reverse 
primer (5' - CCCATTCTATCATCAACGGGTACAA -3'). Sample DNA was pipetted in a 96 -wells plate at a final concentration of $10 \mathrm{ng} / \mu \mathrm{l}$. Subsequently, $20 \mu \mathrm{l}$ of the mastermix was added and the plate was shortly centrifuged. Each sample was run in triplicates. The coefficient of variation for the triplicates of the telomere reaction was $4.11 \%$ and for the reference gene $3.03 \%$. For the standard curve a reference DNA sample was diluted serially to produce three concentrations of $1.25,5$, and $10 \mathrm{ng} / \mu \mathrm{l}$. In every run, negative controls (MQ + mastermix) and reference samples were included. The references were derived from two different Hela cell lines, one with relatively short telomeres (Hela S3: $5.5 \mathrm{~kb}$ ) and one with long telomeres (Hela 229: 14-15 kb). Hela cell lines were kindly provided by Prof. Alexander Bürkle, University of Konstanz, Germany. Thermal cycling profile of the PCR protocol were as follows: Telomere PCR: cycle 1 (1x): $95^{\circ} \mathrm{C}$ for 03.00 , cycle $2(30 \mathrm{x})$ : $95^{\circ} \mathrm{C}$ for 00.15 and $54^{\circ} \mathrm{C}$ for 02.00 , cycle $3(1 \mathrm{x})$ : $95^{\circ} \mathrm{C}$ for 01.00 , cycle $4(1 \mathrm{x}): 65^{\circ} \mathrm{C}$ for 01.00 and cycle $5(60 \mathrm{x}): 65^{\circ} \mathrm{C}$ for 00.10 (melt curve). HBG PCR: cycle $1(1 \mathrm{x}): 95^{\circ} \mathrm{C}$ for 03.00 , cycle $2(40 \mathrm{x})$ : $95^{\circ} \mathrm{C}$ for 00.15 and $58^{\circ} \mathrm{C}$ for 01.00 , cycle $3(1 \mathrm{x}): 95^{\circ} \mathrm{C}$ for 01.00 , cycle $4(1 \mathrm{x}): 65^{\circ} \mathrm{C}$ for 01.00 and cycle 5 (60x): $65^{\circ} \mathrm{C}$ for 00.10 (melt curve). The polymerase chain reaction (PCR) was performed using a BioRad MyiQ iCycler Single Color RT-PCR detection system using iQTM SYBR ${ }^{\circledR}$ Green Supermix, containing iTaq Polymerase, dNTPs, SYBRGreen I, and buffers (BioRad, CA, USA).

\section{Collection of data on lifestyle and history of chronic diseases}

Information on cigarette smoking was collected by standardized questionnaires. Information about habitual consumption of foods, including alcohol, coffee and tea beverages, was collected in 1993 by using the cross-check, dietary history method, adapted to the Dutch food consumption pattern [23]. During a physical examination, height and body weight were measured according to standardized procedures. Body mass index (BMI) was calculated by dividing weight (kg) by the square of the height $(\mathrm{m} 2)$. As a sedentary lifestyle was associated with shorter LTL [24], a validated questionnaire on physical activity designed for retired men (that participants were asked to complete at home) was used to calculate the total minutes spent in physical activity per week [of an intensity of more than $2 \mathrm{kcal} /(\mathrm{kg} \bullet \mathrm{h})$ ] [25]. Information on marital status (dichotomized) and education (dichotomized into lower and higher education, the later defined as higher vocational education, college, or university) was obtained by a selfadministered questionnaire. The prevalence of chronic diseases such as 
cardiovascular diseases, cancer, and the presence of diabetes mellitus was assessed by questionnaire and verified by information from general practitioners. Information on the vital status of the participants until July 1 , 2000 was obtained from municipal population registries and the participants' general practitioners. Information was verified with either hospital discharge data or information from the Netherlands Cancer Registry. The initial coding of the causes of death was done by 3 physicians and the final coding by an experienced clinical epidemiologist, who was unaware of the outcome of the LTL measurement. CVD was defined as codes 390 to 459 as the primary cause of death according to the International Classification of Diseases, Ninth Revision (ICD-9), and cancer as codes 140-172 and 174-208 (referring to malignant neoplasm, except non-melanocytic skin cancers).

\section{Statistical analysis}

All data are presented as number (percentage), mean $\pm S D$, or median, when appropriate. The baseline characteristics of the participants were compared according to tertiles of LTL by using the one-way analysis of variance or the chisquare test, when appropriate. The mean LTL shortening over 7 years was estimated using a t-test for paired samples. The Pearson's correlation coefficient was used to analyse LTL data from 1993 and 2000. Although we tested for normality, and this showed a near normal distribution, the analyses with mortality were performed with tertiles of $L T L$, in which a normal distribution is of minor importance. The Kaplan-Meier method was used to present crude all-cause mortality and cause-specific mortality. Hazard ratios with $95 \%$ confidence intervals $(\mathrm{Cl})$ of all three endpoints were estimated by Cox proportional hazards models. Three multivariate models were tested. First, we tested the association in a crude model. Subsequently, two additional multivariable models were tested. Model 1 adjusted for age, and in model 2 we additionally adjusted for potential confounders such as smoking $[26,27]$, alcohol use [28], BMI [27], education (and the related socioeconomic status) [29], marital status, physical activity [30] and the presence of chronic diseases $[6,22,31-35]$, since they were associated with $T L$ in previous studies $[9,14,22]$. Furthermore, we performed two sensitivity analyses in which we first repeated the Cox proportional hazards models using data from 193 men who died after a lag time of 1 year of follow-up, excluding 10 subjects who had died within the first year of follow-up, and subsequently using data from 144 men 
without a history of chronic diseases. Tests of linear trend across increasing tertiles of LTL were performed by using the median values of LTL for each tertile. Two-tailed $p<0.05$ was considered statistically significant. Statistical analyses were performed with SPSS for Windows (SPSS 17.0; SPSS Inc, Chicago, IL, USA).

\section{Results}

Sociodemographic and clinical characteristics at baseline are presented in Table 1. The mean age at baseline was 78 years (range: $73-91$ years). During 7 years of follow-up, 105 men died (51.7\%), of whom 45 (42.9\%) from cardiovascular causes, 36 (34.3\%) from cancer (of whom 12 from lung cancer). The 75 surviving and participating men had an average age of 83.1 years (range: 79-92) in 2000. No association was found of sociodemographic and lifestyle factors with tertiles of LTL. 
Table 1. Sociodemographic and lifestyle factors of 203 Dutch men from Zutphen in 1993 according to tertiles of leukocyte telomere length

\begin{tabular}{|c|c|c|c|c|}
\hline \multicolumn{5}{|c|}{ Telomere length in 1993} \\
\hline & Tertile 1 & Tertile 2 & Tertile 3 & P-value for trend* \\
\hline No of participants & 67 & 68 & 68 & \\
\hline $\begin{array}{l}\text { Telomere length }(\mathrm{Kbp}) \text {, } \\
\text { median (range) }\end{array}$ & $4.6(3.8-4.8)$ & $5.0(4.8-5.2)$ & $5.5(5.2-6.4)$ & - \\
\hline Age (years), mean \pm SD & $78.8 \pm 4.1$ & $78.5 \pm 4.7$ & $78.1 \pm 4.1$ & 0.38 \\
\hline \multicolumn{5}{|c|}{ Education, n (\%) } \\
\hline Lower & $51(78.5 \%)$ & $51(77.3 \%)$ & $51(83.6 \%)$ & 0.48 \\
\hline Higher & $14(21.5 \%)$ & $15(22.7 \%)$ & $10(16.4 \%)$ & \\
\hline \multicolumn{5}{|c|}{ Marital status, n (\%) } \\
\hline Unmarried & $16(23.9 \%)$ & $20(29.9 \%)$ & $17(26.2 \%)$ & 0.76 \\
\hline Married & $51(76.1 \%)$ & $47(70.1 \%)$ & $48(73.8 \%)$ & \\
\hline \multicolumn{5}{|c|}{ Smoking status, n (\%) } \\
\hline Never & $15(23.8 \%)$ & $6(9.5 \%)$ & $11(17.5 \%)$ & 0.5 \\
\hline Former & $32(50.8 \%)$ & $36(57.1 \%)$ & $35(55.6 \%)$ & \\
\hline Current & $16(25.4 \%)$ & $21(33.3 \%)$ & $17(27.0 \%)$ & \\
\hline \multicolumn{5}{|c|}{ Alcohol intake, $n$ (\%) } \\
\hline $0 \mathrm{~g} / \mathrm{d}$ & 21 (34.4\%) & $13(21.0 \%)$ & 10 (16.1\%) & 0.28 \\
\hline $1-19 \mathrm{~g} / \mathrm{d}$ & 29 (47.5\%) & $43(69.4 \%)$ & 45 (72.6\%) & \\
\hline$\geq 20 \mathrm{~g} / \mathrm{d}$ & $11(18.0 \%)$ & $6(9.7 \%)$ & $7(11.3 \%)$ & \\
\hline Coffee, non-users & $2(3.2 \%)$ & $2(3.1 \%)$ & $1(1.6 \%)$ & 0.56 \\
\hline Tea, non-users & $7(11.5 \%)$ & $5(8.8 \%)$ & $5(8.3 \%)$ & 0.8 \\
\hline \multicolumn{5}{|c|}{ Self-rated health, n (\%) } \\
\hline Healthy & 25 (37.3\%) & $27(40.3 \%)$ & $32(47.1 \%)$ & 0.25 \\
\hline Unhealthy & $42(62.7 \%)$ & $40(59.7 \%)$ & $36(52.9 \%)$ & \\
\hline Chronic diseasest, n (\%) & $22(32.8 \%)$ & $20(29.4 \%)$ & $17(25.0 \%)$ & 0.32 \\
\hline $\begin{array}{l}\text { Body Mass Index, mean } \pm \\
\text { SD }\end{array}$ & $25.7 \pm 2.9$ & $25.7 \pm 2.9$ & $25.7 \pm 2.9$ & 0.96 \\
\hline $\begin{array}{l}\text { Physical activity } \\
\text { (min/week) }\end{array}$ & $\begin{array}{l}540(45 \\
1170)\end{array}$ & $\begin{array}{l}480(111 ; \\
1176)\end{array}$ & $518(81 ; 1599)$ & 0.63 \\
\hline
\end{tabular}

Data are presented as $\mathrm{n}(\%)$, mean ( \pm SD) or median (percentiles P10; P90), when appropriate.

* P-values for linear trend based on chi-square test for categorical variables, F-test for continuous variables.

+ Chronic disease was defined as having either a cardiovascular disease (myocardial infarction, stroke, heart failure), cancer or diabetes mellitus.

We analyzed paired DNA samples from 75 individuals (elderly men), which were collected in 1993 and in 2000 . The mean LTL in 1993 was $5.03 \mathrm{kbp}$, whereas the mean LTL in 2000 was $4.76 \mathrm{kbp}$. The mean decline in leukocyte LTL during 7 years of follow-up was 40.2 bp per year (95\% confidence interval [Cl]: 26.9-53.5; $\mathrm{p}<0.001)$. Although most individuals showed a decrease in $\mathrm{TL}$, for 12 subjects (16\%) we found an increase. Pearson's correlation coefficient showed a 
moderately strong relationship between LTL in 1993 and 2000 in 75 men $(r=0.51 ; p<0.001$ ) (Figure 1).

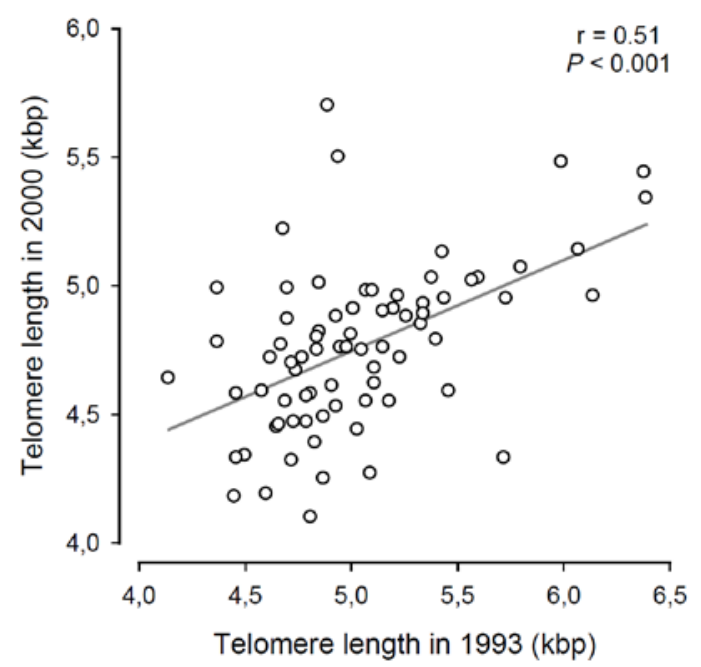

Figure 1. Relationship between leukocyte telomere length in 1993 and 2000 for 75 elderly men.

Results from the Kaplan-Meier analysis of survival according to LTL are depicted in Figure 2. No statistically significant differences in all-cause, cardiovascular or cancer mortality were found in relation to LTL tertiles.
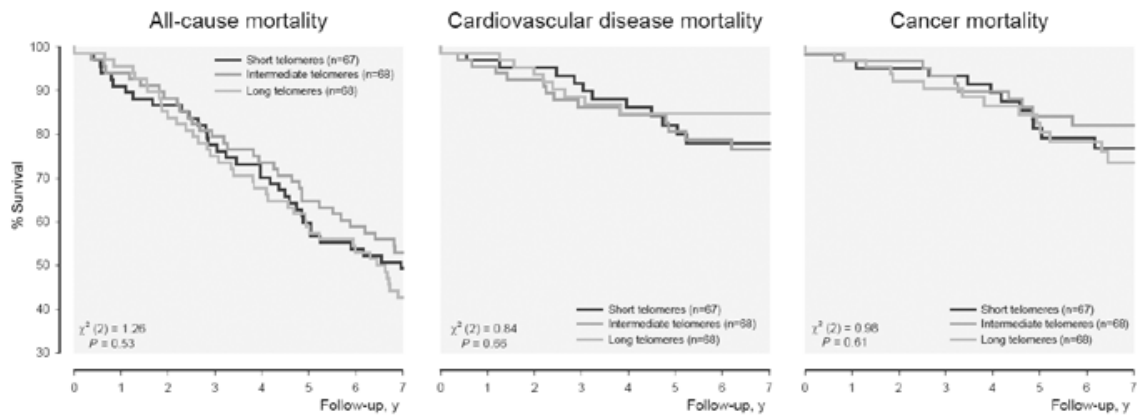

Figure 2. Kaplan-Meier analysis of survival according to the tertiles of leukocyte telomere length status in 203 Dutch men. In log-rank overall tests, men with a shorter telomere length had similar survival rates as compared to men with a longer telomere length. 
Table 2 summarizes the results of the survival analysis according to tertiles of LTL. Again, LTL was not related to all-cause mortality. Both cardiovascular and cancer mortality were not related to LTL. Results from the sensitivity analyses with a lag time of 1 year showed no indication of a potential reverse causation owing to pre-existing chronic diseases (data not shown).

Table 2. Hazard ratios of mortality for 203 elderly men according to tertiles of leukocyte telomere length

\begin{tabular}{|c|c|c|c|c|}
\hline \multicolumn{5}{|c|}{ Telomere length in 1993} \\
\hline & Tertile 1 & Tertile 2 & Tertile 3 & $\begin{array}{l}\text { P-value for } \\
\text { trend * }\end{array}$ \\
\hline No of participants & 67 & 68 & 68 & \\
\hline \multicolumn{5}{|c|}{ All-cause mortality: } \\
\hline No. of cases & $34(50.7 \%)$ & $32(47.1 \%)$ & 39 (57.4\%) & \\
\hline Crude & 1 & $0.89(0.55-1.44)$ & $1.16(0.73-1.83)$ & 0.49 \\
\hline Model 1 & 1 & $0.86(0.53-1.40)$ & $1.24(0.78-1.96)$ & 0.33 \\
\hline Model 2 & 1 & $1.19(0.70-2.03)$ & $1.50(0.87-2.58)$ & 0.14 \\
\hline \multicolumn{5}{|c|}{ Cardiovascular disease mortality: } \\
\hline No. of cases & $17(25.4 \%)$ & $15(22.1 \%)$ & $13(19.1 \%)$ & \\
\hline Crude & 1 & $0.83(0.42-1.67)$ & $0.77(0.37-1.58)$ & 0.47 \\
\hline Model 1 & 1 & $0.82(0.41-1.65)$ & $0.81(0.39-1.67)$ & 0.57 \\
\hline Model 2 & 1 & $0.92(0.44-1.94)$ & $0.92(0.40-2.14)$ & 0.84 \\
\hline \multicolumn{5}{|c|}{ Cancer mortality: } \\
\hline No. of cases & $12(17.9 \%)$ & $10(14.7 \%)$ & $14(20.6 \%)$ & \\
\hline Crude & 1 & $0.78(0.34-1.81)$ & $1.18(0.54-2.54)$ & 0.63 \\
\hline Model 1 & 1 & $0.77(0.33-1.78)$ & $1.25(0.58-2.70)$ & 0.53 \\
\hline Model 2 & 1 & $1.12(0.45-2.75)$ & $1.39(0.56-3.44)$ & 0.47 \\
\hline
\end{tabular}

* P-value for trend refers to a linear trend across tertiles of telomere length using the median values of each tertile.

Crude: unadjusted in Cox proportional-hazards models,

Model 1: adjusted for age,

Model 2: additionally adjusted for smoking status, alcohol use, BMI, education, marital status, physical activity, and chronic diseases.

\section{Discussion}

In a prospective analysis among elderly men, we observed a substantial decrease in mean LTL per year between 1993 and 2000. LTL measured in 1993 was strongly correlated with LTL measured in 2000. LTL was not related to allcause or disease specific mortality. 
In previous cross-sectional studies the decrease in average TL ranged from 31-63 bp/year [36-40], and in prospective studies a mean decrease of 38$71 \mathrm{bp} /$ year was observed $[8,13,14]$. These studies included different study populations (i.e. premenopausal women, patients with colorectal carcinomas and healthy subjects) with a mean age ranged from 31.4-75 years. These results were in accord with the $40 \mathrm{bp}$ average decrease in LTL per year in the present study. For $16 \%$ of the subjects we found an increase in $T L$, which is consistent with five other prospective studies. In about $10-34 \%$ of the subjects in these studies, a stabilization or increase in TL was observed with a time interval ranging from 2.5-12.9 years $[8,13,14,41,42]$. However, these results should be interpreted with caution because of random variation.

With increasing age telomeres shorten, but they are also influenced by oxidative stress $[43,44]$. Several inflammatory diseases, such as cardiovascular diseases and cancer have been linked to chronic oxidative stress and accelerated telomere shortening $[6,16]$. Therefore, we hypothesized LTL is a marker for all-cause or cause-specific mortality, but this was not found in the present analysis. Likewise, three studies with similar study populations, e.g. elderly and the oldest old and similar follow-up periods, found also no association between TL and mortality $[41,42,45]$. A possible explanation for these negative findings might be that there is a higher degree of TL instability in the oldest old compared to younger populations. In two recent studies carried out in younger populations an inverse association was observed between TL and survival $[13,14]$. Also in studies carried out in patients with coronary artery disease, diabetes or stroke survivors an association was found between TL and survival $[3,9,12]$. Other differences between the present study and the ones showing an association were: follow-up period (varying from 2.5 to 15 years), a higher number of participants (ranging from 510 to 1542 subjects) $[6,9,13,14,46]$ and the method used to determine $\operatorname{TL}[3,5,7,8,12,46]$.

In a study by Halaschek-Wiener et al. TL was measured in exceptionally healthy elderly. They concluded that there was less TL variation in the healthy oldest old when compared to younger subjects [47]. In the study by Cawthon et al. it was concluded that TL was a significant predictor of mortality for subjects aged 60-74 years, but in the older age group (of 75 years or older) this association was not significant. In the present study, LTL was determined with the same method as in the study by Cawthon [7]. These data support our findings that in the oldest old LTL is not related to mortality. 
Shorter TL in leukocytes has been associated with CVD [8] and its risk factors, such as myocardial infarction [48] although not in all studies [49]. LTL has also been shown to predict myocardial infarction and stroke in men under 73 years old [15] and shorter length of telomeres was shown to predict the occurrence of death or hospitalization in patients with chronic heart failure [50]. However, other studies, notably those with elderly cohorts, have failed to find an association between LTL and mortality $[41,45]$. In the present study we were also not able to find an association between LTL and CVD mortality. In previous studies, a positive instead of an inverse relationship was noted between long telomeres and risk of death through cancer for breast cancer [20], skin cancer [19], and non-Hodgkin lymphoma [16]. A possible explanation for this association may be that cancer is associated with increased telomerase activity that lengthens telomeres [51], which is normally very low or absent in somatic cells [52]. In the present study LTL was not related to total cancer.

Potential limitations of our study should be considered. The Zutphen Elderly Study cohort is a random sample of the general population of white, Dutch elderly men, which may limit the generalizability of our findings to other ethnic groups, to women, and men of younger age. TL was determined in the total white blood cell population (WBC), which may not accurately reflect TL dynamics. Lymphocytes showed a greater age-related decline in TL [53] and recently it was shown that subpopulations of lymphocytes display differences in TL and in telomerase activity [54]. Determining TL in specific subpopulations of lymphocytes may therefore better reflect the age-related shortening of telomeres. For the individual diseases the number of subjects was too small and therefore we combined all cardiovascular diseases and all different types of cancer, but these endpoints were not related to LTL. This study has also several strengths. The high reliability of our TL analysis was confirmed in 20 samples with a different reference gene (reliability coefficient of $0.87, p<0.001$ ), rendering potential fragmentation or loss of DNA during isolation unlikely. Finally, we had an almost complete mortality follow-up and could estimate the LTL shortening over 7 years of follow-up, whereas previous studies used mostly cross-sectional designs.

In conclusion, our data showed that the average telomere shortening is 40 bp per year in elderly men and LTL measured 7 years apart was strongly correlated. On the other hand we did not confirm the hypothesis that LTL is a 
marker for mortality in elderly men. Future studies should focus on TL measurement in populations with a wider age range.

\section{Funding}

The Zutphen Elderly Study was supported by grants from The Netherlands Prevention Foundation (Preventiefonds). Part of this study was funded by a grant from The Netherlands Brain Foundation (Hersenstichting, Nederland, grantnr. 15F07(2).24). 


\section{References}

1. Greider CW, Blackburn EH: Telomeres, telomerase and cancer. Sci Am 1996;274:9297.

2. Joosten SA, van Ham V, Nolan CE, Borrias MC, Jardine AG, Shiels PG, van Kooten C, Paul LC: Telomere shortening and cellular senescence in a model of chronic renal allograft rejection. Am J Pathol 2003;162:1305-1312.

3. Astrup AS, Tarnow L, Jorsal A, Lajer M, Nzietchueng R, Benetos A, Rossing P, Parving $\mathrm{HH}$ : Telomere length predicts all-cause mortality in patients with type 1 diabetes. Diabetologia 2009.

4. Atzmon G, Cho M, Cawthon RM, Budagov T, Katz M, Yang X, Siegel G, Bergman A, Huffman DM, Schechter CB, Wright WE, Shay JW, Barzilai N, Govindaraju DR, Suh Y: Genetic variation in human telomerase is associated with telomere length in Ashkenazi centenarians. Proc Natl Acad Sci U S A 2009.

5. Bakaysa SL, Mucci LA, Slagboom PE, Boomsma DI, McClearn GE, Johansson B, Pedersen NL: Telomere length predicts survival independent of genetic influences. Aging Cell 2007;6:769-774.

6. Brouilette SW, Moore JS, McMahon AD, Thompson JR, Ford I, Shepherd J, Packard $\mathrm{CJ}$, Samani NJ: Telomere length, risk of coronary heart disease, and statin treatment in the West of Scotland Primary Prevention Study: a nested case-control study. Lancet 2007;369:107-114.

7. Cawthon RM, Smith KR, O'Brien E, Sivatchenko A, Kerber RA: Association between telomere length in blood and mortality in people aged 60 years or older. Lancet 2003;361:393-395.

8. Epel E, Merkin S, Cawthon R, Blackburn E, Adler N, Pletcher M, Seeman T: The rate of leukocyte telomere shortening predicts mortality from cardiovascular disease in elderly men. Aging 2009;1:81-88.

9. Farzaneh-Far R, Cawthon RM, Na B, Browner WS, Schiller NB, Whooley MA: Prognostic value of leukocyte telomere length in patients with stable coronary artery disease: data from the Heart and Soul Study. Arterioscler Thromb Vasc Biol 2008;28:1379-1384.

10. Honig LS, Schupf N, Lee JH, Tang MX, Mayeux R: Shorter telomeres are associated with mortality in those with APOE epsilon4 and dementia. Ann Neurol 2006;60:181-187.

11. Kimura M, Barbieri M, Gardner JP, Skurnick J, Cao X, van Riel N, Rizzo MR, Paolisso G, Aviv A: Leukocytes of Exceptionally Old Persons Display Ultra-short Telomeres. Am J Physiol Regul Integr Comp Physiol 2007. 
12. Martin-Ruiz C, Dickinson HO, Keys B, Rowan E, Kenny RA, Von Zglinicki T: Telomere length predicts poststroke mortality, dementia, and cognitive decline. Ann Neurol 2006;60:174-180.

13. Aviv A, Chen W, Gardner JP, Kimura M, Brimacombe M, Cao X, Srinivasan SR, Berenson GS: Leukocyte telomere dynamics: longitudinal findings among young adults in the Bogalusa Heart Study. Am J Epidemiol 2009;169:323-329.

14. Ehrlenbach S, Willeit P, Kiechl S, Willeit J, Reindl M, Schanda K, Kronenberg F, Brandstatter A: Influences on the reduction of relative telomere length over 10 years in the population-based Bruneck Study: introduction of a well-controlled high-throughput assay. Int J Epidemiol 2009;38:1725-1734.

15. Fitzpatrick AL, Kronmal RA, Gardner JP, Psaty BM, Jenny NS, Tracy RP, Walston J, Kimura M, Aviv A: Leukocyte telomere length and cardiovascular disease in the cardiovascular health study. Am J Epidemiol 2007;165:14-21.

16. Lan $Q$, Cawthon R, Shen M, Weinstein SJ, Virtamo J, Lim U, Hosgood HD, 3rd, Albanes $\mathrm{D}$, Rothman $\mathrm{N}$ : A prospective study of telomere length measured by monochrome multiplex quantitative PCR and risk of non-Hodgkin lymphoma. Clin Cancer Res 2009;15:7429-7433.

17. Hou L, Savage SA, Blaser MJ, Perez-Perez G, Hoxha M, Dioni L, Pegoraro V, Dong LM, Zatonski W, Lissowska J, Chow WH, Baccarelli A: Telomere length in peripheral leukocyte DNA and gastric cancer risk. Cancer Epidemiol Biomarkers Prev 2009;18:3103-3109.

18. Jang JS, Choi YY, Lee WK, Choi JE, Cha SI, Kim YJ, Kim CH, Kam S, Jung TH, Park JY: Telomere length and the risk of lung cancer. Cancer Sci 2008;99:1385-1389.

19. Han J, Qureshi AA, Prescott J, Guo Q, Ye L, Hunter DJ, De Vivo I: A prospective study of telomere length and the risk of skin cancer. J Invest Dermatol 2009;129:415-421.

20. Svenson U, Nordfjall K, Stegmayr B, Manjer J, Nilsson P, Tavelin B, Henriksson R, Lenner $\mathrm{P}$, Roos $\mathrm{G}$ : Breast cancer survival is associated with telomere length in peripheral blood cells. Cancer Res 2008;68:3618-3623.

21. Cawthon RM: Telomere measurement by quantitative PCR. Nucleic Acids Res 2002;30:e47.

22. Houben JM, Mercken EM, Ketelslegers HB, Bast A, Wouters EF, Hageman GJ, Schols AM: Telomere shortening in chronic obstructive pulmonary disease. Respir Med 2009;103:230-236.

23. Bloemberg BP, Kromhout D, Obermann-De Boer GL, Van Kampen-Donker M: The reproducibility of dietary intake data assessed with the cross-check dietary history method. Am J Epidemiol 1989;130:1047-1056.

24. Cherkas LF, Hunkin JL, Kato BS, Richards JB, Gardner JP, Surdulescu GL, Kimura M, Lu X, Spector TD, Aviv A: The association between physical activity in leisure time and leukocyte telomere length. Arch Intern Med 2008;168:154-158.

25. Caspersen CJ, Bloemberg BP, Saris WH, Merritt RK, Kromhout D: The prevalence of selected physical activities and their relation with coronary heart disease risk 
factors in elderly men: the Zutphen Study, 1985. Am J Epidemiol 1991;133:10781092.

26. Morla M, Busquets X, Pons J, Sauleda J, MacNee W, Agusti AG: Telomere shortening in smokers with and without COPD. Eur Respir J 2006;27:525-528.

27. Valdes AM, Andrew T, Gardner JP, Kimura M, Oelsner E, Cherkas LF, Aviv A, Spector TD: Obesity, cigarette smoking, and telomere length in women. Lancet 2005;366:662-664.

28. Wu D, Cederbaum Al: Alcohol, oxidative stress, and free radical damage. Alcohol Res Health 2003;27:277-284.

29. Cherkas LF, Aviv A, Valdes AM, Hunkin JL, Gardner JP, Surdulescu GL, Kimura M, Spector TD: The effects of social status on biological aging as measured by whiteblood-cell telomere length. Aging Cell 2006;5:361-365.

30. Kadi F, Ponsot E: The biology of satellite cells and telomeres in human skeletal muscle: effects of aging and physical activity. Scand J Med Sci Sports 2009.

31. Adaikalakoteswari A, Balasubramanyam M, Mohan V: Telomere shortening occurs in Asian Indian Type 2 diabetic patients. Diabet Med 2005;22:1151-1156.

32. Adaikalakoteswari A, Balasubramanyam M, Ravikumar R, Deepa R, Mohan V: Association of telomere shortening with impaired glucose tolerance and diabetic macroangiopathy. Atherosclerosis 2007.

33. Jeanclos E, Krolewski A, Skurnick J, Kimura M, Aviv H, Warram JH, Aviv A: Shortened telomere length in white blood cells of patients with IDDM. Diabetes 1998;47:482486.

34. Kinouchi Y, Hiwatashi N, Chida M, Nagashima F, Takagi S, Maekawa H, Toyota T: Telomere shortening in the colonic mucosa of patients with ulcerative colitis. J Gastroenterol 1998;33:343-348.

35. Savale L, Chaouat A, Bastuji-Garin S, Marcos E, Boyer L, Maitre B, Sarni M, Housset B, Weitzenblum E, Matrat M, Le Corvoisier P, Rideau D, Boczkowski J, Dubois-Rande JL, Chouaid C, Adnot S: Shortened Telomeres in Circulating Leukocytes of Patients with Chronic Obstructive Pulmonary Disease. Am J Respir Crit Care Med 2009.

36. Epel ES, Blackburn EH, Lin J, Dhabhar FS, Adler NE, Morrow JD, Cawthon RM: Accelerated telomere shortening in response to life stress. Proc Natl Acad Sci U S A 2004;101:17312-17315.

37. Hastie ND, Dempster M, Dunlop MG, Thompson AM, Green DK, Allshire RC: Telomere reduction in human colorectal carcinoma and with ageing. Nature 1990;346:866-868.

38. Iwama H, Ohyashiki K, Ohyashiki JH, Hayashi S, Yahata N, Ando K, Toyama K, Hoshika A, Takasaki M, Mori M, Shay JW: Telomeric length and telomerase activity vary with age in peripheral blood cells obtained from normal individuals. Hum Genet 1998;102:397-402. 
39. Satoh H, Hiyama K, Takeda M, Awaya Y, Watanabe K, Ihara Y, Maeda H, Ishioka S, Yamakido M: Telomere shortening in peripheral blood cells was related with aging but not with white blood cell count. Jpn J Hum Genet 1996;41:413-417.

40. Slagboom PE, Droog S, Boomsma DI: Genetic determination of telomere size in humans: a twin study of three age groups. Am J Hum Genet 1994;55:876-882.

41. Martin-Ruiz CM, Gussekloo J, van Heemst D, von Zglinicki T, Westendorp RG: Telomere length in white blood cells is not associated with morbidity or mortality in the oldest old: a population-based study. Aging Cell 2005;4:287-290.

42. Nordfjall K, Svenson U, Norrback KF, Adolfsson R, Lenner P, Roos G: The individual blood cell telomere attrition rate is telomere length dependent. PLoS Genet 2009;5:e1000375.

43. von Zglinicki T: Role of oxidative stress in telomere length regulation and replicative senescence. Ann N Y Acad Sci 2000;908:99-110.

44. von Zglinicki T: Oxidative stress shortens telomeres. Trends Biochem Sci 2002;27:339-344.

45. Bischoff C, Petersen HC, Graakjaer J, Andersen-Ranberg K, Vaupel JW, Bohr VA, Kolvraa S, Christensen K: No association between telomere length and survival among the elderly and oldest old. Epidemiology 2006;17:190-194.

46. Kimura M, Hjelmborg JV, Gardner JP, Bathum L, Brimacombe M, Lu X, Christiansen L, Vaupel JW, Aviv A, Christensen K: Telomere length and mortality: a study of leukocytes in elderly Danish twins. Am J Epidemiol 2008;167:799-806.

47. Halaschek-Wiener J, Vulto I, Fornika D, Collins J, Connors JM, Le ND, Lansdorp PM, Brooks-Wilson A: Reduced telomere length variation in healthy oldest old. Mech Ageing Dev 2008;129:638-641.

48. Brouilette S, Singh RK, Thompson JR, Goodall AH, Samani NJ: White cell telomere length and risk of premature myocardial infarction. Arterioscler Thromb Vasc Biol 2003;23:842-846.

49. Kurz DJ, Kloeckener-Gruissem B, Akhmedov A, Eberli FR, Buhler I, Berger W, Bertel $O$, Luscher TF: Degenerative aortic valve stenosis, but not coronary disease, is associated with shorter telomere length in the elderly. Arterioscler Thromb Vasc Biol 2006;26:e114-117.

50. van der Harst P, de Boer RA, Samani NJ, Wong LS, Huzen J, Codd V, Hillege HL, Voors AA, van Gilst WH, Jaarsma T, van Veldhuisen DJ: Telomere length and outcome in heart failure. Ann Med;42:36-44.

51. Blasco MA: Mammalian telomeres and telomerase: why they matter for cancer and aging. Eur J Cell Biol 2003;82:441-446.

52. von Zglinicki T, Martin-Ruiz C, Saretzki G: Telomeres, cell senescence and human ageing. Signal Transduction 2005;3.

53. Greenwood MJ, Lansdorp PM: Telomeres, telomerase, and hematopoietic stem cell biology. Arch Med Res 2003;34:489-495. 
54. Lin J, Epel E, Cheon J, Kroenke C, Sinclair E, Bigos M, Wolkowitz O, Mellon S, Blackburn E: Analyses and comparisons of telomerase activity and telomere length in human T and B cells: insights for epidemiology of telomere maintenance. J Immunol Methods 2009;352:71-80. 




\section{Chapter 4}

\section{Telomere shortening in chronic obstructive pulmonary disease}

Resp Med. 2009 Feb 103(2):230-6. Epub 2008 Oct 21.
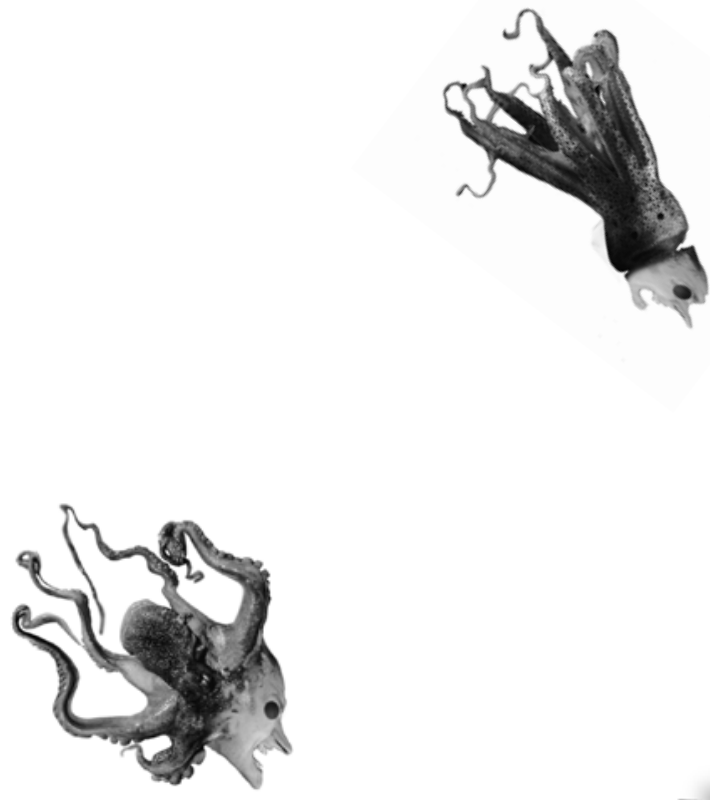

Joyce M.J. Houben

Evi M. Mercken

Hans B. Ketelslegers

Aalt Bast

Emiel F. Wouters

Geja J. Hageman

Annemie M.W.J. Schols 


\begin{abstract}
Chronic oxidative stress and systemic inflammation contribute to the pathology of several chronic diseases, among which chronic obstructive pulmonary disease (COPD). In addition, increased oxidative stress and inflammation have been observed to be negatively associated with telomere length (TL). Our aim was to investigate TL in COPD patients in relation to pulmonary and extrapulmonary disease severity. Furthermore, based on experimental evidence suggesting effects of oxidative stress on telomere shortening, we studied the association of TL with the antioxidant enzyme superoxide dismutase (SOD). 102 COPD patients with moderate to severe COPD were studied and compared with 19 healthy age matched controls. Patients were characterized by elevated levels of inflammatory markers (CRP, sTNF-receptors) and lower SOD-activity than controls $(p<0.001)$, irrespective of SOD genotype. TL was negatively associated with age $(p<0.01)$ and was significantly shorter in COPD patients than controls $(p<0.05)$. Within the patient group age-adjusted TL variability could not be explained by lung function and smoking history but a modest association was found with percentage fat mass $(p<0.05)$. These data provide evidence for a relationship between a disturbed oxidant/antioxidant balance and telomere shortening and indicate that preservation of fat mass may be protective in delaying telomere shortening in COPD patients.
\end{abstract}




\section{Introduction}

Chronic systemic oxidative stress plays a major role in the pathophysiology of chronic obstructive pulmonary disease (COPD) [1]. COPD is characterized by incompletely reversible airflow obstruction associated with pulmonary inflammation in which monocytes and macrophages are the predominant inflammatory cells [1]. Tobacco smoking is the main risk factor for COPD. However, for reasons that are still poorly understood, only a small proportion of smokers eventually develops COPD [2]. Moreover, in COPD patients oxidative stress, resulting from an imbalance between the production of reactive oxygen species and the antioxidant defense, has been implicated with disease progression and complications such as cachexia [3]. Wasting of fat-free mass and at later stages also of fat mass is a common systemic impairment in COPD, adversely affecting functionality, morbidity and prognosis.

In addition, several animal and in vitro models have shown that chronic oxidative stress induces an accelerated rate of telomere loss [4-6]. Telomeres are nucleoprotein structures at the end of chromosomes and consist of 4-15 $\mathrm{kbp}$ of the hexanucleotides 5'-TTAGGG-3' [6, 7]. Telomeres prevent chromosomal ends from being recognized as double strand breaks and protect them from end to end fusion and degradation [8]. In somatic cells, telomeres shorten with each cell division and cells are triggered into replicative senescence once telomeres shorten to a critical length $[9,10]$. Since telomere length (TL) in somatic cells determines the number of cell divisions, TL has been proposed as a marker for biological age.

Since cell division appeared to account only partially for the loss of telomeres seen in cells, it was suggested that other mechanisms, in particular oxidative stress, might be involved in accelerated telomere shortening [6, 11 , 12]. Recent studies indeed have linked telomere shortening to various chronic metabolic and inflammatory diseases such as atherosclerosis, diabetes type I and inflammatory bowel disease, conditions that are all characterized by systemic oxidative stress [13-17]. Animal studies and in vitro models have shown that the antioxidant enzyme superoxide dismutase (SOD) may protect telomeres from shortening $[4,18]$. We therefore hypothesized that telomere shortening might be accelerated in patients with COPD and serve as a biomarker of disease progression, and more specifically of the risk for muscle wasting. 
The aim of this study was twofold. First, we wanted to investigate TL in COPD patients in relation to cachexia and muscle wasting. Since experimental evidence suggested that oxidative stress is an important determinant of telomere shortening, our second aim was to study the association of TL with the major antioxidant enzymes SOD and catalase. For this purpose, we measured TL in leukocytes of 102 COPD patients and compared these to 19 healthy, agematched controls. TL was measured using quantitative PCR [19]. In addition, SOD and catalase activity were determined as well as the V16A polymorphism in the gene encoding MnSOD.

\section{Subjects and Methods}

\section{Study population}

One hundred and two clinically stable COPD patients with stage II-IV according to the Global Initiative for Chronic Obstructive Lung Disease guidelines were consecutively recruited on admission to a pulmonary rehabilitation center (CIRO, Horn, The Netherlands). Exclusion criteria were the presence of diseases such as malignancies, gastrointestinal or kidney abnormalities, metabolic or endocrine diseases and inflammatory diseases such as diabetes. Most patients were using medication to treat symptoms of the disease, including anticholinergica, $\beta 2$-agonists, theophylline and inhaled- and oral corticosteroids. Written informed consent was obtained from all participants, and the study was approved by the ethical review board of the University Hospital Maastricht. Twenty healthy Dutch volunteers, gender- and agematched, were recruited by an advertisement in a local newspaper. Characteristics of the patients and healthy controls are listed in Table 1. Part of the data used in this study has been described elsewhere [20]. 
Table 1. Definition of abbreviations: HC: healthy controls

\begin{tabular}{lll}
\hline & COPD & HC \\
\hline Sex, M/F & $71 / 31$ & $15 / 5$ \\
\hline Age, yr & $62.9 \pm 9.3$ & $60.7 \pm 3.5$ \\
\hline Packyears of smoking & $36.3 \pm 23.1^{\mathrm{a}}$ & $13.3 \pm 18.0^{\mathrm{b}}$ \\
\hline Body composition & & \\
\hline FFMI & $16.5 \pm 2.2^{\mathrm{a}}$ & $20.2 \pm 2.5^{\mathrm{b}}$ \\
\hline FM (kg) & $16.7 \pm 6.6^{\mathrm{a}}$ & $16.4 \pm 7.5$ \\
\hline BMI, kg/m2 & $22.3 \pm 3.8^{\mathrm{a}}$ & $25.7 \pm 2.8^{\mathrm{b}}$ \\
\hline Lung function & & $105.4 \pm 16.1^{\mathrm{b}}$ \\
\hline FEV1, \% predicted & $34.6 \pm 13.5^{\mathrm{a}}$ & $109.6 \pm 22.8^{\mathrm{b}}$ \\
\hline DLCO, \% predicted & $49.2 \pm 19.9^{\mathrm{a}}$ & \\
\hline Medication & & \\
\hline Anticholinergics, \% & 76 & \\
\hline b2-agonists, \% & 86 & $1.82(0.16,7.09)^{\mathrm{b}}$ \\
\hline Inhaled corticosteroids, \% & 81 & $0.91 \pm 0.21^{\mathrm{b}}$ \\
\hline Oral corticosteroids, \% & 30 \\
\hline Theophylline, \% & 37 \\
\hline Inflammation markers & $3.5(0.4,75.6)^{\mathrm{a}}$ \\
\hline C-reactive proteinc & $1.02 \pm 0.38^{\mathrm{a}}$ \\
\hline sTNFR & \\
\hline FEV1: forced expiratory Vom & \\
\hline
\end{tabular}

FEV1: forced expiratory volume in $1 \mathrm{~s}$; DLCO: diffusing capacity for carbon monoxide. Data are presented as mean \pm SD and tested with one-factor analysis of variance (ANOVA). Values not sharing a common superscript letter $\left({ }^{a, b}\right)$ are significantly different at $p<0.05$. ${ }^{c}$ Values are median (range) and tested with the Mann-Whitney test.

\section{Pulmonary Function Tests}

All participants underwent flow volumes including measurement of FEV1 with the highest value from at least three properly performed measurements being used for analysis. Diffusion capacity for carbon monoxide (DLCo) was measured by using the single breath method (Masterlab, Jaeger, Würzburg, Germany). The values obtained were expressed as a percentage of the reference value [21].

\section{Body composition}

Body composition was estimated using single frequency $(50 \mathrm{kHz})$ bioelectrical impedance analysis (BIA; Xitron Technologies, San Diego, CA, USA). Fat-free mass (FFM) was calculated using the disease-specific equation proposed by Schols [22] and FFM of healthy controls was calculated using the equations of Lukaski [23]. FFM-index (FFMI) was calculated as FFM divided by height2 
$(\mathrm{kg} / \mathrm{m} 2)$. Patients were classified as cachectic when their FFMI was lower than $16 \mathrm{~kg} / \mathrm{m} 2$ for men and lower than $15 \mathrm{~kg} / \mathrm{m} 2$ for women. Fat mass (FM; kg) was estimated as total body weight minus FFM.

\section{Sample preparation}

Fasting venous blood samples $(10 \mathrm{ml})$ were drawn into ethylenediaminetetraacetic acid (EDTA)-containing tubes (Becton Dickinson Vacutainer Systems, Plymouth, UK) in the early morning (08.00-09.00 hours). After centrifugation twice at $1000 \times \mathrm{g}$ for 10 minutes at $4^{\circ} \mathrm{C}$ within 2 hours of collection, plasma for CRP and white blood cells for DNA extraction were stored at $-70^{\circ} \mathrm{C}$. Genomic DNA was extracted from the white blood cells by a salting out procedure [24]. The remaining red blood cells were washed twice with PBS. The hemolysates were diluted 10:1 with distilled water.

\section{TL measurement}

TL was determined by quantitative PCR as described by Cawthon [19]. From 7 patients and 1 healthy subject, no PCR results could be obtained, due to poor quality of the DNA. Two master mixes were prepared, one with telomere primers and one with HBG primers ( 1 I IQ SYBRgreen supermix from BioRad, CA, USA). Sequences and concentrations of the primers are shown in Table 2.

Table 2. Primer sequences and concentrations

\begin{tabular}{lll}
\hline Primer & Sequence & Concentration \\
\hline Telomere 1 & CGGTTTGTTTGGGTTTGGGTTTGGGTTTGGGTTTGGGTT & $100 \mathrm{nM}$ \\
\hline Telomere 2 & GGCTTGCCTTACCCTTACCCTTACCCTTACCCTTACCCT & $900 \mathrm{nM}$ \\
\hline HBG forward & GCTTCTGACACAACTGTGTTCACTAGC & $300 \mathrm{nM}$ \\
\hline HBG reverse & CACCAACTTCATCCACGTTCACC & $700 \mathrm{nM}$ \\
\hline
\end{tabular}

Sample DNA was pipetted in a 96-wells plate at a final concentration of 10 $\mathrm{ng} / \mu \mathrm{l} .20 \mu \mathrm{l}$ of the mastermix was added and the plate was shortly centrifuged. Each sample was run in triplicates. For the standard curve a reference DNA sample was diluted serially to produce three concentrations of 1.25, 5 and 10 $\mathrm{ng} / \mu \mathrm{l}$. Negative controls ( $\mathrm{MQ}+$ mastermix) and positive controls were added every run. The positive controls were derived from two different Hela cell lines, one with relatively short telomeres (Hela S3: $5.5 \mathrm{~kb}$ ) and one with long telomeres (Hela 229: 14-15 kb). Hela cell lines were kindly provided by Prof. Alexander Bürkle, University of Konstanz, Germany. The PCR was performed 
using a BioRad MyiQ iCycler Single Color RT-PCR detection system using iQTM SYBR $^{\circledR}$ Green Supermix, containing iTaq Polymerase, dNTPs, SYBRGreen I and buffers (BioRad, CA, USA).

\section{Superoxide dismutase (SOD) and catalase acitivity}

Hemoglobin $(\mathrm{Hb})$ concentration in the 1:10 hemolysates was determined spectrophotometrically based on the the cyanomethemoglobin method .

SOD-activity was determined according to the method of Sun et al [25]. This method is based on the generation of superoxide radicals produced by xanthine and xanthine oxidase, which react with nitro-blue tetrazolium (NBT) to form a NBT-diformazan. SOD was extracted in chloroform:ethanol mixture in the ratio of 0.15:0.25, shaken for $15 \mathrm{~min}$ and centrifuged at $2500 \mathrm{~g}$ for $5 \mathrm{~min}$ at $4^{\circ} \mathrm{C}$ and the supernatant was used for the assay. The reaction mixture was composed of $20 \mu \mathrm{l}$ sample, $930 \mu \mathrm{l}$ of substrate containing $0.5 \mathrm{mM}$ xanthine (Sigma, St. Louis, USA), 0.5 mM NBT (Sigma, St. Louis, USA) in buffer and 40U/I of xanthine oxidase (Sigma, St. Louis, USA),. One unit of SOD was defined as the amount of enzyme necessary to produce $50 \%$ inhibition in the NBT reduction rate. SOD-activity was measured at $560 \mathrm{~nm}$ and expressed as units per milligram $\mathrm{Hb}$.

The catalase activity was measured according to Aebi [26] in reaction mixture containing $20 \mu$ heamolysate in $100 \mathrm{mM}$ phosphate buffer (pH 7.4). The reaction was started by addition of $\mathrm{H} 2 \mathrm{O} 2$ (Merck, Germany) at a final concentration of $10 \mathrm{mM}$, and the rate was measured spectrophotometrically at $240 \mathrm{~nm}$ (Perkin Elmer Lambda-series) for $1 \mathrm{~min}$ at $25^{\circ} \mathrm{C}$. One unit of catalase activity was defined as the amount of catalase absorbed in $1 \mathrm{~min}$ at $25^{\circ} \mathrm{C}$. The catalase activity was then calculated from the change in absorbance and finally expressed as $\mathrm{U} / \mathrm{g} \mathrm{Hb}$.

\section{C-reactive protein (CRP)}

CRP was assessed in duplicate by high-sensitivity particle-enhanced immunonephelometry ( $\mathrm{N} \mathrm{Hs} \mathrm{CRP}$, Dade Behring).

\section{Polymorphism selection}

DNA sequence and allele frequency was obtained from the Cancer SNP 500 database (http://snp500cancer.nci.nih.gov). 


\section{Genotyping of polymorphism}

Genotyping was performed on the DNA of the white blood cells of 84 COPD patients and 18 controls according to the validated method for genotyping [27, 28]. PCR Primers MnSOD: Left 5'-GGTGACGTTCAGGTTGTTCA-3'; Right 5' GGCTGTGCTTTCTCGTCTTC-3'.

The PCR was carried out in a T-gradient 96-well Thermal cycler (Biometra, Goettingen, Germany) in a $10 \mu$ volume, containing PCR buffer (Invitrogen, Breda, The Netherlands), $0.2 \mathrm{mmol} / \mathrm{l}$ deoxynucleotide triphosphates (Invitrogen), and $40 \mathrm{ng}$ template DNA. The final concentration of the primers was $0.1 \mu \mathrm{M} / \mathrm{I}$. Afterwards, PCR products were incubated with $4 \mu \mathrm{l}$ Exo-Sap-IT (Amersham, Roosendaal, The Netherlands) for 55 minutes at $37 \circ \mathrm{C}$ to digest contaminating deoxynucleotide triphosphates and PCR primers. Enzymes were deactivated at $72^{\circ} \mathrm{C}$ for 15 minutes. Genotyping was done by Single Base Extension (SBE) using SNaPshot (Applied Biosystems, Nieuwekerk a.d. IJssel, The Netherlands) as described previously [28]. SBE primers were designed using Primer 3 and Netprimer software to bind immediately adjacent $5^{\prime}$ to the specific SNP. SBE primer: 5'-CCTGGAGCCCAGATACCCCAAA-3'. After SBE, the samples were incubated at $37{ }^{\circ} \mathrm{C}$ for 1 hour with 1 unit shrimp alkaline phosphatase (Amersham) to degrade the unincorporated dideoxynucleotide triphosphates. Afterwards, SBE products were diluted and mixed with deionized formamide containing Genescan 120 LIZ size standard and denatured at 95ㅇ for 5 minutes. Subsequently, the samples were analyzed on an ABI Prism 3100 genetic analyzer using Genescan Analysis software.

\section{Statistical analysis}

Results are expressed as mean \pm SD for all variables that were normally distributed, and as median (range) when not-normally distributed. Differences between COPD patients and healthy controls were tested using Student's t-test for independent samples and the Mann Whitney U-test when not-normally distributed. Differences in the distribution of the genotypes between groups were examined by using the $\chi 2$ test. To study determinants of TL in COPD, multiple regression analysis was conducted with $T L$ as the dependent variable and gender, age, CRP, smoking history (in packyears), parameters of body composition and SOD-activity as independent variables. A difference with $\mathrm{p}<0.05$ was considered statistically significant. Statistical analyses were analyzed with SPSS for Windows (version 13.0; SPSS, Inc., Chicago, IL). 


\section{Results}

General characteristics of the subjects are shown in Table 1. COPD patients were characterized by lower values for FEV1, DLCO and FFMI $(p<0.001)$ than the control group. COPD patients had shorter telomeres when compared to the control group ( $p<0.05$; Figure $1 \mathrm{~A}$ ). Age negatively correlated with $T L$ in patients $(r=0.079, p<0.05 ;$ Figure 2$)$ and in controls $(r=0.145, p=0.108$; Figure 2$)$. No associations of smoking history, lung function parameters, FFMI or CRP could be found with TL. COPD patients had lower levels of SOD-activity than healthy controls ( $p<0.001$; Figure 1B). The distribution of SOD genotypes among patients and healthy controls is shown in Table 3.

A.

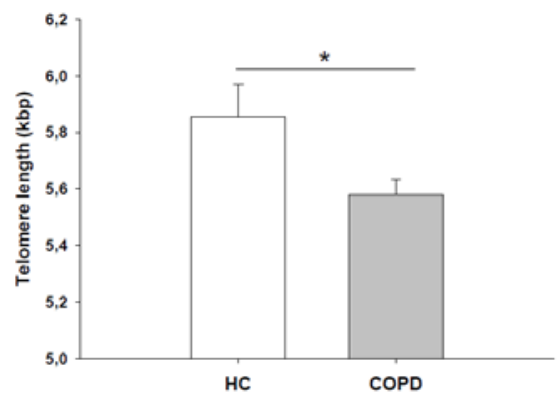

B.

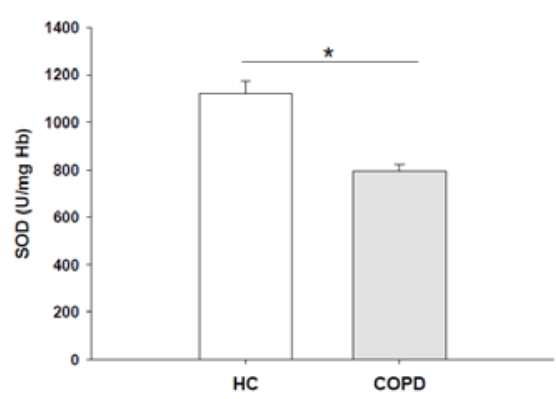

Figure 1. Telomere length in white blood cells (A) and SODactivity (B) in red blood cells in healthy controls $(H C)$, and COPD patients $\left({ }^{*} p<0.001 ; * * p<0.05\right)$. Significantly different between the different groups based on Student's t-test. Results are expressed as mean SEM.

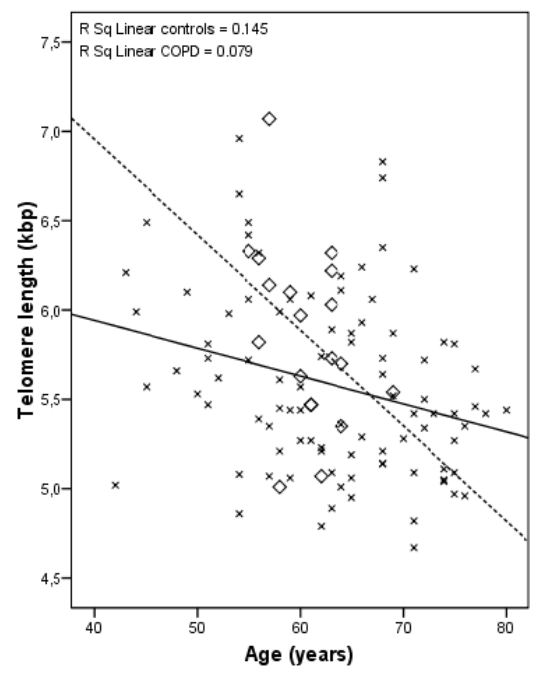

Figure 2. Relationship between telomere length and age for healthy controls and patients. Telomere length significantly correlated with age in patients ( $r Z 0.079 ; p<0.05)$ and in the total study population ( $r Z 0.087 ; p<0.01)$. 
Table 3. Distribution of genotype of COPD patients and controls.

\begin{tabular}{|c|c|c|c|c|c|}
\hline & & \multicolumn{2}{|c|}{ COPD } & \multicolumn{2}{|c|}{$\mathrm{HC}$} \\
\hline & & $\mathrm{n}$ & $\%$ & $\mathrm{n}$ & $\%$ \\
\hline \multirow[t]{4}{*}{ MnSOD } & Total & 84 & & & 18 \\
\hline & $\mathrm{TT}$ & 25 & 29.8 & 4 & 22.2 \\
\hline & $\mathrm{TC}$ & 34 & 40.5 & 8 & 44.4 \\
\hline & $\mathrm{CC}$ & 25 & 29.8 & 6 & 33.3 \\
\hline \multirow[t]{2}{*}{ Genotype } & $\mathrm{T}>\mathrm{C}$ & \multicolumn{4}{|c|}{ Effect polymorphism: } \\
\hline & & \multicolumn{4}{|c|}{$\begin{array}{l}\text { Decreased enzyme activity: less efficient antioxidant } \\
\text { defense }\end{array}$} \\
\hline
\end{tabular}

There was no significant association between SOD activity and the SOD polymorphism, neither in patients nor in controls. Furthermore, we found a correlation between SOD-activity and TL in the complete study population (Figure 3A), which was not dependent on SOD-genotype. This association remained statistical significant after controlling for age, gender, disease state (patient or control), smoking history and CRP (Table 4).

Table 4. Regression model with telomere length as the dependent variable

\begin{tabular}{ll}
\hline Variables & p-value \\
\hline Age & 0.001 \\
\hline SOD activity & 0.012 \\
\hline Smoking (packyears) & 0.151 \\
\hline Gender & 0.198 \\
\hline Disease (patient/control) & 0.054 \\
\hline C-reactive protein & 0.472 \\
\hline
\end{tabular}

Catalase activity was also measured and tended to be lower in COPD patients, but no significant differences or correlations were observed (data not shown).

Within the patient group, after controlling for age and gender, TL variability could not be explained by lung function and smoking history, but a modest association was found with percentage fat mass $(r=0.25, p<0.05$; Figure 3B). 
A.

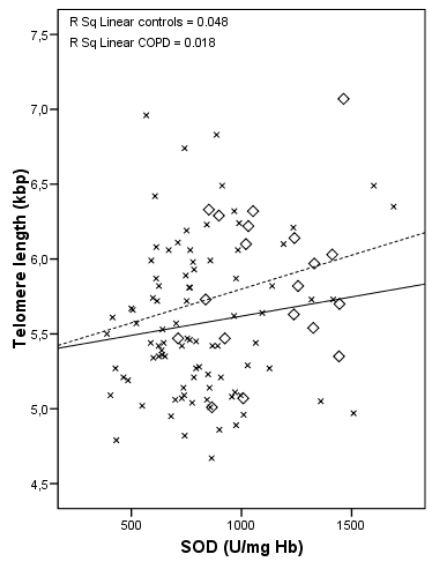

B.

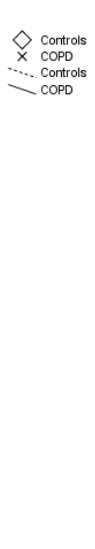

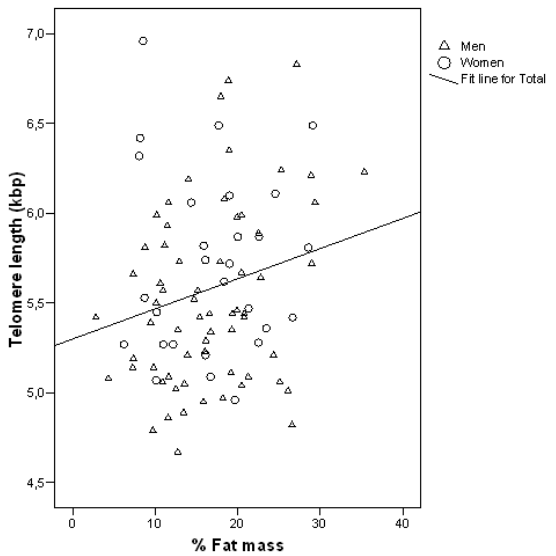

Figure 3. Associations between telomere length and SOD-activity in healthy controls ( $r Z 0.048$; pZ0.368) and COPD patients ( $r Z 0.018 ; p Z 121)(A)$ and between telomere length and fat mass in COPD patients (B). SOD-activity positively correlated with telomere length in the complete study population after adjustment for age, gender, disease state (patient or control), smoking history and CRP ( $r Z 0.049 ; p<0.05)$. Fat mass positively correlated with telomere length in COPD patients after adjustment for age and gender $(r Z 0.25 ; p<0.05)$.

\section{Discussion}

This study presents three observations that warrant further investigation in larger population studies. Patients with moderate to severe COPD were characterized by shorter telomeres of their leukocytes than healthy agematched controls, which previously was reported for other chronic inflammatory diseases as well [13-17]. In addition, we observed that TL was positively associated with SOD-activity. Furthermore, within the patient group fat mass-index (FMI) and fat percentage were positively associated with TL.

In this study, TL in leukocytes of COPD patients and in healthy controls appeared not related to smoking exposure, which is in contrast to data presented by Morla et al. [29], who observed an effect of cumulative smoking exposure on TL in lymphocytes of both healthy smokers and COPD patients. Several factors may explain this discrepancy, such as different white blood cell fractions that were studied, the fact that Morla et al. included only males in their study, and the relatively small population sizes of both studies. The general conclusion, however, was that chronic exposure to oxidative stress from cigarette smoking significantly contributed to accelerated telomere loss [29]. In our study population, we observed a decreased SOD-activity and a 
slightly decreased catalase activity in COPD patients when compared to healthy controls, indicating a reduced antioxidant defense in patients. Together with the observation that TL in leukocytes of COPD patients was significantly shorter than TL in leukocytes of healthy, age-matched controls, these data indicate that increased oxidative stress is contributing to shortening of telomeres. In addition, a positive correlation between SOD-activity and TL was found for the entire study population, providing the first evidence that antioxidant defenses protects against telomere shortening in a human population. Until now, this has only been observed in animal models and in vitro studies $[4,18]$.

When COPD patients were analyzed as a separate group, however, the association between SOD activity and TL was not as strong as found for the entire group. Moreover, in the patient group FMI and fat percentage were positively associated with $\mathrm{TL}$, indicating that fat mass may have a role in protecting telomeres from shortening in COPD patients. Recently, Mizoue et al. [30] reported that weight loss was associated with increased markers of oxidative DNA damage, which also indicated that preservation of body mass may be protective against oxidative DNA damage. Paradoxally, in normal adult populations shorter TLs and telomere attrition were recently reported to be positively associated with fat mass and insulin resistance [31, 32]. The positive association found between fat mass and TL in COPD patients in our study may point to a pleiotropic effect of fat mass; a higher fat mass is associated with an increased risk for diseases associated with metabolic derangements, but in patients with a chronic inflammatory disease a higher fat mass appears to be associated with a better protection against degenerative processes.

In COPD patients no association was found between the FFMI and telomere shortening, which was a surprising finding since a low FFMI was earlier found to be an independent predictor of mortality in COPD [33]. Previously, it was observed that in athletes with exercise-associated fatigue, the TL of skeletal muscle tissue was dramatically shortened and the authors suggested that this might indicate an exhaustion of the proliferative capacity of satellite cells [34]. Loss of telomeres may affect the regenerative capacity of skeletal muscle tissue and enhance muscle wasting. It remains to be determined, however, whether TL in muscle tissue of COPD patients is reduced, and whether this relates to muscle wasting. 
It should be noted that this study has potential limitations. The control group is rather small when compared to the number of COPD patients. Despite this limitation, a difference in telomere length was observed between the two groups. This may indicate that with a larger control population these differences are likely to be more distinct. Furthermore, we studied COPD patients that were entering a rehabilitation programme. Although we corrected in our analysis for disease severity (cachectic/non-cachectic), there is a possibility that the findings can be different for COPD patients outside the clinic, which tend to have milder disease symptoms. We should also mention that the number of subjects studied for the genetic association is relatively small and might therefore, not be definitive.

The data obtained in this study indicate a relationship between a disturbed oxidant/antioxidant balance and TL shortening in a human population. However, it still needs to be determined whether shorter telomeres are a cause or consequence of this disturbed balance. Future, longitudinal studies are required to unravel the relationship between chronic oxidative stress and telomere shortening and the potential consequences for the pathophysiology of COPD. 


\section{References}

55. Aldonyte R, Jansson L, Piitulainen E, Janciauskiene S: Circulating monocytes from healthy individuals and COPD patients. Respir Res 2003; 4(1):11.

56. Celli BR, MacNee W: Standards for the diagnosis and treatment of patients with COPD: a summary of the ATS/ERS position paper. Eur Respir J 2004; 23(6):932-946.

57. Van Helvoort HA, Heijdra YF, Thijs HM, Vina J, Wanten GJ, Dekhuijzen PN: Exerciseinduced systemic effects in muscle-wasted patients with COPD. Med Sci Sports Exerc 2006; 38(9):1543-1552.

58. Tarry-Adkins JL, Ozanne SE, Norden A, Cherif H, Hales CN: Lower antioxidant capacity and elevated p53 and p21 may be a link between gender disparity in renal telomere shortening, albuminuria, and longevity. Am J Physiol Renal Physiol 2006; 290(2):F509-516.

59. Tchirkov A, Lansdorp PM: Role of oxidative stress in telomere shortening in cultured fibroblasts from normal individuals and patients with ataxia-telangiectasia. Hum Mol Genet 2003; 12(3):227-232.

60. von Zglinicki T: Oxidative stress shortens telomeres. Trends Biochem Sci 2002; 27(7):339-344.

61. Harrington L: Those dam-aged telomeres! Curr Opin Genet Dev 2004; 14(1):22-28.

62. von Zglinicki T, Martin-Ruiz CM: Telomeres as biomarkers for ageing and agerelated diseases. Curr Mol Med 2005; 5(2):197-203.

63. von Zglinicki T: Telomeres and replicative senescence: Is it only length that counts? Cancer Lett 2001; 168(2):111-116.

64. Joosten SA, van Ham V, Nolan CE, Borrias MC, Jardine AG, Shiels PG, van Kooten C, Paul LC: Telomere shortening and cellular senescence in a model of chronic renal allograft rejection. Am J Pathol 2003; 162(4):1305-1312.

65. Makarov VL, Hirose $Y$, Langmore JP: Long $G$ tails at both ends of human chromosomes suggest a $\mathrm{C}$ strand degradation mechanism for telomere shortening. Cell 1997; 88(5):657-666.

66. Serra V, Grune T, Sitte N, Saretzki G, von Zglinicki T: Telomere length as a marker of oxidative stress in primary human fibroblast cultures. Ann N Y Acad Sci 2000; 908:327-330.

67. Adaikalakoteswari A, Balasubramanyam M, Mohan V: Telomere shortening occurs in Asian Indian Type 2 diabetic patients. Diabet Med 2005; 22(9):1151-1156.

68. Aviv A: Chronology versus biology: telomeres, essential hypertension, and vascular aging. Hypertension 2002; 40(3):229-232.

69. Benetos A, Gardner JP, Zureik M, Labat C, Xiaobin L, Adamopoulos C, Temmar M, Bean KE, Thomas F, Aviv A: Short telomeres are associated with increased carotid atherosclerosis in hypertensive subjects. Hypertension 2004; 43(2):182-185. 
70. Getliffe KM, Martin Ruiz C, Passos JF, von Zglinicki T, Nwokolo CU: Extended lifespan and long telomeres in rectal fibroblasts from late-onset ulcerative colitis patients. Eur J Gastroenterol Hepatol 2006; 18(2):133-141.

71. Sampson MJ, Winterbone MS, Hughes JC, Dozio N, Hughes DA: Monocyte telomere shortening and oxidative DNA damage in type 2 diabetes. Diabetes Care 2006; 29(2):283-289.

72. Serra V, von Zglinicki T, Lorenz M, Saretzki G: Extracellular superoxide dismutase is a major antioxidant in human fibroblasts and slows telomere shortening. J Biol Chem 2003; 278(9):6824-6830.

73. Cawthon RM: Telomere measurement by quantitative PCR. Nucleic Acids Res 2002; 30(10):e47.

74. Broekhuizen R, Grimble RF, Howell WM, Shale DJ, Creutzberg EC, Wouters EF, Schols AM: Pulmonary cachexia, systemic inflammatory profile, and the interleukin 1 beta -511 single nucleotide polymorphism. Am J Clin Nutr 2005; 82(5):1059-1064.

75. Quanjer PH, Tammeling GJ, Cotes JE, Pedersen OF, Peslin R, Yernault JC: Lung volumes and forced ventilatory flows. Report Working Party Standardization of Lung Function Tests, European Community for Steel and Coal. Official Statement of the European Respiratory Society. Eur Respir J Suppl 1993; 16:5-40.

76. Schols AM, Wouters EF, Soeters PB, Westerterp KR: Body composition by bioelectrical-impedance analysis compared with deuterium dilution and skinfold anthropometry in patients with chronic obstructive pulmonary disease. Am J Clin Nutr 1991; 53(2):421-424.

77. Lukaski HC, Johnson PE, Bolonchuk WW, Lykken GI: Assessment of fat-free mass using bioelectrical impedance measurements of the human body. Am J Clin Nutr 1985; 41(4):810-817.

78. Miller SA, Dykes DD, Polesky HF: A simple salting out procedure for extracting DNA from human nucleated cells. Nucleic Acids Res 1988; 16(3):1215.

79. Sun Y, Oberley LW, Li Y: A simple method for clinical assay of superoxide dismutase. Clin Chem 1988; 34(3):497-500.

80. Aebi H: Catalase in vitro. Methods Enzymol 1984; 105:121-126.

81. Ketelslegers HB, Gottschalk RW, Godschalk RW, Knaapen AM, van Schooten FJ, Vlietinck RF, Kleinjans JC, van Delft JH: Interindividual variations in DNA adduct levels assessed by analysis of multiple genetic polymorphisms in smokers. Cancer Epidemiol Biomarkers Prev 2006; 15(4):624-629.

82. Knaapen AM, Ketelslegers HB, Gottschalk RW, Janssen RG, Paulussen AD, Smeets HJ, Godschalk RW, Van Schooten FJ, Kleinjans JC, Van Delft JH: Simultaneous genotyping of nine polymorphisms in xenobiotic-metabolizing enzymes by multiplex PCR amplification and single base extension. Clin Chem 2004; 50(9):16641668.

83. Morla M, Busquets X, Pons J, Sauleda J, MacNee W, Agusti AG: Telomere shortening in smokers with and without COPD. Eur Respir J 2006; 27(3):525-528. 
84. Mizoue T, Tokunaga S, Kasai H, Kawai K, Sato M, Kubo T: Body mass index and oxidative DNA damage: a longitudinal study. Cancer Sci 2007; 98(8):1254-1258.

85. Gardner JP, Li S, Srinivasan SR, Chen W, Kimura M, Lu X, Berenson GS, Aviv A: Rise in insulin resistance is associated with escalated telomere attrition. Circulation 2005; 111(17):2171-2177.

86. Valdes AM, Andrew T, Gardner JP, Kimura M, Oelsner E, Cherkas LF, Aviv A, Spector TD: Obesity, cigarette smoking, and telomere length in women. Lancet 2005; 366(9486):662-664.

87. Schols AM, Broekhuizen R, Weling-Scheepers CA, Wouters EF: Body composition and mortality in chronic obstructive pulmonary disease. Am J Clin Nutr 2005; 82(1):53-59.

88. Collins M, Renault V, Grobler LA, St Clair Gibson A, Lambert MI, Wayne Derman E, Butler-Browne GS, Noakes TD, Mouly V: Athletes with exercise-associated fatigue have abnormally short muscle DNA telomeres. Med Sci Sports Exerc 2003; 35(9):1524-1528. 




\section{Chapter 5}

\section{Telomere shortening in COPD: potential protective}

\section{effects of coffee consumption}

The European Respiratory Journal, submitted
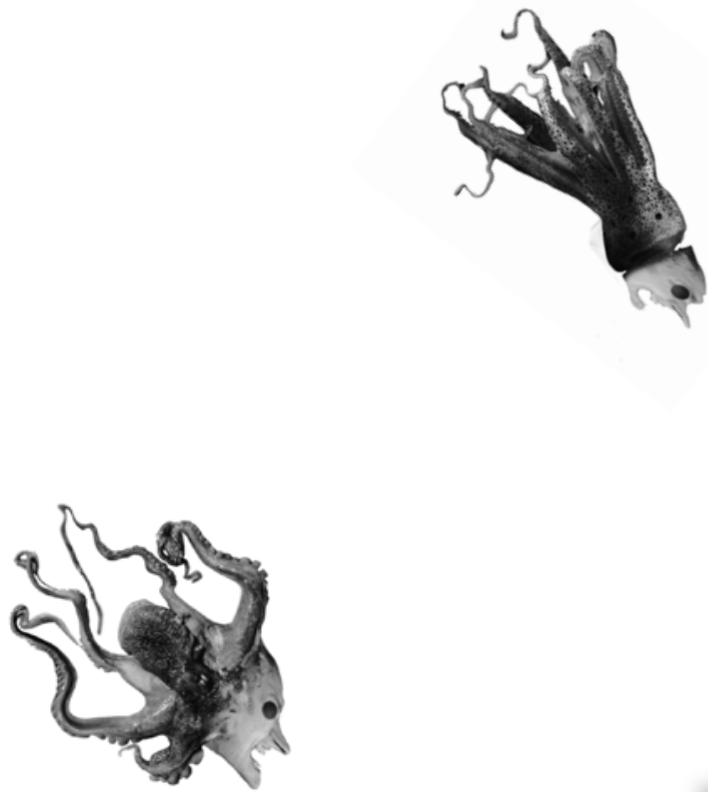

Joyce M.J. Houben

Astrid Schuijlenburch

Martijn A. Spruit

Emiel F. Wouters

Frederik J. van Schooten

Geja J. Hageman

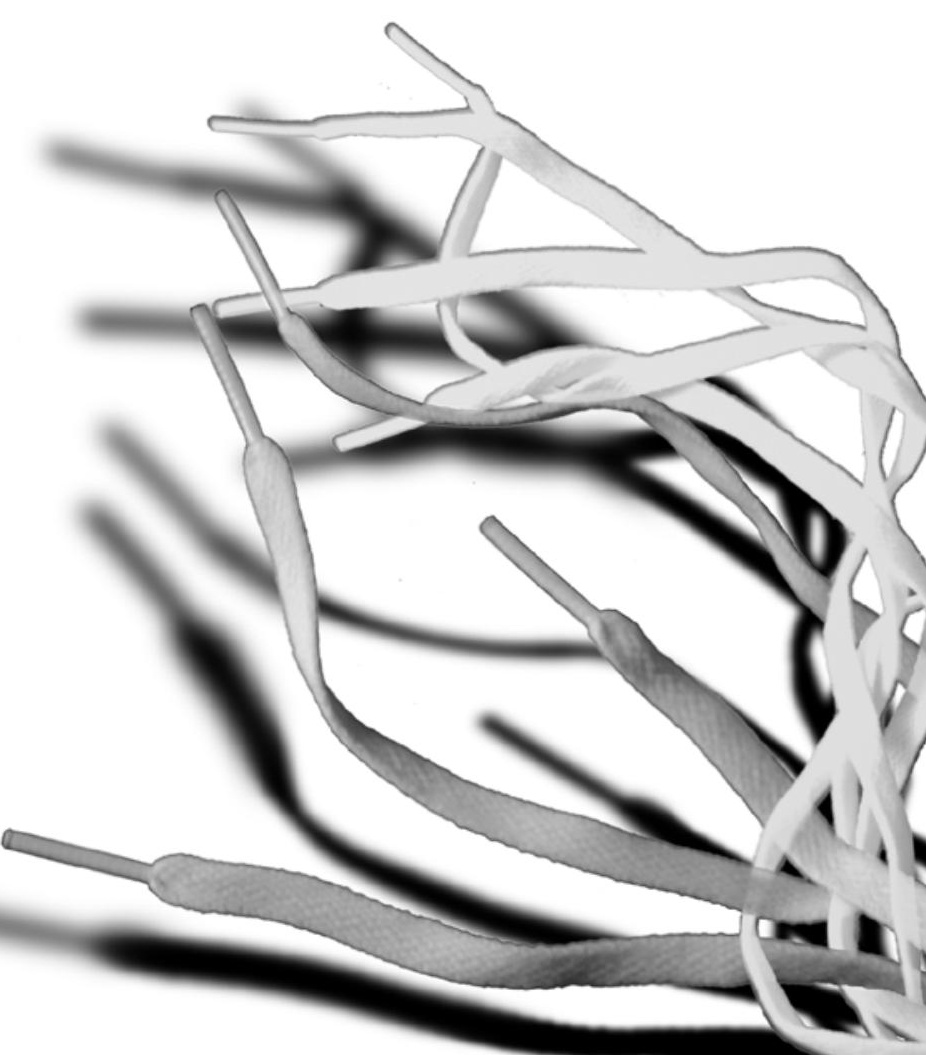




\begin{abstract}
Chronic obstructive pulmonary disease (COPD) is characterized by incompletely reversible airflow obstruction and chronic systemic oxidative stress and inflammation play a major role in the pathophysiology of COPD. Telomere length has been observed to be inversely associated with increased oxidative stress and inflammation. Since chronic oxidative stress plays a major role in COPD, telomere length is hypothesized to reduce at a faster rate in COPD.

The first aim of this study was to investigate telomere length in COPD patients in relation to oxidative stress and inflammation. The second aim of this study was to investigate the effects of caffeine, coffee, tea and alcohol intake, on telomere length in COPD patients and healthy controls. For this purpose, we measured telomere length in PBMCs of 89 COPD patients and compared these with 93 healthy, (ex-)smoking controls. In addition, the cytokines IL-8, IL-6 and TNF- $\alpha$ were determined as well as CRP, SOD and plasma homocysteine.

We found that telomere length was shorter in COPD patients compared to controls. Cytokine plasma levels as well as CRP and homocysteine plasma levels were increased in COPD patients and SOD activity was decreased, indicating elevated oxidative stress in COPD patients. In addition, this study provides a first indication of the possible beneficial effects of coffee consumption and negative effects of alcohol consumption on telomere length. Future studies should focus on interventions with dietary antioxidants or antiinflammatory compounds such as those found in coffee and their possible beneficial health effects in patients with chronic inflammatory diseases.
\end{abstract}




\section{Introduction}

Chronic obstructive pulmonary disease (COPD) poses a major health problem with its still increasing prevalence[1]. COPD is characterized by incompletely reversible airflow obstruction associated with pulmonary and systemic inflammation, as is evident from increased levels of pro-inflammatory cytokines[2-5]. C-reactive protein (CRP) has also been found to be increased in COPD and is often used as a clinical marker of systemic inflammation $[4,6]$. Moreover, in COPD patients, oxidative stress, resulting from an imbalance between the production of reactive oxygen species (ROS) and the antioxidant defense, has been implicated with disease progression [7].

We previously reported that COPD patients have shorter leukocyte telomeres than healthy control subjects [8] and this was recently confirmed by a study by Savale et al. [9]. Since telomere length (TL) in somatic cells determines the number of cell divisions, TL has been proposed as a marker for biological age. Furthermore, TL has been observed to be inversely associated with increased oxidative stress and inflammation [10-12]. Recent studies indeed have linked telomere shortening to various chronic inflammatory diseases, which are all characterized by systemic oxidative stress [13-17].

Consumption of food ingredients that counteract chronic oxidative stress may influence $T L$ in patients suffering from COPD. Recently, coffee consumption has been positively associated with lung function as determined by forced expiratory volume in one second (FEV1) values in healthy subjects[18]. Coffee contains several components that may have beneficial health effects[19], and it has been previously shown that caffeine metabolites have anti-inflammatory properties, which are capable of inhibiting the inflammatory response in mouse lungs and ex vivo in blood of COPD patients [20].

The first aim of this study was to investigate telomere length in peripheral blood mononuclear cells (PBMCs) in COPD patients in relation to oxidative stress and inflammation. The second aim of this study was to investigate the effects of caffeine, coffee, tea and alcohol intake on TL in COPD patients and healthy (ex-)smokers. 


\section{Subjects and Methods}

\section{Study population}

89 Clinically stable COPD patients were recruited at a pulmonary rehabilitation center (CIRO, Horn, The Netherlands)[21]. Exclusion criteria were the presence of inflammatory diseases such as diabetes. Most patients were using medication to treat symptoms of the disease, including anticholinergics, $\beta 2$ agonists, theophylline and inhaled- and oral corticosteroids.

93 Healthy (ex-) smokers were recruited as control subjects through the COSMO study [22]. Inclusion criteria were: Caucasian origin, 40 years of age or older, smoking history of 10 pack-years or more, and no history of inflammatory diseases. Written informed consent was obtained from all participants, and the study was approved by the ethical review board of the University Hospital Maastricht.

\section{Consumption questionnaire}

A questionnaire was filled out by all participating subjects to collect data on consumption of caffeine containing products i.e. coffee, espresso, tea, coke, ice tea and energy drinks, and alcoholic beverages. During an interview this information was orally confirmed. Caffeine intake was estimated using caffeine data from Nawrot et al. [23] and from Casal et al. [24]. These data were also reported by the European Food Information Council (http://www.eufic.org/).

Lung function dataln all participants the forced expiratory volume in one second (FEV1) was measured, with the highest value from at least three properly performed measurements being used for analysis (Masterlab, Jaeger, Würzburg, Germany).

\section{Body composition}

Body composition was estimated using single frequency $(50 \mathrm{kHz})$ bioelectrical impedance analysis (BIA; Xitron Technologies, San Diego, CA, USA). Fat-free mass (FFM) was calculated using the disease-specific equation proposed by Schols [25] and FFM of healthy controls was calculated using the equations of Lukaski [26]. Fat mass (FM; kg) was estimated as total body weight minus FFM. Body mass index (BMI) was calculated by dividing weight $(\mathrm{kg})$ by the square of the height $(\mathrm{m} 2)$. 


\section{Sample preparation}

Venous blood samples $(8 \mathrm{ml})$ were drawn into sodium citrate-containing cell preparation tubes (Becton Dickinson Vacutainer Systems, Plymouth, UK). $500 \mu \mathrm{l}$ whole blood was stored at $-80^{\circ} \mathrm{C}$ until SOD analysis. After centrifugation at 1800 $\mathrm{x} g$ for 20 minutes at room temperature within 2 hours of collection, plasma for cytokine analysis and PBMCs for DNA extraction were stored at $-80^{\circ} \mathrm{C}$. Genomic DNA was extracted using the QIAamp DNA Mini Kit (Qiagen, Venlo, The Netherlands).

\section{TL measurement}

TL was determined by quantitative PCR as described previously $[8,27]$. From 4 patients no PCR results could be obtained, due to poor quality of the DNA.

Two master mixes were prepared, one with telomere primers and one with Human $\beta$ globin (HBG) primers (1x IQ SYBRgreen supermix from BioRad, CA, USA). Negative controls ( $M Q+$ mastermix) and reference samples with known TL were added to every run. The PCR was performed using a BioRad RTPCR detection system using iQTM SYBR ${ }^{\circledR}$ Green Supermix, containing iTaq Polymerase, dNTPs, SYBRGreen I and buffers (BioRad, CA, USA).

\section{Superoxide dismutase (SOD) activity}

SOD-activity and hemoglobin $(\mathrm{Hb})$ concentrations were determined as described previously [8]. SOD-activity was determined according to the method of Sun et al., which is based on the generation of superoxide radicals produced by xanthine and xanthine oxidase, which react with nitro-blue tetrazolium (NBT) to form NBT-diformazan [28]. SOD-activity was expressed as units per milligram $\mathrm{Hb}$.

\section{C-reactive protein (CRP) and cytokine analysis}

For the measurement of CRP concentrations, blood collected in EDTA tubes was centrifuged at $1000 \times \mathrm{g} ; 4^{\circ} \mathrm{C}$ for $10 \mathrm{~min}$. Aliquots of plasma were immediately stored at $-80^{\circ} \mathrm{C}$. CRP levels were measured using a latex-enhanced immunoturbidimetric assay ( $A B X$ Pentra CRP $C P, A B X$ Diagnostics). The detection limit of this method was $0.23 \mathrm{mg} / \mathrm{L}$. IL-6, IL-8 and TNF- $\alpha$ were quantified with the PeliKineTM ELISA kits (Sanquin, Amsterdam, the Netherlands). Assays were performed according to manufacturer's instructions. 


\section{Homocysteine}

Total plasma homocysteine (tHcy) levels were measured by HPLC as described by Ubbink and Vermaak [29]. Briefly, $10 \mu \mathrm{L}$ of Tri (2-carboxylethyl) phosphine, $25 \mu \mathrm{L}$ internal standard and $25 \mu \mathrm{L}$ PBS was added to $50 \mu \mathrm{L}$ sample. After mixing this was incubated for 30 minutes at room temperature. Samples were centrifuged and $50 \mu \mathrm{L}$ was transferred to an autosampler vial containing $10 \mu \mathrm{L}$ of $1.55 \mathrm{M} \mathrm{NaOH}, 125 \mu \mathrm{L}$ of $0.125 \mathrm{M}$ borate buffer (containing 4mM EDTA, pH 9.5, and $50 \mu \mathrm{L}$ of SBD-F, $1 \mathrm{~g} / \mathrm{L}$ in borate buffer). After mixing, the solution was incubated for 1 hour at $60^{\circ} \mathrm{C}$. $10 \mu \mathrm{L}$ was injected onto a C18 column to run at a flow rate of $1.5 \mathrm{~mL} / \mathrm{min}$.

\section{Statistical analysis}

Results are expressed as mean \pm SEM. Differences between COPD patients and healthy controls were tested using Student's t-test for the independent samples and the Mann Whitney U-test when not normally distributed. The association between variables was evaluated using the non-parametric Spearman's rank correlation coefficient. To study the determinants of TL in COPD and controls, multiple regression analyses were conducted (Table 2 and 3). To evaluate the differences in $T L$, homocysteine and SOD activity in different age groups, we stratified the subjects by age (40-55 years, 56-65 years and 66 years and older). A difference with $p<0.05$ was considered statistically significant. Statistical analyses were analyzed with SPSS for Windows (version 15.0; SPSS Inc., Chicago, IL, USA).

\section{Results}

The characteristics of the patients and healthy controls are listed in Table 1. Controls consumed more coffee than COPD patients and had also a higher caffeine intake. Tea consumption was higher in the COPD patients, whereas alcohol consumption was higher in the control subjects. COPD patients were characterized by lower values for FEV1 $(p<0.001)$ and were significantly older $(p<0.001)$. 
Table 1. General characteristics of healthy controls and COPD patients

\begin{tabular}{lll}
\hline Gender M/F & Healthy controls & COPD patients \\
\hline Age (years) & $41 / 52$ & $51 / 38$ \\
\hline Smoking (packyears) & $52.3 \pm 0.77^{* *}$ & $63.0 \pm 0.97^{* *}$ \\
\hline BMI (kg/m2) & $32.13 \pm 1.4$ & $41.0 \pm 3.69$ \\
\hline CRP (mg/l) & $26.38 \pm 0.43$ & $26.37 \pm 0.69$ \\
\hline FEV1 & $3.47 \pm 0.42^{* *}$ & $7.42 \pm 1.08^{* *}$ \\
\hline & $3.13 \pm 0.06^{* *}$ & $1.42 \pm 0.07^{* *}$ \\
\hline Anticholinergics (\%) & Medication & \\
\hline$\beta 2-$ Agonists (\%) & & $85(95 \%)$ \\
\hline Inhaled corticosteroids (\%) & $44(49 \%)$ \\
\hline Oral corticosteroids (\%) & $21(24 \%)$ \\
\hline Theophylline (\%) & & $20(22 \%)$ \\
\hline Coffee consumption (cups/day) & $20(22 \%)$ \\
\hline Caffeine intake (mg/day) & $6.14 \pm 0.39^{* *}$ & $4.60 \pm 0.39 * *$ \\
\hline Tea consumption (cups/day) & $427.11 \pm 22.96$ & $391.28 \pm 24.96$ \\
\hline Alcohol consumption (glasses/day) & $0.84 \pm 0.20^{*}$ & $1.38 \pm 0.20^{*}$ \\
\hline Telomere length (kbp) & $0.65 \pm 0.05^{*}$ & $0.44 \pm 0.05^{*}$ \\
\hline Data are presented as mean \pm SEM and tested & $6.32 \pm 0.08^{* *}$ & $5.35 \pm 0.05^{* *}$ \\
\hline
\end{tabular}

Data are presented as mean \pm SEM and tested with a Student's t-test for independent variables or a Mann Whitney U-test when not normally distributed.

** Significantly different between patient and controls $(p<0.001)$ * Significantly different between patient and controls $(p<0.02)$.

COPD patients had shorter telomeres when compared to the controls $(p<0.001$; Figure $1 \mathrm{~A})$ and TL was negatively correlated with age $(r=0.122, p<0.01)$. When stratified into three different age groups, mean TL was found to be significantly shorter in COPD patients than in controls within the same age group (Figure 1B, C and D).

A.

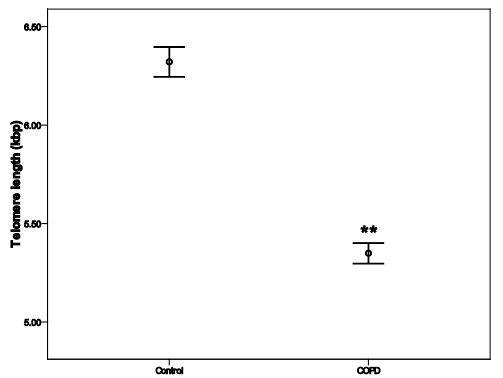

B.

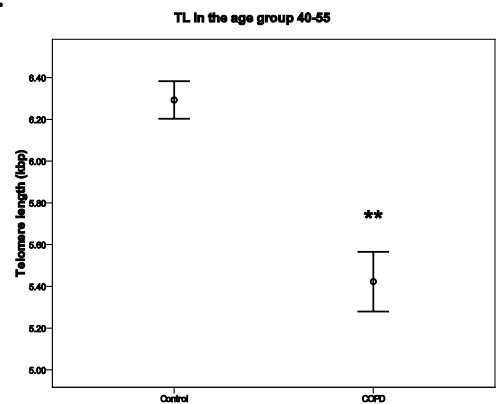


C.

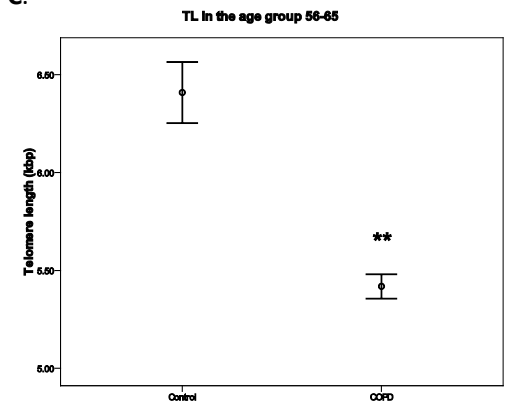

D.

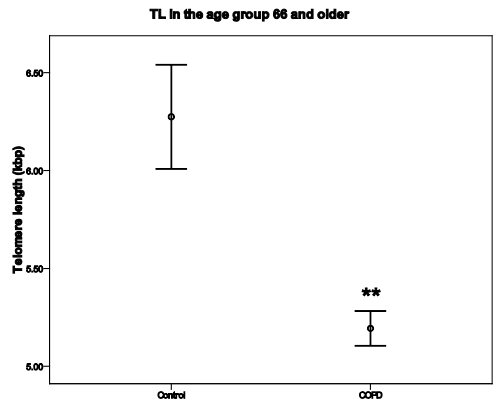

Figure 1. TL in PBMC's in COPD patients and healthy controls (A). TL in COPD patients $(n=21)$ and healthy controls $(n=59)$ in the age group 40-55 (B); TL in COPD patients $(n=35)$ and healthy controls $(n=29)$ in the age group 56-65 (C); and TL in COPD patients $(n=33)$ and healthy controls $(n$ $=5$ ) in the age group 66 years and older (D). Results are expressed as mean \pm SEM. ${ }^{* *}$ Significantly different between the two groups based on Mann Whitney U-test $(p<0.001)$.

tHcy levels were significantly lower in healthy controls than in COPD patients $(p<0.05$; Figure $2 A)$ and positively correlated with age $(r=0.083, p<0.01)$. When stratified in three age groups, the difference in tHcy between COPD patients and controls was less pronounced (Figure 2B, C and D).

A.

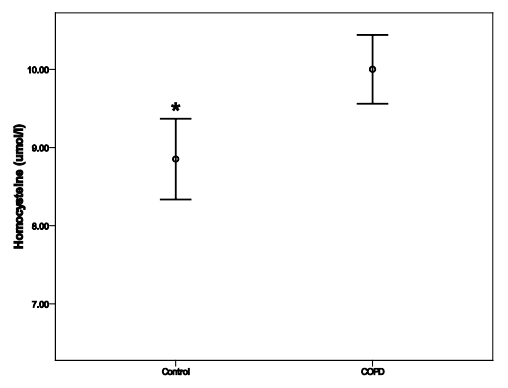

C.

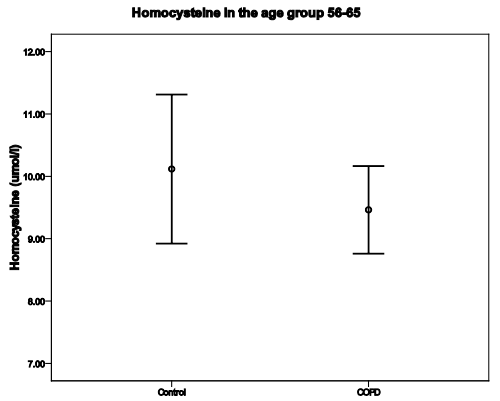

B.

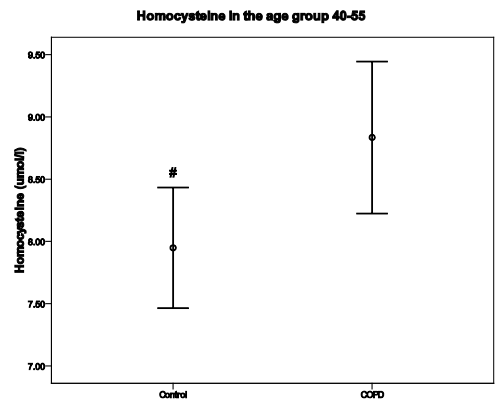

D.

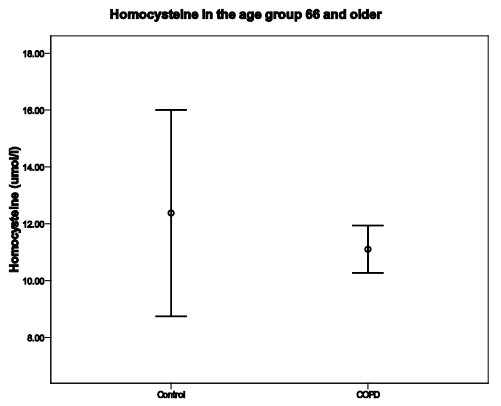


Figure 2. Plasma homocysteine levels in COPD patients and healthy controls (A). Plasma homocysteine in COPD patients and healthy controls in the age group 40-55 (B); in the age group 56-65 (C); and in the age group 66 years and older (D). Results are expressed as mean \pm SEM.

* Significantly different between the two groups based on Mann Whitney U-test $(p<0.05)$. COPD patients had lower levels of SOD activity than healthy controls $(p<0.01$;

Figure 3A). When stratified into three age groups, the differences in SOD activity between COPD patients and controls remained significant (Figure 3B, C and D). Although in the controls an age-associated decrease in SOD activity was found, this was not significant. In COPD patients there was no association between age and SOD activity.

A.

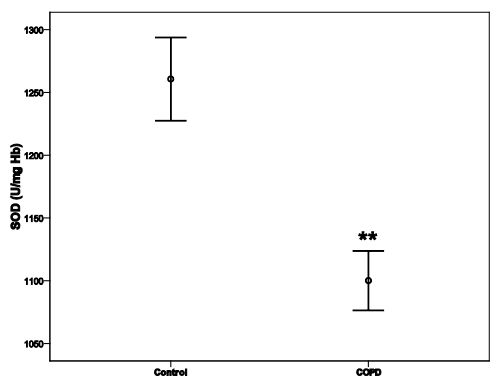

C.

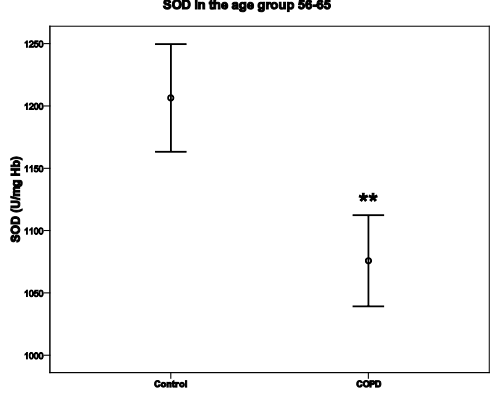

B.

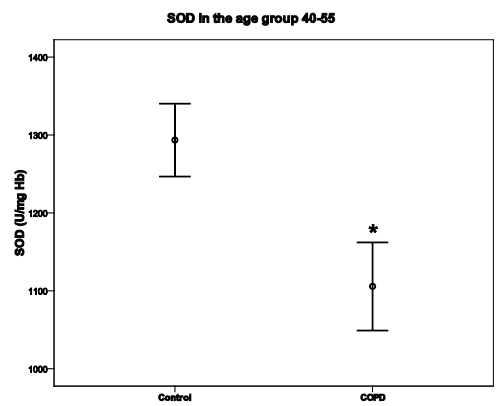

D.

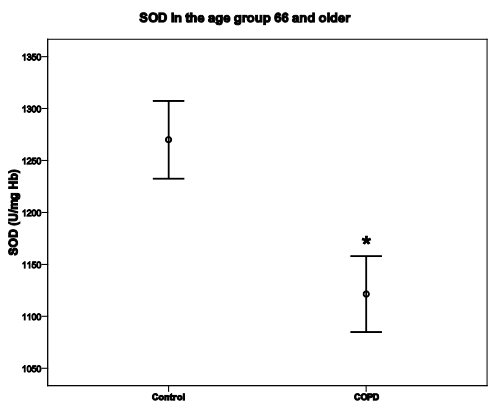

Figure 3. SOD activity in blood of COPD patients and healthy controls (A). SOD activity in COPD patients and healthy controls in the age group 40-55 (B); in the age group 56-65 (C); and in the age group 66 years and older (D). Results are expressed as mean \pm SEM. * Significantly different between the two groups based on Mann Whitney U-test $(p<0.05) . * *$ Significantly different between the two groups based on Mann Whitney U-test $(p<0.01)$ 
COPD patients had significantly higher CRP levels than control subjects (Figure 4).

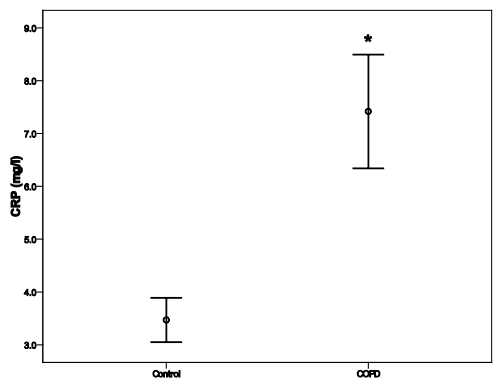

Figure 4. Plasma CRP levels in COPD patients and healthy controls. Results are expressed as mean \pm SEM. * Significantly different between the two groups based on Mann Whitney U-test $(p<0.01)$.

In all patients and controls, cytokine levels were detectable. Plasma IL-6 levels were significantly higher in COPD patients and the same trend was observed with TNF- $\alpha$ (Figure 5A and B). No difference was found for plasma IL-8 concentrations between patients and controls (Figure $5 \mathrm{C}$ ) and we also found no association between cytokine levels and age. When analyzing both groups combined or separately, no associations between TL and smoking history, FEV1, FM, FFM or CRP were observed.

A.

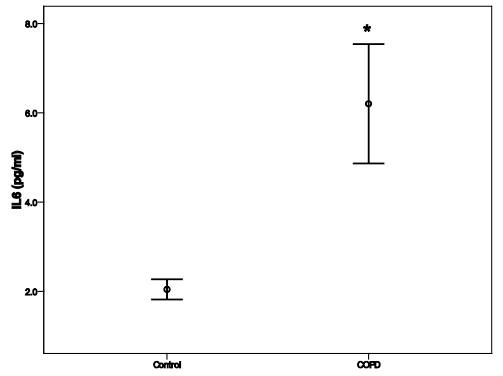

c.

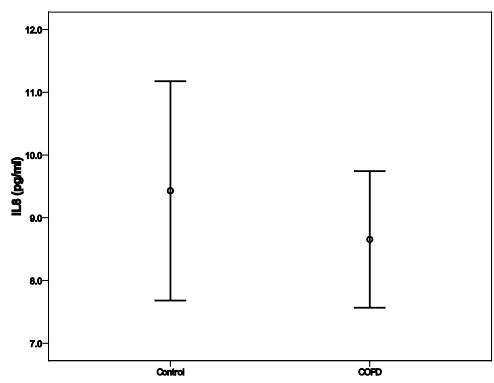

B.

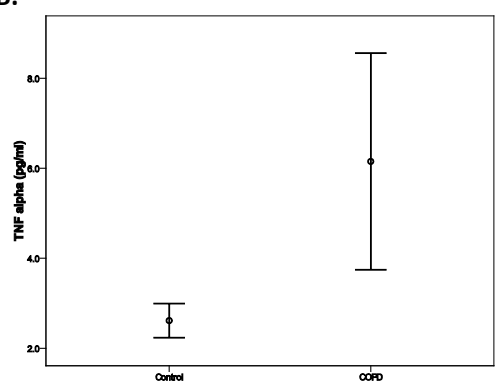

Figure 5. Plasma IL-6 (A), TNF- $\alpha$ (B) and IL-8 (C) levels in COPD patients and healthy controls. Results are expressed as mean \pm SEM. * Significantly different between the two groups based on Mann Whitney U-test $(p<0.05)$. 
In both the control group and the COPD group, coffee consumption was positively associated with $\mathrm{TL}$ and alcohol consumption was negatively associated with TL (Figure 6A and B), which remained after adjusting for age, gender, packyears, BMI, FEV1, and caffeine intake.

A.

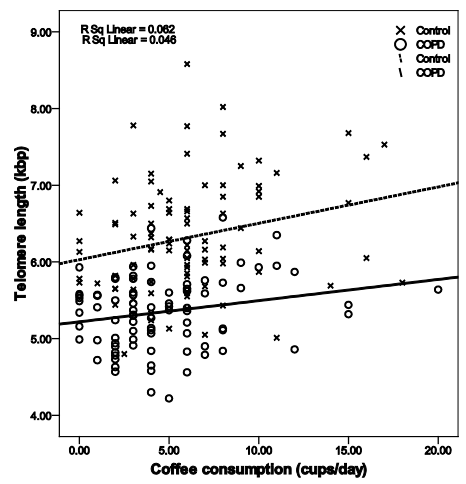

B.

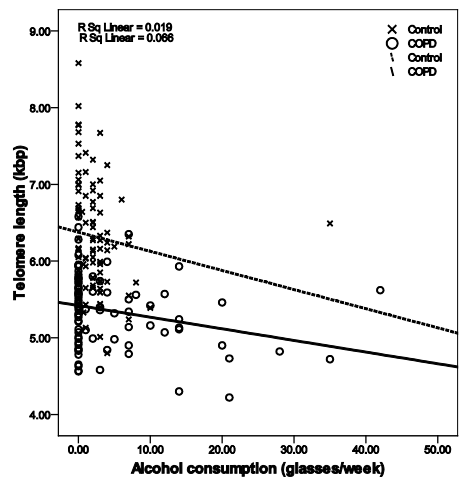

Figure 6. Correlation between coffee consumption and TL in healthy controls $(r=0.062 ; p=0.017)$ and COPD patients $(r=0.046 ; p=0.061)(A)$. Correlation between alcohol consumption and TL in healthy controls $(r=0.019 ; p=0.114)$ and COPD patients $(r=0.066 ; p=0.01)(B)$. The association between variables was evaluated using the non-parametric Spearman's rank correlation coefficient.

When analyzing TL in alcohol users versus non-alcohol users, TL was shorter in alcohol users (COPD patients $p<0.056$; healthy controls $p<0.021$ ). Coffee consumption could not be linked to FEV1 values, but was negatively associated with plasma CRP levels $(\mathrm{p}=0.013)$ and weakly negatively associated with IL-6 (ns), TNF- $\alpha$ (ns) when both groups were combined. No correlations between caffeine intake or tea consumption and TL were observed.

Using multiple regression analysis, the best predictors of TL in COPD patients were IL-8 and alcohol consumption (Table 2). Both markers were negatively associated with TL. 
Table 2. Multiple Regression Analysis in healthy controls with TL as dependent variable

\begin{tabular}{ll}
\hline Independent variables & $\boldsymbol{p}$-value \\
\hline IL-8 & 0.002 \\
\hline Homocysteine & 0.012 \\
\hline Age & 0.376 \\
\hline Alcohol consumption & 0.192 \\
\hline Gender & 0.719 \\
\hline Packyears & 0.206 \\
\hline IL-6 & 0.554 \\
\hline TNF-a & 0.167 \\
\hline CRP & 0.671 \\
\hline Caffeine & 0.085 \\
\hline Coffee & 0.063 \\
\hline BMI & 0.753 \\
\hline FEV1 & 0.977 \\
\hline SOD & 0.23 \\
\hline Values are considered signficantly different at p 0.05
\end{tabular}

Values are considered significantly different at $p<0.05$

In the control group, TL was best predicted by IL-8 and homocysteine (Table 3). IL-8 was positively associated with $\mathrm{TL}$, whereas homocysteine was negatively associated with TL. The best predictors of TL in the total study population were the presence of COPD $(p=0.000)$, coffee consumption $(p=0.008)$ and IL-8 $(p=$ 0.037).

Table 3. Multiple Regression Analysis in COPD patients with TL as dependent variable

\begin{tabular}{ll}
\hline Independent variables & P-value \\
\hline IL-8 & 0.01 \\
\hline Alcohol consumption & 0.014 \\
\hline Age & 0.28 \\
\hline Homocysteine & 0.143 \\
\hline Gender & 0.476 \\
\hline Packyears & 0.76 \\
\hline IL-6 & 0.42 \\
\hline TNF-a & 0.317 \\
\hline CRP & 0.63 \\
\hline Caffeine & 0.527 \\
\hline Coffee & 0.193 \\
\hline BMI & 0.956 \\
\hline FEV1 & 0.904 \\
\hline SOD & 0.318 \\
\hline Valuesare considered Sgnificantly different at P<0.05
\end{tabular}

Values are considered significantly different at $p<0.05$ 


\section{Discussion}

In the present study we confirmed results obtained in previous research which showed that leukocytes of COPD patients have shorter telomeres than those of healthy controls $[8,9]$. In this study we used DNA from the PBMCs instead of leukocytes, which is considered to better reflect systemic changes in $T L$, since lymphocytes are not directly derived from hematopoietic stem cells, making them better representatives of somatic cells [30]. To control for differences in age between the COPD and control group, we stratified the participants into three age groups: 40-55, 56-65 and 66 years and older. In all three age groups, COPD patients had significantly shorter telomeres than healthy (ex-)smoking controls. Accelerated aging has been postulated to play an important role in the pathogenesis of COPD, which is characterized by increased markers of oxidative stress and cell senescence in both lung cells and circulating leukocytes/PBMCs $[7,31]$.

We could not find a relationship between TL and tobacco smoke exposure, which was quantified as pack years of smoking, confirming previous results from other studies [8,9]. We observed increased levels of tHcy in COPD patients. Hyperhomocysteinemia was reported to induce vascular oxidative stress and to activate circulating mononuclear cells, indicating increased systemic inflammation and oxidative stress [32,33]. Previously, increased tHcy levels have been observed in COPD patients [34]. In this study, it was suggested that increased homocysteine levels were caused by a decreased concentration of B vitamins [34]. In our study we found increased tHcy levels in COPD patients which positively correlated with age. Therefore, we also stratified the participants into three age groups as described for TL. The difference in tHcy between COPD and controls disappeared with increasing age, indicating a strong influence of age on tHcy. We also found that tHcy was negatively associated with TL in controls $(r=0.061, p=0.012)$, which was previously described by Bull et al. and Richards et al. for healthy populations $[35,36]$. The negative association observed in the controls may be due to their smoking history, as smoking is known to be associated with an increased tHcy level [37]. We indeed found a positive association between tHcy and smoking history in healthy controls ( $r=0.189 ; p=0.001)$, which was less pronounced in COPD patients ( $r=0.034 ; p=0.039)$. It appears that in COPD patients in this study, homocysteine levels have a minor effect on TL. 
Animal studies and in vitro models have shown that the antioxidant enzyme SOD may protect telomeres from shortening [38,39]. SOD activity was significantly lower in COPD patients, indicating a decreased antioxidant capacity. When stratified into age groups, this difference remained significant and although we could see a negative association between age and SOD activity in the healthy control subjects ( $p=0.062)$, which was not observed in the COPD group. The lower SOD activity in COPD patients therefore is likely to be a consequence of the disease.

In COPD patients, increased levels of circulating cytokines (IL-6, IL-8 and TNF- $\alpha$ ) and acute phase proteins such as CRP have been reported $[40,41]$. The elevated CRP levels in patients with COPD are likely to be caused by systemic inflammation which is accompanied by an elevated expression of proinflammatory cytokines [42]. We also observed that IL-6 and TNF- $\alpha$ were increased in COPD patients, but this was not found for IL-8. IL-6, which is thought to be the major cytokine involved in CRP release from the liver, was positively correlated with CRP in COPD patients in our study, as was also reported previously by others $[42,43]$. CRP has also been linked to BMI in COPD patients in several studies, suggesting an adipocyte-induced systemic inflammation $[42,44]$. Adipose tissue induces increased levels of adipocytokines, which in turn are involved in CRP release from the liver $[45,46]$. In our study, we could neither find an association between CRP and BMI, nor between CRP and fat mass in COPD patients, but we did find a positive association between CRP and $\mathrm{BMI}$ in the control subjects $(r=0.088, p=0.002)$. This may indicate that obesity or overweight plays a less significant role in the elevated CRP levels in COPD patients in our study than in healthy controls.

In both groups, coffee consumption was positively associated with $\mathrm{TL}$, whereas alcohol was negatively associated with TL. Coffee contains antioxidant substances such as coffee melanoidins, brown-coloured nitrogen-containing anionic polymers [47], and chlorogenic acid [19,48], which may decrease oxidative stress, and protect the telomeres from oxidative damage and shortening.

In our total study population, plasma CRP levels and to a lesser extent IL6 and TNF- $\alpha$, were negatively associated with coffee consumption, indicating a possible attenuating effect of coffee on circulating pro-inflammatory mediators in the plasma. This may be explained by the presence of anti-inflammatory 
compounds in coffee, which decrease the inflammatory response by inhibition of NF-KB [49], protecting the telomeres form accelerated shortening.

Previously, high levels of coffee consumption have been linked to increased tHcy levels $[50,51]$, but in our study we could not find an association between coffee consumption and increased homocysteine levels. This lack of association was also reported by Sakamoto et al. and by Esposito et al. [52,53]. Since TL could not be linked to caffeine intake, it is considered likely that other compounds present in coffee are associated with beneficial effects observed in this study.

Although TL correlated with coffee in both groups, it appeared not to be the best predictor of TL. In the COPD group, TL was best predicted by IL- 8 and alcohol consumption. TL was negatively associated with both parameters. Alcohol can increase the production of ROS in a number of different/concurrent ways, leading to increased damage to the telomeres [54].

Since IL-8 is associated with increased inflammation and proliferation of the lung tissue in COPD $[55,56]$, this may explain the relation of IL- 8 to accelerated shortening of the telomeres in COPD patients. Moreover, TNF- $\alpha$ was reported to inhibit the expression of human telomerase reverse transcriptase (hTERT) [57]. A reduced hTERT activity due to increased levels of TNF- $\alpha$ in COPD in combination with proliferative stimuli exerted by IL-8 may explain the increased telomere shortening in this group. In the control group, TL was best predicted by IL- 8 and tHcy levels, but in this group IL- 8 was positively associated with TL. This may indicate potentially adaptive effects of IL-8 in healthy smoking controls by diminishing the damaging effects on tissues exerted by cigarette smoke. A protective effect was previously reported by Wieczorowska-Tobis et al. [58], who observed a positive association of plasma IL-8 with survival to advanced age, in a study with centenarians. Since little is known about the function of IL-8 in healthy persons, future studies should try to further unravel these contradictory associations of IL-8.

In general, it appears that nutritional lifestyle factors, such as consumption of foods high in antioxidants/anti-inflammatory compounds or alcohol consumption, can affect telomere shortening, both in healthy persons and in COPD patients. Recently, Mirabello et al. showed that a healthier lifestyle tended to be associated with longer telomeres, in a combined group of healthy subjects and prostate cancer cases. This healthy lifestyle was defined as low or no cigarette use, higher fruit and vegetable intake, lower BMI, and a higher 
level of physical activity [59]. On the other hand, increased levels of oxidative stress and the intake of foods low in antioxidants and anti-inflammatory compounds have been associated with shorter telomeres [60].

This study confirms previous studies, indicating that COPD patients acquire an accelerated aging phenotype. It has to be taken into account that COPD is a heterogeneous disease, with varying severity between patients. The mechanisms resulting in these changes are also likely to be different, making it difficult to find a general therapeutic target $[7,31]$. This study provides a first indication for the possible attenuating effects of coffee consumption and accelerating effect of alcohol consumption on telomere shortening. Since coffee is a highly popular drink, it can have a substantial effect on both individual wellbeing and public health. In conclusion, a healthier lifestyle and interventions with dietary antioxidants or anti-inflammatory compounds such as those found in coffee appear worthwhile to be further investigated for their possible beneficial effects on telomere shortening and aging-associated degenerative processes in patients with COPD and other chronic inflammatory diseases. 


\section{References}

1. WHO: Global surveillance, prevention and control of chronic respiratory diseases. A comprehensive approach. 2007.

2. Boots AW, Haenen GR, Bast A: Oxidant metabolism in chronic obstructive pulmonary disease. Eur Respir J Suppl 2003;46:14s-27s.

3. Rahman I, Gilmour PS, Jimenez LA, MacNee W: Oxidative stress and TNF-alpha induce histone acetylation and NF-kappaB/AP-1 activation in alveolar epithelial cells: potential mechanism in gene transcription in lung inflammation. Mol Cell Biochem 2002;234-235:239-248.

4. Stockley RA, Mannino D, Barnes PJ: Burden and pathogenesis of chronic obstructive pulmonary disease. Proc Am Thorac Soc 2009;6:524-526.

5. Yao H, Rahman I: Current concepts on the role of inflammation in COPD and lung cancer. Curr Opin Pharmacol 2009;9:375-383.

6. Broekhuizen R, Wouters EF, Creutzberg EC, Schols AM: Elevated CRP levels mark metabolic and functional impairment in advanced COPD. Thorax 2005.

7. MacNee W: Accelerated lung aging: a novel pathogenic mechanism of chronic obstructive pulmonary disease (COPD). Biochem Soc Trans 2009;37:819-823.

8. Houben JM, Mercken EM, Ketelslegers HB, Bast A, Wouters EF, Hageman GJ, Schols AM: Telomere shortening in chronic obstructive pulmonary disease. Respir Med 2009;103:230-236.

9. Savale L, Chaouat A, Bastuji-Garin S, Marcos E, Boyer L, Maitre B, Sarni M, Housset B, Weitzenblum E, Matrat M, Le Corvoisier P, Rideau D, Boczkowski J, Dubois-Rande $\mathrm{JL}$, Chouaid C, Adnot S: Shortened Telomeres in Circulating Leukocytes of Patients with Chronic Obstructive Pulmonary Disease. Am J Respir Crit Care Med 2009.

10. von Zglinicki $\mathrm{T}$ : Role of oxidative stress in telomere length regulation and replicative senescence. Ann N Y Acad Sci 2000;908:99-110.

11. von Zglinicki T, Martin-Ruiz C, Saretzki G: Telomeres, cell senescence and human ageing. Signal Transduction 2005;3.

12. von Zglinicki T, Martin-Ruiz CM: Telomeres as biomarkers for ageing and agerelated diseases. Curr Mol Med 2005;5:197-203.

13. Adaikalakoteswari A, Balasubramanyam M, Mohan V: Telomere shortening occurs in Asian Indian Type 2 diabetic patients. Diabet Med 2005;22:1151-1156.

14. Aviv A: Chronology versus biology: telomeres, essential hypertension, and vascular aging. Hypertension 2002;40:229-232.

15. Benetos A, Gardner JP, Zureik M, Labat C, Xiaobin L, Adamopoulos C, Temmar M, Bean KE, Thomas F, Aviv A: Short telomeres are associated with increased carotid atherosclerosis in hypertensive subjects. Hypertension 2004;43:182-185. 
16. Getliffe KM, Martin Ruiz C, Passos JF, von Zglinicki T, Nwokolo CU: Extended lifespan and long telomeres in rectal fibroblasts from late-onset ulcerative colitis patients. Eur J Gastroenterol Hepatol 2006;18:133-141.

17. Sampson MJ, Hughes DA: Chromosomal telomere attrition as a mechanism for the increased risk of epithelial cancers and senescent phenotypes in type 2 diabetes. Diabetologia 2006;49:1726-1731.

18. Nettleton JA, Follis JL, Schabath MB: Coffee intake, smoking, and pulmonary function in the Atherosclerosis Risk in Communities Study. Am J Epidemiol 2009;169:1445-1453.

19. Ranheim T, Halvorsen B: Coffee consumption and human health--beneficial or detrimental?--Mechanisms for effects of coffee consumption on different risk factors for cardiovascular disease and type 2 diabetes mellitus. Mol Nutr Food Res 2005;49:274-284.

20. Geraets L, Haegens A, Weseler AR, Brauers K, Vernooy JH, Wouters EF, Bast A, Hageman GJ: Inhibition of acute pulmonary and systemic inflammation by 1,7dimethylxanthine. Eur J Pharmacol 2009;629:132-139.

21. Spruit MA, Vanderhoven-Augustin I, Janssen PP, Wouters EF: Integration of pulmonary rehabilitation in COPD. Lancet 2008;371:12-13.

22. Kotz D, Wesseling G, Huibers MJ, van Schayck OC: Efficacy of confrontational counselling for smoking cessation in smokers with previously undiagnosed mild to moderate airflow limitation: study protocol of a randomized controlled trial. BMC Public Health 2007;7:332.

23. Nawrot $P$, Jordan $S$, Eastwood J, Rotstein J, Hugenholtz A, Feeley M: Effects of caffeine on human health. Food Addit Contam 2003;20:1-30.

24. Casal S, Fernandes JO, Oliveira MB, Ferreira MA: Gas chromatographic-mass spectrometric quantification of 4-(5-)methylimidazole in roasted coffee after ionpair extraction. J Chromatogr A 2002;976:285-291.

25. Schols AM, Wouters EF, Soeters PB, Westerterp KR: Body composition by bioelectrical-impedance analysis compared with deuterium dilution and skinfold anthropometry in patients with chronic obstructive pulmonary disease. Am J Clin Nutr 1991;53:421-424.

26. Lukaski HC, Johnson PE, Bolonchuk WW, Lykken GI: Assessment of fat-free mass using bioelectrical impedance measurements of the human body. Am J Clin Nutr 1985;41:810-817.

27. Cawthon RM: Telomere measurement by quantitative PCR. Nucleic Acids Res 2002;30:e47.

28. Sun Y, Oberley LW, Li Y: A simple method for clinical assay of superoxide dismutase. Clin Chem 1988;34:497-500.

29. Ubbink JB, Hayward Vermaak WJ, Bissbort S: Rapid high-performance liquid chromatographic assay for total homocysteine levels in human serum. J Chromatogr 1991;565:441-446. 
30. Greenwood MJ, Lansdorp PM: Telomeres, telomerase, and hematopoietic stem cell biology. Arch Med Res 2003;34:489-495.

31. MacNee W, Tuder RM: New paradigms in the pathogenesis of chronic obstructive pulmonary disease I. Proc Am Thorac Soc 2009;6:527-531.

32. Lin CP, Chen YH, Leu HB, Lin SJ, Chen YL, Huang SL, Chen JW: Anti-inflammatory strategies for homocysteine-related cardiovascular disease. Front Biosci 2009;14:3836-3845.

33. Papatheodorou L, Weiss N: Vascular oxidant stress and inflammation in hyperhomocysteinemia. Antioxid Redox Signal 2007;9:1941-1958.

34. Fimognari FL, Loffredo L, Di Simone S, Sampietro F, Pastorelli R, Monaldo M, Violi F, D'Angelo A: Hyperhomocysteinaemia and poor vitamin B status in chronic obstructive pulmonary disease. Nutr Metab Cardiovasc Dis 2009;19:654-659.

35. Bull CF, O'Callaghan NJ, Mayrhofer G, Fenech MF: Telomere Length in Lymphocytes of Older South Australian Men May Be Inversely Associated with Plasma Homocysteine. Rejuvenation Res 2009.

36. Richards JB, Valdes AM, Gardner JP, Kato BS, Siva A, Kimura M, Lu X, Brown MJ, Aviv A, Spector TD: Homocysteine levels and leukocyte telomere length. Atherosclerosis 2008.

37. O'Callaghan P, Meleady R, Fitzgerald T, Graham I: Smoking and plasma homocysteine. Eur Heart J 2002;23:1580-1586.

38. Serra V, von Zglinicki T, Lorenz M, Saretzki G: Extracellular superoxide dismutase is a major antioxidant in human fibroblasts and slows telomere shortening. J Biol Chem 2003;278:6824-6830.

39. Tarry-Adkins JL, Ozanne SE, Norden A, Cherif H, Hales CN: Lower antioxidant capacity and elevated p53 and p21 may be a link between gender disparity in renal telomere shortening, albuminuria, and longevity. Am J Physiol Renal Physiol 2006;290:F509-516.

40. Broekhuizen R, Wouters EF, Creutzberg EC, Schols AM: Raised CRP levels mark metabolic and functional impairment in advanced COPD. Thorax 2006;61:17-22.

41. Godoy I, Campana AO, Geraldo RR, Padovani CR, Paiva SA: Cytokines and dietary energy restriction in stable chronic obstructive pulmonary disease patients. Eur Respir J 2003;22:920-925.

42. Thorleifsson SJ, Margretardottir OB, Gudmundsson G, Olafsson I, Benediktsdottir B, Janson C, Buist AS, Gislason T: Chronic airflow obstruction and markers of systemic inflammation: results from the BOLD study in Iceland. Respir Med 2009;103:15481553.

43. Khera A, Vega GL, Das SR, Ayers C, McGuire DK, Grundy SM, de Lemos JA: Sex differences in the relationship between C-reactive protein and body fat. J Clin Endocrinol Metab 2009;94:3251-3258. 
44. Breyer MK, Spruit MA, Celis AP, Rutten EP, Janssen PP, Wouters EF: Highly elevated C-reactive protein levels in obese patients with COPD: a fat chance? Clin Nutr 2009;28:642-647.

45. Fantuzzi G: Adiponectin and inflammation: consensus and controversy. J Allergy Clin Immunol 2008;121:326-330.

46. Fantuzzi G, Mazzone T: Adipose tissue and atherosclerosis: exploring the connection. Arterioscler Thromb Vasc Biol 2007;27:996-1003.

47. Daglia M, Papetti A, Aceti C, Sordelli B, Gregotti C, Gazzani G: Isolation of high molecular weight components and contribution to the protective activity of coffee against lipid peroxidation in a rat liver microsome system. J Agric Food Chem 2008;56:11653-11660.

48. Moura-Nunes N, Perrone D, Farah A, Donangelo CM: The increase in human plasma antioxidant capacity after acute coffee intake is not associated with endogenous non-enzymatic antioxidant components. Int J Food Sci Nutr 2009:1-9.

49. Paur I, Balstad TR, Blomhoff R: Degree of roasting is the main determinant of the effects of coffee on NF-kappaB and EpRE. Free Radic Biol Med.

50. Nygard O, Refsum H, Ueland PM, Stensvold I, Nordrehaug JE, Kvale G, Vollset SE: Coffee consumption and plasma total homocysteine: The Hordaland Homocysteine Study. Am J Clin Nutr 1997;65:136-143.

51. Verhoef $P$, Pasman WJ, Van Vliet T, Urgert R, Katan MB: Contribution of caffeine to the homocysteine-raising effect of coffee: a randomized controlled trial in humans. Am J Clin Nutr 2002;76:1244-1248.

52. Esposito F, Morisco F, Verde V, Ritieni A, Alezio A, Caporaso N, Fogliano V: Moderate coffee consumption increases plasma glutathione but not homocysteine in healthy subjects. Aliment Pharmacol Ther 2003;17:595-601.

53. Sakamoto W, Isomura H, Fujie K, Takahashi K, Nakao K, Izumi H: Relationship of coffee consumption with risk factors of atherosclerosis in rats. Ann Nutr Metab 2005;49:149-154.

54. Wu D, Cederbaum Al: Alcohol, oxidative stress, and free radical damage. Alcohol Res Health 2003;27:277-284.

55. de Boer WI: Perspectives for cytokine antagonist therapy in COPD. Drug Discov Today 2005;10:93-106.

56. de Boer WI, Alagappan VK, Sharma HS: Molecular mechanisms in chronic obstructive pulmonary disease: potential targets for therapy. Cell Biochem Biophys 2007;47:131-148.

57. Beyne-Rauzy O, Prade-Houdellier N, Demur C, Recher C, Ayel J, Laurent G, MansatDe Mas V: Tumor necrosis factor-alpha inhibits hTERT gene expression in human myeloid normal and leukemic cells. Blood 2005;106:3200-3205.

58. Wieczorowska-Tobis K, Niemir ZI, Podkowka R, Korybalska K, Mossakowska M, Breborowicz A: Can an increased level of circulating IL- 8 be a predictor of human longevity? Med Sci Monit 2006;12:CR118-121. 
59. Mirabello L, Huang WY, Wong JY, Chatterjee N, Reding D, Crawford ED, De Vivo I, Hayes RB, Savage SA: The association between leukocyte telomere length and cigarette smoking, dietary and physical variables, and risk of prostate cancer. Aging Cell 2009;8:405-413.

60. Bekaert S, De Meyer T, Rietzschel ER, De Buyzere ML, De Bacquer D, Langlois $M$, Segers P, Cooman L, Van Damme P, Cassiman P, Van Criekinge W, Verdonck P, De Backer GG, Gillebert TC, Van Oostveldt P: Telomere length and cardiovascular risk factors in a middle-aged population free of overt cardiovascular disease. Aging Cell 2007;6:639-647. 



\section{Chapter 6}

\section{Telomere shortening in diabetic rats: effects of dietary}

intervention with fisetin and n-acetylcysteine
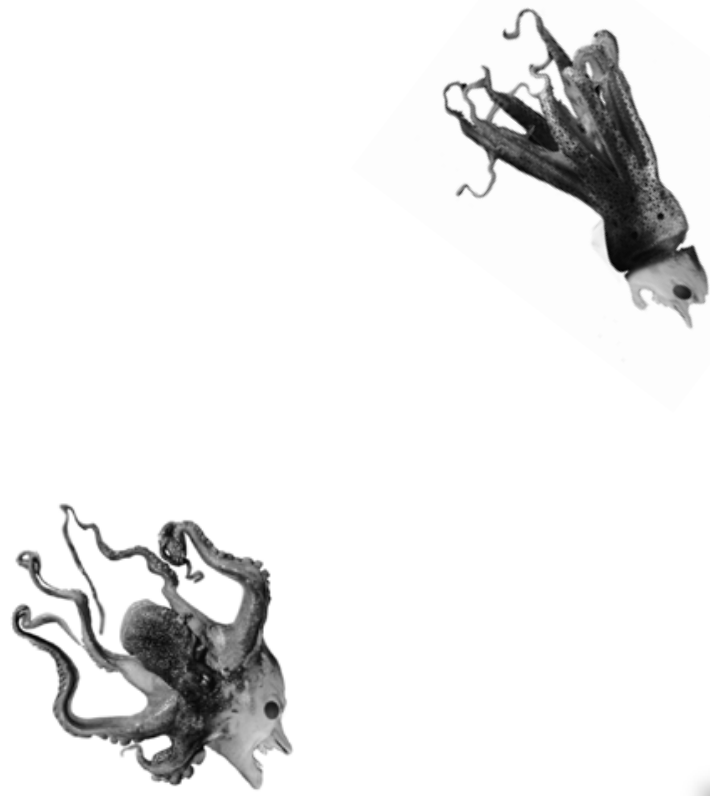

Joyce M.J. Houben

Olaf Brouwers

Danielle M.P.H.J. Boesten

Casper G. Schalkwijk

Frederik J. van Schooten

Geja J. Hageman

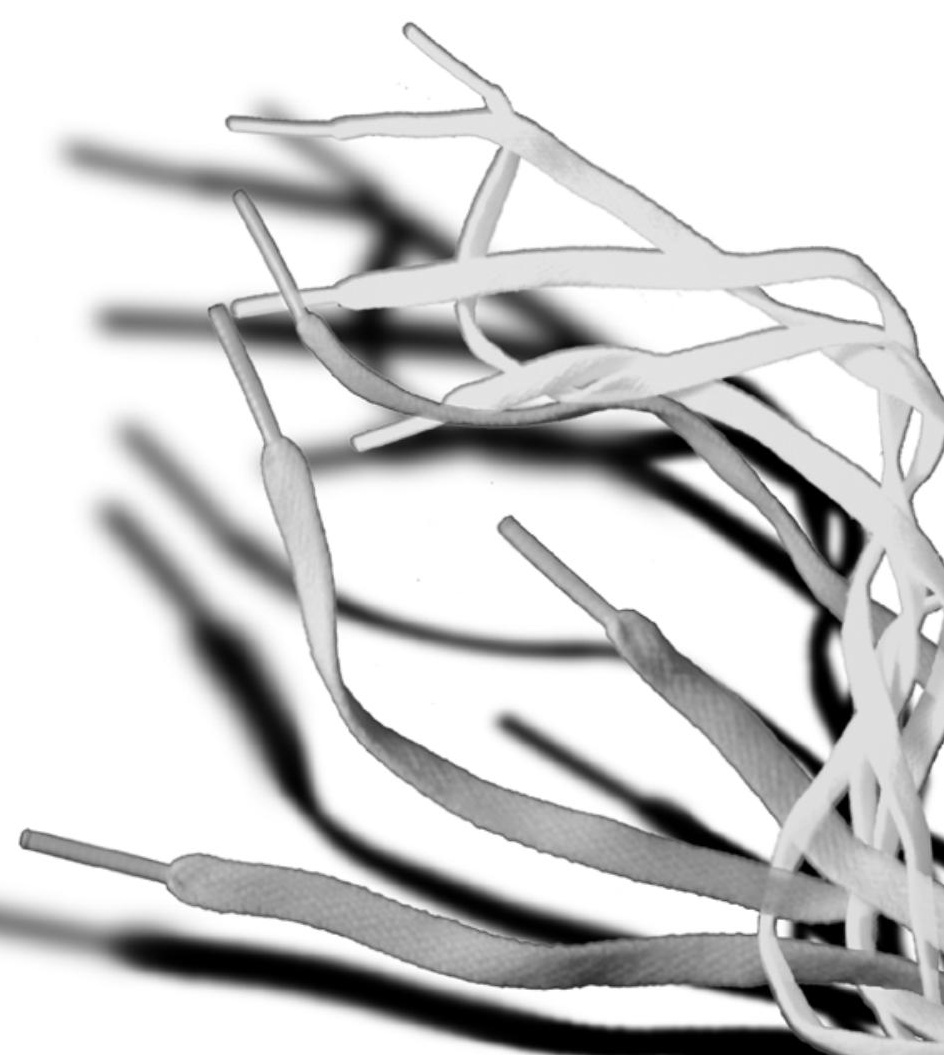




\section{Abstract}

Diabetes mellitus and hyperglycaemia cause severe damage to cells and tissues, and are marked by low grade inflammation and an increased production of reactive oxygen species leading to oxidative stress. Several animal and in vitro models have shown that chronic oxidative stress induces an accelerated rate of telomere shortening. Since diabetes is associated with chronic systemic oxidative stress and accelerated aging, dietary interventions with antioxidants and/or anti-inflammatory agents are therefore hypothesized to decrease the levels of oxidative stress and slow the rate of aging.

In the present study, we hypothesized that chronic oxidative stress and systemic inflammation in diabetes lead to an increased rate of telomere shortening. We further investigated the effects of dietary interventions with the antioxidant $n$-acetylcysteine (NAC) and the anti-inflammatory flavonoid fisetin, on oxidative stress, inflammation and the rate of telomere shortening. A 24 week dietary intervention with fisetin and NAC was performed in streptozotocin-induced diabetic Wistar rats. Kidney function parameters were determined and in leukocytes, oxidative-DNA damage was measured by 8oxodG staining and the Comet assay. In blood, heart and kidney, telomere length was determined and additionally changes in inflammatory, antioxidant and DNA repair gene expression were measured by quantitative PCR. We observed significantly shorter telomeres in the diabetic rat hearts, and both fisetin and NAC seemed to partially counteract this accelerated telomere shortening in heart. The diabetic status increased the expression of antioxidant, DNA repair and inflammation related genes in heart and kidneys. Moreover, dietary intervention with fisetin and NAC attenuated these responses. Results of this study provide evidence that antioxidant and anti-inflammatory dietary compounds can contribute to a reduction in oxidative stress and inflammatory conditions and partially counteract the accelerated telomere shortening in the diabetic heart.

\section{Introduction}

Diabetes mellitus and hyperglycaemia cause severe damage to cells and tissues, especially vital organs such as the kidneys and the heart. It has been demonstrated that patients with diabetes type 1 exhibit increased inflammation as demonstrated by increased plasma C-reactive protein (CRP) levels and 
increased monocyte activity [1]. The increased low grade inflammation and production of reactive oxygen species (ROS) leads to oxidative stress [2,3]. An increase in 7,8-Dihydro-8-oxo-2'-deoxyguanosine (8-oxodG) levels in tissue of diabetic rats and in the urine of patients with diabetes [4] indicates that diabetes also induces oxidative DNA modifications. At present, increased oxidative stress and a reduced antioxidant defence are considered to contribute significantly to the development of complications in diabetes, such as vascular dysfunction, cardiovascular diseases and renal dysfunction [5].

Several animal and in vitro models have shown that chronic oxidative stress induces an aging phenotype with an accelerated rate of telomere loss $[6,7]$. Telomeres are nucleoprotein structures at the end of chromosomes and they prevent chromosomal ends from being recognized as double strand breaks and protect them from end to end fusion and degradation [8-12]. In somatic cells, telomeres shorten with each cell division and cells are triggered into replicative senescence once the telomeres shorten to a critical length [13,14]. Cell division only partially accounts for the loss of telomeres seen in cells, so it was suggested that other mechanisms, in particular oxidative stress, might be involved in accelerated telomere shortening $[12,15]$. Due to their high content of guanines, telomeres were demonstrated highly sensitive to damage by oxidative stress $[16,17]$. Recent studies indeed have linked telomere shortening to various chronic metabolic and inflammatory diseases including diabetes [1822]. In addition higher glucose levels in patients with type 2 diabetes were associated with lower levels of plasma total antioxidant status, and this correlated with shorter telomeres [22]. Since diabetes is associated with chronic oxidative stress and accelerated aging, dietary interventions with antioxidants and/or anti-inflammatory agents are therefore hypothesized to decrease the levels of oxidative stress and slow the rate of aging.

In the present study, we hypothesized that chronic oxidative stress and systemic inflammation in diabetes lead to an increased rate of telomere shortening. We also investigated the effects of dietary interventions with the antioxidant n-acetylcysteine (NAC) and the flavonoid fisetin, on oxidative stress, inflammation and the rate of telomere shortening. Fisetin is a flavonoid with antioxidant activity and is present in small amounts in fruits and vegetables such as strawberries, apples, onions and cucumber. It has been reported to exert anti-inflammatory effects and to inhibit the activation of NFKB [23] and of the nuclear enzyme poly(ADP-ribose) polymerase 1 (PARP1) [24,25]. PARP1 has 
been reported to play a role in the development of diabetic complications $[2,26]$. In diabetic rats it has previously been shown that administration of NAC, an antioxidant and precursor of glutathione, is capable of lowering the glucose levels and reducing oxidative stress $[27,28]$.

The effects of 24 week dietary interventions with fisetin and NAC on telomere shortening were evaluated in streptozotocin-induced diabetic Wistar rats. Kidney function parameters were determined and DNA damage in leukocytes was measured by 8-oxodG staining and the Comet assay. In blood, heart and kidney, telomere length (TL) and changes in inflammatory, antioxidant and DNA repair gene expression were measured by quantitative PCR.

\section{Materials and Methods}

\section{Animals and induction of diabetes}

Male Wistar rats ( 6 weeks old) were obtained from Charles River (Horst, the Netherlands) and allowed to acclimatize for 1 week. Animals were housed together with 2 or 3 animals/cage and had unlimited access to water and food. The experiments were approved by the Ethics Committee for Animal Experiments of Maastricht University (Maastricht, The Netherlands). Diabetes was induced by a single intra venous (IV) injection of streptozotocin (STZ) $(65 \mathrm{mg} / \mathrm{kg})$. STZ induces an autoimmune process that results in the destruction of the Langerhans islets beta cells of the pancreas (Weiss 1982). The rats were considered diabetic if they had hyperglycemia (glucose $\geq 15 \mathrm{mmol} / \mathrm{L}$ ) at 1 week after STZ injection. Glucose levels were measured 1 week after injection, at 12 weeks and at 20 weeks. At week 0, 8, 16 and 23, the rats were placed in metabolic cages for urine collection and to obtain information on food and water intake.

\section{Experimental protocol}

Animals were divided in four groups that included a control group $(n=6)$, a diabetic group $(n=8)$, a diabetic group with fisetin intervention $(n=8)$ and a diabetic group with $n$-acetylcysteine (NAC) intervention $(n=8)$. When the diabetic state was confirmed one week after streptozotocin treatment, fisetin (Fit ingredients, Grenzach-Wyhlen, Germany) and NAC (Sigma-Aldrich, Zwijndrecht, The Netherlands) were administered through the food for 24 
weeks. Fisetin and NAC were mixed through the regular pellets by Bio Services (Uden, The Netherlands). Fisetin and NAC were administered at concentrations of $120 \mathrm{mg} / \mathrm{kg}$ food and $7.5 \mathrm{~g} / \mathrm{kg}$ food respectively. At this concentration, NAC has been shown to lower glucose levels and to reduce oxidative stress $[27,28]$.

After 24 weeks, rats were sacrificed and blood and organs were collected for RNA and DNA isolation. Blood and organs for RNA isolation were stored in RNA later (Applied biosystems, Nieuwerkerk a/d IJssel, The Netherlands) to preserve the RNA. Samples were kept at $4^{\circ} \mathrm{C}$ for 24 hours and afterwards stored at $-80^{\circ} \mathrm{C}$ until further processing. For DNA isolation blood and organs were snapfrozen in liquid nitrogen and stored at $-80^{\circ} \mathrm{C}$ until further processing.

\section{Markers of kidney function}

Rat kidney injury panel 1 was purchased from mesoscale diagnostics (MSD; K15162C-1). This assay detects lipocalin-2, osteopontin, and TIM-1 in a sandwich immunoassay and uses a competitive assay format to detect albumin. All reagents were provided with the MSD kit. Each 96-well plate had 4-carbon electrodes in the bottom of each well, each pre-coated with one of the 4-antikidney injury markers antibodies of interest.

After the blocking step, urine samples, standards and controls (premixed with albumin tracer) were added at $50 \mu \mathrm{l}$ per well. The plate was sealed and incubated for $2 \mathrm{~h}$ at room temperature on an orbital shaker (600 rpm). At the end of the incubation the wells were washed three times using $200 \mu \mathrm{PBS}+$ $0.05 \%$ Tween 20 , soaking for $30 \mathrm{~s}$ and then discarding. Detection antibody was added at $25 \mu \mathrm{l}$ per well, and the plate sealed and incubated for $2 \mathrm{~h}$ at room temperature on an orbital shaker (600 rpm). At the end of the incubation the plate was washed three times as before. $150 \mu \mathrm{l}$ of the MSD Read Buffer was added to each well and the MSD plates were measured on the MSD Sector Imager 2400 plate reader. The raw data was measured as electrochemiluminescence signal (light) detected by photodetectors and analysed using the Discovery Workbench 3.0 software (MSD). A 4-parameter logistic fit curve was generated for each analyte using the standards, and the concentration of each sample was calculated.

\section{Comet assay}

DNA single strand breakage was determined by the Comet assay under alkaline conditions $(\mathrm{pH}>13)$ according to the method of Singh et al. [29]. Shortly, $10 \mu \mathrm{l}$ 
of whole blood was mixed with $90 \mu \mathrm{l}$ low melting point agarose (Sigma, Zwijndrecht, The Netherlands) and placed on the slides coated with $1 \%$ of normal melting point agarose. Further procedures were as described earlier [30]. The slides were stained with ethidium bromide and examined using a Zeiss Axioskop fluorescence microscope. One hundred cells per sample (two slides), randomly selected, were analysed using the image analysis system Comet Assay III (Perceptive Instruments, Haverhill, UK). DNA damage was expressed as tail moment (TM, the product of tail DNA content and mean tail migration distance).

\section{8-oxodG detection}

A Biotrin OxyDNA Assay kit (Biotrin, Lyon, France) was used for the evaluation of oxidative DNA damage in leukocytes. The Biotrin OxyDNA Assay is an in vitro fluorescent protein binding method used for the detection of 8-oxodG in fixed permeabilized cells. After cells have been fixed and permeabilized, the FITC labeled protein conjugate is added and binds to the 8-oxoguanine moiety present in the 8-oxoguanosine of oxidized DNA. The presence of oxidized DNA is indicated by a green/yellow fluorescence that can be read using a fluorescence microscope. Blood cells were fixed on a microscopic slide and were lysed in lysis buffer according to the protocol of the comet assay. Before staining, the cells were treated with $5 \mathrm{mg} / \mathrm{ml}$ pepsin for 20 minutes at $37^{\circ} \mathrm{C}$. Afterwards, slides were washed in washing buffer supplied with the kit. Cells were incubated with $100 \mu \mathrm{l}$ of FITC-conjugate antibody specific for 8-oxodG (30x diluted) for $1 \mathrm{~h}$ in the dark at room temperature. Cells were washed in washing buffer and dehydrated in $70 \% \mathrm{EtOH}, 95 \% \mathrm{EtOH}$ and finally $100 \% \mathrm{EtOH}$. Slides were allowed to dry for 10 minutes. Cells were mounted with DAPI (to stain the nucleus) containing mounting medium. Cells were observed under a CCD (chargecoupled device) camera-equipped fluorescence DMRBE microscope (Leica, Germany). The microscope was equipped with a cooled CCD camera. Both positive controls (cells exposed to $\mathrm{H} 2 \mathrm{O} 2$ ) as well as negative controls (untreated cells) were included in the analysis. Cells were evaluated visually and classified from 0 to 3, based on the fluorescence intensity of the nuclear FITC-signal observed. For each animal, 2 slides were scored, 50 cells per slide. The scoring was done by a well trained technician with the slides coded in such a way, that it was not clear from which animal the cells were derived. 


\section{DNA isolation and telomere length measurement}

DNA was extracted using the QIAamp DNA Mini Kit (Qiagen, Venlo, The Netherlands) according to the manufacturer's protocol and quantified using a Nanodrop instrument (Isogen Life Science, Belgium). TL was determined by quantitative PCR as described by Cawthon [21,31]. Two master mixtures were prepared, one with telomere primers and one with (PGK-1) primers ( $1 \mathrm{x} I \mathrm{Q}$ SYBRgreen supermix from Biorad). Sequences and concentrations of the primers are shown in Table 1. The relative TL was calculated as the ratio of telomere repeats to single-copy gene copies ( $\mathrm{T} / \mathrm{S}$ ratio). This means that $\mathrm{T} / \mathrm{S}=1$ when the unknown DNA is identical to the reference DNA in its ratio of telomere repeat copy number to single copy gene copy number [31].

Table 1. Primer sequences and concentrations

\begin{tabular}{|c|c|c|}
\hline Primer & Sequence $\left(5^{\prime}-3^{\prime}\right)$ & Concentration \\
\hline \multicolumn{3}{|c|}{ Telomere pcr } \\
\hline Telomere 1 & CGGTTTGTTTGGGTTTGGGTTTGGGTTTGGGTTTGGGTT & $100 \mathrm{nM}$ \\
\hline Telomere 2 & GGCTTGCCTTACCCTTACCCTTACCCTTACCCTTACCCT & $900 \mathrm{nM}$ \\
\hline PGK1 forward & CGGAGACACCGCCACTTG & $1500 \mathrm{nM}$ \\
\hline PGK1 reverse & AAGGCAGGAAAATACTAAACAT & $1500 \mathrm{nM}$ \\
\hline \multicolumn{3}{|c|}{ Antioxidant related genes } \\
\hline SOD3 forward & CTTCCCAGCCGAGCAGAA & $300 \mathrm{nM}$ \\
\hline SOD3 reverse & TCAGGTCCCCGAACTCATG & $300 \mathrm{nM}$ \\
\hline SOD2 forward & CAGGACCCACTGCAAGGAA & $300 \mathrm{nM}$ \\
\hline SOD2 reverse & CGTGCTCCCACACATCAATC & $300 \mathrm{nM}$ \\
\hline GPX1 forward & AATTCCCTCAAGTACGTCCG & $300 \mathrm{nM}$ \\
\hline GPX1 reverse & TCAGGTTCGATGTCGATGGT & $300 \mathrm{nM}$ \\
\hline CAT forward & TCCTGAGAGAGTGGTACATGC & $300 \mathrm{nM}$ \\
\hline CAT reverse & AAGGTGTGTGAGCCATAGCC & $300 \mathrm{nM}$ \\
\hline \multicolumn{3}{|c|}{ DNA repair related genes } \\
\hline PARP1 forward & CAGGGATTCCGTCTGGTGTT & $300 \mathrm{nM}$ \\
\hline PARP 1 reverse & ACCTGAGCAATGTCGTAGACAATG & $300 \mathrm{nM}$ \\
\hline OGG1 forward & CGGCTGGCAGCCTAAGAC & $300 \mathrm{nM}$ \\
\hline OGG1 reverse & CCGGAAAAAGTTTCCCAGTTC & $300 \mathrm{nM}$ \\
\hline APEX1 forward & GAATGTGGATGGGCTTCGA & $300 \mathrm{nM}$ \\
\hline APEX1 reverse & AAGATGTCTGGTGCTTCTTCCTTT & $300 \mathrm{nM}$ \\
\hline \multicolumn{3}{|c|}{ Inflammation related genes } \\
\hline COX2 forward & GGGTTAAAAACCGACGCAATC & $300 \mathrm{nM}$ \\
\hline cOX2 reverse & TAGACCTGGTCGGTTTGATGTG & $300 \mathrm{nM}$ \\
\hline NADPH4 forward & TGGGTGTCAAACAAGAGATTGC & $300 \mathrm{nM}$ \\
\hline NADPH4 reverse & GGCTCAGGAGGTTCTTCATGTAG & $300 \mathrm{nM}$ \\
\hline IL1 $\beta$ forward & GCACCTTCTTTTCCTTCATCTTTG & $300 \mathrm{nM}$ \\
\hline
\end{tabular}




\begin{tabular}{lll}
\hline IL1 $\beta$ reverse & CACACTAGCAGGTCGTCATCATC & $300 \mathrm{nM}$ \\
\hline TNF $\alpha$ forward & TGATCGGTCCCAACAAGGA & $300 \mathrm{nM}$ \\
\hline TNF $\alpha$ reverse & GGGCCATGGAACTGATGAGA & $300 \mathrm{nM}$ \\
\hline IL6 forward & GAAACCCTAGTTCATATCTTCAAACAAG & $300 \mathrm{nM}$ \\
\hline IL6 reverse & CCATTAGGAGAGCATTGGAAGTTG & $300 \mathrm{nM}$ \\
\hline & \multicolumn{1}{c}{ Other genes } & $300 \mathrm{nM}$ \\
\hline H01 forward & GGCCTGGCTTTTTTCACCTT & $300 \mathrm{nM}$ \\
\hline H01 reverse & CGAGCACGATAGAGCTGTTTGA & $300 \mathrm{nM}$ \\
\hline P53 forward & GACAGCTTTGAGGTTCGTGTTTG & $300 \mathrm{nM}$ \\
\hline P53 reverse & TGCTCTTCTTTTTTGCGGAAA &
\end{tabular}

\section{RNA isolation, cDNA syntheses and quantitative PCR}

Tissues were stored in RNA later until further processing. Tissues ( $\pm 30 \mathrm{mg}$ ) were homogenized in $1 \mathrm{ml}$ Trizol using a mechanical homogenizer (Ultra turrax). RNA was isolated from the Trizol suspended cells according to the manufacturer's protocol (Invitrogen, Carlsbad, CA, USA) and quantified using a Nanodrop instrument (Isogen Life Science, Belgium).

Blood was stored in RNA later until further processing. RNA was isolated using the Mouse RiboPure ${ }^{\mathrm{TM}}$-blood RNA isolation kit according to the manufacturer's protocol (Applied biosystems, Nieuwerkerk a/d IJssel, The Netherlands). RNA yields were determined by UV absorbance using a Nanodrop instrument (Isogen Life Science, Belgium). Reverse transcription reaction was performed using $500 \mathrm{ng}$ of total RNA, which was reverse-transcribed into CDNA using iScriptTM cDNA synthesis kit (Biorad Laboratories, Hercules, CA, USA). The analyzed genes with primer sequences and concentrations are summarized in Table 1.

Real time PCR was performed with a BioRad MyiQ Single Color RT-PCR detection system (Biorad) using SensiMixPlusSYBR \& Fluorescein, $5 \mu$ ldiluted (10x) cDNA and $0.3 \mu \mathrm{M}$ primers in a total volume of $25 \mu \mathrm{l}$. PCR was conducted as follows: 10 minutes at $95^{\circ} \mathrm{C}, 35 \mathrm{cycles}$ of $15 \mathrm{sec}$ at $95^{\circ} \mathrm{C}, 30 \mathrm{sec}$ at $60^{\circ} \mathrm{C}$ and 45 sec at $72^{\circ} \mathrm{C}$.

After PCR a melt curve $\left(60-95^{\circ} \mathrm{C}\right)$ was produced for product identification and purity. $\beta$-actin was included as housekeeping gene and a standard curve was included each run. Primer sequences are shown in Table 1. In each run a pool sample was added against which all samples were plotted. Data were analyzed using the MyiQ software system (Biorad) and were expressed as 
relative gene expression (expressed as fold change, with the pooled DNA as reference sample) using the $2 \Delta \Delta \mathrm{Ct}$ method.

\section{Statistical analysis}

Results are shown as mean \pm standard deviation/standard error of the mean, or as percentage. Differences between the groups were tested using One-way analysis of variance between groups. For comparisons between 2 groups, the Student's t-test for the independent samples and the Mann Whitney U-test when not normally distributed was used. Percentages (with the control rats as a reference group) were calculated for the gene expression results. With these percentages, the results of respectively the antioxidant related genes, the DNA repair related genes and the inflammation related genes could be grouped together. A difference with $p<0.05$ was considered statistically significant. Statistical analyses were analyzed with SPSS for Windows (version 15.0; SPSS Inc., Chicago, IL, USA).

\section{Results}

\section{General characteristics}

No mortality was observed in control rats, diabetic rats, or the intervention groups. The rats in the three diabetic groups had a significantly lower total bodyweight than control rats at week 24 . In contrast, the relative weight of kidneys and heart was significantly higher in the diabetic groups. The mean intake of fisetin was $12.84 \pm 5.27 \mathrm{mg} / \mathrm{kg}$ bodyweight, and the mean intake of NAC was $774.58 \pm 178.36$ bodyweight. No effect of the dietary interventions was observed on total body weight or the weight of the organs (Table 2). The diabetic rats consumed more food than the control group over the 24 week period $(p<0.01)$.

We also found that the glucose levels were increased in the diabetic groups $(p<0.001)$ during the whole experiment. 
Table 2. General characteristics of the study groups

\begin{tabular}{|c|c|c|c|c|}
\hline & Control rats & Diabetic rats & $\begin{array}{l}\text { Diabetic rats } \\
\text { on Fisetin diet }\end{array}$ & $\begin{array}{l}\text { Diabetic rats on } \\
\mathrm{N} \text {-acetylcysteine } \\
\text { diet }\end{array}$ \\
\hline Total bodyweight (g) & $488.83 \pm 21.82$ & $309.38 \pm 37.76^{*}$ & $337.63 \pm 31.96 *$ & $350.63 \pm 61.97 *$ \\
\hline $\begin{array}{l}\text { Relative weight heart } \\
\text { (\% of total bodyweight) }\end{array}$ & $0.299 \pm 0.021$ & $0.321 \pm 0.033^{*}$ & $0.323 \pm 0.058 *$ & $0.339 \pm 0.039 *$ \\
\hline \multicolumn{5}{|l|}{ Relative weight left } \\
\hline $\begin{array}{l}\text { kidney (\% of total } \\
\text { bodyweight) }\end{array}$ & $0.319 \pm 0.022$ & $0.403 \pm 0.049^{*}$ & $0.447 \pm 0.081 *$ & $0.50 \pm 0.0116^{*}$ \\
\hline $\begin{array}{l}\text { Relative weight right } \\
\text { kidney (\% of total } \\
\text { bodyweight) }\end{array}$ & $0.327 \pm 0.026$ & $0.396 \pm 0.051^{*}$ & $0.443 \pm 0.047^{*}$ & $0.495 \pm 0.099 *$ \\
\hline $\begin{array}{l}\text { Blood glucose levels } \\
\text { after } 20 \text { weeks ( } \mathrm{mmol} / \mathrm{l})\end{array}$ & $5.57 \pm 0.60$ & $30.14 \pm 4.67^{*}$ & $30.16 \pm 4.02 *$ & $24.74 \pm 9.72 *$ \\
\hline
\end{tabular}

Data are presented as mean \pm SD. * Significantly different from the control rats based on a Mann Whitney U-test $(p<0.01)$.

\section{Kidney function}

In Table 3 kidney function parameters are shown. Kidney function is significantly decreased in diabetic rats as can been seen by enhanced excretion of kidney injury molecule-1 (TIM1), lipolcalin-2 and osteopontin. Fisetin and NAC had no significant influences on these kidney parameters but TIM1 is significantly decreased in the fisetin and NAC intervention groups compared to the diabetic rats.

Table 3. Kidney function parameters

\begin{tabular}{|c|c|c|c|c|}
\hline & Control rats & Diabetic rats & $\begin{array}{l}\text { Diabetic rats } \\
\text { on Fisetin diet }\end{array}$ & $\begin{array}{l}\text { Diabetic rats on } \\
\mathrm{N} \text {-acetylcysteine } \\
\text { diet }\end{array}$ \\
\hline $\mathrm{CCr}(\mathrm{mL} / \mathrm{min} / 100 \mathrm{~g} \mathrm{BW})$ & $0.67 \pm 0.05$ & $0.90 \pm 0.25$ & $1.09 \pm 0.24$ & $1.07 \pm 0.24$ \\
\hline TIM1 (ng/mg Creatinine) & $0.49 \pm 0.18$ & $1.89 \pm 0.69 *$ & $1.18 \pm 0.81 * *$ & $1.22 \pm 0.60 * *$ \\
\hline $\begin{array}{l}\text { Lipocalin-2 (ng/mg } \\
\text { Creatinine) }\end{array}$ & $193.5 \pm 64.66$ & $878.8 \pm 590.81^{*}$ & $1738.9 \pm 3874.32$ & $1160.0 \pm 1233.54$ \\
\hline $\begin{array}{l}\text { Osteopontin (ng/mg } \\
\text { Creatinine) }\end{array}$ & $3.45 \pm 1.54$ & $49.0 \pm 35.94^{*}$ & $49.64 \pm 52.17$ & $194.56 \pm 231.41$ \\
\hline $\begin{array}{l}\text { Albumin (ng/mg } \\
\text { Creatinine) }\end{array}$ & $334.5 \pm 446.86$ & $2161.1 \pm 3149.45$ & $717.6 \pm 656.57$ & $2203.3 \pm 1850.94$ \\
\hline
\end{tabular}

\section{Telomere length}

TL was measured by quantitative PCR in DNA isolated from white blood cells (WBC), heart and kidney. No significant differences were observed between the 
four groups for TL in the kidney and white blood cells. In the heart, the telomeres of the diabetic rats were significantly shorter. Fisetin and NAC appeared to counteract this effect in the heart, but this was not statistically significant (Figure 1A, B and C).

A.

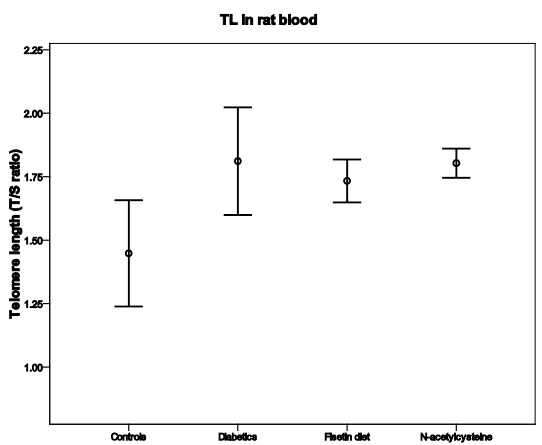

C.

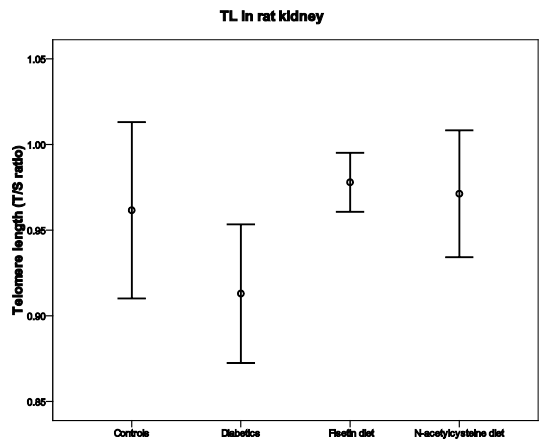

B.

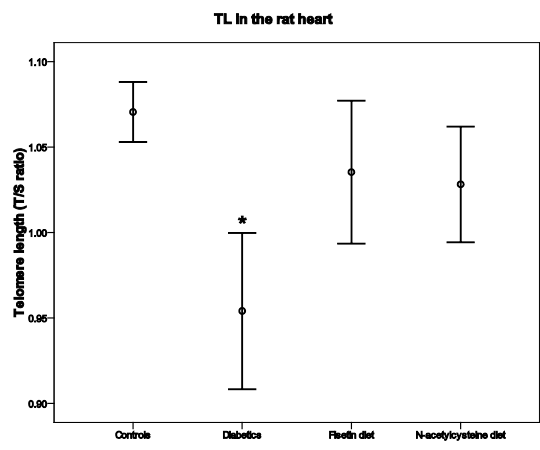

Figure 1. TL in the different groups in the blood (A), heart (B) and the kidney (C). Data are presented as $\mathrm{T} / \mathrm{S}$ ratio $\pm \mathrm{SEM}$. * Significantly different from the control group based on One-way analysis of variance $(p<0.05)$

\section{Oxidative DNA damage}

As an index of oxidative DNA damage, DNA strand breaks in WBC were measured using the Comet assay. No significant differences were observed in DNA damage between the four groups (Table 4). Additionally we measured the formation of 8-oxodG in WBC of the rats using fluorescence labeling. In cells treated with $\mathrm{H} 2 \mathrm{O} 2$ to induce 8-oxodG within the nuclei of the cells, positive staining could be obtained via binding of the FITC conjugated 8-oxodG antibody. On the contrary we could not observe any 8-oxodG in untreated cells. 
Quantitation of the signal by scoring of positive nuclei showed an increase of 8oxodG in WBC of the diabetic rats, although this was not significant.

Unexpectedly, we also observed a nonsignificant increase in the fisetin intervention group (Table 4). For NAC, no effects were observed.

Table 4. Level of oxidative DNA damage in white blood cells as measured by the Comet assay and 8oxodG fluorescence staining.

\begin{tabular}{llll} 
Control rats & Diabetic rats & $\begin{array}{l}\text { Diabetic rats } \\
\text { on Fisetin diet }\end{array}$ & $\begin{array}{l}\text { Diabetic rats on } \\
\text { N-acetylcysteine } \\
\text { diet }\end{array}$ \\
\hline $0.27 \pm 0.08$ & $0.27 \pm 0.21$ & $0.22 \pm 0.08$ & $0.23 \pm 0.05$ \\
\hline $100 \pm 69.73$ & $117.29 \pm 47.84$ & $134.74 \pm 59.31$ & $99.25 \pm 51.0$ \\
\hline
\end{tabular}

Data are presented as mean tail moment \pm SD (Comet assay) or as percentage positive cells (8oxodG). Differences in values between groups were tested with a Mann Whitney U-test. No significant differences were observed.

Data of the comet assay were expressed as mean tail moment and data of the 8-oxodG staining were expressed as percentages of the control group, and the combined measurements (both expressed as percentages of the control group) were used to analyze effects on oxidative DNA damage using ANOVA. Although the observed differences were not significant, we did observe a trend towards higher levels of DNA damage in the diabetic group and an attenuating effect for both interventions.

\section{Gene expression}

Gene expression was measured in blood, heart and kidney. Genes involved in inflammation, antioxidant defense, and DNA repair were selected. Diabetic rats showed a significant upregulation of catalase and glutathione peroxidase 1 (GPX1) transcription in heart and kidney. Furthermore, an upregulation of the genes 8-oxoguanine DNA glycosylase 1 (OGG1), NADPH-oxidase 4 (NOX4) and interleukin $1 \beta$ (IL1 $\beta$ ) in the heart and tumor necrosis factor $\alpha$ (TNF $\alpha$ ) in the kidney was observed. Apurinic apyrimidinic endonuclease redox effector factor-1 (APE1/REF1), catalase, p53, OGG1, GPX1 and PARP1 showed a tendency to be downregulated in the kidney in the fisetin group when compared to the diabetic rats without intervention (Table 5, 6 and 7). Inflammation related genes were not detectable in blood.

To investigate whether genes involved in similar processes were influenced by the diabetic status or by one of the interventions, we classified 
the genes into three groups: Antioxidant defense, DNA repair and inflammation related genes (Table 5, 6 and 7). The antioxidant genes were significantly upregulated in the diabetic group compared to non-diabetic controls, both in the heart and the kidney. In addition, DNA repair genes as well as inflammatory genes were significantly upregulated in the heart of the diabetic group. Dietary intervention with fisetin caused a significant decrease in the expression of antioxidant genes and DNA repair genes in the kidney of rats compared to de diabetic rats without intervention. In blood, an increased expression of DNA repair genes was observed in the fisetin group when compared to the diabetic group without intervention. In diabetic rats that were treated with NAC, transcription of inflammation associated genes in the kidney showed a tendency to be decreased when compared to diabetic rats without interventions, but this was not statistically significant. 
Table 5. Transcription of antioxidant related genes (A), DNA repair related genes (B) and inflammation related genes $(C)$ in the rat heart expressed as percentage \pm SD from the control group

A.

Diabetic rats on $\mathbf{N}$ acetylcysteine diet

Control rats Diabetic rats Diabetic rats Diabetic rats on on Fisetin diet $\mathrm{N}$-acetylcysteine diet

\begin{tabular}{lllll}
\hline HO1 & $100 \pm 36.14$ & $97.10 \pm 22.56$ & $91.72 \pm 32.30$ & $86.71 \pm 35.04$ \\
\hline CAT & $100 \pm 23.28$ & $\mathbf{2 2 6 . 0 5} \pm \mathbf{1 2 9 . 5 5 *}$ & $194.61 \pm 46.67$ & $151.11 \pm 75.45$ \\
\hline SOD2 & $100 \pm 6.66$ & $92.37 \pm 12.74$ & $87.68 \pm 17.59$ & $98.65 \pm 11.93$ \\
\hline SOD3 & $100 \pm 20.78$ & $121.88 \pm 24.66$ & $121.13 \pm 21.06$ & $110.63 \pm 34.67$ \\
\hline GPX1 & $100 \pm 13.51$ & $\mathbf{1 4 8 . 7 1} \pm \mathbf{3 4 . 8 0 *}$ & $122.49 \pm 33.42$ & $127.36 \pm 31.54$ \\
\hline $\begin{array}{l}\text { Mean expression of all } \\
\text { antioxidant related genes }\end{array}$ & $100 \pm 20.79$ & $\mathbf{1 3 7 . 2 2} \pm \mathbf{7 6 . 7 9 *}$ & $123.53 \pm 49.22$ & $114.89 \pm 46.73$ \\
\hline
\end{tabular}

Significantly different from the control group, based on a Mann Whitney U-test $(p<0.05)$.

B.

\begin{tabular}{lllll}
\hline $\begin{array}{l}\text { DNA repair related genes in Control rats } \\
\text { the heart }\end{array}$ & Diabetic rats & $\begin{array}{l}\text { Diabetic rats } \\
\text { on Fisetin diet }\end{array}$ & $\begin{array}{l}\text { Diabetic rats on } \\
\text { N-acetylcysteine } \\
\text { diet }\end{array}$ \\
\hline OGG1 & $100 \pm 13.57$ & $\mathbf{1 2 0 . 6 5} \pm \mathbf{1 2 . 3 6 *}$ & $112.65 \pm 18.31$ & $116.50 \pm 15.77$ \\
\hline PARP-1 & $100 \pm 17.86$ & $96.93 \pm 7.52$ & $108.38 \pm 14.21$ & $103.49 \pm 23.23$ \\
\hline P53 & $100 \pm 61.49$ & $132.85 \pm 81.45$ & $327.03 \pm 345.87$ & $86.05 \pm 36.90$ \\
\hline APE1/REF1 & $100 \pm 3.61$ & $121 \pm 26.18$ & $108.62 \pm 13.84$ & $104.67 \pm 13.48$ \\
\hline $\begin{array}{l}\text { Mean expression of all DNA } \\
\text { repair related genes }\end{array}$ & $100 \pm 30.57$ & $117.56 \pm 43.31$ & $151.36 \pm 190.54102 .24 \pm 25.46$ \\
\hline
\end{tabular}

Significantly different from the control group, based on a Mann Whitney U-test $(p<0.05)$.

C.

Inflammation related genes Control rats Diabetic rats Diabetic rats Diabetic rats on in the heart on Fisetin diet $\mathrm{N}$-acetylcysteine diet

\begin{tabular}{lllll}
\hline IL1 $\beta$ & $100 \pm 25.98$ & $\mathbf{2 1 6 . 4 7} \pm \mathbf{7 4 . 1 8 *}$ & $176.90 \pm 30.03$ & $157.87 \pm 59.81$ \\
\hline TNF $\boldsymbol{\alpha}$ & $100 \pm 28.85$ & $126.58 \pm 47.11$ & $122.15 \pm 27.53$ & $107.59 \pm 41.51$ \\
\hline IL6 & $100 \pm 57.54$ & $100.34 \pm 51.51$ & $93.80 \pm 29.63$ & $97.48 \pm 57.70$ \\
\hline COX2 & $100 \pm 9.11$ & $103.57 \pm 31.86$ & $87.93 \pm 22.35$ & $105.91 \pm 33.63$ \\
\hline NADPH-ox 4 & $100 \pm 23.83$ & $\mathbf{1 3 0 . 2 8} \pm \mathbf{2 6 . 1 0 *}$ & $128.26 \pm 24.94$ & $120.03 \pm 32.70$ \\
\hline $\begin{array}{l}\text { Mean expression of all } \\
\text { inflammation related genes }\end{array}$ & $100 \pm 30.71$ & $\mathbf{1 3 5 . 4 5} \pm \mathbf{6 3 . 2 2 *}$ & $\mathbf{1 2 1 . 8 1} \pm \mathbf{3 7 . 5 3}$ & $117.78 \pm 49.08$ \\
\hline
\end{tabular}

* Significantly different from the control group, based on a Mann Whitney U-test $(p<0.05)$. 
Table 6. Transcription of antioxidant related genes (A), DNA repair related genes (B) and inflammation related genes $(C)$ in the rat kidney expressed as percentage \pm SD from the control group.

A.

\begin{tabular}{lllll}
\hline $\begin{array}{l}\text { Antioxidant related genes } \\
\text { in the kidney }\end{array}$ & Control rats & Diabetic rats & $\begin{array}{l}\text { Diabetic rats } \\
\text { on Fisetin diet }\end{array}$ & $\begin{array}{l}\text { Diabetic rats on } \\
\text { N-acetylcysteine } \\
\text { diet }\end{array}$ \\
\hline HO1 & $100 \pm 11.98$ & $134.84 \pm 65.15$ & $\mathbf{1 2 9 . 1 3} \pm \mathbf{4 8 . 3 2}$ & $88.19 \pm 18.52$ \\
\hline CAT & $100 \pm 26.93$ & $\mathbf{1 6 7 . 2 3} \pm \mathbf{7 3 . 0 4 *}$ & $\mathbf{7 3 . 1 4} \pm \mathbf{7 0 . 3 4 * *} 73.14 \pm 70.34$ \\
\hline SOD2 & $100 \pm 35.22$ & $94.23 \pm 18.61$ & $69.93 \pm 30.27$ & $109.89 \pm 12.77$ \\
\hline SOD3 & $100 \pm 16.62$ & $114.38 \pm 59.70$ & $141.90 \pm 95.13$ & $95.97 \pm 19.77$ \\
\hline GPX1 & $100 \pm 18.57$ & $\mathbf{1 5 4 . 7 8} \pm \mathbf{5 1 . 5 5 *}$ & $\mathbf{6 1 . 4 6} \pm \mathbf{4 1 . 0 1 * *} 147.97 \pm 45.80$ \\
\hline $\begin{array}{l}\text { Mean expression of all } \\
\text { antioxidant related genes }\end{array}$ & $100 \pm 21.70$ & $\mathbf{1 3 3 . 1 0} \pm \mathbf{6 0 . 1 3 *}$ & $\mathbf{8 1 . 1 8} \pm \mathbf{5 0 . 0 4 * *} 122.00 \pm 48.06$ \\
\hline
\end{tabular}

* Significantly different from the control group, based on a Mann Whitney U-test $(p<0.05)$.

**Significantly different from the diabetic group, based on a Mann Whitney U-test ( $p 0.05)$.

B.

\begin{tabular}{llll}
\hline $\begin{array}{l}\text { DNA repair related genes in Control rats } \\
\text { the kidney }\end{array}$ & Diabetic rats & $\begin{array}{l}\text { Diabetic rats } \\
\text { on Fisetin diet }\end{array}$ & $\begin{array}{l}\text { Diabetic rats on } \\
\text { N-acetylcysteine } \\
\text { diet }\end{array}$ \\
\hline OGG1 & $100 \pm 29.82$ & $111.31 \pm 21.09$ & $\mathbf{7 0 . 0 8} \pm \mathbf{2 9 . 2 1 * *} 101.48 \pm 13.63$ \\
\hline PARP-1 & $100 \pm 14.91$ & $99.78 \pm 14.58$ & $\mathbf{5 6 . 7 4} \pm \mathbf{2 6 . 8 6 * *} 100.65 \pm 19.15$ \\
\hline P53 & $100 \pm 17.19$ & $99.43 \pm 14.41$ & $\mathbf{7 3 . 0 1} \pm \mathbf{1 9 . 1 1 * *} 100.57 \pm 13.73$ \\
\hline APE1/REF1 & $100 \pm 18.54$ & $111.08 \pm 17.49$ & $\mathbf{8 0 . 8 6} \pm \mathbf{1 8 . 8 1 * *} 113.73 \pm 23.73$ \\
\hline $\begin{array}{l}\text { Mean expression of all DNA } \\
\text { repair related genes }\end{array}$ & $100 \pm 19.51$ & $105.40 \pm 17.30$ & $\mathbf{6 6 . 7 9} \pm \mathbf{2 4 . 4 1 * * 1 0 4 . 1 1 \pm 1 7 . 7 9}$ \\
\hline
\end{tabular}

**Significantly different from the diabetic group, based on a Mann Whitney U-test $(p<0.05)$.

c.

Inflammation related genes Control rats Diabetic rats Diabetic rats Diabetic rats on in the kidney

on Fisetin diet $\mathrm{N}$-acetylcysteine

diet

\begin{tabular}{lllll}
\hline IL1 $\beta$ & $100 \pm 38.95$ & $94.98 \pm 18.10$ & $74.19 \pm 51.43$ & $113.11 \pm 63.40$ \\
\hline TNF $\boldsymbol{\alpha}$ & $100 \pm 25.35$ & $\mathbf{1 5 2 . 0 7} \pm \mathbf{4 5 . 6 8 *}$ & $143.28 \pm 91.60$ & $138.48 \pm 42.85$ \\
\hline IL6 & $100 \pm 89.91$ & $66.93 \pm 55.51$ & $51.72 \pm 33.64$ & $62.88 \pm 31.07$ \\
\hline COX2 & $100 \pm 15.94$ & $99.41 \pm 25.69$ & $178.09 \pm 134.9$ & $95.29 \pm 24.69$ \\
\hline NADPH-ox 4 & $100 \pm 19.99$ & $115.07 \pm 45.06$ & $68.26 \pm 60.19$ & $98.28 \pm 26.67$ \\
\hline $\begin{array}{l}\text { Mean expression of all } \\
\text { inflammation related genes }\end{array}$ & $100 \pm 43.85$ & $142.27 \pm 172.77$ & $103.73 \pm 89.95$ & $100.66 \pm 45.34$
\end{tabular}

* Significantly different from the control group, based on a Mann Whitney U-test $(p<0.05)$. 
Table 7. Transcription of antioxidant related genes (A) and DNA repair related genes (B) in white blood cells expressed as percentage \pm SD from the control group.

A.

\begin{tabular}{lllll}
\hline $\begin{array}{l}\text { Antioxidant related genes in Control rats } \\
\text { the blood }\end{array}$ & Diabetic rats & $\begin{array}{l}\text { Diabetic rats } \\
\text { on Fisetin diet }\end{array}$ & $\begin{array}{l}\text { Diabetic rats on } \\
\text { N-acetylcysteine } \\
\text { diet }\end{array}$ \\
\hline HO1 & $100 \pm 43.95$ & $97.86 \pm 42.42$ & $135.96 \pm 97.02$ & $116.10 \pm 119.83$ \\
\hline SOD2 & $100 \pm 48.15$ & $74.46 \pm 9.50$ & $112.16 \pm 32.32$ & $68.92 \pm 15.03$ \\
\hline SOD3 & $100 \pm 42.05$ & $98.57 \pm 42.75$ & $141.90 \pm 95.13$ & $126.62 \pm 126.81$ \\
\hline $\begin{array}{l}\text { Mean expression of all } \\
\text { antioxidant related genes }\end{array}$ & $100 \pm 41.47$ & $90.30 \pm 35.53$ & $130.01 \pm 78.16$ & $103.88 \pm 88.40$ \\
\hline
\end{tabular}

Differences in values between groups were tested with a Mann Whitney U-test. No significant differences were observed.

\begin{tabular}{|c|c|c|c|c|}
\hline \multicolumn{5}{|l|}{ B. } \\
\hline $\begin{array}{l}\text { DNA repair related genes } \\
\text { in the blood }\end{array}$ & Control rats & Diabetic rats & $\begin{array}{l}\text { Diabetic rats } \\
\text { on Fisetin diet }\end{array}$ & $\begin{array}{l}\text { Diabetic rats on } \\
\mathrm{N} \text {-acetylcysteine } \\
\text { diet }\end{array}$ \\
\hline OGG1 & $100 \pm 36.91$ & $62.56 \pm 8.82^{*}$ & $112.01 \pm 51.65$ & $64.72 \pm 21.63$ \\
\hline P53 & $100 \pm 41.51$ & $100.81 \pm 38.13$ & $122.40 \pm 72.07$ & $94.58 \pm 66.22$ \\
\hline APE1/REF1 & $100 \pm 36.04$ & $62.37 \pm 26.60$ & $103.15 \pm 39.56$ & $58.95 \pm 17.17$ \\
\hline $\begin{array}{l}\text { Mean expression of all DNA } \\
\text { repair related genes }\end{array}$ & $100 \pm 35.39$ & $75.25 \pm 31.98$ & $112.52 \pm 54.16$ & $72.75 \pm 42.67$ \\
\hline
\end{tabular}

Differences in values between groups were tested with a Mann Whitney U-test. * Significantly different from the control group, based on a Mann Whitney U-test $(p<0.05)$.

\section{Discussion}

In the present study we induced diabetes in rats by a single injection of streptozotocin (STZ) and we observed after 24 weeks increased blood glucose levels, a decrease in body weight and an increase in relative heart and kidney weights. As a marker of accelerated aging we determined TL and found in the DNA of heart tissue a significantly shorter TL when compared to non-diabetic rats. In the kidney and in WBC no effect could be detected. Previously, others showed telomere shortening in the rat heart after 12 weeks of severe renal failure, as can also occur in diabetes and hypertension [32]. Since this was not observed during mild renal failure as measured by plasma creatinine, proteinuria and focal glomerulosclerosis, these data indicated that severe renal failure may lead to hypertrophy and telomere shortening in the heart [32]. In our study, we also observed severe renal failure, and increased telomere shortening in the heart. There is accumulating evidence that oxidative stress may be involved in telomere shortening in the diabetic heart. The telomeric DNA structure, with its high content of guanines, has an enhanced vulnerability 
towards oxidative DNA damage. Moreover, repair of single-strand breaks in telomeres is less efficient than in the bulk of the genome [33]. Additionally, reactive oxygen species (ROS) may have a negative effect on signaling proteins which in turn can modulate cellular processes, leading to cardiac growth remodeling and dysfunction [34].

In WBC no effects on telomere length could be observed. A possible explanation may be that the effects of the diabetic status are more pronounced in target tissues such as heart and kidney as compared to WBC, which are for the greater part directly derived from the hematopoietic stem cells. Since these hematopoietic cells possess telomerase activity, TL in WBC may be less sensitive for the effects of hyperglycemia [35].

To examine whether oxidative stress in diabetic rats leads to DNA damage we measured DNA strand breaks and 8-oxodG detection in WBC. No significant increase in oxidative DNA damage could be detected with the Comet assay in WBC of diabetic rats, but levels of 8-oxodG tended to be increased. Although in several human studies higher levels of 8-oxodG and DNA strand breaks were reported in type II diabetic patients [4,36], there are also studies in which no association between oxidative stress, as measured by 8-oxodG and the Comet assay in WBC, and glycaemic control in diabetic patients (type I and type II diabetes) was found $[37,38]$.

Furthermore, we measured gene expression of genes involved in antioxidant defense, DNA repair and inflammation, in blood, heart and kidney. In heart and kidney, we observed significant changes caused by the diabetic status of the rats and as well as effects of dietary interventions. Both catalase and GPX1 gene expression were significantly increased in the heart en the kidney, indicating increased oxidative stress caused by the diabetic status. Several studies previously showed an increase in catalase activity in the heart and the kidney of diabetic rats supporting the increased gene expression of catalase found in our study $[39,40]$. Catalase as well as GPX1 is involved in the detoxification of radicals, and previous studies showed that protection against oxidative stress requires the up-regulation of catalase activity, i.e. catalase activity is increased under conditions of oxidative stress $[40,41]$.

We did not observe any effects on the expression of the antioxidant enzymes superoxide dismutase 2 and 3 (SOD2 and 3) and the stress responsive enzyme haem oxygenase 1 (HO-1). Previous studies indicated that the expression of extracellular SOD (SOD3) might be more sensitive to oxidative 
stress caused by diabetes, but in our study we could not find evidence to support this hypothesis [42]. Sadi et al. also showed that decreasing levels of catalase activity and gene expression was counterbalanced by increasing levels of GPX activity and gene expression in diabetes, indicating that very delicate mechanisms may regulate the activities of the antioxidant enzymes [42]. In our study we did not observe these effects with regard to catalase and GPX1 gene expression.

In concordance with the results from the oxidative stress parameters in the blood, we could not observe any significant changes in antioxidant gene expression in the blood, but OGG1 was significantly downregulated in diabetic rats when compared to the non-diabetic controls. OGG1 is a DNA repair gene that removes 8-oxodG from the DNA [43] and previously it has been demonstrated that diabetes type I was associated with a decrease in OGG1 expression and accumulation of 8-oxodG in kidney cortex of diabetic rats [44]. In our study we saw the same tendency in WBC, in the kidneys no effect was observed, and in the heart of diabetic rats we observed an increase in the expression of OGG1. This may indicate that oxidative stress induced DNA damage in the heart is inducing an up-regulation of OGG1. Other studies have also reported an enhancing effect of oxidative DNA damage on over-expression of OGG1 $[43,45]$. In our study, we observed differential expression of OGG1 in WBC and in the heart of diabetic rats, which may be explained by differences in tissue-specific control of the expression of genes [46].

Diabetic rats showed increased expression of inflammation related genes both in the heart and the kidney, indicating an increase in oxidative stress and inflammation. More specifically, the expression of TNF- $\alpha$ and NOX4 was increased in both organs. NOX4 as well as cyclooxygenase 2 (COX2) have been recognized as important sources of ROS and play a role in the development of inflammatory diseases $[47,48]$. Furthermore, it has been demonstrated that NOX4 is a major source of ROS in the kidney of diabetic animals [49] and the production of ROS increases the transcription of NF-KB, causing an increase in the inflammatory response by enhanced transcription of pro-inflammatory genes such as TNF- $\alpha$ [50].

We hypothesized that n-acetyl cysteine (NAC) and fisetin may counteract the deleterious effects of the diabetic state. The intervention with fisetin and NAC during 24 weeks after induction of diabetes appeared to be capable of partially counteracting telomere shortening in both the heart and the kidney. 
Furthermore, intervention with fisetin resulted in a reduced expression of antioxidant genes and DNA repair genes in the kidney of diabetic rats when compared to the diabetic rats without intervention. This might be explained by the fact that fisetin is an antioxidant and an inhibitor of NFKB [23] and the DNArepair associated enzyme PARP1, which is also a co-activator of NFKB $[25,51,52]$. Flavonoids undergo extensive metabolism prior to entry in the systemic circulation. The liver is the main organ responsible for the biotransformation, but the kidney is also involved in their metabolism and excretion $[53,54]$. This may explain the effects of fisetin on gene expression in the kidney, which were not observed in the heart. In a similar study with diabetic rats, intervention with the flavonoid quercetin attenuated renal damage, by decreasing the level of oxidative stress, as measured by lipid peroxidation [55]. We observed a decrease in TIM1, indicating protective effects of fisetin on kidney function. A recent study also showed that PARP activation plays an important role in kidney disease in long-term diabetes type 1 , and that PARP inhibitors appear to be useful in the prevention and treatment of diabetic nephropathy [56].

Intervention with NAC did not induce significant changes in gene expression in heart, kidney and blood when compared to the diabetic group without intervention. Several intervention studies with STZ induced diabetic rats showed protective effects of NAC $[27,28,50,57,58]$. Most studies administered NAC at a dose of $1.5 \mathrm{~g} / \mathrm{kg}$ bodyweight, for eight weeks through the drinking water, which is approximately twice the dose received by rats in our study. Only one study performed a long-term intervention of 24 weeks [58]. These studies all reported that NAC lowered the glucose levels, inhibited lipid peroxidation, restored antioxidant activity and decreased inflammation related cytokines, such as TNF- $\alpha$. This was attributed to its free radical scavenging activity, leading to decreased levels of inflammation and oxidative stress $[27,28,50,57,58]$.

\section{Conclusions}

In summary, in our study significantly shorter telomeres were observed in the diabetic rat hearts and administration of both fisetin and NAC via the diet seemed to partially counteract this accelerated telomere shortening in heart. The diabetic status increased the expression of pro-inflammatory and oxidative stress related genes in heart and kidneys, indicating increased levels of 
oxidative stress in these organs. Although these are counteracted by the increased expression of DNA repair genes and antioxidant genes, still a significant reduction in TL in heart was found. Moreover, dietary intervention with fisetin and NAC was found to attenuate these responses. Dietary intervention with fisetin caused a significant decrease in the expression of antioxidant genes and DNA repair genes in the kidney of rats compared to de diabetic rats without intervention, possibly related to the role of kidneys in excretion and elimination of fisetin. In diabetic rats treated with NAC, transcription of inflammation associated genes in the kidney showed a tendency to be decreased when compared to diabetic rats without interventions, but this was not statistically significant. Results of this study provide evidence that antioxidant and anti-inflammatory dietary compounds can contribute to a reduction in oxidative stress and inflammatory conditions and a reduction in the rate of telomere shortening in the diabetic rat heart. Future studies should focus on evaluation of the effects of prolonged interventions with higher doses or measures that increase the biological availability of the administered compounds. This may provide more insight in the efficacy of treatment with dietary anti-oxidant and anti-inflammatory compounds on diabetes induced complications and accelerated aging. 


\section{References}

1. Devaraj S, Jialal I, Yun JM, Bremer A: Demonstration of increased toll-like receptor 2 and toll-like receptor 4 expression in monocytes of type 1 diabetes mellitus patients with microvascular complications. Metabolism 2010.

2. Szabo C: Role of nitrosative stress in the pathogenesis of diabetic vascular dysfunction. Br J Pharmacol 2009;156:713-727.

3. Yao D, Brownlee M: Hyperglycemia-Induced Reactive Oxygen Species Increase Expression of RAGE and RAGE Ligands. Diabetes 2009.

4. Hinokio $Y$, Suzuki S, Hirai M, Chiba M, Hirai A, Toyota T: Oxidative DNA damage in diabetes mellitus: its association with diabetic complications. Diabetologia 1999;42:995-998.

5. Roberts CK, Sindhu KK: Oxidative stress and metabolic syndrome. Life Sci 2009;84:705-712.

6. Oikawa S, Tada-Oikawa S, Kawanishi S: Site-specific DNA damage at the GGG sequence by UVA involves acceleration of telomere shortening. Biochemistry 2001;40:4763-4768.

7. Tarry-Adkins JL, Chen JH, Smith NS, Jones RH, Cherif H, Ozanne SE: Poor maternal nutrition followed by accelerated postnatal growth leads to telomere shortening and increased markers of cell senescence in rat islets. Faseb J 2009;23:1521-1528.

8. Blackburn EH: Structure and function of telomeres. Nature 1991;350:569-573.

9. Harley $C B$, Futcher $A B$, Greider $C W$ : Telomeres shorten during ageing of human fibroblasts. Nature 1990;345:458-460.

10. Harrington L: Those dam-aged telomeres! Curr Opin Genet Dev 2004;14:22-28.

11. Hayflick L: The Limited in Vitro Lifetime of Human Diploid Cell Strains. Exp Cell Res 1965;37:614-636.

12. von Zglinicki T: Oxidative stress shortens telomeres. Trends Biochem Sci 2002;27:339-344.

13. Greider CW, Blackburn EH: Telomeres, telomerase and cancer. Sci Am 1996;274:9297.

14. Joosten SA, van Ham V, Nolan CE, Borrias MC, Jardine AG, Shiels PG, van Kooten C, Paul LC: Telomere shortening and cellular senescence in a model of chronic renal allograft rejection. Am J Pathol 2003;162:1305-1312.

15. von Zglinicki T: Role of oxidative stress in telomere length regulation and replicative senescence. Ann N Y Acad Sci 2000;908:99-110.

16. Kawanishi S, Oikawa S: Mechanism of telomere shortening by oxidative stress. Ann N Y Acad Sci 2004;1019:278-284.

17. Sitte N, Saretzki G, von Zglinicki T: Accelerated telomere shortening in fibroblasts after extended periods of confluency. Free Radic Biol Med 1998;24:885-893. 
18. Adaikalakoteswari A, Balasubramanyam M, Ravikumar R, Deepa R, Mohan V: Association of telomere shortening with impaired glucose tolerance and diabetic macroangiopathy. Atherosclerosis 2007.

19. Astrup AS, Tarnow L, Jorsal A, Lajer M, Nzietchueng R, Benetos A, Rossing P, Parving $\mathrm{HH}$ : Telomere length predicts all-cause mortality in patients with type 1 diabetes. Diabetologia 2009.

20. Brouilette SW, Moore JS, McMahon AD, Thompson JR, Ford I, Shepherd J, Packard $\mathrm{CJ}$, Samani NJ: Telomere length, risk of coronary heart disease, and statin treatment in the West of Scotland Primary Prevention Study: a nested case-control study. Lancet 2007;369:107-114.

21. Houben JM, Mercken EM, Ketelslegers HB, Bast A, Wouters EF, Hageman GJ, Schols AM: Telomere shortening in chronic obstructive pulmonary disease. Respir Med 2009;103:230-236.

22. Salpea KD, Talmud PJ, Cooper JA, Maubaret CG, Stephens JW, Abelak K, Humphries $\mathrm{SE}$ : Association of telomere length with type 2 diabetes, oxidative stress and UCP2 gene variation. Atherosclerosis 2009.

23. de Sousa RR, Queiroz KC, Souza AC, Gurgueira SA, Augusto AC, Miranda MA, Peppelenbosch MP, Ferreira CV, Aoyama H: Phosphoprotein levels, MAPK activities and NFkappaB expression are affected by fisetin. J Enzyme Inhib Med Chem 2007;22:439-444.

24. Geraets L, Haegens A, Weseler AR, Brauers K, Vernooy JH, Wouters EF, Bast A, Hageman GJ: Inhibition of acute pulmonary and systemic inflammation by 1,7dimethylxanthine. Eur J Pharmacol 2009;629:132-139.

25. Geraets L, Moonen HJ, Brauers K, Wouters EF, Bast A, Hageman GJ: Dietary flavones and flavonoles are inhibitors of poly(ADP-ribose)polymerase-1 in pulmonary epithelial cells. J Nutr 2007;137:2190-2195.

26. Zheng L, Kern TS: Role of nitric oxide, superoxide, peroxynitrite and PARP in diabetic retinopathy. Front Biosci 2009;14:3974-3987.

27. Kamboj SS, Vasishta RK, Sandhir R: N-acetylcysteine inhibits hyperglycemia-induced oxidative stress and apoptosis markers in diabetic neuropathy. J Neurochem 2009;112:77-91.

28. Xia Z, Kuo KH, Nagareddy PR, Wang F, Guo Z, Guo T, Jiang J, McNeill JH: Nacetylcysteine attenuates PKCbeta2 overexpression and myocardial hypertrophy in streptozotocin-induced diabetic rats. Cardiovasc Res 2007;73:770-782.

29. Singh NP, McCoy MT, Tice RR, Schneider EL: A simple technique for quantitation of low levels of DNA damage in individual cells. Exp Cell Res 1988;175:184-191.

30. Knaapen AM, Schins RP, Borm PJ, van Schooten FJ: Nitrite enhances neutrophilinduced DNA strand breakage in pulmonary epithelial cells by inhibition of myeloperoxidase. Carcinogenesis 2005;26:1642-1648.

31. Cawthon RM: Telomere measurement by quantitative PCR. Nucleic Acids Res 2002;30:e47. 
32. Wong LS, Windt WA, Roks AJ, van Dokkum RP, Schoemaker RG, de Zeeuw D, Henning RH: Renal failure induces telomere shortening in the rat heart. Neth Heart J 2009;17:190-194.

33. Petersen S, Saretzki G, von Zglinicki T: Preferential accumulation of single-stranded regions in telomeres of human fibroblasts. Exp Cell Res 1998;239:152-160.

34. Mellor KM, Ritchie RH, Delbridge LM: Reactive Oxygen Species and Insulin Resistant Cardiomyopathy. Clin Exp Pharmacol Physiol 2009.

35. Lin J, Epel E, Cheon J, Kroenke C, Sinclair E, Bigos M, Wolkowitz O, Mellon S, Blackburn E: Analyses and comparisons of telomerase activity and telomere length in human $\mathrm{T}$ and $\mathrm{B}$ cells: insights for epidemiology of telomere maintenance. $\mathrm{J}$ Immunol Methods 2009;352:71-80.

36. Sliwinska A, Blasiak J, Kasznicki J, Drzewoski J: In vitro effect of gliclazide on DNA damage and repair in patients with type 2 diabetes mellitus (T2DM). Chem Biol Interact 2008;173:159-165.

37. Astley S, Langrish-Smith A, Southon S, Sampson M: Vitamin E supplementation and oxidative damage to DNA and plasma LDL in type 1 diabetes. Diabetes Care 1999;22:1626-1631.

38. Rytter E, Vessby B, Asgard R, Johansson C, Sjodin A, Abramsson-Zetterberg L, Moller L, Basu S: Glycaemic status in relation to oxidative stress and inflammation in well-controlled type 2 diabetes subjects. Br J Nutr 2009;101:1423-1426.

39. Maritim AC, Sanders RA, Watkins JB, 3rd: Diabetes, oxidative stress, and antioxidants: a review. J Biochem Mol Toxicol 2003;17:24-38.

40. Turkseven S, Kruger A, Mingone CJ, Kaminski P, Inaba M, Rodella LF, Ikehara S, Wolin MS, Abraham NG: Antioxidant mechanism of heme oxygenase-1 involves an increase in superoxide dismutase and catalase in experimental diabetes. Am J Physiol Heart Circ Physiol 2005;289:H701-707.

41. Soto C, Recoba R, Barron H, Alvarez C, Favari L: Silymarin increases antioxidant enzymes in alloxan-induced diabetes in rat pancreas. Comp Biochem Physiol $\mathrm{C}$ Toxicol Pharmacol 2003;136:205-212.

42. Sadi G, Guray T: Gene expressions of Mn-SOD and GPx-1 in streptozotocin-induced diabetes: effect of antioxidants. Mol Cell Biochem 2009;327:127-134.

43. Zhang H, Mizumachi T, Carcel-Trullols J, Li L, Naito A, Spencer HJ, Spring PM, Smoller BR, Watson AJ, Margison GP, Higuchi M, Fan CY: Targeting human 8oxoguanine DNA glycosylase (hOGG1) to mitochondria enhances cisplatin cytotoxicity in hepatoma cells. Carcinogenesis 2007;28:1629-1637.

44. Simone S, Gorin Y, Velagapudi C, Abboud HE, Habib SL: Mechanism of oxidative DNA damage in diabetes: tuberin inactivation and downregulation of DNA repair enzyme 8-oxo-7,8-dihydro-2'-deoxyguanosine-DNA glycosylase. Diabetes 2008;57:2626-2636. 
45. Madsen-Bouterse SA, Zhong Q, Mohammad G, Ho YS, Kowluru RA: Oxidative damage of mitochondrial DNA in diabetes and its protection by manganese superoxide dismutase. Free Radic Res 2010;44:313-321.

46. Hazra TK, Izumi T, Boldogh I, Imhoff B, Kow YW, Jaruga P, Dizdaroglu M, Mitra S: Identification and characterization of a human DNA glycosylase for repair of modified bases in oxidatively damaged DNA. Proc Natl Acad Sci U S A 2002;99:3523-3528.

47. Block K, Gorin Y, Abboud HE: Subcellular localization of Nox4 and regulation in diabetes. Proc Natl Acad Sci U S A 2009;106:14385-14390.

48. Murakami A, Ohigashi H: Targeting NOX, INOS and COX-2 in inflammatory cells: chemoprevention using food phytochemicals. Int J Cancer 2007;121:2357-2363.

49. Gorin Y, Block K, Hernandez J, Bhandari B, Wagner B, Barnes JL, Abboud HE: Nox4 $\mathrm{NAD}(\mathrm{P}) \mathrm{H}$ oxidase mediates hypertrophy and fibronectin expression in the diabetic kidney. J Biol Chem 2005;280:39616-39626.

50. Tsai GY, Cui JZ, Syed H, Xia Z, Ozerdem U, McNeill JH, Matsubara JA: Effect of Nacetylcysteine on the early expression of inflammatory markers in the retina and plasma of diabetic rats. Clin Experiment Ophthalmol 2009;37:223-231.

51. Kraus WL, Lis JT: PARP goes transcription. Cell 2003;113:677-683.

52. Veuger SJ, Hunter JE, Durkacz BW: Ionizing radiation-induced NF-kappaB activation requires PARP-1 function to confer radioresistance. Oncogene 2009;28:832-842.

53. Hollman PC, Katan MB: Health effects and bioavailability of dietary flavonols. Free Radic Res 1999;31 Suppl:S75-80.

54. Wang Y, Ho CT: Polyphenolic chemistry of tea and coffee: a century of progress. J Agric Food Chem 2009;57:8109-8114.

55. Anjaneyulu M, Chopra K: Quercetin, an anti-oxidant bioflavonoid, attenuates diabetic nephropathy in rats. Clin Exp Pharmacol Physiol 2004;31:244-248.

56. Shevalye $\mathrm{H}$, Maksimchyk $\mathrm{Y}$, Watcho P, I GO: Poly(ADP-ribose) polymerase-1 (PARP1) gene deficiency alleviates diabetic kidney disease. Biochim Biophys Acta 2010.

57. Kamboj SS, Chopra K, Sandhir R: Neuroprotective effect of N-acetylcysteine in the development of diabetic encephalopathy in streptozotocin-induced diabetes. Metab Brain Dis 2008;23:427-443.

58. Odetti P, Pesce C, Traverso N, Menini S, Maineri EP, Cosso L, Valentini S, Patriarca S, Cottalasso D, Marinari UM, Pronzato MA: Comparative trial of $\mathrm{N}$-acetyl-cysteine, taurine, and oxerutin on skin and kidney damage in long-term experimental diabetes. Diabetes 2003;52:499-505 




\section{Chapter 7}

\section{Summary and general discussion}
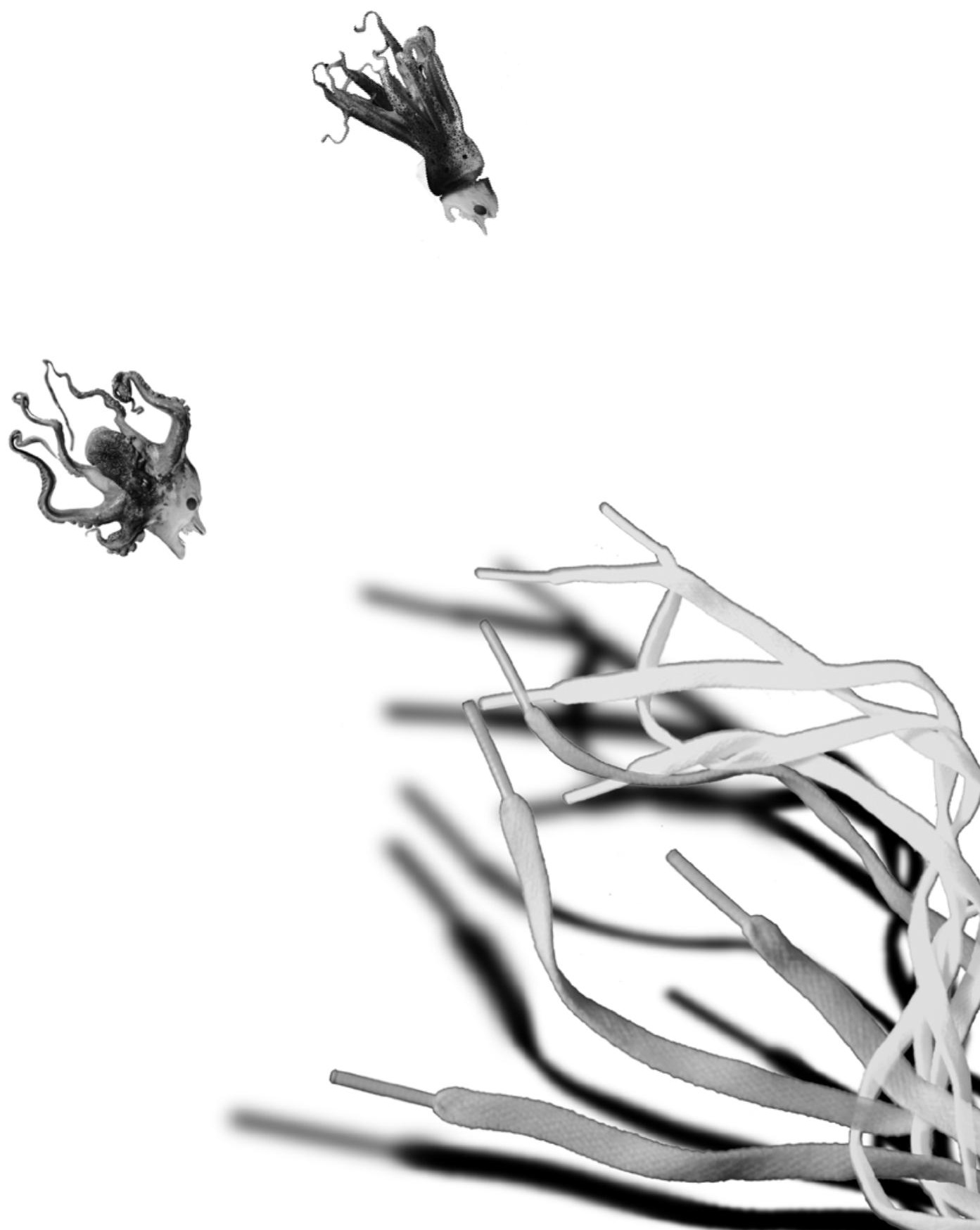
The major objective of the studies presented in this thesis was to examine the relationship between chronic oxidative stress and telomere shortening and the possible use of telomere length (TL) as a biological marker of aging, disease progression, and mortality.

To investigate this, we focussed in chapter $\mathbf{2}$ and $\mathbf{3}$ on the general population, whereas in chapter $\mathbf{4}$ and $\mathbf{5}$ the differences between healthy individuals and patients with chronic obstructive pulmonary disease (COPD) were studied. In chapter 6 we evaluated the effects of interventions with fisetin and $n$-acetylcysteine on telomere shortening and markers of oxidative stress in a diabetic rat model.

This general discussion will integrate the most important findings of this thesis and potential areas for future research will also be discussed.

\section{Main findings}

TL is influenced by several factors and besides the end-replication problem, oxidative stress appears to play an important role. High levels of oxidative stress increase the rate of shortening of the ends of the chromosomes and a good antioxidant status and antioxidant defence are hypothesized to decrease the rate of telomere shortening [1-3]. The most common sources of oxidative stress and inflammation are unhealthy nutrition, little exercise, obesity, chronic emotional stress and chronic diseases, such as atherosclerosis, inflammatory bowel disease, and diabetes, in which telomeres were hypothesized and confirmed to be shorter in patients suffering from such chronic inflammatory diseases [4-8]. Previous research showed that the incidences of several agingrelated chronic diseases were lower in Southern than Northern Europe, indicating a potential role for a higher antioxidant status and lower levels of oxidative stress in people living around the Mediterranean Sea [9-12]. For measurement of TL in DNA we applied a quantitative PCR technique. This technique is high-throughput, time-saving and requires only small amounts of DNA. We studied leukocyte TL (LTL) in elderly men from two different regions in Europe, from Zutphen (the Netherlands) and Crete (Greece). These groups were previously identified to differ with respect to lifestyle, and more specifically, they consume a different diet. We found that Greek elderly men had significantly longer LTL compared to their Dutch counterparts. The endogenous antioxidants albumin and uric acid were positively associated with longer 
telomeres. Dietary antioxidants including carotenoïds and tocopherols were not observed to be associated with LTL.

The next step was to measure LTL in the general elderly male population over a period of time. This would give us information on the individual rate of telomere shortening and the potential use of LTL as a marker for all-cause and disease specific mortality. We found that LTL declined with a mean of $40.2 \mathrm{bp}$ per year. We observed a good correlation between LTL in 1993 and 2000 for 75 men, but we could not confirm previous research showing that LTL is a marker for mortality. LTL was neither associated with the risk of cardiovascular disease mortality nor with cancer mortality. After studying the general population, we performed two different COPD - control studies. COPD is characterized by incompletely reversible airflow obstruction. Chronic systemic oxidative stress and inflammation play a major role in the pathophysiology of COPD [13-16]. In the first study we observed shorter LTL in COPD patients compared to healthy controls and also found a positive association between LTL and blood SOD activity and in COPD patients a modest positive association between LTL and fat mass. In the second study we additionally measured the cytokines IL-8, IL-6 and TNF- $\alpha$ as well as CRP, SOD and plasma homocysteine. Coffee, tea and alcohol consumption were also assessed in relation to inflammation and TL in lymphocytes. We found that COPD patients had shorter telomeres than their healthy counterparts, after adjusting for age. The best predictors of TL in the total study population (healthy controls as well as COPD patients included) were the presence of COPD, coffee consumption and IL-8. This study gives a first indication for the potential beneficial effects of coffee consumption and for negative effects of alcohol consumption on TL.

Finally we investigated the effects of dietary interventions on TL in a diabetic rat model. Rats were injected with streptozotocin to induce diabetes, a disease that is also accompanied by chronic oxidative stress $[17,18]$. The effect of fisetin, a flavonoid, and n-acetylcysteine, an antioxidant, administered via the food, was investigated. Several markers of oxidative stress were measured, $\mathrm{TL}$ was determined and gene expression of relevant genes was measured by quantitative PCR. We observed significantly shorter telomeres in the diabetic rat hearts, and both fisetin and NAC seemed to partially counteract this accelerated telomere shortening. The diabetic status increased the expression of antioxidant, DNA repair and inflammation related genes in heart and kidneys. 
Moreover, dietary intervention with fisetin and NAC reduced/attenuated these responses.

\section{Discussion and future directions}

Several aspects of the potential application of TL as a marker for disease progression and mortality and the potential protective effects of antioxidants, either taken as supplements or consumed with the diet, since these are present mostly in fruits and vegetables, require further discussion.

\section{Telomere length: marker for mortality?}

Cross-sectional studies have indicated that TL might be a relevant biomarker of disease progression and survival. However, this needs to be confirmed by longitudinal studies. To address these questions, we measured LTL in a prospective study (chapter $\mathbf{3}$ ) in male subjects from the Zutphen Elderly Study. TL was measured in 203 men in 1993 and 75 surviving subjects in 2000 . We found that LTL declined with a mean rate of 40.2 bp per year. We could not confirm previous research showing that TL is a marker for mortality. LTL was neither associated with the risk of cardiovascular disease mortality nor with cancer mortality in our study population. Likewise, three studies with similar study populations, e.g. elderly and the oldest old and similar follow-up periods, also found no association between LTL and mortality (bisschoff, martin-ruiz and nordfjall). A possible explanation for these negative findings might be that there is a higher degree of TL instability in the oldest old compared to younger populations, as we discussed in chapter $\mathbf{3}$, which makes elderly men over 70 years not representative of the younger population. Furthermore, as humans reach advanced age, a survival effect may modify associations with LTL [19]. Recent research confirms that people older than 86 years of age exhibit longer telomeres than younger individuals, suggesting that the rate of telomere attrition may be an important determinant of overall survival in the general population. The relatively older group may be affected by survival bias that selected out individuals with aging-related disease or those who would have died before reaching the age of 85 years, leaving the survivors with relatively longer telomeres [20]. Investigation into cellular mechanisms involved in telomere attrition across age groups might ultimately unravel the underlying mechanisms causing this difference. 


\section{Protection of telomeres by antioxidants?}

In chapter 2 we compared LTL in 109 Greek elderly men and in 143 Dutch elderly men. We aimed to compare LTL between these two European regions and to investigate the possible relationship between antioxidant status/oxidative stress levels and LTL within these two European regions that were previously found to have marked differences in oxidative stress status [912].

Greek elderly men had significantly longer LTL compared to their Dutch counterparts. In Greek men a positive association was found between LTL and plasma zeaxanthin and albumin, whereas in Dutch men a positive relationship was found with uric acid. When both groups were combined, albumin and uric acid levels remained positively correlated with LTL. Oxidative stress parameters could not be linked to LTL, except for hydroperoxides which were positively associated with LTL in Zutphen. High levels of the enzyme gamma-glutamyl transferase (GGT) are associated with an increased turnover of glutathione, indicating an increased antioxidant status [21]. However, when we determined the ratio between hydroperoxides and GGT we found that the increase in hydroperoxides was more pronounced than the increase in GGT in the men from Zutphen, indicating higher levels of oxidative stress. Although this was not expected, it is known that oxidant species can act as signalling molecules promoting cell survival [22]. If the concentration of hydroperoxides is high, oxidation processes may lead to irreversible damage, followed by cell death. However, hydroperoxides are also capable of inhibition of phosphatases that negatively regulate cell survival pathways [23], promoting cell survival. The data of our study indicate that endogenous antioxidants play an important role in protecting telomeres from shortening. In Greek men, also zeaxanthin was positively associated with LTL, indicating that dietary antioxidants additionally contribute to telomere stability. Several studies have reported positive associations between telomere length and the use of nutritional supplements such as vitamin C, E and folic acid [24-27]. Recently, omega-3 fatty acids have also been found to be inversely associated with the rate of telomere shortening over time [28].

Supplementation with omega-3 fatty acids has been associated with lower levels of F2-isoprostanes, an established standard for measurement of systemic oxidative stress, and with higher levels of the antioxidant enzymes catalase and superoxide dismutase [29]. Furthermore, daily supplementation 
with omega-3 fish oil, was associated with a significant increase in telomerase activity in normal adult human leukocytes [7].

To answer the question whether these supplements are also capable of reducing the mortality risk, prospective intervention studies with these supplements are required.

\section{TL as a marker of disease progression in COPD: what about nutrition?}

In chapter 4 we investigated LTL in COPD patients in relation to pulmonary function and disease severity, i.e. cachexia. Furthermore, based on experimental evidence suggesting the effects of oxidative stress on telomere shortening, we studied the association of LTL with the antioxidant enzyme superoxide dismutase (SOD). 102 COPD patients with moderate to severe COPD were studied and compared with 19 healthy age-matched controls. Patients were characterized by elevated levels of inflammatory markers (CRP, sTNFreceptors) and lower SOD-activity than healthy controls, irrespective of SOD genotype. LTL was negatively associated with age and was significantly shorter in COPD patients than in controls. Within the patient group age-adjusted LTL variability could not be explained by lung function and smoking history, but a modest association was found with the percentage of fat mass. These data provide evidence for a relationship between a disturbed oxidant/antioxidant balance and telomere shortening and indicate that preservation of fat mass may be protective in delaying telomere shortening in COPD patients.

In chapter 5 we investigated TL in COPD patients and healthy (ex)smoking controls in relation to oxidative stress and inflammation. The second aim of this study was to investigate the potential protective effects of caffeine, coffee and tea intake on TL in COPD patients and healthy (ex) smokers. For this purpose, we measured TL in PBMCs of 89 COPD patients and compared these with 93 healthy controls. In addition, the cytokines IL-8, IL-6 and TNF $\alpha$ were determined as well as CRP, SOD and plasma homocysteine. Coffee consumption, tea consumption, caffeine intake and alcohol consumption were assessed by a questionnaire.

We found that COPD patients had shorter TL than healthy controls, even after controlling for age. This study gives a first indication for the potential beneficial effects of coffee consumption and for negative effects of alcohol consumption on TL. Coffee consumption has been associated with reduced risks 
for type 2 diabetes [30,31] and the occurrence of diabetic complications, and it was proposed that coffee contains compounds with antioxidant and antiinflammatory activity [32-34]. Recently, Cassidy et al. showed that a diet high in cereal fiber was positively associated with LTL. They also concluded that a diet high in plant-based foods may favourably influence TL via anti-inflammatory and antioxidant mechanisms [35]. Other studies also indicated that a high intake of plant-based diets and whole grains is inversely associated with risk factors for chronic disease [36,37]. Interestingly, Ornish et al. showed that a healthy lifestyle (lifestyle modifications included a lowfat, plant-based diet high in fruits, vegetables, unrefined grains, legumes, and low in refined carbohydrates; moderate exercise and stress management) was associated with an increase in telomerase activity in PBMCs and that a decrease in LDL cholesterol was associated with an increase in telomerase activity [7]. In addition, statins, which exhibit anti-inflammatory effects, were also found to be capable of decreasing the cardiovascular risk and inhibit the rate of telomere shortening in vitro $[38,39]$. This indicates that a reduction of inflammation may be associated with a decrease the rate of telomere shortening. In our study, we also found that cytokine plasma levels as well as CRP and homocysteine plasma levels were increased in COPD patients and SOD activity was decreased, indicating elevated inflammation and oxidative stress in COPD patients. Future studies should elucidate whether interventions with dietary antioxidants or anti-inflammatory compounds, for instance with bioactive substances found in coffee, are able to reduce inflammation and oxidative stress, and reduce disease progression in patients with chronic inflammatory diseases.

It has to be taken into account that the studies described in chapter 4 and 5 differ in several aspects. First of all, in chapter $\mathbf{4}$, we measured TL in blood leukocytes whereas in chapter 5, we determined TL in PBMCs. Measurement of TL in leukocytes has been reported to be less accurate than in PBMCs, because PBMCs showed a greater age-related decline in $T L[40,41]$ and subpopulations of lymphocytes displayed differences in $T L$ and in telomerase activity [42]. However, a very recent study demonstrated that there is synchrony among leukocyte subsets throughout the human lifespan. It was found that individuals with long telomeres in one subset also have long telomeres in other leukocyte subsets. Therefore it was concluded that LTL is a useful index of TL in other subsets of blood cells [43]. 
Secondly, we did not find a relationship between fat mass and TL in chapter 5, whereas we did in chapter $\mathbf{4}$. Importantly to note here is that we studied quite different groups of COPD patients in both studies. In chapter $\mathbf{4}$, we studied TL in severely ill COPD patients with many of them having cachectic symptoms. In chapter 5 , the COPD group studied consisted of a more heterogeneous sample of the COPD population, with only few patients showing cachectic symptoms. Previous studies investigating the association between fat mass/obesity and COPD also found contradictory results. On the one hand it has been hypothesized that fat mass has a negative effect on the prognosis of COPD, but on the other hand it has also been speculated that fat mass may be protective [44-47]. Adipose tissue was found to produce over 50 adipokines, including TNF- $\alpha$ and IL-6, causing an enhanced inflammatory state [48], which is associated with the development of cardiovascular diseases and diabetes [49]. On the other hand, it has to be taken into account that body fat can be subdivided in visceral fat and subcutaneous fat. Unlike visceral fat, subcutaneous fat may confer survival advantages in patients subject to catabolic events such as infectious complications. It may therefore be hypothesized that subcutaneous fat provides greater energy stores, which protects against the risk of complications [50].

In both chapters $\mathbf{4}$ and $\mathbf{5}$ we did not find a relationship between smoking and TL, although this was expected since smoking is a major source of ROS. Previous studies also showed contradictory results. In some studies smoking was associated with shorter telomeres [51], but not in all [52], which may be explained that these studies may have been under powered to detect an association ( $n<1000$ participants). In studies with larger numbers of participants a small significant correlation has been observed between TL and smoking, and appears therefore likely that this relationship is only detectable in studies with sufficiently large sample sizes [53].

\section{Can dietary interventions with flavonoids or antioxidants attenuate the rate of telomere shortening?}

In chapter $\mathbf{6}$ the effects of the flavonoid fisetin and the antioxidant $\mathrm{n}$ acetylcysteine on telomere shortening in a diabetic rat model was described. Diabetes mellitus and hyperglycaemia cause severe damage to cells and tissues, especially the arteries and vital organs such as the kidneys and the heart. The 
disease is also marked by low grade inflammation and an increased production of reactive oxygen species leading to oxidative stress $[17,18]$.

Since diabetes is associated with chronic oxidative stress and accelerated aging, dietary interventions with antioxidants and/or anti-inflammatory agents were therefore hypothesized to decrease the levels of oxidative stress and slow the rate of aging. We also hypothesized that chronic oxidative stress and systemic inflammation in diabetes lead to an increased rate of telomere shortening and investigated the effects of dietary interventions with the antioxidant n-acetylcysteine (NAC) and the anti-inflammatory flavonoid fisetin, on oxidative stress, inflammation and the rate of telomere shortening. The effects of 24-week dietary interventions with fisetin and NAC on oxidative stress, inflammation and telomere shortening were evaluated in streptozotocininduced diabetic Wistar rats. We observed significantly shorter telomeres in the diabetic rat hearts, and both fisetin and NAC seemed to partially counteract this accelerated telomere shortening in the heart. The diabetic status increased the expression of antioxidant, DNA repair and inflammation related genes in heart and kidneys. Moreover, dietary intervention with fisetin and NAC attenuated these responses. Interestingly, in addition to its antioxidant and PARP-1 inhibiting activity, fisetin has also been identified as a sirtuin activator [54]. Sirtuins are deacetylases that are dependent on NAD+ for their activity. Calorie restriction, which increases lifespan and is beneficial in age-related disorders, was capable of activating sirtuins [55]. The nuclear sirtuin SIRT1 has been found to promote longevity mammalian cells in several ways [55]. SIRT1 was reported to down-regulate p53 activity, thereby increasing lifespan, cell survival, and neuroprotection [55]. This implies that not only the antioxidant and PARPinhibiting properties of fisetin may have an effect on TL and disease progression, but also its sirtuin activating property warrants further investigation.

Future studies should focus on evaluation of the effects of prolonged interventions with higher doses or measures that increase the biological availability of the administered compounds. Trials longer than 24 weeks in diabetic rats are probably not achievable, and not ethically approvable, since the health of these animals deteriorates significantly during 24 weeks. Although in human studies TL is mainly studied in white blood cells (WBC), animal studies usually only focus on target organs. To our knowledge we are the first to have measured TL in the WBC of rats, but we did not observe any effects on TL. A 
possible explanation may be that the effects of the diabetic status are more pronounced in target tissues such as heart and kidney as compared to WBC, which are for the greater part directly derived from the hematopoietic stem cells. Since these hematopoietic cells have been shown to possess telomerase activity, TL in WBC may be less sensitive for the effects of hyperglycemia [42]. Previous research also suggests a tissue-specific regulation of telomeres during aging in the rat [56]. Cherif et al. showed that the percentage of short telomeres increased with age in the kidney, liver, pancreas and lung, but not in the brain. The liver, kidney, pancreas and lung are expanding cell populations while the brain is a more static cell population [56]. Previous human as well as animal studies, showed that increased levels of oxidative stress, as in hypertension and hemodynamic stress, induced accelerated telomere shortening in arterial tissue, the aorta and in the myocardium [57-61]. In leukocyte DNA as well as in monocyte DNA, accelerated telomere shortening was found in type 2 diabetes patients [8,62]. Few studies have investigated telomere shortening in patients with type 1 diabetes and these results are not conclusive. Jeanclos et al. showed that TL in patients with diabetes type 1 was significantly shorter than TL in healthy control subjects [63]. In a study by Fyhrquist et al. no difference was found in TL between healthy controls and patients with diabetes type 1 , but patients with progressive nephropathy had the shortest telomeres [64]. On the contrary, in a study by Astrup et al., no difference was found in TL between diabetes type 1 patients with or without diabetic nephropathy [65]. Although we confirmed in our study the increased (tissue-specific) rate of telomere shortening in diabetes type 1 in a rat model, our knowledge on telomere shortening in patients with type 1diabetes is still limited.

\section{Does lifestyle matter?}

As discussed in chapter $\mathbf{2}$, Cretan men were approximately 5 years younger, in terms of LTL, when compared to their Dutch peers. Additionally in chapter $\mathbf{5}$ we reported that coffee consumption was associated with increased LTL, whereas alcohol consumption was associated with shorter telomeres. These data provide evidence for the hypothesis that lifestyle and dietary factors do influence TL and possibly also life expectancy. Besides nutritional factors [35] that are involved in the rate of telomere shortening, other environmental and lifestyle factors seem to play a pivotal role in telomere biology. Shortened 
telomeres have been associated with psychological stress [66], low physical activity levels [67], BMI [68,69], smoking [68,69] and socioeconomic status [51]. In addition to lifestyle, genetic background also plays a role in telomere maintenance as will be discussed in the last section of this discussion.

\section{Telomerase in (accelerated) aging and gene-environment interactions}

Although we did not measure telomerase activity in our studies, it may also play a role in healthy ageing as well as in accelerated aging.

It has been shown that stress and senescence can influence telomerase levels in lymphocytes $[70,71]$. Changes in telomerase activity in cell types such as lymphocytes, endothelial cells and tissue stem/progenitor cells could influence processes relevant for healthy ageing. Importantly, even lifestyle factors known to promote cancer and cardiovascular disease could affect telomerase function. Recently, it has been shown in a longitudinal study that improvements in nutrition and lifestyle were associated with increases in telomerase activity which were associated with decreases in low-density lipoprotein cholesterol and psychological distress [7]. Thus, comprehensive lifestyle changes could significantly increase telomerase activity, stabilise telomeres and decrease oxidative stress within tissues and organs [72]. In addition to telomerase activity, it is likely that many of the proteins that are important in regulating $T L$ and function, such as the telomere repeat binding factors, and proteins involved in DNA repair, will also have an important role in healthy/accelerated aging since they can regulate the action of telomerase at telomeres [73].

Furthermore, variations in the two major genes associated with telomerase activity, hTERT and hTERC, have been described. Atzmon et al. identified a common hTERT haplotype that is associated with both exceptional longevity and longer telomeres. They concluded that variations in the telomerase gene are associated with a better maintenance of the telomeres which may be associated with healthier aging [20]. On the other hand, there have also been several mutations (hTERT, hTERC and in dyskerin gene 1) described that cause telomerase deficiencies, which results in failure to elongate or maintain telomeres and induce progressive shortening [40].

Not only telomerase activity, but also TL appears to be partly genetically determined $[74,75]$. In a study by Nordfjäll et al., TL was investigated in PBMCs 
of 132 individuals from 49 unrelated families using quantitative PCR. A statistically significant association between TL comparing father-son $(P=0.011$, $n=20)$ and father-daughter $(P=0.005, n=22)$ pairs was found while this was not found in mother-offspring pairs. In this study a relationship between TL and genetics was demonstrated, and evidence for a father-to-offspring heritage was obtained [75]. More evidence for genetic factors influencing TL was obtained from a study by Okuda et al. In this study, TL was determined by Southern blot analysis in white blood cells from newborns. TL was not different between male and female newborns, but there was a high variability among donors. This indicates that variations among adults may be in large part attributed to genetic determinants that probably start exerting their effect in utero [76]. In a twinstudy by Slagboom et al., TL was determined by Southern blot analysis in 123 twin pairs, both dizygous and monozygous twins of 2-95 years of age. Statistical analysis in 115 pairs, 2-63 years of age, indicated a $78 \%$ heritability for mean TL in this age cohort. Telomeric restriction fragment length variation among unrelated individuals was higher than variation within twin pairs, and the variation within monozygous twins was observed to be least [77]. In conclusion, TL appears to be a highly heritable trait.

Since there is quite some variation in TL among individuals of the same age, polymorphisms in genes associated with telomere maintenance, oxidative stress and DNA repair were hypothesized to be involved in TL regulation. In a study by Broberg et al., polymorphisms in genes involved in the metabolism of genotoxic carcinogens and DNA repair were determined in the DNA of patients with bladder cancer and in the DNA of control subjects. In this study no association was found between cancer risk, TL, smoking and susceptibility genotypes [78]. In a recent study by Starr et al., it was found that some polymorphisms related to oxidative stress are also linked to increased telomere shortening [79]. The related genes in which polymorphisms were found included: 2 mitochondrial genes, heme oxygenase 2, vimentin (stress response), ceruloplasmin (involved in the catalyzation of $\mathrm{Fe} 2+$ to $\mathrm{Fe} 3+$ ), methionine sulfoxide reductase $A$, lipoprotein carriage gene and nitric oxide synthase 3 [79]. It can be concluded that the clinical manifestation of inflammation/oxidative stress related diseases depends on several factors, among which inherited TL and telomerase activity, exposure of specific tissues to pathogens (i.e. oxidative damage), and tissue-specific genetic alterations that result in an increase in cellular turnover. 


\section{Conclusions}

Based on the results presented in this thesis, it can be concluded that telomeres shorten faster under conditions of chronic inflammation and oxidative stress. Furthermore, we showed that endogenous antioxidants, exogenous antioxidants as well as foods containing antioxidants are associated with reduced telomere shortening. This was found in elderly male populations, in COPD patients and in diabetic rats. We conclude that lifestyle factors do not only contribute to disease risk, but also affect TL. To confirm our results and to investigate the potential beneficial effects of antioxidants and antiinflammatory compounds, either administered as supplements, or consumed with the diet, on the rate of telomere shortening, future studies should focus on interventions with these compounds. Preferably these studies should be prospective, and genetic determinants should also be taken into account. Since beneficial effects may be expected specifically in patients with chronic oxidative stress, such as COPD and diabetes patients, these are considered relevant target populations. If future studies can confirm that $T L$ is causally involved in the development and progression of these age-associated diseases, it will pave the way for new therapeutic or preventive strategies. 


\section{References}

1. von Zglinicki T: Role of oxidative stress in telomere length regulation and replicative senescence. Ann N Y Acad Sci 2000;908:99-110.

2. von Zglinicki T, Martin-Ruiz C, Saretzki G: Telomeres, cell senescence and human ageing. Signal Transduction 2005;3.

3. von Zglinicki T, Martin-Ruiz CM: Telomeres as biomarkers for ageing and agerelated diseases. Curr Mol Med 2005;5:197-203.

4. Adaikalakoteswari A, Balasubramanyam M, Mohan V: Telomere shortening occurs in Asian Indian Type 2 diabetic patients. Diabet Med 2005;22:1151-1156.

5. Benetos A, Gardner JP, Zureik M, Labat C, Xiaobin L, Adamopoulos C, Temmar M, Bean KE, Thomas F, Aviv A: Short telomeres are associated with increased carotid atherosclerosis in hypertensive subjects. Hypertension 2004;43:182-185.

6. Getliffe KM, Martin Ruiz C, Passos JF, von Zglinicki T, Nwokolo CU: Extended lifespan and long telomeres in rectal fibroblasts from late-onset ulcerative colitis patients. Eur J Gastroenterol Hepatol 2006;18:133-141.

7. Ornish D, Lin J, Daubenmier J, Weidner G, Epel E, Kemp C, Magbanua MJ, Marlin R, Yglecias L, Carroll PR, Blackburn EH: Increased telomerase activity and comprehensive lifestyle changes: a pilot study. Lancet Oncol 2008;9:1048-1057.

8. Sampson MJ, Winterbone MS, Hughes JC, Dozio N, Hughes DA: Monocyte telomere shortening and oxidative DNA damage in type 2 diabetes. Diabetes Care 2006;29:283-289.

9. Buijsse B, Feskens EJ, Moschandreas J, Jansen EH, Jacobs DR, Jr., Kafatos A, Kok FJ, Kromhout $\mathrm{D}$ : Oxidative stress, and iron and antioxidant status in elderly men: differences between the Mediterranean south (Crete) and northern Europe (Zutphen). Eur J Cardiovasc Prev Rehabil 2007;14:495-500.

10. Lindsay DG, Astley SB: European research on the functional effects of dietary antioxidants - EUROFEDA. Mol Aspects Med 2002;23:1-38.

11. Olmedilla B, Granado F, Southon S, Wright AJ, Blanco I, Gil-Martinez E, Berg H, Corridan B, Roussel AM, Chopra M, Thurnham DI: Serum concentrations of carotenoids and vitamins $A, E$, and $C$ in control subjects from five European countries. Br J Nutr 2001;85:227-238.

12. Parfitt VJ, Rubba P, Bolton C, Marotta G, Hartog M, Mancini M: A comparison of antioxidant status and free radical peroxidation of plasma lipoproteins in healthy young persons from Naples and Bristol. Eur Heart J 1994;15:871-876.

13. Boots AW, Haenen GR, Bast A: Oxidant metabolism in chronic obstructive pulmonary disease. Eur Respir J Suppl 2003;46:14s-27s.

14. Rahman I, Gilmour PS, Jimenez LA, MacNee W: Oxidative stress and TNF-alpha induce histone acetylation and NF-kappaB/AP-1 activation in alveolar epithelial 
cells: potential mechanism in gene transcription in lung inflammation. Mol Cell Biochem 2002;234-235:239-248.

15. Stockley RA, Mannino D, Barnes PJ: Burden and pathogenesis of chronic obstructive pulmonary disease. Proc Am Thorac Soc 2009;6:524-526.

16. Yao H, Rahman I: Current concepts on the role of inflammation in COPD and lung cancer. Curr Opin Pharmacol 2009;9:375-383.

17. Szabo C: Role of nitrosative stress in the pathogenesis of diabetic vascular dysfunction. Br J Pharmacol 2009;156:713-727.

18. Yao D, Brownlee M: Hyperglycemia-Induced Reactive Oxygen Species Increase Expression of RAGE and RAGE Ligands. Diabetes 2009.

19. Fitzpatrick AL, Kronmal RA, Gardner JP, Psaty BM, Jenny NS, Tracy RP, Walston J, Kimura M, Aviv A: Leukocyte telomere length and cardiovascular disease in the cardiovascular health study. Am J Epidemiol 2007;165:14-21.

20. Atzmon G, Cho M, Cawthon RM, Budagov T, Katz M, Yang X, Siegel G, Bergman A, Huffman DM, Schechter CB, Wright WE, Shay JW, Barzilai N, Govindaraju DR, Suh Y: Genetic variation in human telomerase is associated with telomere length in Ashkenazi centenarians. Proc Natl Acad Sci U S A 2009.

21. Klings ES, Lowry MH, Li G, Jean JC, Fernandez BO, Garcia-Saura MF, Feelisch M, Joyce-Brady M: Hyperoxia-induced lung injury in gamma-glutamyl transferase deficiency is associated with alterations in nitrosative and nitrative stress. Am J Pathol 2009;175:2309-2318.

22. Mackey AM, Sanvicens N, Groeger G, Doonan F, Wallace D, Cotter TG: Redox survival signalling in retina-derived $661 \mathrm{~W}$ cells. Cell Death Differ 2008;15:12911303.

23. Groeger G, Quiney C, Cotter TG: Hydrogen peroxide as a cell-survival signaling molecule. Antioxid Redox Signal 2009;11:2655-2671.

24. Furumoto K, Inoue E, Nagao N, Hiyama E, Miwa N: Age-dependent telomere shortening is slowed down by enrichment of intracellular vitamin $\mathrm{C}$ via suppression of oxidative stress. Life Sci 1998;63:935-948.

25. Paul L, Cattaneo M, D'Angelo A, Sampietro F, Fermo I, Razzari C, Fontana G, Eugene $\mathrm{N}$, Jacques PF, Selhub J: Telomere length in peripheral blood mononuclear cells is associated with folate status in men. J Nutr 2009;139:1273-1278.

26. Tanaka H, Mendonca MS, Bradshaw PS, Hoelz DJ, Malkas LH, Meyn MS, Gilley D: DNA damage-induced phosphorylation of the human telomere-associated protein TRF2. Proc Natl Acad Sci U S A 2005.

27. Xu Q, Parks CG, DeRoo LA, Cawthon RM, Sandler DP, Chen H: Multivitamin use and telomere length in women. Am J Clin Nutr 2009;89:1857-1863.

28. Farzaneh-Far R, Cawthon RM, Na B, Browner WS, Schiller NB, Whooley MA: Prognostic value of leukocyte telomere length in patients with stable coronary artery disease: data from the Heart and Soul Study. Arterioscler Thromb Vasc Biol 2008;28:1379-1384. 
29. Jolly CA, Muthukumar A, Avula CP, Troyer D, Fernandes G: Life span is prolonged in food-restricted autoimmune-prone (NZB $\times$ NZW)F(1) mice fed a diet enriched with (n-3) fatty acids. J Nutr 2001;131:2753-2760.

30. Tunnicliffe JM, Shearer J: Coffee, glucose homeostasis, and insulin resistance: physiological mechanisms and mediators. Appl Physiol Nutr Metab 2008;33:12901300.

31. van Dieren S, Uiterwaal CS, van der Schouw YT, van der AD, Boer JM, Spijkerman A, Grobbee DE, Beulens JW: Coffee and tea consumption and risk of type 2 diabetes. Diabetologia 2009.

32. Daglia M, Papetti A, Aceti C, Sordelli B, Gregotti C, Gazzani G: Isolation of high molecular weight components and contribution to the protective activity of coffee against lipid peroxidation in a rat liver microsome system. J Agric Food Chem 2008;56:11653-11660.

33. Moura-Nunes N, Perrone D, Farah A, Donangelo CM: The increase in human plasma antioxidant capacity after acute coffee intake is not associated with endogenous non-enzymatic antioxidant components. Int J Food Sci Nutr 2009:1-9.

34. Ranheim T, Halvorsen B: Coffee consumption and human health--beneficial or detrimental?--Mechanisms for effects of coffee consumption on different risk factors for cardiovascular disease and type 2 diabetes mellitus. Mol Nutr Food Res 2005;49:274-284.

35. Cassidy A, De Vivo I, Liu Y, Han J, Prescott J, Hunter DJ, Rimm EB: Associations between diet, lifestyle factors, and telomere length in women. Am J Clin Nutr 2010;91:1273-1280.

36. Newby PK, Maras J, Bakun P, Muller D, Ferrucci L, Tucker KL: Intake of whole grains, refined grains, and cereal fiber measured with 7-d diet records and associations with risk factors for chronic disease. Am J Clin Nutr 2007;86:1745-1753.

37. Qi L, Hu FB: Dietary glycemic load, whole grains, and systemic inflammation in diabetes: the epidemiological evidence. Curr Opin Lipidol 2007;18:3-8.

38. Brouilette SW, Moore JS, McMahon AD, Thompson JR, Ford I, Shepherd J, Packard $\mathrm{CJ}$, Samani NJ: Telomere length, risk of coronary heart disease, and statin treatment in the West of Scotland Primary Prevention Study: a nested case-control study. Lancet 2007;369:107-114.

39. Satoh M, Minami Y, Takahashi Y, Tabuchi T, Itoh T, Nakamura M: Effect of intensive lipid-lowering therapy on telomere erosion in endothelial progenitor cells obtained from patients with coronary artery disease. Clin Sci (Lond) 2009;116:827-835.

40. Aubert G, Lansdorp PM: Telomeres and aging. Physiol Rev 2008;88:557-579.

41. Greenwood MJ, Lansdorp PM: Telomeres, telomerase, and hematopoietic stem cell biology. Arch Med Res 2003;34:489-495.

42. Lin J, Epel E, Cheon J, Kroenke C, Sinclair E, Bigos M, Wolkowitz O, Mellon S, Blackburn E: Analyses and comparisons of telomerase activity and telomere length 
in human T and B cells: insights for epidemiology of telomere maintenance. J Immunol Methods 2009;352:71-80.

43. Kimura M, Gazitt Y, Cao X, Zhao X, Lansdorp PM, Aviv A: Synchrony of telomere length among hematopoietic cells. Experimental Hematology 2010.

44. Celli BR, MacNee W: Standards for the diagnosis and treatment of patients with COPD: a summary of the ATS/ERS position paper. Eur Respir J 2004;23:932-946.

45. Landbo C, Prescott E, Lange P, Vestbo J, Almdal TP: Prognostic value of nutritional status in chronic obstructive pulmonary disease. Am J Respir Crit Care Med 1999;160:1856-1861.

46. Schols AM, Broekhuizen R, Weling-Scheepers CA, Wouters EF: Body composition and mortality in chronic obstructive pulmonary disease. Am J Clin Nutr 2005;82:5359.

47. Vestbo J, Prescott E, Almdal T, Dahl M, Nordestgaard BG, Andersen T, Sorensen TI, Lange P: Body mass, fat-free body mass, and prognosis in patients with chronic obstructive pulmonary disease from a random population sample: findings from the Copenhagen City Heart Study. Am J Respir Crit Care Med 2006;173:79-83.

48. Sood A: Obesity, adipokines, and lung disease. J Appl Physiol 2010;108:744-753.

49. Poulain M, Doucet M, Drapeau V, Fournier G, Tremblay A, Poirier P, Maltais F: Metabolic and inflammatory profile in obese patients with chronic obstructive pulmonary disease. Chron Respir Dis 2008;5:35-41.

50. Bouillanne O, Dupont-Belmont C, Hay P, Hamon-Vilcot B, Cynober L, Aussel C: Fat mass protects hospitalized elderly persons against morbidity and mortality. Am J Clin Nutr 2009;90:505-510.

51. Cherkas LF, Aviv A, Valdes AM, Hunkin JL, Gardner JP, Surdulescu GL, Kimura M, Spector TD: The effects of social status on biological aging as measured by whiteblood-cell telomere length. Aging Cell 2006;5:361-365.

52. Bischoff C, Petersen HC, Graakjaer J, Andersen-Ranberg K, Vaupel JW, Bohr VA, Kolvraa S, Christensen K: No association between telomere length and survival among the elderly and oldest old. Epidemiology 2006;17:190-194.

53. Mirabello L, Huang WY, Wong JY, Chatterjee N, Reding D, Crawford ED, De Vivo I, Hayes RB, Savage SA: The association between leukocyte telomere length and cigarette smoking, dietary and physical variables, and risk of prostate cancer. Aging Cell 2009;8:405-413.

54. Wood JG, Rogina B, Lavu S, Howitz K, Helfand SL, Tatar M, Sinclair D: Sirtuin activators mimic caloric restriction and delay ageing in metazoans. Nature 2004;430:686-689.

55. Haigis MC, Sinclair DA: Mammalian sirtuins: biological insights and disease relevance. Annu Rev Pathol;5:253-295.

56. Cherif H, Tarry JL, Ozanne SE, Hales CN: Ageing and telomeres: a study into organand gender-specific telomere shortening. Nucleic Acids Res 2003;31:1576-1583. 
57. Cao Y, Li H, Mu FT, Ebisui O, Funder JW, Liu JP: Telomerase activation causes vascular smooth muscle cell proliferation in genetic hypertension. Faseb J 2002;16:96-98.

58. Chang $\mathrm{E}$, Harley $\mathrm{CB}$ : Telomere length and replicative aging in human vascular tissues. Proc Natl Acad Sci U S A 1995;92:11190-11194.

59. Hamet $P$, Thorin-Trescases N, Moreau P, Dumas P, Tea BS, deBlois D, Kren V, Pravenec $M$, Kunes J, Sun $Y$, Tremblay J: Workshop: excess growth and apoptosis: is hypertension a case of accelerated aging of cardiovascular cells? Hypertension 2001;37:760-766.

60. Minamino T, Miyauchi H, Yoshida T, Ishida Y, Yoshida H, Komuro I: Endothelial cell senescence in human atherosclerosis: role of telomere in endothelial dysfunction. Circulation 2002;105:1541-1544.

61. Serrano AL, Andres V: Telomeres and cardiovascular disease: does size matter? Circ Res 2004;94:575-584.

62. Zee RY, Castonguay AJ, Barton NS, Germer S, Martin M: Mean leukocyte telomere length shortening and type 2 diabetes mellitus: a case-control study. Transl Res 2010;155:166-169.

63. Jeanclos E, Krolewski A, Skurnick J, Kimura M, Aviv H, Warram JH, Aviv A: Shortened telomere length in white blood cells of patients with IDDM. Diabetes 1998;47:482486.

64. Fyhrquist F, Tiitu A, Saijonmaa O, Forsblom C, Groop PH: Telomere length and progression of diabetic nephropathy in patients with type 1 diabetes. J Intern Med 2010;267:278-286.

65. Astrup AS, Tarnow L, Jorsal A, Lajer M, Nzietchueng R, Benetos A, Rossing P, Parving $\mathrm{HH}$ : Telomere length predicts all-cause mortality in patients with type 1 diabetes. Diabetologia 2009.

66. Epel ES, Blackburn EH, Lin J, Dhabhar FS, Adler NE, Morrow JD, Cawthon RM: Accelerated telomere shortening in response to life stress. Proc Natl Acad Sci U S A 2004;101:17312-17315.

67. Cherkas LF, Hunkin JL, Kato BS, Richards JB, Gardner JP, Surdulescu GL, Kimura M, Lu X, Spector TD, Aviv A: The association between physical activity in leisure time and leukocyte telomere length. Arch Intern Med 2008;168:154-158.

68. Nawrot TS, Staessen JA, Gardner JP, Aviv A: Telomere length and possible link to X chromosome. Lancet 2004;363:507-510.

69. Valdes AM, Andrew T, Gardner JP, Kimura M, Oelsner E, Cherkas LF, Aviv A, Spector TD: Obesity, cigarette smoking, and telomere length in women. Lancet 2005;366:662-664.

70. Plunkett FJ, Franzese O, Finney HM, Fletcher JM, Belaramani LL, Salmon M, Dokal I, Webster D, Lawson AD, Akbar AN: The loss of telomerase activity in highly differentiated CD8+CD28-CD27- T cells is associated with decreased Akt (Ser473) phosphorylation. J Immunol 2007;178:7710-7719. 
71. Porton B, Delisi LE, Bertisch HC, Ji F, Gordon D, Li P, Benedict MM, Greenberg WM, Kao HT: Telomerase levels in schizophrenia: a preliminary study. Schizophr Res 2008;106:242-247.

72. Saretzki G: Telomerase, mitochondria and oxidative stress. Exp Gerontol 2009;44:485-492.

73. Blasco MA: Mice with bad ends: mouse models for the study of telomeres and telomerase in cancer and aging. Embo J 2005;24:1095-1103.

74. Cawthon RM, Smith KR, O'Brien E, Sivatchenko A, Kerber RA: Association between telomere length in blood and mortality in people aged 60 years or older. Lancet 2003;361:393-395.

75. Nordfjall K, Larefalk A, Lindgren P, Holmberg D, Roos G: Telomere length and heredity: Indications of paternal inheritance. Proc Natl Acad Sci U S A 2005;102:16374-16378.

76. Okuda K, Bardeguez A, Gardner JP, Rodriguez P, Ganesh V, Kimura M, Skurnick J, Awad G, Aviv A: Telomere length in the newborn. Pediatr Res 2002;52:377-381.

77. Slagboom PE, Droog S, Boomsma DI: Genetic determination of telomere size in humans: a twin study of three age groups. Am J Hum Genet 1994;55:876-882.

78. Broberg K, Bjork J, Paulsson K, Hoglund M, Albin M: Constitutional short telomeres are strong genetic susceptibility markers for bladder cancer. Carcinogenesis 2005;26:1263-1271.

79. Starr JM, Shiels PG, Harris SE, Pattie A, Pearce MS, Relton CL, Deary IJ: Oxidative stress, telomere length and biomarkers of physical aging in a cohort aged 79 years from the 1932 Scottish Mental Survey. Mech Ageing Dev 2008;129:745-751. 



\section{Nederlandse samenvatting}
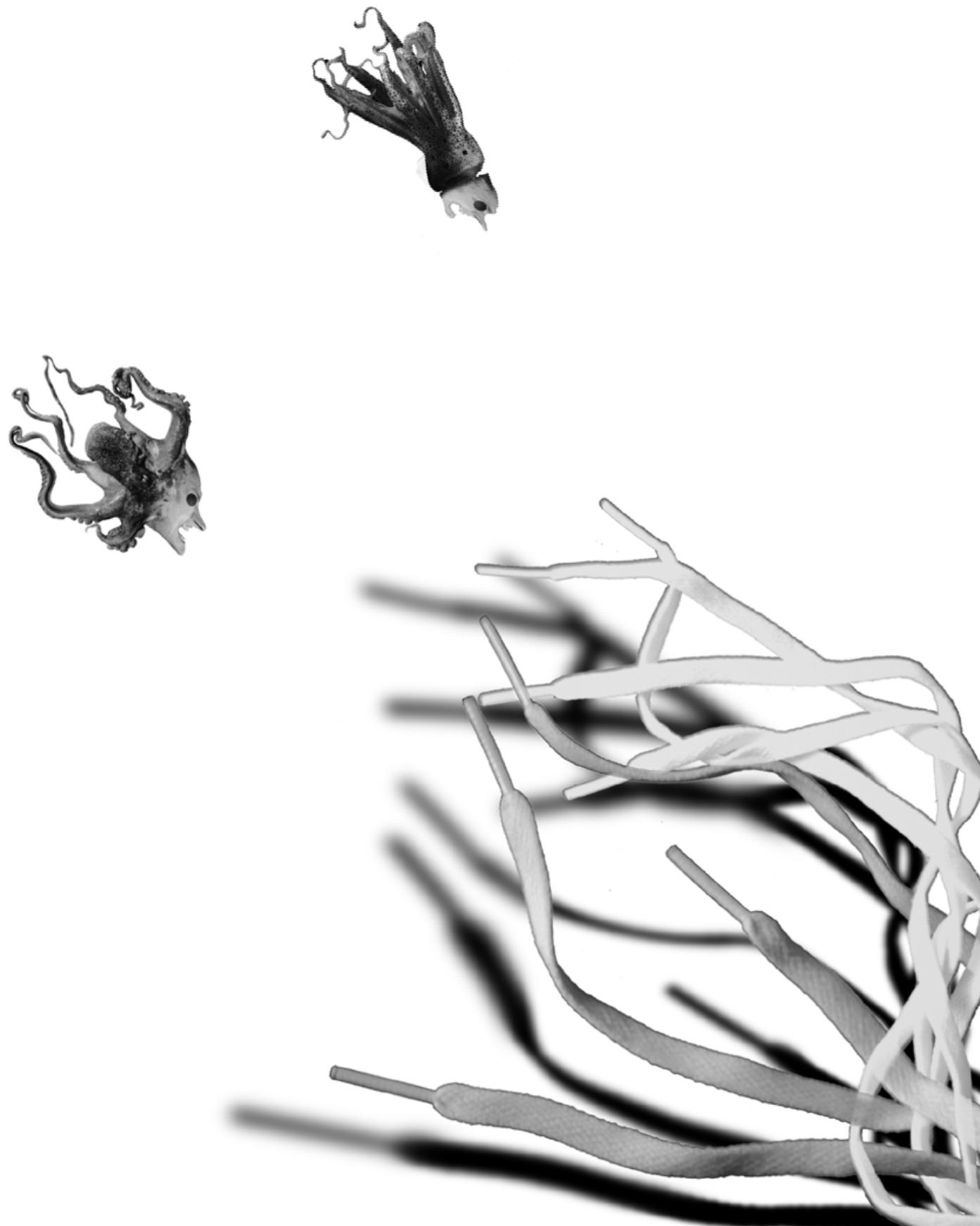
Dit proefschrift beschrijft de relatie tussen chronisch oxidatieve stress en telomeerverkorting, en de mogelijke effecten van voedingsinterventies op deze relatie. Telomeren zijn de uiteinden van onze chromosomen en ze verkorten met elke celdeling. De hypothese die in dit proefschrift is onderzocht luidt: onder condities van chronische oxidatieve stress vindt er een versnelde telomeerverkorting plaats wat leidt tot versnelde veroudering en ouderdomsgerelateerde aandoeningen.

Om dit te onderzoeken, hebben we ons in hoofdstuk 2 en $\mathbf{3}$ gericht op de algemene (oudere) populatie. Vervolgens hebben we in hoofdstuk $\mathbf{4}$ en $\mathbf{5}$ de verschillen tussen gezonde mensen en mensen met chronisch obstructief longlijden (COPD) bestudeerd. In hoofdstuk 6 hebben we gekeken naar de effecten van voedingsinterventies met fisetine en $n$-acteylcysteine op telomeerverkorting en markers voor oxidatieve stress in een diermodel (diabete ratten).

\section{Belangrijkste bevindingen}

De telomeerlengte (TL) wordt door verschillende factoren beïnvloed. Naast het zogenaamde "end-replication problem" lijkt oxidatieve stress/schade ook een belangrijke rol te spelen. Hoge concentraties van deze oxidatieve stress, oftewel DNA beschadigende deeltjes, zorgen voor een versnelde verkorting van de uiteinden van de chromosomen. Daarom wordt er ook wel gedacht dat een goede antioxidant status en antioxidant verdediging in het lichaam deze versnelde verkorting tegen kan gaan. Aangezien oxidatieve stress betrokken is bij een heleboel chronische ziekten, zoals hart- en vaatziekten, diabetes, chronische darmziekten en COPD, werd er gespeculeerd en bevestigd dat de telomeren korter zijn bij patiënten die aan deze ziektes lijden. Uit voorgaand onderzoek is gebleken dat de incidentie van verscheidene ouderdomsgerelateerde aandoeningen lager is in het zuiden van Europa dan in het noorden. Dit impliceert een potentiële rol voor een hogere antioxidant status en lagere niveaus van oxidatieve stress in mensen die leven rond het Middellandse Zee gebied. Om de TL te kunnen bepalen in het DNA, maakten we gebruik van de zogenaamde kwantitatieve PCR techniek. Deze techniek is niet alleen snel, maar er kunnen ook veel monsters tegelijk gemeten worden en er zijn slechts kleine hoeveelheden DNA nodig. Allereerst bestudeerden we in hoofdstuk 2 de TL in leukocyten (LTL) in oudere mannen uit 2 verschillende regio's in Europa: Zutphen (Nederland) en Kreta (Griekenland). Van deze 2 
groepen is bekend dat ze een verschillende leefstijl en voeding hebben. In deze studie vonden wij dat Griekse oudere mannen duidelijk langere telomeren hadden dan hun Nederlands leeftijdsgenoten. Verder vonden we ook dat de endogene antioxidanten, albumine en urinezuur, positief geassocieerd waren met LTL.

De volgende stap was om LTL te meten in de algemene oudere mannelijke populatie over de tijd (hoofdstuk 3). Dit zou ons informatie kunnen verschaffen over de individuele snelheid waarmee de telomeren verkorten, en de mogelijkheid om LTL te gebruiken als een marker voor (ziekte specifieke) mortaliteit. Uit de resultaten van deze studie bleek, dat LTL afnam met 40.2 bp per jaar en dat LTL niet was geassocieerd met cardiovasculaire mortaliteit en ook niet met mortaliteit door kanker.

In hoofdstuk $\mathbf{4}$ en $\mathbf{5}$ hebben we TL in 2 COPD-controle studies onderzocht. COPD wordt gekenmerkt door obstructie van de luchtwegen en is een verzamelnaam voor chronische bronchitis en longemfyseem. Chronische systemische oxidatieve stress en ontstekingsreacties spelen hierin een grote rol. In hoofdstuk 4 zagen we dat COPD patiënten kortere telomeren hadden dan de gezonde controles en we vonden een positieve associatie tussen LTL en SOD activiteit (een antioxidant die in het lichaam voorkomt) en vetmassa. In hoofdstuk 5 hebben we een aantal extra bepalingen gedaan, waaronder de cytokines IL-8, IL-6 en TNF- $\alpha$, als ook CRP, SOD en plasma homocysteine. Verder hebben we gekeken naar koffie, thee en alcoholconsumptie in relatie tot inflammatie en TL. We zagen dat er een negatieve associatie bestond tussen TL en COPD en we toonden aan dat koffie consumptie mogelijk positief geassocieerd was met TL, terwijl alcohol consumptie negatief geassocieerd was met TL. In het laatste hoofdstuk hebben we de effecten van voedingsinterventies op TL bestudeerd in een diabetisch ratten model. De ratten werden geïnjecteerd met streptozotocine, waardoor diabetes werd geïnduceerd, een aandoening die gekenmerkt wordt door chronisch oxidatieve stress. De effecten van fisetine, een flavonoid, en n-acetylcysteine (NAC), een antioxidant, werden onderzocht. Verschillende markers van oxidatieve stress werden gemeten, als ook TL en de genexpressie van relevante genen. In het hart van de diabete ratten vonden we significant kortere telomeren in vergelijking met de gezonde controle ratten. Zowel fisetine als NAC leken deze verkorting gedeeltelijk tegen te gaan. In de diabete ratten was de expressie van antioxidant genen, DNA herstel genen en inflammatie gerelateerde genen 
verhoogd. Verder zagen we dat de interventie met fisetine en NAC deze responsen verminderden.

Samenvattend kan geconcludeerd worden dat, gebaseerd op de resultaten in dit proefschrift, de telomeren sneller verkorten onder omstandigheden van chronisch oxidatieve stress. Verder toonden we aan dat enzymatische antioxidanten, endogene antioxidanten als ook voeding die antioxidanten bevat, positief geassocieerd zijn met TL. Dit vonden we in gezonde mensen, COPD patiënten en in diabete ratten. Leefstijl lijkt dus niet alleen een effect te hebben op de gezondheid, maar ook op de telomeren. Om deze resultaten te bevestigen en om de mogelijk positieve effecten van antioxidanten, zowel in supplementen als in fruit en groenten, op TL verder te onderzoeken, zouden toekomstige studies zich moeten richten op interventies met antiinflammatoire stoffen in patiënten met een chronische ziekte zoals COPD of diabetes. Daarnaast is het van belang dat er meer prospectieve studies worden uitgevoerd en dat er rekening gehouden wordt met de genetische determinanten die ook een rol spelen bij TL. 




\section{Dankwoord}
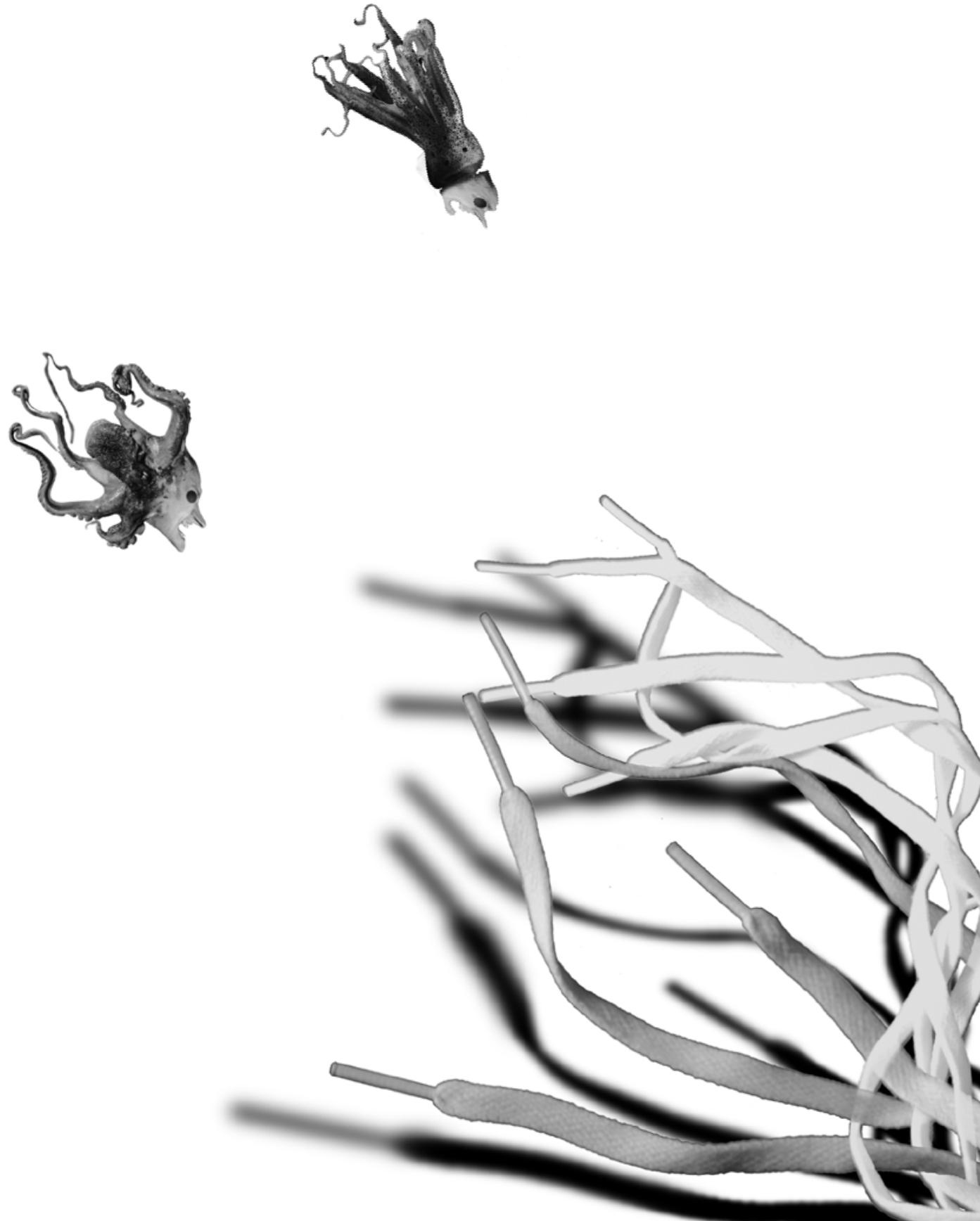
Na ruim 4 jaar onderzoek en vele leerervaringen rijker is het dan zover, het proefschrift is bijna af. In dit laatste, maar meestal als eerst gelezen hoofdstuk, wil ik graag een aantal mensen bedanken en in het bijzonder de mensen die me altijd onvoorwaardelijk zijn blijven steunen.

Allereerst wil ik de proefpersonen bedanken die hebben deelgenomen aan mijn onderzoek. Ze deinsden niet terug voor bloedafnames, vragenlijsten en de bepaling van hun lichaamssamenstelling. Werken met patiënten geeft een heel goed beeld van wat een slopende ziekte zoals COPD met iemand doet. Mede dankzij deze ervaringen ben ik tot de conclusie gekomen dat ik op mijn best functioneer in de patiëntenzorg.

Mijn promotor Frederik-Jan van Schooten wil ik bedanken voor de mogelijkheid om op de afdeling GRAT te kunnen promoveren. Jij zette altijd de puntjes op de i, bedankt! Professor Wouters wil ik ook graag bedanken voor zijn interesse en het mogelijk maken van mijn onderzoek. Mijn copromotor Geja Hageman wil ik graag bedanken voor haar enthousiasme en haar enorme inspiratie. Ik heb erg veel bewondering voor jouw inzet. Zelfs als de resultaten tegenvielen wist jij er altijd weer een positieve draai aan te geven. Ook bekeek je de manuscripten kritisch zodat we de reviewers een stapje voor konden zijn.

Naast mijn promotieteam wil ik ook graag alle GRAT-collega's bedanken. In het bijzonder wil ik Ralph bedanken voor zijn hulp bij het opzetten van de telomeerPCR. Bedankt dat ik met al mijn vragen bij je terecht kon. Danielle Pachen wil ik bedanken voor de hulp bij de DNA isolaties en Edwin voor de homocysteine bepaling. Daarnaast wil ik graag Karen en Sandra bedanken voor de hulp met "de laatste loodjes".

Uiteraard wil ik ook mijn kamergenootjes bedanken. Toen ik net begon zat ik samen met Hans, Danitsja en Lonneke op de kamer. Ik wil hen graag bedanken voor alle tips die ze me hebben gegeven als beginnende AIO. Al snel kwam Dennie op de plek van Danitsja te zitten en tja, toen werd het een drukke boel. Je probeerde me altijd te overtuigen (soms werden er zelfs keiharde pepernoten in de strijd gegooid) van je favoriete films en muziek, maar dat is niet echt gelukt hè? Mede dankzij jou heb ik ontzettend veel lol gehad en heb ik me toch door de moeilijkere periodes heen weten te slaan, bedankt voor alle 
fun. Yvonne wil ik ook graag bedanken. Je hebt een tijdje bij ons op de kamer gezeten en we hebben het zeer gezellig gehad: van het bespreken van de nieuwe badkamer tot goede tips en ideeën voor mijn onderzoek. Marieke en Joost wil ik natuurlijk ook bedanken voor de gezelligheid en de hulp met de (kerst)versieringen op onze kamer. Uiteraard wil ik ook de rest van de collega's en AIO's bedanken. Sabine, eerst heb ik als stagiaire op jouw project gewerkt en daarna werden we collega's. Heel erg bedankt voor de goede begeleiding tijdens mijn stage en voor alle gezelligheid! Evi, je werkte dan wel niet bij GRAT, maar we hebben wel samen een artikel geschreven. Ik vond het erg leuk om met je samen te werken en onze ervaringen als AIO te delen. En natuurlijk ook alle andere collega's van GRAT wil ik bedanken voor de gezelligheid.

Twee mensen wil ik nog in het bijzonder bedanken: Danielle en Astrid. Astrid, hoewel het in eerste instantie niet de bedoeling was dat je stage kwam lopen bij mij, ben ik erg blij voor alle hulp bij het uitvoeren van de ELISA's van mijn patiëntenstudie en natuurlijk met de data-analyses! Danielle, jij hebt me enorm geholpen met de dierstudie, wat absoluut niet mijn favoriete onderdeel was van mijn promotie. Ik wil je hier heel erg voor bedanken, want mede dankzij jou is dat toch nog allemaal goed gekomen. Ik vond het enorm gezellig om met je samen te werken en we hebben dan ook veel lol gehad. Heel veel succes met je eigen promotie!

Voor mijn patiëntenstudie heb ik ook een paar maanden bij CIRO in Horn gewerkt. Hoewel het al erg druk was op het lab, werden er nooit problemen gemaakt als ik weer eens een van mijn bloedbuizen moest centrifugeren. Martijn, bedankt voor deze mogelijkheid en je interesse in mijn onderzoek.

Petra en Olaf van de afdeling Interne Geneeskunde wil ik ook graag bedanken voor de fijne samenwerking bij de dierstudie. Dankzij jullie is alles vlotjes verlopen.

En we zijn er nog niet...ik wil ook graag de mensen van het Universitair Medisch Centrum in Leiden en de Universiteit van Wageningen bedanken voor de fantastische samenwerking. Professor Kromhout, Erik en Nathaly, bedankt voor jullie enorme ondersteuning bij de statistische analyses van de Zutphen studie 
en het schrijven van de manuscripten. Ik heb deze samenwerking als zeer leerzaam, maar vooral ook als erg leuk ondervonden.

Dan zijn er nog een heleboel mensen buiten mijn werk die ontzettend belangrijk voor me zijn. Allereerst wil ik Caroline, Janneke, Anne, Marieke en Inge bedanken voor alle gezellige avonden waarop ik mijn verhalen kwijt kon, ik hoop dat er nog vele avonden mogen volgen.

En dan natuurlijk Karen, Merdan en Dennie. Karen en Dennie, niet alleen vrienden maar ook nog eens (ex-)collega's. Alles werd met jullie besproken en jullie stonden altijd klaar met advies en vooral een flinke dosis humor. Bedankt voor de gezellige lunches en koffiepauzes. Jullie hebben me niet alleen door de moeilijke periodes heen gesleept, maar ook hebben we samen gezellige tripjes gemaakt en mojito-avonden gehouden waar ik met veel plezier op terugkijk. Heel erg bedankt voor jullie vriendschap en steun. Mijn paranimfen Karen en Audrey wil ik laten weten dat ik het een heel prettig idee vind dat jullie tijdens de promotie letterlijk en figuurlijk achter me zullen staan!

Mijn grootste dank gaat natuurlijk uit naar mijn man, ouders en mijn zus. Mijn ouders wil ik bedanken voor alle interesse die ze altijd hebben getoond. Zij hebben het mogelijk gemaakt dat ik kon studeren en dat ik het zover heb kunnen schoppen. Hoewel jullie af en toe geen idee hadden waar ik allemaal mee bezig was hebben jullie me altijd onvoorwaardelijk gesteund. Pap, je hebt je zelfs opgeofferd om als oefen-proefpersoon te dienen. Pap en mam heel erg bedankt voor jullie steun en liefde. Audrey, je bent een geweldige zus. Jij kunt je erg goed in mij verplaatsen en je begrijpt goed wat een promotieonderzoek inhoudt. Je zit zelf ook in de "gezondheids-hoek" als voedingsdeskundige en woont samen met Bart, die druk bezig is met zijn eigen promotie. Ik hoop dat er nog vele spelletjes- en wokavonden met jou, Bart en Tim zullen volgen en dat we nog veel kunnen lachen! Super bedankt voor al je interesse, gekkigheid en nog veel meer. En dan Tim. Je hebt heel wat met mij te stellen gehad de afgelopen jaren en altijd ben je in me blijven geloven en heb je me onvoorwaardelijk gesteund. Ik wil je heel erg bedanken voor alle liefde, nuchterheid, vriendschap, gezelligheid en eerlijkheid. En natuurlijk voor alle hulp bij de lay-out en het ontwerp van mijn boekje. Ik ben er trots op te kunnen zeggen dat je mijn man bent! 
Bedankt!

$$
\text { joyce }
$$





\section{Curriculum Vitae}
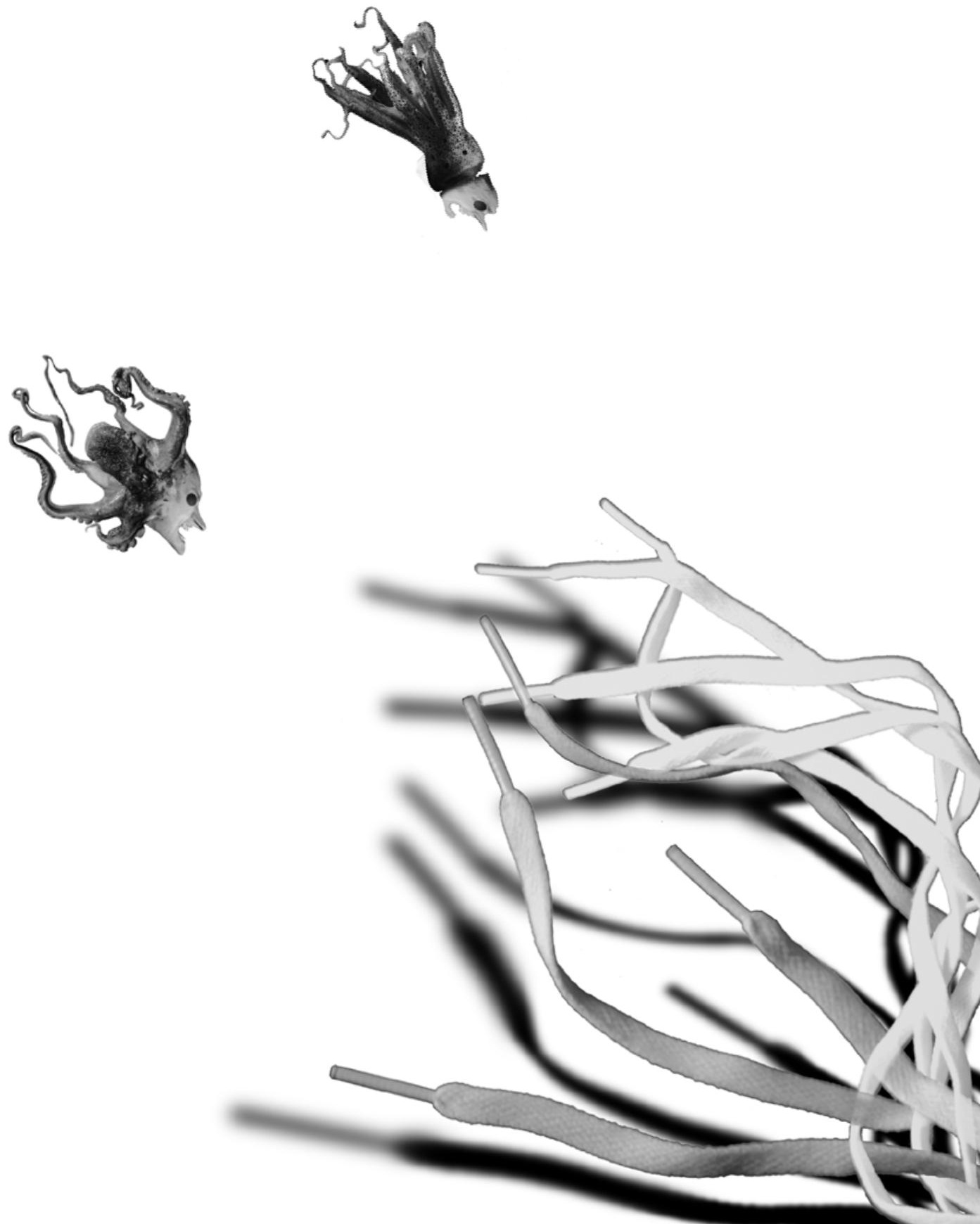


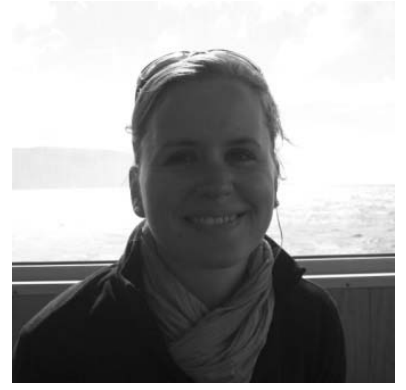

Joyce de Vos-Houben was born on April 18th 1983 in Sittard, The Netherlands. After finishing secondary school at the Trevianum in Sittard, she started in 2001 her study in "Health Sciences" in the discipline "Biological Health Sciences" at the University of Maastricht, The Netherlands. In 2004 she worked as a trainee at the department of Human Biology, at the University of Maastricht and she performed research on the effects of nutrition on cytokine expression in inflammatory bowel disease. In 2005 she graduated on the subject "Redox modulation of DNA repair". From September 2005 until November 2009 she worked as a PhD student at the department of Health Risk Analysis and Toxicology at the University of Maastricht. The title of her thesis was "Chronic oxidative stress and telomere shortening". She attended several congresses on free radical biology and oxidative stress. In 2006 she received a participation and accommodation fee for the Free Radical Summer School in Spetses, Greece. Besides doing research she also attended several courses and obtained licenses for working with radioactive material and handling laboratory animals. She also obtained a certificate on Cambridge Proficiency Exam. The completion of several courses and the attendance of meetings and other activities within NUTRIM and the Graduate School VLAG qualify her for a VLAG-certificate. Since May 2010 she works as a genetic counselor at the department of Clinical Genetics at Maastricht University Medical Centre+. 




\section{List of Publications}
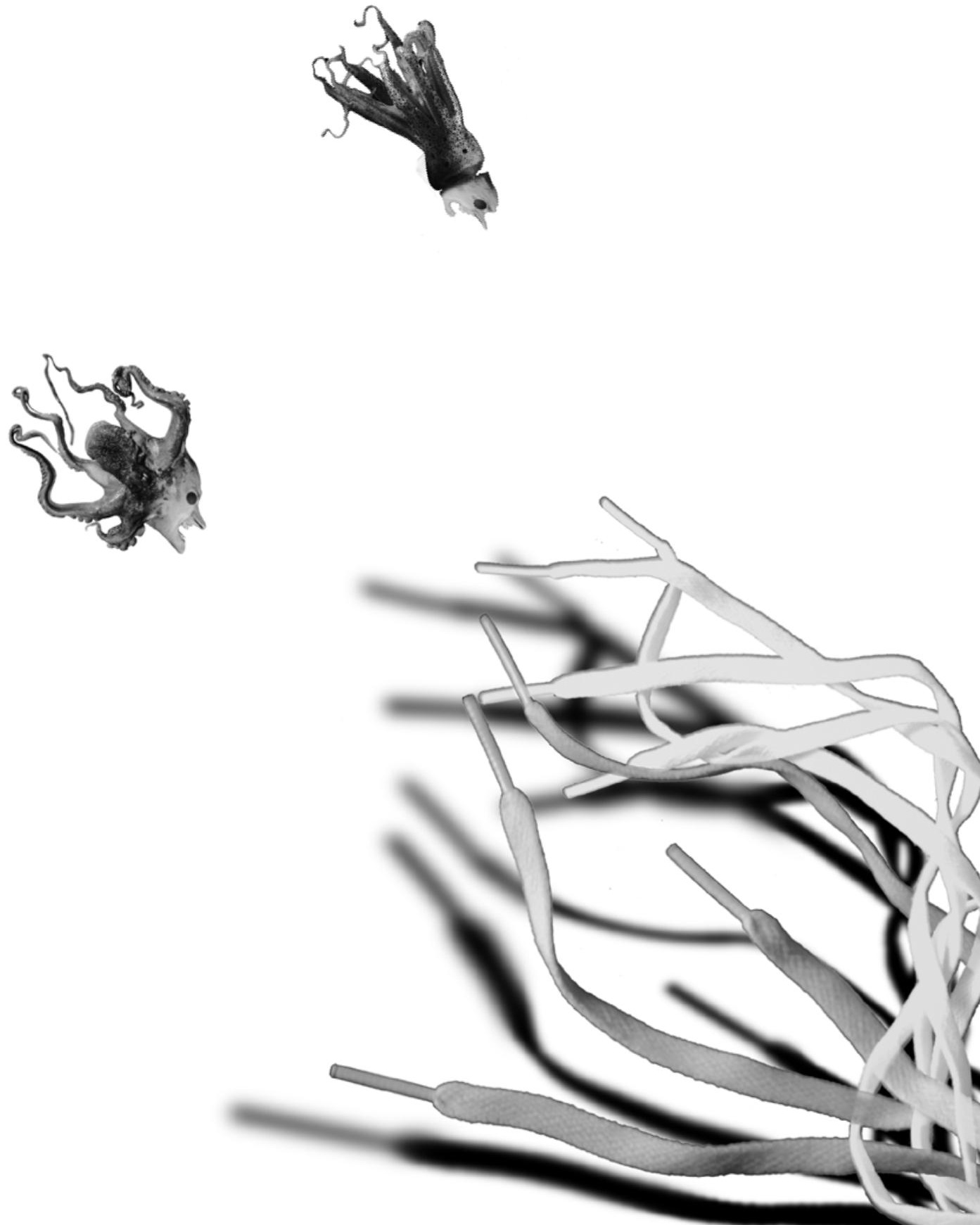
Langie SA, Knaapen AM, Houben JM, van Kempen FC, de Hoon JP, Gottschalk RW, Godschalk RW, van Schooten FJ.

The role of glutathione in the regulation of nucleotide excision repair during oxidative stress.

Toxicol Lett. 2007 Feb 5;168(3):302-9. Epub 2006 Nov 16. PMID: 17207589

Houben JM, Moonen HJ, van Schooten FJ, Hageman GJ.

Telomere length assessment: Biomarker of chronic oxidative stress?

Free Radic Biol Med. 2008 Feb 1;44(3):235-46. Epub 2007 Oct 10.

PMID: 18021748

Joyce M.J. Houben, Evi M. Mercken, Hans B. Ketelslegers, Aalt Bast, Emiel F. Wouters, Geja J. Hageman and Annemie M.W.J. Schols

Telomere shortening in chronic obstructive pulmonary disease

Resp Med. 2009 Feb 103(2):230-6. Epub 2008 Oct 21. PMID: 18945604

Joyce M.J. Houben, Olaf Brouwers, Danielle M.P.H.J. Boesten, Casper G.

Schalkwijk and Geja J. Hageman

Telomere shortening in diabetic rats: effects of dietary intervention with fisetin and $n$-acetylcysteine

Joyce M.J. Houben, Astrid Schuijlenburch, Martijn A. Spruit, Emiel F. Wouters, Frederik J. van Schooten and Geja J. Hageman

Telomere shortening in COPD: potential protective effects of coffee consumption

Submitted: The European Respiratory Journal

Joyce M.J. Houben, Nathaly Rius-Ottenheim, Erik J. Giltay, Geja J. Hageman and Daan Kromhout

Telomere shortening in the Zutphen elderly study: marker for mortality?

Accepted (in press) by the Journal of Gerontology: Biological Sciences 
Joyce M.J. Houben, Nathaly Rius Ottenheim, Anthony Kafatos, Brian Buijsse, , Geja J. Hageman, Daan Kromhout and Erik J. Giltay

Telomere length, oxidative stress, and antioxidant status in elderly men: differences between Zutphen and Crete

Submitted: Proceedings of the National Academy of Sciences (PNAS)

Nathaly Rius Ottenheim, MD, Joyce MJ Houben, MSc, Daan Kromhout, MPH, $\mathrm{PhD}$, Anthony Kafatos, MD, PhD, Roos C van der Mast, MD, PhD, Frans G

Zitman, MD, PhD, Johanna M Geleijnse, PhD, Geja J Hageman, PhD, and Erik J Giltay, MD, PhD.

Leukocyte telomere length and mental well-being in elderly men from The Netherlands and Greece

Submitted: Brain Behavior and Immunity 

Samenvatting voor de niet-wetenschapper
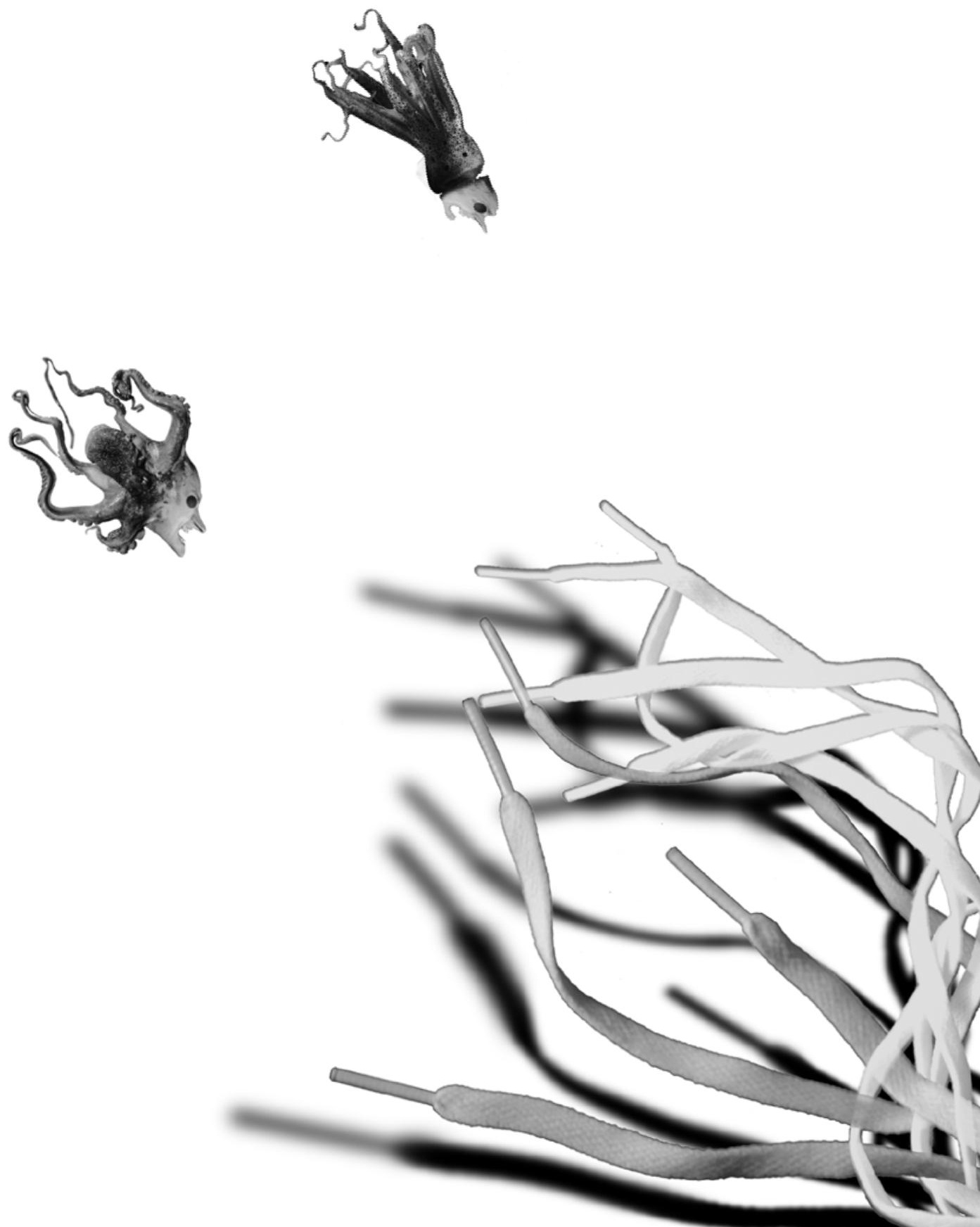


\section{Veroudering overkomt ons allemaal, maar bij mensen met een chronische ziekte lijkt dit proces sneller te verlopen. Zou het niet mooi zijn als we dit proces zouden kunnen tegengaan of vertragen? Om dit mogelijk te maken, moeten we eerst weten wat er gebeurt tijdens het proces van veroudering.}

\section{Telomeren}

Het blijkt dat de uiteinden van onze chromosomen (waar ons erfelijk materiaal zich op bevindt) steeds een stukje korter worden: de telomeren. Deze telomeren beschermen ons erfelijke materiaal (het DNA) en ze zijn vergelijkbaar met het harde stukje plastic op het uiteinde van een schoenveter. Wanneer dit stukje plastic verdwijnt, gaat de schoenveter rafelen en is deze niet langer bruikbaar. Met elke celdeling (het proces waarbij cellen zich vermenigvuldigen met als gevolg groei of vervanging van weefsels) worden de telomeren een stukje korter. Wanneer de telomeer een kritieke lengte bereikt, stopt de cel met functioneren. Dit is geassocieerd met veroudering en ouderdomsgerelateerde aandoeningen.

\section{Chronische ziekten ("the bad guys")}

Chronische ziekten (zoals bijvoorbeeld diabetes, hart- en vaatziekten, chronische longziekten en chronische darmziekten) worden gekenmerkt door verhoogde productie van radicalen, stofjes die schade toebrengen aan het DNA. Dit wordt ook wel oxidatieve stress genoemd en kan de telomeren beschadigen, waardoor deze sneller verkorten. Dit gaat dan weer gepaard met versnelde veroudering en ouderdomsgerelateerde aandoeningen.

De doelstelling van het onderzoek dat in dit proefschrift staat beschreven, was om te onderzoeken of er daadwerkelijk een snellere telomeerverkorting optreedt onder condities van chronisch oxidatieve stress.

\section{Antioxidanten ("the good guys")}

Naast de radicalen, ofwel de oxidanten, zijn er ook de zogenaamde antioxidanten: stofjes die in staat zijn om deze radicalen te verwijderen. Voorbeelden van antioxidanten zijn vitamine E en C, maar ook lichaamseigen enzymen zoals superoxide dismutase en catalase.

Een tweede doel van dit onderzoek was dan ook om te kijken of een verhoogde antioxidantcapaciteit of een verhoogde inname van antioxidanten, ervoor kan zorgen dat de negatieve effecten van de radicalen kunnen worden 
teruggedraaid, met als uiteindelijke gevolg, een minder snelle telomeerverkorting.

\section{Telomeren: beginning to understand the end?}

We hebben inderdaad kunnen bevestigen dat mensen met een chronische longziekte (COPD) kortere telomeren hebben in vergelijking met gezonde leeftijdsgenoten. Daarnaast hebben we ook kunnen vaststellen dat antioxidanten een positief effect hebben op de telomeerlengte. Toch moeten we niet vergeten dat er meerdere factoren van invloed zijn op het verouderingsproces, en we dus niet alles kunnen toeschrijven aan telomeerverkorting. Ook moeten we in ons achterhoofd houden dat de telomeren niet alleen beïnvloed worden door invloeden van buitenaf, maar dat er ook een genetische achtergrond aan ten grondslag ligt. Denk aan het verschil tussen schoenveters: je hebt sterke en minder sterke varianten, wat op zich al bepalend is voor de levensduur van je veters. Zo is het ook voor de telomeren: bij de geboorte zijn er al verschillen die medebepalend zijn voor het verloop van iemands leven.

Samenvattend zouden we dan ook kunnen stellen dat de telomeerlengte een zeer interessante en relevante maat is voor chronische aandoeningen en het verouderingsproces. 